\title{
Dagmar Christians
}

\section{Die Sprachrubrik in der "Literaturnaja gazeta" von 1964 bis 1978}

\section{Dokumentation und Auswertung}

Verlag Otto Sagner München · Berlin · Washington D.C.

Digitalisiert im Rahmen der Kooperation mit dem DFG-Projekt „Digi20“

der Bayerischen Staatsbibliothek, München. OCR-Bearbeitung und Erstellung des eBooks durch den Verlag Otto Sagner:

http://verlag.kubon-sagner.de

( $)$ bei Verlag Otto Sagner. Eine Verwertung oder Weitergabe der Texte und Abbildungen, insbesondere durch Vervielfältigung, ist ohne vorherige schriftliche Genehmigung des Verlages unzulässig. 


\title{
SLAVISTISCHE BEITRÄGE
}

\author{
BEGRÜNDET VON \\ ALOIS SCHMAUS \\ HERAUSGEGEBEN VON \\ JOHANNES HOLTHUSEN - HEINRICH KUNSTMANN \\ PETER REHDER - JOSEF SCHRENK \\ REDAKTION \\ PETER REHDER \\ Band 165
}

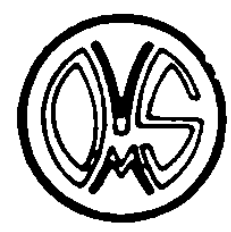

\section{VERLAG OTTO SAGNER \\ MÜNCHEN}




\section{DAGMAR CHRISTIANS \\ DIE SPRACHRUBRIK DER LITERATURNAJA \\ GAZETA VON 1964 BIS 1978 \\ Dokumentation und Auswertung}

\section{VERLAG OTTO SAGNER • MÜNCHEN 1983}


ISBN 3-87690-255-X

(C) Verlag Otto Sagner, München 1983

Abteilung der Firma Kubon \& Sagner, München 
Inhalt

I. Die Literaturnaja gazeta in der Sprachpolitik des Institut russkogo jazyka (IRJaz)

- Einleitende Bemerkungen zum Hintergrund

der Diskussion - .................. 11

1. Die Sprachpolitik des Institut russkogo jazyka ....... 11

2. Die Literaturnają gazeta als Forum für Sprachdiskussionen . . . 17

II. Die Sprachbeiträge in der Literaturnaja gazeta als Forum für Sprachdiskussionen

- Auswertung des Materials - ............. 21

1. Entwicklung der Sprachrubrik in der Literaturnajazgazeta 1964-1978 . . . . . . . . . . . . . . . . . 21

2. Die Verfasser der Sprachbeiträge und ihre Rolle in der Literaturnaja gazeta . . . . . . . . . . . . 25

2.1. Die Schriftsteller: „mastera slova" oder Vorbilder für normgerechten Sprachgebrauch? . . . . . . . . . 26

2.2. Die Laien: „bolel'šiki za jazyk“ ............. 32

2.3. Die Sprachwissenschaftler als Vertreter der offiziellen Sprachpolitik ......................... 39

3. Einstellungen zur Standardsprache und ihrer Realisierung im Sprachgebrauch der Bevölkerung . . . . . . . . . . 43

3.1. Der Kampf für die Reinheit der russischen Sprache ....... 44

3.2. „Antinormalizatorstvo“................. 51

3.3. Die Haltung der Linguisten in der Sprachrubrik der Literaturnaja gazeta ................. 56

4. Zur konkreten Auseinandersetzung um Sprachgebrauch und Norm . . . . . . . . . . . . . . . 62

4.1. Meldungen von Normverstößen im Bereich der Grammatik ... 63

4.1.1. Orthoepie ......................6 63

4.1.2. Orthographie .................... 65

4.1.3. Morphologie ...................66 66

4.1.4. Syntax ..................... 68 


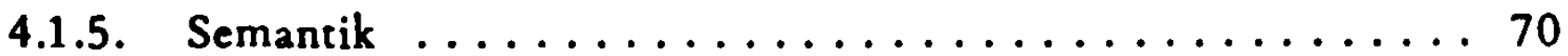

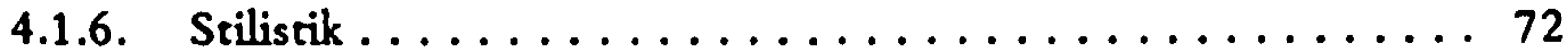

4.2. Auseinandersetzungen um Fragen des Lexikons . . . . . . . 76

4.2.1. Neologismen . . . . . . . . . . . . . . . 76

4.2.2. Dialektismen . . . . . . . . . . . . . . . 81

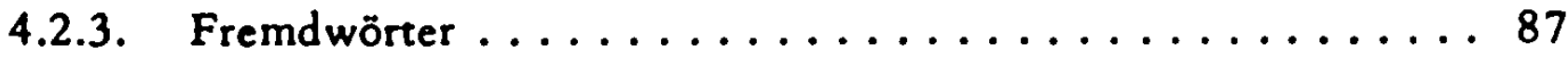

5. Die Bedeutung der Sprachrubrik für die Arbeit des IRJaz . . . . 95

5.1. Der Dialog mit dem Sprachbenutzer . . . . . . . . . . . . . 98

5.2. Die Diskussion über das Verhältnis des Schriftsteller zur standardsprachlichen Norm . . . . . . . . . . . 100

6. Resümee ...................... 105

III. Dokumentation .................. 109

IV. Anhang ......................... 245

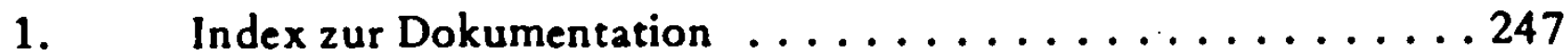

2. Namensregister zur Dokumentation . . . . . . . . . 258

3. Literaturverzeichnis ................. 260

4. Verzeichnis benutzter Abkürzungen ............ 266 


\section{Vorwort}

Vordringliches Anliegen dieser Arbeit ist es, die in der Literaturnaja gazeta in der Zeit von 1964 bis 1978 veröffentlichten Beiträge zu Sprachfragen, die über dreizehn Jahrgangsbände verteilt sind, weiteren Forschungen zugänglich zu machen. Diesem Zweck dient nicht allein die vollständige Dokumentation der Beiträge (Teil III), sondern auch eine erste Auswertung des sehr umfangreichen und thematisch äußerst vielseitigen Materials, für die sich zwei Fragestellungen anboten.

1. Welche Rolle spielt die Sprachrubrik in der Literaturnaja gazeta als Massenmedium in der praktischen sprachpolitischen Arbeit des Institut russkogo jazyka?

und

2. Wie reagiert der Sprachbenutzer auf solche sprachlenkenden Maßnahmen?

In der Dokumentation referiere ich möglichst knapp die wesentlichen Aussagen der einzelnen Beiträge, wobei ich Wert darauf gelegt habe, daß sowohl die aus sprachwissenschaftlicher Sicht zuweilen unlogische Argumentationsweise der Verfasser als auch ihre Beispiele erhalten blieben. Auf eine Kommentierung der Beiträge innerhalb der Dokumentation wurde deshalb verzichtet. Vollständige Angaben zu dort erwähnten Titeln wurden nur in solchen Fällen ergänzt, wo sie eindeutig zu identifizieren waren. Verweisungen auf die Dokumentation werden im Text im Unterschied zu Verweisungen auf wissenschaftliche Literatur mit Kürzeln angegeben, die den Autor (in einigen Fällen den Titel) des Aufsatzes, die Nummer und den Jahrgang der Literaturnaja gazeta nennen. 
Einige der hier dokumentierten Beiträge sind bereits in anderen Publikationen unter themenspezifischen Gesichtspunkten berücksichtigt worden. Dazu gehört die 1969 erschienene Broschüre von BukXina/Kalakuckaja/Cel'cova (1969), in der die anläßlich der 1964 vorgeschlagenen Orthographiereform in sowjetischen Zeitungen und Zeitschriften veröffentlichten Diskussionsbeiträge ausgewertet und verzeichnet werden; die Artikelserie in der Literaturnaja gazeta von 1964 ist darin allerdings nur unvollständig vertreten. Bei Ljustrova/Skvorcov/Derjagin (1978) werden drei Beiträge der Diskussion von 1971 erwähnt. In der erst kürzlich erschienenen Arbeit von Skvorcov über theoretische Grundlagen der Sprachkultur (Skvorcov 1980) sind neben der Fremdwortdiskussion von 1974 noch drei einzelne Artikel aus den Jahren 1976 (Filin und Gusev) und 1972 (Abramov) genannt. Keipert (1978) behandelt fremdwortpuristische Außerungen bei Solženicyn und Jugov (1965).

$\mathrm{Da}$ trotz nur gelegentlicher Erwähnung solche Zeitungsartikel in der Sowjetunion für wichtig gehalten werden, zeigt der Wiederabdruck einiger Schriftstellerbeiträge in dem Sammelband Russkie pisateli o literatumom jazyke (1974). Uber diesen übrigens von der LG-Mitarbeiterin A. Latynina herausgegebenen Band fanden auch die dort vertretenen LG-Aufsätze Eingang in die sowjetische Bibliographie Sovetskoe jazykoznanie (1980). Selbständig erfaßt werden neuerdings mehrere Artikel von Schriftstellern und Linguisten in der Kommentierten Bibliographie zur slavischen Linguistik von P. Brang und M. Züllig (1981). Dort ist die Diskussion von 1965/66 fast vollständig verzeichnet, teilweise auch die von 1971 (Alekseev ua., Lipatov, Solouchin, Surtakov), ferner das Interview mit F. Abramov (1972), zwei Beiträge des Jahrgangs 1973 (Procerov, ,Russkij jazyk ...") und die Artikel von Filin und Fedorenko zur Fremdwortfrage (1974). Weil sie aber unter verschiedene Themenkomplexe eingeordnet sind, werden sie aus ihrem Diskussionszusam. menhang gerissen und erscheinen so als zufällig in der Literaturnaja gazeta veröffentlichte sprachwissenschaftliche Aufsätze. Deshalb und weil die Leserbeiträge bisher weder in der Bibliographie erwähnt werden noch in den übrigen genannten Arbeiten Beachtung gefunden haben, halte ich es für sinnvoll, alle Aufsätze, die im Rahmen der Sprachrubrik in der Literaturnaja gazeta erschienen sind, zu sammeln und sie im Gang der Diskussion vorzustellen. 
Die vorliegende Untersuchung wurde im Sommersemester 1981 von der Philosophischen Fakultät der Rheinischen Friedrich-Wilhelms-Universität Bonn als Dissertation angenommen. Herrn Prof. Dr. H. Keipert danke ich für die Anregung zu der Arbeit und ihre Betreuung.

Bonn, im Oktober 1982

Dagmar Christians 
I Die Literaturnaja gazeta in der Sprachpolitik des Institut russkogo jazyka (IRJaz)

- Einleitende Bemerkungen zum Hintergrund der Diskussion -

Seit 1964 besitzt die Literaturnaja gazeta (LG) eine feste Rubrik für die Behandlung von Fragen der russischen Standardsprache. Auf dieser Seite beanstanden Leser grammatische Fehler und Stilblüten in der Presse oder auf Reklametafeln, erfragen in strittigen Fällen die derzeit gültige Norm. Hier wird diskutiert über die Zulässigkeit von Dialektwörtern in der Belletristik, über Slangausdrücke und Modewörter. Die LG reiht sich also ein in die vielzähligen Bemühungen der sowjetischen Gesellschaft um die Sprachkultur (,kul'tura reči“).

\section{Die Sprachpolitik des Institut russkogo jazyka}

Der in der sowjetischen Gesellschaft gebräuchliche Terminus „kul'tura reXi" steht für eine Fülle der verschiedensten Teilaspekte einer weitgefaßten Grundbedeutung von Sprachkultur. Einmal bezeichnet er das Niveau der Sprachbeherrschung in der Bevölkerung, dann wieder meint er das Bemühen der Gesellschaft um Regulierung der russischen Sprache oder aber ihrer Verwendung, schließlich auch die Fähigkeit des Individuums, sich adäquat ausdrükken zu können. Größer wird die terminologische Verwirrung noch dadurch, daß neben "kul'tura reči" in der sowjetischen Sprachwissenschaft weitere Bezeichnungen für gesellschaftliches Eingreifen in die Entwicklung und das Funktionieren von Sprache verwendet werden, teils als Synonyme, teils unterschiedlich definiert: „jazykovoe stroitel'stvo", "lingvistǐ̌eskaja technologija“" oder "praktǐeskaja stilistika".1 Einen Ausweg aus diesem begrifflichen Durcheinander bietet W.Schmidt, der die verschiedenartigen Verwendungs- 
bereiche des Begriffes Sprachkultur systematisiert und in zwei Graphiken veranschaulicht hat. 2 Diese Schaubilder sollen hier - leicht erweitert - wiedergegeben werden, weil sie helfen, die Eingrenzung des Untersuchungsgegenstandes meiner Arbeit durchschaubar zu machen:
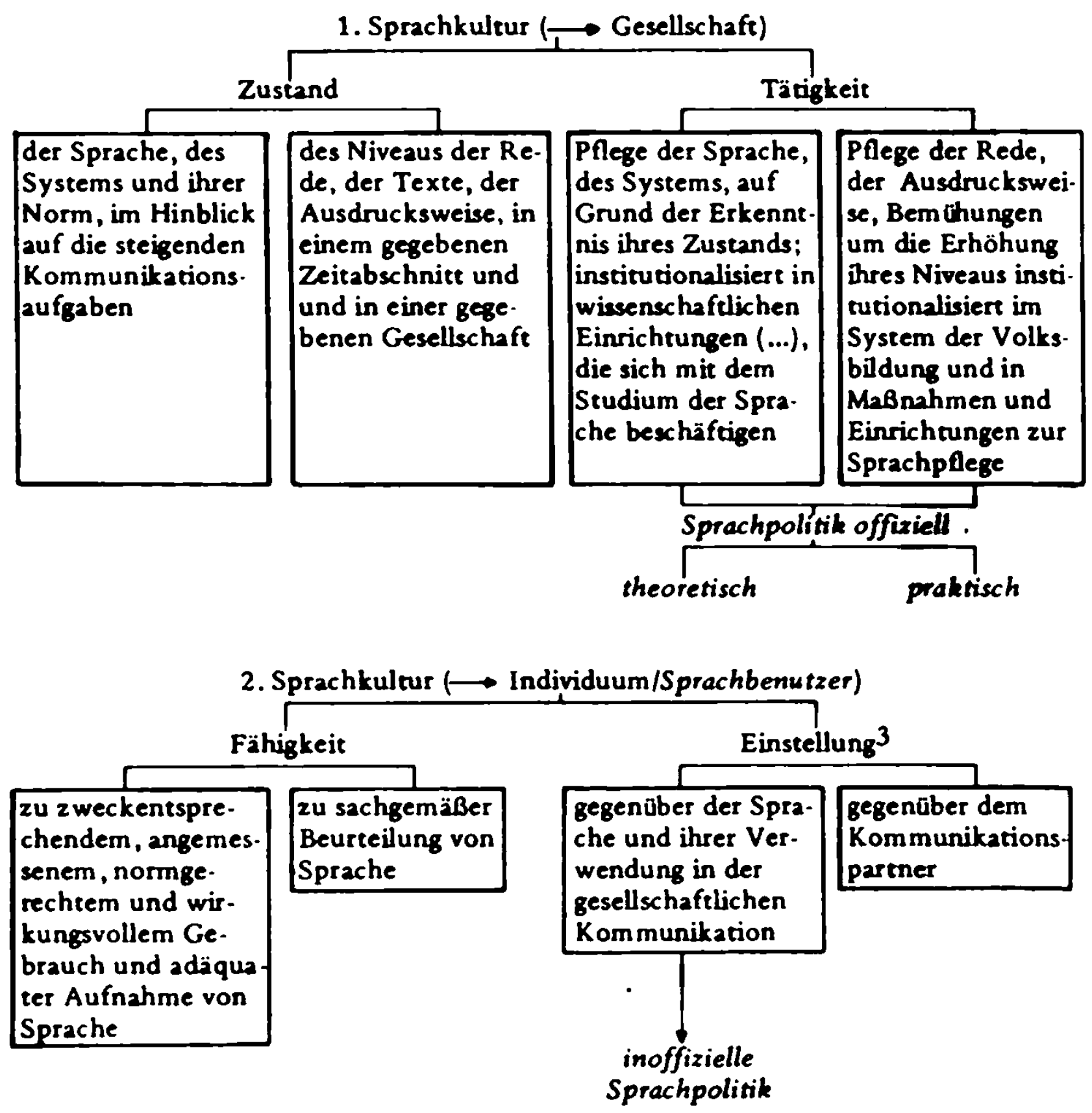

Die institutionalisierte Pflege der Sprache/Rede - bei Schmidt der aktive Aspekt gesellschaftsbezogener Sprachkultur - ist nichts anderes als zielge-

2 Schmidt 1976, S. 136 f.

3 Schmidts Graphik enthält hier den Zusatz "verantwortungsbewrußt" und fügt dem Begriff "Sprachkultur" damit anders als in der Graphik 1 die Wertung "hoch, positiv' zu, was den Begriff unnötig einschränkt. - Die kursiv gesetzten Erläuterungen sind von mir hinzugefügt. 
richtetes regulierendes Eingreifen in die Sprache oder ihre Verwendung, also Sprachpolitik. In Abgrenzung zu dem mit Sprachpolitik meist ausschlieBlich assoziierten Teilbereich der Regelung von nebeneinander existierenden Sprachen in polyglossischen Verhältnissen wird dieser Bereich im Deutschen ublicherweise mit dem Ausdruck "Sprachpflege" bedacht. 4 Weil "Sprachpflege“" aber den politischen Charakter eines solchen institutionalisierten Eingreifens verschleiert, ziehe ich den neuerdings von Girke und Jachnow geprägten Terminus 'intraethnische Sprachpolitik'5 vor.

Nur bedingt läBt sich anhand der LG die offizielle Sprachpolitik beschreiben, wie sie von dem dafür zuständigen Institut für russische Sprache (Institut russkogo jazyka - IRJaz) konzipiert und durchgefürt wird. Die Teilnahme von Sprachwissenschaftlern an der Sprachrubrik ermöglicht es lediglich, einen Teilbereich der praktischen Arbeit des Instituts zu beleuchten - nämlich den Einsatz von Massenmedien zur sprachlichen Erziehung der Bevölkerung. Die zugrundeliegende Konzeption des Instituts muB als gegeben vorausgesetzt werden. Dem nichteingeweihten Leser kann sie hier nur in ihren wesentichen Zügen knapp geschildert werden, wobei davon abgesehen werden muB, daB unter den einzelnen Vertretern des Instituts sehr wohl ausgeprägte Differenzen in ihrem Verständnis von Sprachpolitik bestehen.

Die Sprachpolitik des IRJaz zielt in ihrer Grundtendenz darauf ab, die russische Standardsprache ("russkij literaturnyj jazyk“6) als verbindliche einheitliche Sp:achform für den russischen Teil der Sowjetunion - die RSFSR durchzusetzen.7 Dabei obliegt es dem IRJaz als zuständiger Institution nicht nur, die Normen der Standardsprache zu erforschen und zu kodifizieren, sondern es hat auch für eine allgemeine Verbreitung dieser Sprachform und

4 so z.B. noch 1974 bei Girke und Jachnow

5 Girke.Jachnow 1975, S. 13 und Girke 1977 S. 134

6 Die in der sowjetischen Linguistik für Standardsprache übliche Bezeichnung .literaturnyj jazyk" ist wie ihr deutsches Pendant "Literatursprache" nicht genau genug gegenüber dem Begriff "Sprache der Literatur" abgegrenzt. Gerade für die Darstellusg der Diskussion in der LG, bei der es vielfach um die "Sprache der Literatur" im Uzterschied zur "Literatursprache" geht, ist daher der Terminus „Standardsprache" rorzuzichen.

7 Vgl. asch: Girke/Jachnow 1975, S. 13 
deren normengerechte Verwendung in der Bevölkerung zu sorgen. ${ }^{8}$ Wichtig ist dabei zu wissen, da $\beta$ die russische Standardsprache von ihrem Ursprung her keineswegs eine Volkssprache ist, wie es von einigen sowjetischen Linguisten gern behauptet wird.9 Der , literaturnyj jazyk" hat sich im 18. Jahrhundert als eine nationale Sprachform entwickelt, deren Verwendung noch bis 1917 auf den Adel und Teile des Großbürgertums beschränkt war. Dabei hatten Vertreter des Adels die von ihnen neben dem Französischen verwendete Umgangssprache nach dem Vorbild des Französischen zu einer Standardsprache ausgebaut. 10 Nach der Oktoberrevolution wurde nicht eine neue Standardsprache entwickelt, etwa mit stärkerer Orientierung an der Sprachpraxis der breiten Masse der russischen Bevölkerung, wie man es bei einer derartigen gesellschaftlichen Umwälzung hätte erwarten können und wie es noch 1934 von Panferov gefordert wurde 11 . Stattdessen knüpfte die Sprachpolitik an den Normen der bereits bestehenden Hochsprache an, die eher eine Elite- denn eine Standardsprache war, idealisierte diese zu einer allgemeinen Volkssprache 12 und bemühte sich lediglich, deren Trägerkreis zu erweitern ${ }^{13}$.

Die Sprachverwendung in der russischen Bevölkerung der sechziger und siebziger Jahre (das "Niveau der Rede") als Ansatzpunkt konkreter sprachlenkender Maßnahmen läßt sich hier nur unbefriedigend charakterisieren, da eine zusammenhängende Beschreibung dessen in der sowjetischen Literatur fehlt. Für die Beurteilung der Sprachbeiträge in der LG wäre eine Aufschlüsselung über die tatsächliche Verteilung der verschiedenen Sprachformen der russischen Ethnosprache - Standard, Dialekt, Prostorečie - in der Bevölkerung der russischen Sowjetrepublik (RSFSR) sehr hilfreich gewesen.

8 Einen Eindruck über die Ziele und Grundzüge der sowjetischen intraethnischen Sprachpolitik vermittelt die Arbeit von Girke und Jachnow (1974), Kapitel 4; für den neuesten Stand vgl. Skvorcov 1980; zur Aufgabenstellung und Struktur des IRJaz vgl. z.B. Filin 1969 und Proťenko 1974.

9 Einen Überblick über derartige Fehlinterpretationen gibt Issatschenko 1975.

$10 \mathrm{Vgl}$. dazu: Issatschenko 1974, besonders S. 260 und $27 \mathrm{ff}$.

11 Vgl dazu: Eismann 1978, S. 72 f.

12 ebd., S. $65 \mathrm{f}$.

13 Vgl. dazu 2.B. Kostomarov 1976, S. 4; Issatschenko 1974, S. 274; Boeck/Fleckenstein/Freydank 1974. S. 17 
So mangelt es an Informationen darüber, wie hoch im Beobachtungszeitraum der Anteil der Bevölkerung war, der sich überwiegend der Standardsprache bedient. Die Dialektologin Kogotkova hält den Kreis der reinen Standardsprecher für sehr begrenzt. Sie zählt hierzu ausschließlich Personen, die den Gebrauch der Standardsprache bereits von der vorausgegangenen Generation oder sogar mehreren Generationen übernommen haben. 14 Angaben über die soziale Stellung, das Bildungsniveau und die regionale Herkunft von Standardsprechern, die bei Kogotkova fehlen, findet man bei L.P. Krysin. Für seine Umfrage zu Varianten im Standardsprachgebrauch stützt er sich als sichere Standardsprecher auf Informanten, die folgende drei Kriterien erfüllen: Sie müssen 1. Russisch als Muttersprache sprechen, 2. eine höhere oder sogar Hochschulbildung (srednee/vysłee obrazovanie) genossen haben und 3. Städter sein. 15

Offen bleibt auch die Frage nach der kommunikativen Bedeutung der zahlreichen russischen Dialekte. Während F.P. Filin behauptet, sie seien im Aussterben begriffen:

„Obšteizvestno, tto mestnye govory $v$ nastojasxee vremja nachodjatsja v stadii razruYenija i otmiranija. “16,

zeichnet Kogotkova ein wohl realistischeres Bild vom Zustand der Dialekte. Sie räumt ein, daß der Personenkreis von ausschließlich Mundart sprechenden Personen vorwiegend aus Dorfbewohnern der äteren Generation bestehe und sich mehr und mehr verringere. Der größte Teil aller Russischsprecher verwendet jedoch ihren Angaben zufolge Mischformen aus standardsprachlichen und dialektalen Elementen, von ihr Halbdialekte genannt. 17 Zwar spricht auch Filin davon, daß halbdialektale Sprachformen in der Bevölkerung weit verbreitet seien; er sieht in ihnen jedoch nur Ubergangsformen, die verschwinden, sobald alle Sprecher gelernt haben werden, die Standardsprache richtig zu beherrschen:

„Podavljajuščce bol'šinstvo naselenija vadeet literaturnym jazykom ili pol'zuetsja svoego roda poludialektami - reł'ju,

14 Kogotkova 1970, S. 105

15 Krysin 1974, S. 17

16 Filin 1973, S. 4

17 Kogotkova 1970, S. 105 ff. 
perechodnoj ot mestnych govorov $k$ pravil'nomu literaturnomu jazyku.“18

Kogotkova dagegen begreift die Halbdialekte als Ergebnis einer gegenseitigen Angleichung von Standardsprache und Dialekten, die individuell unterschiedlich realisiert wird, je nachdem, ob der Sprecher in ländlichem oder städtischem Milieu lebt.19 Auch Girke und Jachnow gehen davon aus, daß die Dialekte auf dem Land noch eine wesentliche Bedeutung als Kommunikationsmittel haben. 20

Die untersuchten Texte der LG liefern unter anderem Hinweise darauf, bis zu welchem Grad die Bevölkerung die Normen der Standardsprache beherrscht - jedoch nur vermittelt aus der Sicht des nicht linguistisch vorgebildeten Sprachbenutzers. Normverletzungen, die hier kontextunabhängig vorgebracht werden, sind nicht selten lediglich Abweichungen vom individuellen Sprachgeschmack des betreffenden Leserbrief- oder Artikelschreibers. Die Häufigkeit, mit der gewisse „Fehler" auftreten, wird bisweilen zwar behauptet, aber nicht anhand empirischer Daten nachgewiesen. Gerade die aus dem Kontext losgelöste Auflistung von vermeintlichen oder tatsächlichen Normverstößen erschwert es dem außerhalb der Sprechergemeinschaft stehenden Betrachter, der den Kontext ja nicht wie etwa der LG-Leser direkt assozïert, die Abweichung zu beurteilen. Daher beschränke ich mich darauf, sie gesammelt vorzustellen.

Auch die Einstellung des Individuums zu seiner Sprache und ihrer Verwendung in der Sprechergemeinschaft verstehe ich als Teil von Sprachpolitik. Selbst wenn diese nicht geäußert wird, trägt sie doch dazu bei, bei sprachlenkende Maßnahmen zu fördern oder aber zu behindern. 21 Die Bedeutung einer solchen inoffiziellen Sprachpolitik wächst in dem Maße, wie die Sprachbenutzer Gelegenheit finden, ihre Meinung zu veröffentlichen und so aktiv auf die Sprachpraxis der Gesellschaft Einfluß zu nehmen.

18 Filin 1973, $\ddot{\mathrm{S} .4}$

19 Kogotkova 1970, S. 106

20 Girke/ Jachnow 1974, S. 128

21 Kuchaś/Stich 1976, S. 339 
Mit ihrer Sprachrubrik bietet die LG der sowjetischen Bevölkerung die Möglichkeit, ihre Haltung zur Sprache, zur Sprachverwendung und zu der Arbeit des IRJaz mitzuteilen. Dieses Material von Meinungsäußerungen steht im Mittelpunkt meiner Arbeit.

\section{Die Literaturnaja gazeta als Forum für Sprachdiskussionen}

Die Literaturnaja gazeta (LG) ist seit der Gründung des sowjetischen Schriftstellerverbandes im Jahre 1934 dessen offizielles Organ. 22 Dennoch ist sie keine reine Literaturzeitschrift, sondern eine überregionale Zeitung, in der die Berichterstattung über sowjetische und ausländische Literatur nur einen von mehreren Schwerpunkten ausmacht. 23 Dies gilt besonders seit 1967, als die LG zu einer 16-seitigen Wochenzeitschrift mit regelmäßiger Berichterstattung zu den Bereichen Sowjetische Literatur, Okonomie, Wissenschaft, Kunst und Leben im Ausland umgestaltet wurde. 24

Die sowjetische Enzyklopädie verzeichnet sie als eine der auflagenstärksten Zeitungen der Sowjetunion: 1975 stand sie mit einer Auflagenhöhe von 2,3 iMillionen Exemplaren an zehnter Stelle.25 Beliebt ist sie vor allem deshalb, weil sie dem Leser in ihrer Berichterstattung ein breites Themenspektrum anbietet. 26

Außerdem erhebt die LG den Anspruch, Diskussionsforum für gesellschaftlich relevante Probleme zu sein, in das jeder beliebige Leser seine Meinung einbrinIgen kann. 27 In einem einer Ausgabe der LG des Jahres 1966 beigelegten Informationsblatt 28 , das für 1967 eine Änderung der Konzeption der Zeitung ankündigt, schreibt die Redaktion, daß sie in Zukunft noch mehr Raum für

22 Vgl. BSE், Bd. 25/1954 u. Bd. 14/1973 unter dem Stichwort „Literaturnaja gazeta“" U. Kuznecov/Fingert 1972, S. 223

23 BSE், Bd. 14, 1973

24 Kuznecov/Fingert 1972, S. 227

25 BSÉ, Bd. 24, II, 1977, S. 414 f.

26 Kuznecov/Fingert 1972, S. 228

.27 s.o.

$28 \mathrm{Da}$ es sich hier um ein loses Blatt handelt, das dem Bd. 1966 beigefügt ist, läBt sich nicht mit Sicherheit feststellen, in welcher Ausgabe der LG es erschien. 
die Veröffentlichung von Leserzuschriften bereitzustellen gedenkt. Nach Kuznecov/Fingert machen die Leser von dieser Möglichkeit der Meinungsäußerung regen Gebrauch. Es wird von ca. 30000 Leserbriefen im Jahre 1967 und sogar 60000 Zuschriften im Jahre 1970 berichtet. 29

Als Forum für die Auseinandersetzung mit Sprachfragen ist die LG bereits 1934 in Erscheinung getreten. Damals veröffentlichte sie einen Teil des Disputs zwischen Gor'kij und Serafimovič über die Zulässigkeit von Dialektismen und umgangssprachlichen Wendungen in der Belletristik. 30

Die Aufnahme einer speziellen Sprachrubrik erfolgte, wie die Redaktion berichtet, auf Anregung eines Lesers. ${ }^{3} 1$ Im selben Jahr führen allerdings noch zwei weitere sowjetische Zeitungen ähnliche Sprachspalten ein, nämlich die Zeitung Rabotnica (,Jazyk moj-drug moj") und Sem'ja i škola (,Pogovorim o jazyke"). .2 Bereits zwei Jahre zuvor hatte der sowjetische Rundfunk damit begonnen, eine feste Sendung zu Sprachfragen unter dem Titel „V mire slov“ auszustrahlen. 33 Die Verantwortung für diese Rubriken tragen - außer in der LG - Mitarbeiter des IRJaz: Krysin und Skvorcov sind zuständig für die Rundfunksendung, Efimov für ,Jazyk moj - drug moj“ und für „Pogovorim o jazyke" Reformatskij.34 Diese Tatsache und die Gleichzeitigkeit, mit der Sprachglossen nicht allein in drei verschiedenen Zeitschriften, sondern auch im Rundfunk auftreten, läßt eine den einzelnen Redaktionen übergeordnete Planung vermuten.

Tatsächlich sind auch gewisse Parallelen zu Aktivitäten der tschechischen Linguistik, auf deren Sprachkulturtheorie sich das IRJaz bezieht ${ }^{35}$, nich $z u$ übersehen.

29 Kuznecov/Fingert 1972, S. 230

30 Die Diskussion ist bibliographisch erfaßt in: Sovetskoe literaturovedenie i krütika 1966 in dem Abschnitt ,.Literaturnye diskussii . . . o jazyke, S. 343; Näheres cdazu siehe bei Muratova 1958, S. 354 ff und Eismann 1978, S. 73 f.

$31 \mathrm{Vgl}$. dazu die redaktionelle Vorbemerkung in der LG $80 / 64$.

32 Kostomarov/Švarckopf 1965, S. 123

33 Proť̌enko 1974, S. 11; vgl. auch Kostomarov/Švarckopf 1965, S. 123

34 Kostomarov/Švarckopf 1965, S. 123

35 Vgl. z.B. Skvorcov 1970, S. 78 ff., ders. 1980. Einen Überblick über die Prager Sprachkulturtheorie bietet der Sammelband von Scharnhorst/lsing (1976); in Kaur. form auch Girke 1977. 
Die tschechische Linguistik hatte bereits Ende der vierziger Jahre erkannt, welch wichtige Rolle die Massenmedien bei der Propagierung sprachlenkender $\mathrm{M}_{2} ß n$ ahmen in der Bevölkerung spielen. Daher begann das Institut für tschechische Sprache gleich nach seiner Gründung im Jahre 1946, sowohl den Rundfunk als auch die Presse für die Spracherziehung der Bevölkerung einzusetzen: im Rundfunk wurde eine regelmäßige Sprachsendung eingeführt, und Zeitungen erhielten Sprachecken. 36

Dies wiederum war eine Konsequenz aus der Einsicht, dab man bei der Planung und Durchführung sprachpolitischer MaBnahmen den Sprachbenutzer nicht länger völlig außer acht lassen konnte. Tschechische Linguisten hatten nämlich beobachtet, da $B$ in der breiten Offentlichkeit Tendenzen, wie besonders puristische Bestrebungen, noch derart fest verankert waren, daB sie die sprachpolitische Arbeit behinderten, obwohl sie von der theoretischen Sprachwissenschaft längst als überholt abgetan worden waren. 37 Daraus leitete die tschechische Linguistik die Aufgabe ab, „sich einerseits mit diesem ständigen Sprachbenutzer zu beschäftigen, seine Ansichten und Haltungen zu analysieren und gleichzeitig ständig einen Dialog mit ihm zu führen."38

Ein solcher Dialog - für den sich als Forum Sprachecken geradezu anbieten sollte nicht nur der sprachlichen Erziehung der nicht mehr schulpflichtigen Bevölkerung dienen, sondern auch Außerungen der Sprachbenutzer über ihre Ansichten zu Sprachgebrauch, Sprachnormen und Sprachpolitik auslösen, die durch die Veröffentlichung greifbar und somit auswertbar werden. Von Untersuchungen derartiger Meinungsäußerungen versprach man sich Aufschluß darüber, auf welchem Bewußtseinsstand der Sprecher die Propagierung sprachlicher Maßnahmen ansetzen müse, auf welche Weise dieses Bewußtsein beeinflußt werden könne und welche eventuellen Vorurteile dabei auszuräumen seien. Auf der anderen Seite erwartete das Institut für tschechische Sprache von dem Kontakt mit dem Sprachbenutzer eine realistische Ein-

38 ebd., S. 339 
schätzung des Bedarfs, aber auch der Grenzen möglicher Eingriffe in den Sprachgebrauch. 39

Das Auftauchen von Sprachrubriken in sowjetischen Zeitungen dürfte demnach auch darauf zurückzuführen sein, daß das IRJaz in den sechziger Jahren in Anlehnung an die Erfahrungen der Prager Linguistik beginnt, die Presse systematisch in seine Arbeit einzubeziehen. In diesem Sinne begrüßen Kostomarov und Švarckopf die Einrichtung von Sprachecken, denen sie eine bedeutende Rolle für die sprachliche Erziehung der breiten Offentlichkeit beimessen. 40 Beide Mitarbeiter des IRJaz sehen eine Auseinandersetzung mit den Ansichten der Sprachbenutzer zu ihrer Sprache und der Kodifikation als dringliche Aufgabe der Sprachkultur an. 41

Hier bietet gerade die LG mit ihrem Anspruch, wichtige Probleme der sowjetischen Gesellschaft mehr als andere vergleichbare Zeitungen unter Einbeziehung von Meinungsäußerungen der Leser zu erörtern, zusammen mit ihrer großen Verbreitung denkbar gute Voraussetzungen für einen Dialog mit dem Sprachbenutzer. Einschränkend muß an dieser Stelle gesagt werden, daß die LG ihre Leserschicht vorwiegend in höheren Bildungsschichten findet. Mehrere Umfragen in den Jahren 1968, 1970 und 1973 haben ergeben, daß ein überaus großer Prozentsatz der befragten Leser eine höhere oder sogar Hochschulausbildung aufwiesen. 42 Es kann also kaum erwartet werden, daß sich an den Diskussionen über Sprachfragen die breite Masse der Bevölkerung beteiligt.

Andererseits stellt sie sich ihren Lesern als Forum zur Verfügung, damit sie ihre Meinung zur Sprachpolitik öffentlich äußern können. Die Frage, wie die Sprachrubrik den zweifellos unterschiedlichen Anforderungen nachkommt, ob sie primär den Bedürfnissen des IRJaz oder aber denen der Sprachbenutzer entspricht, gilt es in der Untersuchung zu beantworten.

39 ebd., S. $341 \mathrm{f}$.

40 Kostomarov/Svarckopf 1965, S. 123

41 dies. 1966, S. 22 und Svarckopf 1970, S. 283

42 Vgl. FomiXeva 1978, S. 9 und die Tabellen 4 und 5, S. 31 ff. 
II Die Sprachbeiträge in der Literaturnaja gazeta als Forum für Sprachdiskussionen

- Auswertung des Materials -

1. Entwicklung der Sprachrubrik in der Literaturnaja gazeta 1964-1978

Seit der Einrichtung einer speziellen Rubrik im Jahre 1964 sind in der LG regelmäßig Beiträge zu Problemen der russischen Standardsprache vertreten. Sie haben von Anfang an einen festen Platz in der Zeitung: zunächst die Seite 2 (bzw. 2 und 3, oder 3), nach der Neukonzipierung der LG zu einer 16-seitigen Wochenzeitschrift 1967 die Seite 6 (bzw. 6/7 oder 7). Die Rubrik, die anfangs ,Služba russkogo jazyka" heißț. wird 1971 umbenannt in „Jazyk i vremja“. 1977 läuft sie unter dem Titel „Russkij jazyk - spornye problemy" und 1978 schließlich unter „Kak my govorim, kak my pišem“.

Der Eröffnung der Rubrik „Služba russkogo jazyka“ in der Nr. 80/64 geht ein Leserbrief voraus, in dem die Einrichtung einer „Služba cistoty russkogo jazyka" vorgeschlagen wird. 43 Wie der Name der Rubrik bereits andeutet, ist sie konzipiert als Sprachdienst zur Beantwortung von Leserfragen durch Sachverständige. Diese Struktur sticht besonders 1964 und 1965 hervor, wo unter SLUŽBA thematisch nicht zusammenhängende kurze Leserbriefe veroffentlicht werden, denen ein Kommentar des Schriftstellers L.I. Uspenskij folgt. Letzterer wird gemeinsam mit K.I. Čukovskij als für die Rubrik verantwortlich genannt. Während sich Čukovskij jedoch nur selten beteiligt, spielt Uspenskij eine wichtige Rolle für die Sprachspalte: neben der ihm zugewiesenen redaktionellen Verantwortung und seiner daraus resultierenden regelmäßigen Teilnahme vor allem - wie noch zu zeigen sein wird - wegen seiner Stellung unter den unterschiedlichen Verfassern von Beiträgen für diese Rubrik.

43 Vgl. dazu den Leserbrief von Ponomarev unter der Uberschrift „O čem nam piłut", in: LG 72/64, S. 1 und den redaktionellen Vorspann zur Eröffnung der Rubrik in der LG 80/64, S. 2. Der Übersichtlichkeit halber wird der Name der Rubrik im folgenden als SLUŽBA wiedergegeben. 
Ebenfalls in den ersten beiden Jahrgängen wird deutlich, daß eine offene und breite Erörterung sprachlicher Probleme innerhalb der Rubrik ursprünglich nicht geplant war. Zusammenhängende Diskussionen über Sprachfragen werden 1964 und 1965 zwar auf derselben Seite geführt, auf der auch die SLUŽBA zu finden ist, stehen jedoch unter der Rubrik für Diskussionsreihen über allgemeine Probleme der sowjetischen Gesellschaft "Spor idet". Unter dieser Rubrik werden alljährlich Artikelreihen abgehandelt. Dabei geschah die Einordnung der Orthographiediskussion von 1964 unter "Spor idet" aus aktuellem Anlaß. Zuvor waren nämlich die Vorschläge für eine damals geplante, sehr einschneidende Orthographiereform 44 in der sowjetischen Presse veroffentlicht worden, was auch außerhalb der LG in der Bevölkerung eine stürmische Auseinandersetzung über den Sinn einer Veränderung der Orthographie auslöste. 45 Die Erörterung des Themas, „Schriftsteller und sprachliche Norm", die 1965 unter "Spor idet" zu finden ist, schliebt an zum Teil erwähnte ähnliche Diskussionen fruherer Jahre an 46 und ergibt sich aus der Funktion der LG als Organ des Schriftstellerverbandes.

Während unter SLUŽBA kurze kommentierte Leserbriefe erscheinen, enthalten die Diskussionsreihen unter "Spor idet" umfangreiche, vorwiegend von Schriftstellern aber auch von Sprachwissenschaftlern verfaßte Artikel. Die Orthographiediskussion wurde zwar durch eine Leserzuschrift ausgelöst, den zweiten, eigentlichen Teil der Diskussion, in dem die anfangs nur spärliche Erorterung nach drei Monaten Unterbrechung wieder aufgenommen wird, bestreiten jedoch ausschließlich Schriftsteller und Linguisten.

1966 und 1967 fehlt die Rubrik SLUŽBA. 1966 erscheinen lediglich weitere Reaktionen von Schriftstellern zur Diskussion von 1965. 1967 sind dagegen vorwiegend Leserbriefe zu sprachlichen Fragen zu finden, die jedoch unter die allgemeine Leserpost (,Poťta redaktora") eingeordnet werden.

$44 V_{g l}$. dazu die Reformvorschläge, veröffentlicht in Izvestija 228/64 (24.9.64)

45 Bukčina/Kalakuckaja/Cel'cova 1969, S. 5

46 siehe S. 18 
1968 wird die Sprachecke auf Bitten von Lesern neu eingerichtet 47 , wobei allerdings der Sprachdienstcharakter zurücktritt. Letzteres mag darauf zurückzuführen sein, daß die Aufgaben eines reinen Beratungsdienstes in Sprachfragen seit 1967 von zwei anderen, direkt dem IRJaz unterstellten Institutionen ausgeführt werden, nämlich von dem telefonischen Sprachdienst des IRJaz (,Skoraja lingvističeskaja“) 48 und der Zeitschrift Russkaja reł' (RR), die dieser Aufgabe regelmäßig nachkommt. 1971 findet die Konzeptionsänderung der Rubrik, unter der nun auch längere Diskussionsreihen veröffentlicht werden, ihren Ausdruck in der Umbenennung in ,Jazyk i vremja". 49

Es gibt Anzeichen dafür, daß die Rubrik seit der Neueinrichtung in enger $\mathrm{Zu}$ sammenarbeit mit dem IRJaz gestaltet wird. So geht die Aufgabe des Kommentierens und Beantwortens von Leserzuschriften, die anfangs L.I. Uspenskij erfüllt hatte, auf Mitarbeiter des IRJaz über, auf L. Kapanadze und L.P. Krysin (1968), A. Babkin (1972), F.P. Filin (1973 und 1974), L. Rachmanova und N. Formanovskaja (1977) und K.S. Gorbačevič (1969 und 1978).

Außerdem erscheinen in der Zeit von 1967 bis 1975 regelmäBig Artikel über die Arbeit des IRJaz. Diese Beiträge unterscheiden sich von den übrigen nicht nur thematisch, sondern auch durch ihre Einkleidung in größere Artikelformen wie z.B. Reportagen, Rezensionen und Interviews. Hierzu gehören eine Reportage über den telefonischen Sprachdienst des IRJaz 50, ein Interview mit dem leitenden Herausgeber von RR, Borkovskij, mit zwei RR-Aufsätzen 51, die Rezension von Gorbačevič's Buch "Izmenenie norm russkogo jazy a $^{\text {" } 52}$, eine Replik zu einem Aufsatz aus RR53 und zwei Interviews über Wörterbuchprojekte 54 .

47 Vgl.: redaktioneller Vorspann zu Borovoj 2/68

48 Barykin 34/67

49 Vgl: Red. 34/71

50 Barykin 34/67

51 ,Znat' i ljubit'“ $51 / 68$

52 Petuškov $40 / 71$

53 Es'kova 29/68

54 "Kakoj nam nužen slovar'?“ 23/72 und „U slovarnych bogatstv“ $16 / 75$ 
1965 - also kurz vor der zweijährigen Unterbrechung und der anschließenden Umgestaltung der Sprachrubrik - hatten die Mitarbeiter des IRJaz, Kostomarov und Švarckopf, in einem Uberblick über die Arbeit des Instituts die Einrichtung von Sprachspalten in Zeitschriften zwar lobend hervorgehoben, gleichzeitig aber auf die fehlende Planung solcher Rubriken von seiten einer kompetenten Institution, also auf die mangelnde Einflußnahme des IRJaz aufmerksam gemacht:

„K sožaleniju zdes' ne suščestruet ex̌če produmannogo plana; vybor obsuždaemych problem i faktov vo mnogom slučaen, poď̌as slepo sleduet pis'mam, polučaemym redakcijami; recomendacii neredko plocho motivirovany. Vsja èta dejatel'nost' ostro nuždaetsja $v$ tščatel'no razrabotannom strategičeskom i taktiČeskom planach, ischodjašcich iz kompetentnoj i avtoritetnoj štab-kvartiry."55

Die Anderung der Sprachrubrik unter stärkerem Einfluß des IRJaz mag eine Konsequenz dieser Forderung von Kostomarov und Švarckopf gewesen sein. Denn auch das ungeplante Nebeneinander der je nach Leserzuschrift wechselnden Themen, das die Verfasser mißbilligen, verschwindet seit 1968. Fortan verbindet ein thematischer Zusammenhang die einzelnen Beiträge, die teilweise aufeinander Bezug nehmen. 1971, 1973, 1976 und 1978 wird die Rubrik das ganze Jahr über von einem zentralen Thema bestimmt. Die Redaktion der LG fungiert dabei als Diskussionsleitung, indem sie Zusammenhänge herstellt, für den Leser, der die Auseinandersetzung nicht von Anfang an verfolgt hat, die vorangegangenen Artikel kurz referiert oder zumindest erwähnt und eine Auswahl von Leserbriefen zu diesem Thema veröffentlicht. 


\section{Die Verfasser der Sprachbeiträge \\ und ihre Rolle in der Literaturnaja gazeta}

Als Autoren von Beiträgen für die Sprachrubrik der LG wurde bereits zwischen drei Personengruppen - Schriftstellern, Linguisten und Lesern - unterschieden. Diese von der Redaktion der LG vorgegebene Kategorisierung wird hier deswegen übernommen, weil sie sich insofern als sinnvoll erweist, als sie die unterschiedlichen Positionen der Autoren hinsichtlich ihrer Möglichkeiten, auf die offizielle Sprachpolitik des IRJaz Einfluß zu nehmen, widerspiegelt. Wenn auch nicht explizit erwähnt, wird hier differenziert zwischen den Vertretern der offiziellen sprachpolitischen Instanz - den Linguisten -, der Zielgruppe der Sprachpflege - den nicht linguistisch ausgebildeten Sprachbenutzern, hier den Lesern - und den Schriftstellern als Experten für die Sprachpraxis.

Hin und wieder ergaben sich Schwierigkeiten, die Verfasser der Beiträge in der LG diesen drei Gruppen zuzuordnen. So sprengten einige Aufsätze ihrem Umfang nach den Rahmen von Leserzuschriften, ohne daß die Verfasser von der Redaktion eindeutig als Schriftsteller oder Sprach wissenschaftler ausgewiesen wurden. In einigen Fällen halfen hier auch Schriftstellerverzeichnisse nicht weiter. Oft mögen dies Beiträge von festen Redaktionsmitarbeitern gewesen sein. Für die Beschreibung der Teilnehmer und ihrer Rollen in der Auseinandersetzung waren diese Aufsätze wenig aufschluBreich und fanden daher hier keine Berücksichtigung.

Die insgesamt 215 untersuchten Beiträge teilen sich auf die Personengruppen wie folgt auf:

\begin{tabular}{|c|c|c|c|c|}
\hline \multicolumn{2}{|l|}{ Beiträge von } & \multicolumn{2}{|c|}{ von der Redaktion initiierte Beiträge } & \multirow{2}{*}{$\begin{array}{l}\text { nicht eindeutig } \\
\text { zuzuordnende } \\
\text { Beitrïge }\end{array}$} \\
\hline Schriftstellern Laien & Linguisten & $\begin{array}{l}\text { Artikel von } \\
\text { Redaktionsmindiedem }\end{array}$ & $\begin{array}{l}\text { Diskussionen } \\
\text { Incerviews }\end{array}$ & \\
\hline $62(54)^{56}$ & 33 & 4 & 6 & 16 \\
\hline
\end{tabular}

56 Unter den 62 Beiträgen sind allein 8 von Uspenskij, in denen er gemäß seiner Aufgabe als für die Sprachrubrik Verantwortlicher lediglich Leserbriefe kommentiert. 


\subsection{Die Schriftsteller: „mastera slova“ oder Vorbilder für normgerechten Sprachgebrauch?}

Die von Schriftstellern verfaßten Artikel dominieren in der Sprachrubrik, weil sie wesentlich umfangreicher sind als die anzahlmäßig deutlich überwiegenden Leserbriefe. Im einzelnen beteiligen sich folgende Schriftsteller:

Fedor Abramov (1972), Michail Alekseev (1971), P. Antokol'skij (1965), Nikolaj Atarov (1971), Aleksej Baruzdin (1965, 1971), Georgij Berezko (1971), Viktor Bokov (1964, 1973), Leonid Borisov (1968), Maja Borisova (1971, 1974, 1976), Vladimir Civilichin (1965), Kornej Čukovskij (1964, 1965), Iosif Dik (1968), Il'ja Fonjakov (1973, 1978), Anatolij Gladilin (1974), Vera Inber (1964), V.M. Isakovskij (1964), Aleksej Jugov (1965), Semen Kirsanov (1964), Lev Kondyrev (1964), Vadim Koževnikov (1971), Aleksandr Kron (1965), Boris Laskin (1964), Leonid Leonov (1964), Vil' Lipatov (1971), Fedor Malov (1966), V.A. Morozov (1964), Boris Možzev (1976), Vsevolod Roždestvenskij (1971, 1974), Nikolaj Rylenkov (1964), Mariètta Šaginjan (1964), Galina Serebrjakova (1964), Viktor Šklovskij (1964), Vladimir Solouchin (1971), Aleksandr SolŽenicyn (1965), Vasilij Subbotin (1978), Semen Surtakov (1971, 1978), Ljudmila Tat'janiXeva (1971), Lev Uspenskij (1964, 1965, 1968, 1971, 1972, 1975, 1978), Konstantin Vaň̌enkin (1978), Sergej Vasil'ev (1964), Evgenij Vinokurov (1972, 1973), Sergej Zalygin (1973) und Tamara Žirmunskaja (1976).

Schriftsteller spielen in sprachpolitischer Hinsicht eine doppelte, in sich widersprüchliche Rolle. Einerseits dienen sie - als "mastera slova" - mit ihrer Sprachpraxis den normengebenden Institutionen als Richtinie bei der Aufstellung von Sprachnormen, andererseits werden ihnen spracherzieherische Aufgaben zugewiesen. Man erwartet von ihnen, daß sie die Entwicklung der Sprache vorantreiben, was Verletzung der bestehenden Norm impliziert, gleichzeitig sollen sie aber, um der Bevölkerung einen vorbildlichen Sprachgebrauch zu vermitteln, eben diese Norm besonders streng einhalten.

In der Sprachrubrik der LG wird diese Widersprüchlichkeit insofern aufgelöst, als die Mehrzahl der zu Wort kommenden Nichtschriftsteller eine klare Tren- 
nung zwischen den anerkannten großen Dichtern von Pußkin bis Majakovskij und den zeitgenössischen Schriftstellern vornimmt. Sie gestehen dabei ausschließlich den anerkannten großen Dichtern die Rolle der "mastera slova“ zu. Die "großen Meister" dienen den Diskussionsteilnehmern sowohl in ihrer Sprachverwendung als auch in ihrer sprachkritischen Haltung als maßgebende Leitbilder zur Beurteilung des gegenwärtigen Sprachzustandes.

Die Klassikerzitate oder deren Paraphrasierung, die bei den jeweiligen Themen in die Diskussion eingebracht werden, scheinen zum Allgemeinwissen zu gehören. Bekannt gemacht werden sie in der Sowjetunion durch Anthologien, die, nach Schriftstellern geordnet, deren Aussprüche über Sprache - insbesondere über die russische - verzeichnen. 57 Gedacht sind sie zum einen für Lehrer, denen sie als Nachschlagewerk für den Literatur- und Sprachunterricht dienen sollen 58 , oder aber als Handbuch für junge Schriftsteller, um ihnen für die Vervollkommnung ihres „Handwerks" die Erfahrungen der Klassiker bereitzustellen 59 . Geht es um Fremdwörter, fallen unweigerlich die Namen Lomonosov60, Belinskij61, Krylov62 oder Karamzin63. Einer Auseinandersetzung über Dialektismen fehlt selten die Erinnerung an Gor'kij's Auftreten in der Sprachdiskussion von 1934.64 Besonders an diesem Beispiel wird deutlich, daß hier mit Allgemeinplätzen operiert wird: der Inhalt von Gor'kij's Bemerkung steht nicht zur Debatte - der nichteingeweihte Leser erfährt nicht einmal, was Gor'kij gesagt hat. Die Verfasser begnügen sich damit, den Dichter zu nennen:

„O dialektizmach, o mestnych narexijach, ob archaizmach v chudožestvennoj literature v svoe vremja dostatočno govorili $i$ Gor'kij i Lunačarskij.“ (Gorbunov 22/69)65

57 Solche Anthologien sind 2.B.: Russkie pisateli o jazyke (XVIII - XXvv), pod red. B.V. Tomaśevskogo i Ju. Levina, Leningrad 1954 und Russkie pisateli o jazyke (Chrestomatija), pod red. A.M. Dokusova, Leningrad 1954

58 Russkie pisateli o jazyke (Chrestomatija) 1954, S. 3

59 Russkie pisateli o jzz yke (XVIII - XXvv), 1954, S. 3

60 z.B. Birjukov 44/71

61 2.B. Uspenskij $68 / 64$

62 z.B. Birjukov $44 / 71$

63 z.B. Grigorjan 20/69; zu diesen Traditionsbeweisen vgl. auch: Keipert 1978, S. 305

64 siehe S. 18

65 ähnlich auch: Nikolaev 48/73, Rož destvenskij $29 / 74$ 
Ebenso allgemeinbekannt und abgegriffen scheint eine Bemerkung Puskins zu sein, die an einer Stelle wörtlich zitiert wird:

„Istinnyj vkus sostoit ne $v$ bezotčetnom otverženii takogo-to slova, takogo-to oborota, no $v$ čuvstve sorazmernosti i soobraznosti. "66

Die darin enthaltene Kombination „sorazmernost' i soobraznost"“ im Zusammenhang mit Sprachgefühl taucht stereotyp in einer ganzen Reihe von Beiträgen auf, so z.B. auch in der Überschrift eines Artikels von Uspenskij (,Sorazmerno i soobrazno“). 67

Auch die Sprachverwendung der „großen Meister" wird zur Beurteilung der gegenwärtigen Sprachpraxis als Maßstab angelegt. Teilweise halten die Verfasser derart starr am Sprachgebrauch der Klassiker fest, daß sie, wie etwa der Leser Žilin, eine zeitgenössische Formulierung als unzulässig ablehnen, weil sie zur Zeit Puškins nicht verständlich gewesen wäre. 68

Hinter einer solchen Kritik verbirgt sich die Angst vor einem Traditionsbruch, die Befürchtung, daß das klassische Kulturgut bei einem fortgesetzten Abweichen von der Sprache der Klassiker nachfolgenden Generationen nicht weiter vermittelt werden kann. Der Physiker Blochin etwa sieht die Zeit kommen, in der die Jugend weder die Werke Pułkins noch Tolstojs, ja nicht einmal mehr die des Sowjetschriftstellers Šolochov lesen kann, wenn die Struktur des Russischen weiterhin durch Konstruktionen wie 'proizvodit'l osuščestuljat' + Verbalsubstantiv" statt des einfachen Verbs zerstört werde 69.

Nur einige wenige Stimmen warnen davor, den gegenwärtigen Sprachzustand am Sprachgebrauch der Klassiker zu messen:

„Stalo uže nedobroj tradiciej v diskussijach na zlobu dnja, to est' - sovremennom sostojanii jazyka chudožestvennoj literatury, I'vinuju dolju vystuplenij posvja Y̌čat' primeram iz klassikov (...).

66 zitiert nach Grigorjan 10/69; dieses Zitat findet sich übrigens auch an exponierter Stelle bei Ljustrova/Skvorcov/Derjagin 1978, S. 3; in den Anthologien Russkie pisateli o jazyke (XVIII-XXvv), 1954. S.73, Russkie pisateli o jazyke Chrestomatiia; 1954 . S. 115

67 Uspenskij 28/75, Uspenskij $17 / 78$

68 Zilin (38/71)

69 Blochin $8 / 76$ 
Odnako, takie kivki v storonu korifeev (gde nado i gde ne nado) uvodjat razgovor $v$ storonu: ret' to idet o segodnjašnich literaturnych delach." (Nersesov 33/76) 70

Von den zeitgenössischen Schriftstellern - und damit auch oder gerade den an der Sprachseite beteiligten - erwartet man dagegen in erster Linie, daß sie ihren spracherzicherischen Pflichten nachkommen:

„My, učitelja, učim detej. No pisateli, Zurnalisty 'učat' samye širokie krugi naselenija. Nastol'ko bol'še dolžno byt' ich otvetstvennost'“ (Korostyleva 46/73)

„Bezgramotnost' ne smešna, a vozmutitel'na - s nej nado borot'sja $s$ oružiem v rukach. I takim oružiem dolžno byt' pero pisatelja." (Andreeva 44/71)

„ChudoŽestrennaja literatura, chudožestvennye teksty - velikaja i glavenstvujuščaja sredi vsech prožich (TV, kino, radio ...) škola pravil'noj kul'turnoj reti.“ (Prijma 25/78)

Ebenso wie Prijma betrachten die meisten Teilnehmer an der Sprachrubrik die Belletristik als das wichtigste Instrument, mit dem der Sprachgebrauch der Bevölkerung beeinflußt werden kann. ${ }^{71}$ Ihrer Vorstellung nach akzeptiert die Bevölkerung die Sprache des Schriftstellers als Muster für vorbildlichen Sprachgebrauch und ahmt sie daher nach. Sowohl Sprachwissenschaftler als auch Laien befürchten, daß Abweichungen des Schriftstellers von den Standardnormen von Laien unkritisch übernommen werden könnten, da sie den Laien die Fähigkeit absprechen, gültige Normen des Russischen von schriftstellerischen Experimenten zu unterscheiden. Deshalb fordern sie vom zeitgenössischen Schriftsteller eine besonders strikte Einhaltung der Standardnormen, um so einer Ausbreitung und Verfestigung von Normabweichungen in der Bevölkerung vorzubeugen:

„Reč' pisatelja stavjat primerom, ej sleduet naśs čitatel', i poètomu neopravdannoe, nemotivirovannoe, inogda gruboe narušenie obščeprinjatoj, uzakonennoj literaturnoj normy neprostitel'no." (Gorbačevič 12/72)

70 ähnlich bei Petuškov 40/71

71 Ausnahmen bilden Rubakin (31/74), der den Einfluß wissenschaftlicher Fachlitera. tur höher schätzt, und Borisova (20/76), die den Medien mehr Bedeutung beimißt. 
„Chudožnik slova nikogda ne dolžen poryvat's obł̌̌eprinjatymi jazykovymi normami, vsegda objazan dumat' o povyక̌enii svoej reCevoj kul'tury. $\mathrm{Z}_{a}$ dal'nejł̌ie sud'by velikogo russkogo jazyka my otvetstvenny vse, a pisateli v osobennosti." (Filin 16/76)

„Mne kažetsja, Eto $v$ chudožestvennoj literature, kak nigde, trebuetsja berežnoe otnošenie $k$ slovu, $k$ jazykovym normam. $U$ kogo že učit'sja jazyku, kak ne u literatorov, osobenno u tech, kotorye scitajutsja znatokami narodnoj reti." (Filimonov 27/73)

Diese ambivalente Beurteilung der Rolle des Schriftstellers stellt indes keine Besonderheit der Sprachrubrik in der LG dar, sondern ist, wie aus einem Aufsatz von Kalinin in der Nr. 50/73 hervorgeht, in den Lehrbüchern für den Literaturunterricht angelegt. Kalinin zeigt hier am Beispiel der umgangssprachlichen und der dialektalen Lexik, daß die Einbeziehung außerstandardsprachlicher Lexik unterschiedlich bewertet wird, je nachdem, ob sie von einem anerkannten großen Dichter oder von einem zeitgenössischen Schriftsteller vorgenommen wird. So wird seinen Ausführungen zufolge die Verwendung von Dialektismen getadelt, es sei denn, es handelt sich z.B. um ein Werk Nekrasovs. In diesem Fall deute man die sonst negativ bewerteten Dialektismen zu Elementen des positiv markierten „volkssprachlichen Wortguts“ um. 72

Die in den LG-Beiträgen von 1964-1978 auffallende Trennung zwischen einerseits sprachschöpferischen „mastera slova“ (Klassikern und bereits anerkannten Zeitgenossen) und andererseits dem Gros der zeitgenössischen Schriftsteller mit einem rein spracherzieherischen Auftrag, geht wohl auf Gor'kij zurück. Denn spätestens seit der Sprachdiskussion der Jahre 1933 und 1934 mahnte Gor'kij zur Rückbesinnung auf die sprachlichen Traditionen der vorrevolutionären russischen Klassiker. Die neuen Schriftsteller - vor allem die Arbeiterund Bauernkorrespondenten - weist er auf ihre Verantwortung gegenüber der Bevölkerung hin, die die Standardsprache erst erlernen muß. Er war es auch, der für eine Orientierung der Sprachpolitik an der klassischen russischen Literatursprache plädierte und dies kraft seiner Autorität gegen Einwände von 
Serafimovič oder Panferov, die für eine stärkere Ausrichtung an der Sprachpraxis der Bevölkerung eintraten, durchzusetzen vermochte. ${ }^{73}$

Die meisten in der Sprachrubrik vertretenen Schriftsteller wehren sich dagegen, ihre sprachpolitische Bedeutung auf den rein erzieherischen Aspekt reduziert zu sehen. Sie beanspruchen, daß man ihnen ebenso wie den „großen Meistern" eine gewisse Eigenständigkeit im Umgang mit der Sprache zugesteht. Das Verbot, gültige Normen zu übertreten, weisen sie entschieden zurück und betonen, daß die Sprachentwicklung gerade über die bewußte Sprengung der bestehenden Norm vorangetrieben werde:

,Zadą̌ pisatelja - uchodit' ot literaturšxiny, ot obvetłalosti slov, postojanno vozvraščat' slovam žiznennuju sut'." (Bokov 6/73)

„Chudožestvennaja literatura - Żivoj process, otražajušcij živuju そ̌izn' i živuju reč', i esli pisatelju zapretit' vychod za predely jazykovoj normy, vse tut Že zasochnet $i$ ostanovitsja." (Vanšenkin 23/78)

Die Schriftsteller begreifen sich selbst als die allein für die Evolution der Sprache zuständige Instanz und begründen dies damit, daß nur ein Schriftsteller das hierfür erforderliche Sprachgefühl besitze. ${ }^{74}$ Während sie dem Laien jegliche Fähigkeit zu aktiver Mitarbeit bei der Veränderung der Sprache absprechen 75, weisen sie dem Sprachwissenschaftler die Aufgabe des Beobachtens und Beschreibens der durch die Schriftsteller bewirkten Veränderungen $\mathrm{zu}^{76}$.

Ihnen fehlt es allerdings oft an Selbstbewußtsein, um ihr eigenes Rollenverständnis konsequent durchzusetzen. Stattdessen greifen auch sie zur Absicherung auf die „großen Meister" zurück, wenn es darum geht, ihre eigenen Forderungen nach uneingeschränkter Auswahl der sprachlichen Mittel zu formulieren. 77

Eismann 1978

74 2.B. Vinokurov 48/73, Gladilin 32/74

75 z.B. Vanšenkin 23/78, Vasil'ev $109 / 64$

76 Jugov $128 / 65$

77 z.B. Solouchin $45 / 71$, Vinokurov $7 / 72$, Zalygin $46 / 73$ 


\subsection{Die Laien: „bolel'šciki za jazyk“}

Die eigentliche Zielgruppe sprachpolitischer Aktivitäten - die weder sprachwissenschaftlich ausgebildeten noch schriftstellerisch tätigen Laien - ist auf der Sprachseite der LG ausschließlich in Form von Leserbriefen vertreten.

Wie bereits in Kapitel 11.1. angedeutet, sind die Leserbeiträge innerhalb der Rubrik deutlich von den Artikeln der Linguisten oder Schriftsteller abgehoben. 78 Manchmal veröffentlicht die Redaktion nur Auszüge aus den Briefen. ${ }^{79}$ Zuweilen werden die Zuschriften durch das Layout - kleinere Satztypen und engerer Schriftsatz - von den übrigen Beiträgen unterschieden oder ausdrücklich als "Leserbriefe“ (,pis'mo v redakciju“ oder "mnenie Citatelja") gekennzeichnet. 80

An der Erörterung von Problemen des Standardrussischen in der LG beteiligen sich erheblich mehr Laien, als aus der Anzahl der abgedruckten Briefe zu entnehmen ist. In redaktionellen Anmerkungen, aber auch in Beiträgen anderer Diskussionsteilnehmer wird von einer riesigen Flut von Leserbriefen gesprochen:

"Ogromnoe količestvo pisem, kotoroe polučaet naša gazeta ot titatelej ..."(Red. 16/75)

„.. ogromnyj potok Kitatel'skich pisem ..."(Kurtynin, 25/71)

„... za korotkoe vremja v redakciju prisło svy̌̌e dvuchsot pisem.“ (Red. 25/71) 81

Neben derartig pauschalen und deshalb nicht sehr aussagekräftigen Angaben gibt es auch deutliche Hinweise dafür, daß über die publizierten Zuschriften hinaus noch zahlreiche Leserbriefe an die Redaktion gesandt, aber nicht veröffentlicht wurden. So werden unveröffentlichte Briefe in einigen Beiträgen - besonders aber in redaktionellen Vorbemerkungen - erwähnt oder sogar in-

78 Vgl. auch S. 22

79 2.B. sechs Leserbriefausz üge in der LG 38/71

$80 \mathrm{Vgl}$. LG 38/71, 42/71, 33/76

81 ähnlich: Babkin 41/72, „Ctob slovom ... "52/78 
haltlich referiert. 82 Mehrmals schreibt die Redaktion, sie habe Briefe an Sachverständige zur Beantwortung weitergeleitet, etwa an die Linguisten Babkin (1972) und Filin (1974) oder aber an den Schriftsteller Vanšenkin (1978). 83

Was die soziale Zugehörigkeit der Verfasser von Leserbriefen betrifft, so läßt sich leider aus dem Material keine genaue Aufschlüsselung erstellen, da dafür die Angaben über Beruf und Wohnort, zumal auch diese nur sporadisch angeführt werden, nicht ausreichen. In den Beiträgen taucht häufig die Formulierung auf, es beteiligten sich Leser unterschiedlichen Alters und Berufes - von Philologen bis zu Kolchosarbeitern - aus allen Teilen der Sowjetunion: ". . . ta strastnaja zainteresovannost', s kotoroj o russkom jazyke, o russkoj reči pišut ljudi raznych vozrastov, professij $i$, možet by t' samoe glavnoe, raznych nacional'nostej . . " (Glazkov 49/78) „Sredi avtorov korrespondencij - literatory i žumalisty, rabočie i kolchozniki, učenye i studenty ..." (Red. 25/71)

„Sredi avtorov pisem narjadu s pisateljami, učenymi, učiteljami i ljudi po svoej professii dalekie ot filologii, no s glubokoj zainteresovannost'ju sud'bami russkoj rexi." (Babkin 41/72)

Bereits ein Úberblick über die Angaben zu Beruf und Wohnort der Verfasser von veröffentlichten Briefen führt jedoch zu anderen Ergebnissen: Bei zweiundzwanzig von insgesamt achtundvierzig Leserbriefen, in denen die Berufe der Verfasser genannt werden, setzen diese einen Universitätsabschluß voraus: Lehrstuhlinhaber, wissenschaftliche Mitarbeiter und Arzte. Weitere zehn Leserbriefverfasser sind als Lehrer oder Didaktiker tätig, haben also mindestens eine Ausbildung an einem pädagogischen Institut abgeschlossen. Ungefähr die Hälfte der Leser, deren Berufe erwähnt werden, können auf eine intensive sprachliche Ausbildung zurückgreifen: Philologen, Lehrer, vor allem aber Verlagslektoren und Journalisten. Ansonsten beteiligen sich von 1964 bis 1978 fünf Ingenieure und sechs Facharbeiter.

Die breite Masse der Bevölkerung - der "massovyj čitatel"“ - ist also so gut wie gar nicht vertreten. Im Beobachtungszeitraum machte die Bevölkerung

82 z.B. bei: Uspenskij 68/64, 37/65, Red. 34/71, Red. 29/71, „Russkij jazyk ... $16 / 73$ u. öfter

83 Filin 16/74, Babkin 41/72, Vanšenkin 23/78 
mit einem Bildungsniveau, wie es für die angegebenen Berufe vorausgesetzt wird, etwa 10\% der Gesamtbevölkerung der Sowjetunion aus. 84 Eine Beteiligung anderer Bildungsschichten konnte allerdings kaum erwartet werden, da sich, wie bereits eingangs erwähnt, die Leserschaft der LG aus Vertretern eben dicser Bildungskreise zusammensetzt ${ }^{85}$.

Bis auf wenige Ausnahmen kommen die Leserzuschriften aus größeren Städten (42 von insgesamt 54 Angaben), davon mehr als ein Drittel allein aus Moskau und Leningrad. Tatsächlich haben 18 ihrer Verfasser als Adresse einen Wohnort in Republiken angegeben, in denen das Russische nicht als erste Verkehrssprache gilt: neun leben in der Ukraine, die anderen in Kazachstan, Usbekistan, Tadžikistan, Azerbajdžan, Dagestan, Kirgisien oder Turkmenien. Zuschriften aus letztgenannten Republiken kommen allerdings aus Industriestädten (Baku, Tałkent, Ševtenko, Duß̌anbè, Kant) mit einem hohen Anteil an russischer Bevölkerung. Ihre Verfasser - Ingenieur, Philologe, Arzt und Facharbeiter - sind mit großer Wahrscheinlichkeit nicht Vertreter der autochthonen Bevölkerung, sondern eher aus dem russischen Teil der Sowjetunion zugewanderte Fachkräfte, was ihre russischklingenden Namen bestätigen. 86

Zusammenfassend lassen sich die Leserbriefverfasser folgendermaßen charakterisieren: sie sind in erster Linie Städter, sprechen Russisch als Muttersprache und haben eine höhere bis Hochschulausbildung absolviert. Damit erfüllen sie alle von Krysin aufgestellten Kriterien eines Standardsprechers. 87 Es kann also vorausgesetzt werden, daß sie mit den Normen der Standardsprache vertraut sind und sich überwiegend dieser Sprachform bedienen.

84 1970 wurden bei einer statistischen Erhebung, bei der von einer lesamtbevölkerung von 241.7 Millionen ausgegangen wurde. 24.3 Millionen Sowjetbürger mit einem Abschluß der 'srednee special'noe obrazovanie' bis 'vysśee obrazovanie' gezählt: siehe dazu: Narodnoe obrazovanie 1971. Tabelle .'Cislennost' naselenija, imejuščego vyshee i srednee (polnoe i nepolnoe) obrazovanie.", S. 23

85 siehe $\mathrm{S} .20$

$86 \mathrm{~V}$ l.: Lorbunov 28/69. Kosinskij 20/69. Nersesov 33/76. Ponomarev $72 / 64 \mathrm{u}$. 80/6 4. Einen Ausnahme ist der Philologe Chodi.Zade aus Dušanbe (38/71).

(7) Vol.s. Is 
Die Beteiligung von Laien an der Erörterung sprachlicher Probleme wird von den übrigen Diskussionsteilnehmern - Schriftstellem und Linguisten - sehr zwiespältig beurteilt.

Die Redaktion der LG ruft ihre Leser dazu auf, sich mit Kritik und Vorschlägen aktiv in der Sprachrubrik zu engagieren:

„.. . priglałaem nałsich Kitatelej prinjat' aktivnoe učastie $\mathbf{v}$ rubrike Služba russkogo jazyka, kotoruju my vozobnovljaem. Ždem pisem s kritičeskimi zamečanijami, nabljudenijami, predloženijami." (Red. 18/71)

Von allen beteiligten Personengruppen wird das Interesse der Laien an der Sprache, ihre Sorge um das Schicksal des Russischen lobend hervorgehoben:

„OCen' raduet to, čto $v$ poslednee vremja tak zametno vozros interes $\mathbf{k}$ jazyku $\mathbf{v}$ samych گirokich titatel'skich krugach. Bor'ba za tistotu našej reči možet vestis' tol'ko obకtrimi silami." (Kalinin 27/73)

„Privet vam - bolel'šxiki za jazyk. Vy delaete bol'šoe delo!““ (Uspenskij 68/64)

,Možno tol'ko privetstvovat' entuziastov-gramoteev, dobrovol' cev, vyšedšich na propolku reðevoj nivy, bezžalostno korそujuštich slovesnye sornjaki raznogo roda." (Vasil'ev 112/64)

Andererseits klagen sowohl Sprachwissenschaftler als auch Schriftsteller ständig über den Dilettantismus, mit dem Laien Sprachprobleme beurteilen. 88 Derselbe Uspenskij, der im obigen Zitat den Einsatz der Laien für ihre Sprache rühmt, mißbilligt an anderer Stelle, daß in den Leserbriefen „viel Lärm um nichts“ geschlagen werde. 891968 gebraucht er die Bezeichnung „,bolel'ščiki za jazyk" nicht mehr mit der positiven Konnotation „aufrichtiger Kämpfer“, wie 1964, sondern eher abwertend im Sinne von "penetrante Nörgler":

„No kak ćasto my - ja govorju sejęas ne o specialistach po jazyku i literature, a o toj orgomnoj armii čestnych 'bolel'šcikov za jazyk', kotorye pominutno rutsja $\mathbf{v}$ boj protiv ego porči, zasorenija, iskaženija, kotorye vopijut o ego blizkoj gibeli - kak často my ne obrał̌čem nikakogo vnimanija na kategoričeskuju nadobnost' primenjat' tam i tam soverłenno različnye merki." (Uspenskij 15/78)

$88 \mathrm{Vgl}$. Efimov 34/64, Uspenskij 129/64, Lejtes $62 / 65$

89 Uspenskij 84/64 
Diese Zwiespältigkeit entsteht dadurch, da $B$ hier unterschiedliche Vorstellungen über die sprachkritischen Aufgaben von Laien aufeinanderstoßen. Die Erwartungen, die Linguisten und Schriftsteller in dieser Hinsicht an den Laien stellen, stimmen nicht mit dessen Selbstverständnis überein.

Es sind drei unterschiedliche Bereiche, für die die Verfasser der Leserbriefe ein Mitspracherecht beanspruchen:

Nahezu alle beteiligten Laien fühlen sich berechtigt, die Sprachbeherrschung ihrer Mitbürger, oder besser der Mit-Laien, zu kontrollieren. Die meisten Leserbriefe sind Beschwerden über die Unzulänglichkeit des Sprachgebrauchs anderer, über deren tatsächliche oder vermeintliche Verstöße gegen die Norm der russischen Standardsprache. Abweichungen werden registriert, gesammelt und in einem Brief an die LG bekanntgegeben. Oft gehen die Zuschriften kaum über reine Materialsammlungen hinaus. 90 Vielfach wird der Fundort der Normabweichung - etwa ein Hinweisschild oder eine Zeitungsausgabe mitgeteilt. Hier werden „Mißstände“ in der Erwartung gemeldet, daß die dafür zuständige Institution Abhilfe schafft. So wünscht der Leser Blochin ausdrücklich, daß das Institut für Sprachwissenschaft der AN SSSR Stellung zu einer von ihm beobachteten Abweichung bezieht. 91 Der Leser Seleznev ist überzeugt davon, daß unpassende Ausdrücke oft erst durch das Eingreifen besorgter Sprachbenutzer aus dem Verkehr gezogen worden seien. 92

In dieser Selbsteinschätzung wird der Leser sowohl von den Linguisten als auch von den Sprachwissenschaftlern bestätigt. In einem Schriftstelleraufruf werden die Leser der LG ausdrücklich dazu aufgefordert, Beispiele für Normabweichungen im alltäglichen Sprachgebrauch zusammenzutragen.93 Auch der IRJaz-Mitarbeiter Babkin würdigt eine derartige Mitwirkung von Laien als

90 z.B. die Briefe von Guljanickaja (5/68), Zluktenko (18/71), Reznik (18/71), Mocarev (4/65), Moiseev (96/65), Abdullin (96/65), Firsov (23/68), Rubakin (31/74).

91 Blochin $8 / 73$

92 Seleznev $16 / 75$

93 Alekseev/Baruzdin u.a. 21/71 
hilfreiche Unterstützung des Instituts bei der Beseitigung sprachlicher Unzulänglichkeiten. 94

Ein Teil der Leser hält sich darüber hinaus für berechtigt, die sprachliche Form auch literarischer Texte zu kritisieren. 95 Hier treffen sie jedoch auf starken Protest der beteiligten Schriftsteller, die eine Auseinandersetzung über ihre Sprachanwendung mit dem ihrer Meinung nach inkompetenten Laien ablehnen und daher kaum auf derartige Zuschriften eingehen. Das Urteil eines Laien über den Sprachstil des Dichters kann ihrer Meinung nach nicht gelten, weil der Laie den funktionalen Unterschied zwischen Alltagssprache und literarischem Ausdruck nicht berücksichtigt. So beanstandet der Schriftsteller Vasil'ev, daß die Verfasser von Leserbriefen alles sprachlich Ungewöhnliche ohne Unterschied behandeln und somit auch die lyrische Ausdrucksweise als falschen Wortgebrauch brandmarken.96 K. Vanšenkin unterstellt den. Lesern sogar, sie begäben sich bei der Lektüre eines literarischen Textes regelrecht auf Fehlerjagd.97 Die Schriftsteller gestehen dem Laien also wohl das Recht zu, sich zum alltäglichen Sprachgebrauch, nicht aber zur literarischen Sprache zu äußern.

Anders wird dies von einigen Linguisten gesehen, die den Laien durchaus ermuntern, literarische Werke hinsichtlich ihrer sprachlichen Form zu kritisieren. Vinogradov etwa bedauert, daß die breite Masse der Leser dieser Aufgabe viel zu selten nachkomme. 98

Aber auch Sprachwissenschaftler weisen die Leserbriefverfasser in ihre Schranken, sobald diese nämlich mit Kritik oder Vorschlägen den unmittelbaren Zuständigkeitsbereich des IRJaz betreten. Die Verfasser entsprechender Briefe als linguistisch nicht ausreichend qualifiziert bezeichnend, weichen sie einer Auseinandersetzung über ihre Tätigkeit aus:

95 Vgl. z.B. Cernuchin 38/71, Avrachov 38/71, Filimonov 27/73, Korostyleva 46/73

96 Vasil'ev 109/64

97 Vanšenkin $23 / 78$

98 Vinogradov $70 / 64$ 
„Ne sleduet dumat', kak èto mne kažetsja, čto pri prinjatii novych pravil nado pribegat' $k$ zatjažnomu parlamentarizmu, kogda mnenie teoretikov i praktikov, to est' specialistov po pravopisaniju, budut beskonetno i bezdokazano oprovergat' ljubye aktivno mysljašcie ljudi, javljajuščiesja $\mathbf{v}$ ètoj oblasti diletantami." (Efimov 34/64)

Sie unterstellen den Laien, aus Unkenntnis objektiver Bewertungskriterien allein nach ihrem subjektiven Geschmack zu urteilen:

„Ne vsegda možno doverjat'sja sobstvennomu jazykovomu vkusu i na ètom osnovanii otricat' ili utverždat' suščestvujuščie, no subektivno ocenivaemye slova i vyraženija"“ (Skvorcov 80/64)

Der Direktor des IRJaz, F.P. Filin, reagiert sehr herablassend, ja polemisch auf den von einem Journalisten unterbreiteten Vorschlag, ein Sprachzentrum einzurichten:

„No znaete, čto ja vam skažu - mnogie takie predloženija otrałajut manilovšcinu i svidetel'stvujut o nekompetentnosti ich avtorov." 99

Nun ist Filins Reaktion durchaus verständlich, wenn man bedenkt, daß dem vorgeschlagenen Zentrum Aufgabengebiete zugedacht wurden, für die - wie er selbst betont - das von ihm geleitete IRJaz zuständig ist. Der Leservorschlag bedeutet insofern also eine Unkenntnis oder sogar Mißachtung der offiziellen Institutionen.

Auch Uspenskij hält die Laien nicht für kompetent genug, um sprachliche Probleme angemessen beurteilen zu können:

„Oni (bolel'šciki za jazyk - die Verf.) chotjat osuščestvljat' vsesojuznuju, vserossijskuju službu čistoty russkoj rěci. (. . .) No razumeetsja, daleko ne vsegda ich jazykovednoj kvalifikacii dostatočno dlja étogo. Ne vse trebovanija obosnovany, ne každoe zametanie spravedlivo ne vse 'rekomendacii' mogut polutit' 'dobro' so storony nauki o jazyke." (Uspenskij 68/64)

Wenn die Leser zur aktiven Mitarbeit an der Sprachrubrik aufgefordert werden, erwartet man also von ihnen in erster Linie, daß sie Normabweichungen des alltäglichen Sprachgebrauchs sammeln und an die Redaktion einschicken 
oder aber auch Fragen zu konkreten Problemen stellen. Als gleichwertige Gesprächspartner bei der Erörterung von Sprachfragen werden sie jedenfalls nicht akzeptiert. 100

2.3. Die Sprachwissenschaftler als Vertreter der offiziellen Sprachpolitik

Die Linguisten, die in der Sprachrubrik der LG zu Wort kommen, sind gröBtenteils Mitarbeiter des IRJaz und vertreten daher unmittelbar die Interessen der normgebenden Instanz. Sie wirken an den Auseinandersetzungen also nicht so sehr aus persönlichem Interesse und eigenem Antrieb mit, wie dies vor allem bei den Laien aber auch bei den Schriftstellern erwartet werden kann, sondern nehmen im Auftrag des IRJaz Stellung zu aufgeworfenen Problemen.

Im besonderen gilt dies für Vinogradov, Filin und Skvorcov, die eine leitende Stellung im Institut innehaben oder -hatten.

VV. Vinogradov und F.P. Filin treten in der LG als Direktoren des IRJaz auf. Vinogradov, der bis 1968 diesen Posten einnahm 101, beteiligte sich in den Jahren 1964, 1965 und 1967; nach dem Amtswechsel 1968102 tritt sein Nachfolger Filin auch in der Sprachrubrik an seine Stelle, denn von 1972 bis 1976 äußert er sich regelmäßig zu Sprachfragen.

L.I. Skvorcov vertritt das Institut 1975 und 1978 als Leiter der Sektion für Sprachkultur. 103 Auch Babkin (3 Beiträge 1972), Avilova (1969), Derjagin (1969), Es'kova (1968), Grigor'ev (1966), Kapanadze (1968), Krysin (1968),

100 Schon 1964 hat Mariètta ${ }_{2}$ ginjan im Rahmen der Diskussion um die Orthographiereform beobachtet, daß Leserbriefe nur scheinbar gleichberechtigt veröffentlicht werden. Bei den an der Diskussion in verschiedenen sowjetischen Zeitungen beteiligten Linguisten vermißt sie ein angemessenes Eingehen auf kritische Leserbeiträge: Šaginjan $126 / 64$.

101 Russkij jazyk 1979, S. 42

102 dass., S. 370, und Trubačev 1978, S. 84

103 Vgl. Skvorcov 40/75 
Maksimova (1964), Prottenko (1972), Rachmanova (1977) und Formanovskaja (1977) gehören dem IRJaz an.

Andere Linguisten, die in der Sprachrubrik mit Beiträgen vertreten sind, bekleiden Positionen in Universitäten und Pädagogischen Instituten. Kalinin, der mehrmals in die Diskussion eingreift (1971, 1973, 1975, 1976), ist Professor für Journalistik an der Moskauer Universität (MGU), an der auch Efimov derzeit Lehrstuhlinhaber war. Birjukov wiederum leitet den Lehrstuhl für russische Sprache am Gor'kij-Institut für Weltliteratur.104

In Vorbemerkungen zu den jeweiligen Beiträgen klärt die Redaktion ihre Leser nicht nur über die berufliche Stellung, sondern auch über die Titel der einzelnen Linguisten auf. Avilova, Bragina, Es'kova, Derjagin, Gorbačevið und Grigorjan werden als "kandidat filologiteskich nauk" vorgestellt. Bei Vinogradov, Filin und Barchudarov wird darüber hinaus ihre Mitgliedschaft in der Akademie der Wissenschaften erwähnt, die in der UdSSR mit hohem gesellschaftlichen Ansehen verbunden ist. 105

Durch solche Hinweise stattet die Redaktion die Sprachwissenschaftler von vornherein mit einer Autorität aus, die weder den Schriftstellern, geschweige denn den Leserbriefverfassern zuteil wird. Diesen ihnen zugestandenen Autoritätsvorsprung spielen die Linguisten denn auch an gegebener Stelle Laien und Schriftstellern gegenüber aus, indem sie betonen, daß allein die linguistische Fachausbildung dazu befähige und legitimiere, über Sprachangelegenheiten zu urteilen. 106 Wie bereits gesagt, wird dies wohl von den Schriftstellern in Frage gestellt, selten jedoch von Laien. Die Laien verlangen oft ausdrücklich nach einer Stellungnahme von kompetenten linguistischen Fachkräften. 107

Die Linguisten beschränken sich in der Sprachrubrik zunächst vorwiegend auf die Beantwortung von Leseranfragen. Als Sachverständige unterstützen sie

104 Diese Angaben finden sich jeweils in redaktionellen Vorbemerkungen.

$105 V_{\text {gl }}$ : Kasack 1972. S. 29

106 Avilovai Derjagin 13/69. Grigor 'ev 12/66, .Russkij jazyk . . " 16/73

107 so z.B.: Sakk 80;64. Bèlza 15/69. Blochin 8:73 
dabei die Verfasser in "richtigen" Urteilen oder aber korrigieren "falsche" Aussagen.108 Manchmal greifen sie auch konkrete Anfragen auf, um daran einzelne Sprachprobleme ausführlich zu erläutern. 109

In einigen Artikeln wird darüber hinaus versucht, dem Leser Hintergrundwissen zu vermitteln. Hier werden solche Aspekte behandelt, deren Berücksichtigung man in den Leserbriefen vermißt, wie z.B. die stilististische Differenziertheit der Standardsprache, der dynamische Charakter von Sprachnormen oder die Abhängigkeit sprachlicher Aussagen von der kommunikativen Situation, in der sie stehen. 110

Beide Aufgabenbereiche übernimmt während der ersten Jahre, in denen die Rubrik besteht, der Schriftsteller L.I. Uspenskij, den die Redaktion als Verantwortlichen eingesetzt hat. 111 Hinsichtlich seiner Rolle unter den Teilnehmern ist er also weniger der Gruppe der Schriftsteller zuzuordnen als vielmehr den Linguisten. Dem entspricht auch die Tatsache, $d_{2} \beta$ er, wie oben erwähnt, die Linguisten in ihrem Autoritätsvorsprung gegenüber den Laien bestärkt.

Sprachwissenschaftler treten in der LG ferner als Gesprächspartner in von der Redaktion initiierten Interviews auf. Hier ergreifen sie die Gelegenheit, über die Arbeit des IRJaz zu informieren. 112

Selten beginnen die beteiligten Sprachwissenschaftler - wie etwa Vinogradov 1965 und Filin 1976113 - eine längere Diskussion in der LG. Eher wird eine Auseinandersetzung durch Veröffentlichung einer Stellungnahme des IRJaz abgeschlossen, wie z.B. die Artikelreihe über fachsprachliche Terminologie durch den Beitrag Skvorcovs. 114

108 Vgl. z.B.: Kapanadze/Krysin 5/68, Avilova/Derjagin 13/69

109 z.B. Kalinin 21/75, Filin 16/74 oder Gorbačevič 5/78

110 Petułkov 40/71, Kalinin 27/73, Kapanadze/Krysin 5/68, Es'kova 29/68

111 Vgl. dazu die Beiträge von Uspenskij 1964 und 1965 sowie Uspenskij 15/68

112, Znat' i ljubit”“ 51/68, „Kakoj nam nuŽen slovar'?" 23/72 und „U slovarnych bogatstv" $16 / 75$

113 Vinogradov $94 / 65$ und Filin 16/76, beide Diskussionen sind erwähnt bei: Kostomarov 1976, S. 5.

114 Skvorcov $40 / 75$ 
Im großen und ganzen beschränkt sich die Mitwirkung von Linguisten an der Sprachrubrik der LG darauf, die Haltung des IRJaz zu den in Beiträgen anderer Teilnehmer aufgeworfenen Fragen zu vermitteln. 
3. Einstellungen zur Standardsprache und ihrer Realisierung im Sprachgebrauch der russischen Bevölkerung

Bei allen am Meinungsaustausch beteiligten Autoren, die keine spezielle linguistische Ausbildung genossen haben, macht sich deutlich bemerkbar, daß meist klare Vorstellungen darüber fehlen, was Sprache im gesellschaftlichen Kontext leistet, bzw. was sie leisten könnte oder sollte. Sprache wird oft entweder als schutzbedürftiges Ausstellungsstück begriffen, dem der Sprecher bei falscher Behandlung Schaden zufügt, oder aber als vom Sprecher losgelöste, nicht mehr beeinflußbare Erscheinung definiert.

Durchgängig ist eine hohe Bewertung des Russischen anzutreffen, die z. B. darin besteht, daß die russische Sprache stereotyp mit den Attributen "groB(artig)" und "mächtig" bedacht wird:

"... naš moguxij jazyk ... " (Atarov 35/71)

"... naŠemu velikomu i mogučemu jazyku grozit opasnost'.“ (Lipatov 34/71)

"... nałego velikogo i svobodnogo russkogo literaturnogo jazyka

..." (Uspenskij 15/68)

Diese patriotische Gefühle weckenden Epitheta findet man aber auch bei Sprachwissenschaftlem:

„Velikij russkij jazyk sam po sebe dostoin samogo pristal'nogo vnimanija ..." (Filin 15/75)

"... velikij i moguxij russkij jazyk ... “ (Babkin 32/72)

Úber die russische Standardvariante und deren Realisierung durch die Bevölkerung sind die Autoren jedoch geteilter Meinung. Ihre unterschiedlichen $\mathrm{Hal}$ tungen lassen sich zwei entgegengesetzten Lagem zuordnen. Während das eine, an der strikten Einhaltung sprachlicher Normen interessiert, zum Kampf für die Reinheit der russischen Sprache aufruft, steht das andere sprachlenkenden Bestrebungen grundsätzlich skeptisch gegenüber.

- Diese beiden konträren Haltungen zu Sprachfragen sind in der sowjetischen Linguistik unter den Bezeichnungen "purizm" und „antinormalizatorstvo" 
bekannt.115 Der Terminus "Purismus" wird dabei weiter gefaßt als etwa in der westdeutschen Linguistik, wo er ausschlieblich Fremdwortpurismus meint. Skvorcov definiert Purismus als Aversion gegenüber Endehnungen aus Fremdsprachen, aber auch Einflüssen aus Dialekten, Soziolekten, Prostore Xie oder Fachsprachen:

„Purizm (...) - stremlenie otistit' jazyk ot inojazyłn ych slov $i$ vyrał̌enij, ot raznogo roda novoobrazovanij, neprinjatie $v$ lit. reči leksiłeskich i grammatičeskich èlementov, idušcich ot territorial'nych i social'nych dialektov, prostore ${ }_{\mathrm{ijj}}$, professional'nogo upotreblenija i t.p." "116

Antinormalizatorstvo - verstanden als Gegenpol zum Purismus - besteht nach Skvorcov in der Leugnung der Unumgänglichkeit eines bewußten Einwirkens auf die Sprachentwicklung, also in der Nichtanerkennung von wissenschaftlich fundierter Sprachlenkung:

„Protivopoložnost'ju P. (purizma - die Verf.) javljaetsja antinormalizatorstvo - otricanie neobchodimosti soznatel'nogo vmełatel'stva v jazykovoj process i naučnoj normalizacii."117

Uber solche Definitionen hinaus fehlt bisher eine ausführliche Beschreibung der beiden Standpunkte.

Zwischen den Fronten bemühen sich in der LG die beteiligten Linguisten, die Leser in die Grundzüge einer wissenschaftlichen Sprachplanung einzuweisen.

\subsection{Der Kampf für die Reinheit der russischen Sprache}

Für die Teilnehmer, die zum Kampf gegen die Verunreinigung der russischen Sprache aufrufen, ist eine strenge Orientierung an Normen bezeichnend Dabei meinen sie mit der russischen Sprache allein die genormte Standard. variante, für sie die einzig akzeptable Sprachform. Das heißt jedoch nicht, da尺 die Normen, auf die sie sich stützen, unbedingt mit den kodifizierten und der

115 VGl.: Skvorcov 1970, S. 100 f.; ders.: 1980, S. 112; „Predislovie“" in APKR 1970 S. 6 f. und Russkij jzzyk. Ėnciklopedija 1979, S. 244 f.

116 Russkii jazyk. Énciklopediiz 1979, S. 244

117 2.2.O., S. 245 
zeit gültigen Normen des Standardrussischen übereinstimmen. Häufig dient ihnen als Orientierung eher ein Konglomerat aus eigenen, nicht unbedingt der Norm entsprechenden Sprachgewohnheiten, erlernten, aber veralteten neben tatsächlich gültigen Normen.118 Dies führt dazu, dab bisweilen auch Sprachwissenschaftler, ja sogar führende Vertreter des IRJaz, wie etwa Skvorcov, der Normverlezung beschuldigt werden.119

In vielen dieser Beiträge klingt die Vorstellung an, daB die russische Sprache (bzw. die Standardsprache) den Höhepunkt ihrer Entwicklung bereits erreicht habe und daher jede Veränderung einen Niveauverlust bedeute. 120 Eine Angleichung der kodifizierten Normen an den tatsächlichen Sprachgebrauch der Bevölkerung halten die Verfasser för gefährlich, weil sie befürchten, daB das Russische dadurch seine typische Struktur verliere und so ein Uberlieferungsbruch ausgelöst werde.121 Auch wenn bestimmte Normabweichungen in der Bevölkerung bereits gehäuft auftreten, erkennen sie dies nicht als Ausdruck dafür an, daB der tatsächliche Sprachgebrauch die Norm uberholt hat und daher die alte Norm der Sprachentwicklung angepabt werden muB. Ein „Fehler" bleibt ein „Fehler", meint der Schriftsteller Morozov, auch wenn er noch so häufig vorkomme1 22 , und sein Kollege Surtakov führt die starke Verbreitung bestimmter Normabweichungen auf den schlechten Einfluß der Massenmedien zurück. 123

Die Verfechter der puristischen Linie halten es für nötig, daß die russische Sprache ständig geschützt und behütet wird, da sie fortwährend der Gefahr ausgesetzt sei, durch fremde Elemente verunreinigt und entstellt zu werden:

„Stremlenie uberet' russkij jazyk ot vsjateskoj nakipi i kopoti

- odno iz primečatel'nych velenij vremeni." (Tolstichin 101/64)

$118 \mathrm{Vgl}$ :: die Kommentare von Skvorcov (80/64), Uspenskij (92/64) oder Solganik (8/73)

$119 \mathrm{Vgl}$. dazu die Beiträge von Borisov (2/68) und Kapanadze/Krysin (5/68), sowie den angesprochenen Aufsatz von Skvorcov: Skvorcov 1967

120 Karbovskaja 30/68, Alekseev u.2. 21/71, Cernuchin 38/71

121 Blochin $8 / 73$

122 Morozov $101 / 64$

123 Surtakov $47 / 71$ 
„Budem že oberegat' nał jazyk (...) ot nelepych i Čuzdych emu vyraženij." (Firsov, 23/68).124

Als fremde Elemente gelten dabei nicht nur Fremdwörter, sondern jegliche Abweichungen von der Standardnorm, seien es Prostoretie-Elemente, Dialektismen, Technizismen oder Neologismen. Solche nichtstandardsprachlichen Ausdrücke werden mit klischeehaft wiederkehrenden Benennungen bedacht, in denen eine überhebliche und geringschätzige Einstellung gegenüber dem Sprachgebrauch anderer zutagetritt. Solche abwertenden Vergleiche sind z. B. „Wortunkraut" (slova-sornjaki),125 „Wortparasiten“ (slova-parazity)1 26 und „Wortmißgebuiten" (slova-urodcy)127. Oft ist von "Geschwüren" die Rede, die sich in der russischen Sprache festsetzen, von "Krankheiten“ oder von "Schmutz".128 Unterschieden wird zwischen dem "Weizen" und der „Spreu“ (Zaslon slovesnoj šeluche!) 29 oder „flatterhaften“" Wörtern (slovamotyl'ki) und „Wortedelsteinen" (jarkie samocvety slova). 130

Gelegentlich werden so in der emotionalen, von Vorurteilen nicht freien Ablehnung bestimmter Sprachphänomene auch die Verwender solcher Aus. drucksweisen abqualifiziert, weil sie die nach Meinung der Puristen einzig korrekte Sprachform immer noch nicht beherrschen, also vorgeschriebent Verhaltensmuster nicht akzeptieren. Ein besonders krasses Beispiel dafü bietet Roždestvenskij, der solche Sprecher aus dem gesellschaftlichen Leber. verbannt:

„Prodolžaja i ukrepljaja stremlenie $k$ ešce bolee širokoj demokratizacii, $k$ podlinnoj narodnosti, on (literaturnyj jazyk - die Verf.) ne zachočet mutit' svoju čistotu nanosnym sorom vremennych Zargonnych rečenij i vul'garizatorskim uslovnym slovotvorčestvom malych jazykovych grupp, suščestrujušcich vne obక̌ego rusla obščestvennoj žizni." (Roß̌destvenskij 29/74)

124 ähnlich Seliverstova 42/71. Andreeva 44/71

125 z.B. bei: Alekseev/Baruzdin 21/71 oder Kurtynin 25/71

126 z.B. bei: Gazarjan 50/72 oder Blochin 8/73

127 2.B. bei: Red. $29 / 71$ oder Cernuchin 38/71

128 Bedenklicherweise tauchen diese Vergleiche auch in den Beiträgen von Sprachwis senschaftlern auf. Vgl.: Babkin 31/72, Kapanadze/Krysin 5/68, Skvorcov 80/64

129 Alekseev/Baruzdin 21/71

130 Pokrovskij 28/69 
Charakteristisch für die Beiträge des puristischen Lagers ist die Mahnung zur Vorsicht im Umgang mit der russischen Sprache:

,Jazyk - naše nacional'noe bogatstvo, budem že otnosit'sja $k$ nemu berežno i uvažitel'no." (Alekseev/Baruzdin u.2. 21/71)131

Gerade diese Behutsamkeit vermissen sie in der Sprachpraxis der Bevölkerung. In vielen ihrer Beiträge tragen sie Normverletzungen zusammen, die sie bei ihren Mitmenschen beobachtet haben. Außer in der Diskussion von 1978 beziehen sie sich dabei selten auf den Sprachgebrauch insgesamt, sondern kritisieren die Sprachpraxis Einzelner oder bestimmter Personengruppen wie z.B. von Schülern, Studenten und besonders von Schriftstellern. Noch häufiger werden einzelne Wörter oder Ausdrücke außerhalb ihres kontextuellen Zusammenhangs behandelt. Besonders tadelnswert erscheinen den Verfassern Werbetexte132, gängige Formulierungen auf Hinweisschildern 133 und die Sprache der Medien, deren Zustand 1971 eine Welle von Aktivitäten hervorrief. Veranlaßt durch einen Schriftstelleraufruf gegen den desolaten Zustand der Pressesprache werden in vielen Städten Redaktionskonferenzen regionaler Zeitungen einberufen. Man entschließt sich, stilistisch vorbildliche Zeitungsausgaben zu prämieren und ermahnt dazu, Journalisten stilistisch gründlicher auszubilden.134

Es ist die Rede von einem katastrophal niedrigen Niveau der Sprachbeherrschung, das immer weiter abzusinken drohe:

„Bezgramotnost' vo vsech vidach stanovitsja prosto katastrofičeskoj, dnja ne prochodit, čtoby $v$ radio ili teleperedace, na stranicach gazety, Žurnala ili knigi ne vstretilos' grubeǰ̌j ošibki ili ope Łatki." (Gal' 22/78)

„Uroven' gramotnosti $v$ poslednie gody ne povysilsja a skoree ponizilsja." (Roskina, 14/78)135

Als Ursachen für die zunehmende „Verschlechterung“ des sprachlichen Niveaus der Bevölkerung werden drei Gründe genannt:

131 ähnlich auch bei Kurtynin 25/71

132 Borisov 2/68, Zadov 92/64

133 Zadov 92/64, Fonjakov $43 / 73$

134 Kurtynin 25/71, Silina 29/71 u. Red. 29/71

$135 \mathrm{Vgl}$. auch: Cistjakov 14/78, Lebedev 14/78, Povarcov 16/78, Sinel'nikov 31/78, Antokol'skij 7/65, Karbovskaja 30/68, Fonjakov $43 / 73$ 
Die Sprachbenutzer werden beschuldigt, allzu leichtfertig mit ihrer Sprache umzugehen:

„Na moj vzgljad opasnost' ne v zabvenii vyšedłich iz upotreblenija slov, a $v$ oskudenii jazyka Zivogo, sovremennogo, kotoroe proischodit ot ravnodusija $k$ jazyku, ot nebrežnogo i panibratskogo k nemu otnołenija." (Andreeva 44/71)

Zveitens wird in diesem Zusammenhang das Desinteresse vor allem von Jugendlichen an literarischen Werken erwähnt, das man dem Einfluß der Massenmedien, besonders aber dem Fernsehen anlastet. 136 Andererseits warnen gerade die Diskussionsteilnehmer, die um die Reinerhaltung des Russischen besorgt sind, vor dem schlechten Einfluß der zeitgenössischen Schriftsteller mit ihrem Hang zu Normabweichungen auf den Sprachgebrauch von Heranwachsenden. 137 Es ist daher anzunehmen, daß bei der Jugend in erster Linie die Lektüre klassischer russischer Literatur vermißt wird.

Schließlich trifft Kritik auch den Schulunterricht. Antokol'skij etwa hält der Schule vor, sie messe dem muttersprachlichen Unterricht zu wenig Bedeutung bei. 138 Beanstandet wird, daß in den Klassen neun und zehn der Russischunterricht gänzlich fehle1 39 und in den übrigen Jahrgangsstufen zu wenig Unterrichtsstunden dafür zur Verfügung stünden.140 Dem Schriftsteller Fonjakov und der Lehrerin Klenickaja mißfällt die allzu theoretische Ausrichtung des Unterrichts, weil dies die Schüler überfordere und die Zeit für Rechtschreibeübungen einschränke. 141 Die puristische Linie tritt demnach für einen Sprachunterricht ein, der dem Schüler vor allem Regeln für die praktische Sprachbeherrschung bereitstellt und ihre Kenntnis durch Kontrollarbeiten wie z.B. Diktate überwacht. 142 Theoretisches Wissen, das dem Schüler erst ermöglicht, Einsicht in den Aufbau und das Funktionieren der Sprache

136 Karbovskaja 30/68, Fonjakov 43/73, Klenickaja 51/73, Povarcov $16 / 78$

137 Roźdestvenskij 42/71, Cernuchin 38/71

138 Antokol'skij $7 / 65$

139 Arkin $48 / 78$

140 Fonjakov $43 / 73$. Karbovskaja $30 / 68$

141 Fonjakov 43/73, Klenickaja $51 / 73$

142 Roskina fordert. daB mehr Diktate geschrieben werden und wird darin von vielen Lesern unterstützt: Roskina $14 / 78$ 
zu gewinnen und von da aus auch Normen kritisch zu betrachten, halten sie für weniger wichtig oder sogar verunsichernd. 143

Nach Meinung der Puristen wird von offizieller Seite zu wenig untemommen, um die Normen der russischen Standardsprache in der Bevölkerung bekanntzumachen und ihre Einhaltung zu kontrollieren. Deshalb unterbreiten sie in der LG eigene Vorschläge, wie diesem Mangel abgeholfen werden kőnnte:

In zwei Briefen regt 1964 der Leser Sakk an, daß im Rundfunk regelmäßig Sendungen zu Sprachfragen ausgestrahlt werden.144 Seiner Meinung nach sind an solchen Sendungen viele Rundfunkhörer interessiert. In seinem ersten Brief nennt er in dem Zusammenhang eine Sendung mit dem Titel „Besedy o russkom jazyke" und bezieht sich damit wohl auf die kurz zuvor eingerichtete Sprachsendung, deren Titel allerdings von ProtCenko, Kostomarov und Švarckopf als „V mire slov“ angegeben wird.145 Sakk unterstützt also eine Initiative des IRJaz.

Andere Verfasser bringen ihre Unzufriedenheit mit dem IRJaz zum Ausdruck. Wie die Redaktion 1973 feststellt, werden in den Leserzuschriften häufig energischere als nur aufklärende Maßnahmen von seiten des Instituts erwartet. 146

Sehr verbreitet scheint die Überlegung zu sein, Sprachkomitees und gesellschaften in Form von „Bürgerinitiativen“ zu gründen. Uspenskij berichtet 1964, daß viele Leser nach einem Amt zur Bewahrung der Reinheit der russischen Sprache verlangen. 1471973 erwähnt die Redaktion im Zusammenhang mit einem derartigen Vorschlag des Journalisten BaYmakov aus Ussurijsk, daß in der UdSSR bereits mehrere solcher Sprachgesellschaften existieren, die hauptsächlich deswegen gegründet worden seien, weil sich gezeigt habe, daß wissenschaftliche Institutionen nicht in der Lage sind, auf die Sprachpraxis

145 Kostomarov/Svarckopf 1965, S. 123; Proť̌enko 1974, S. 11

146 „Russkij jazyk ..."16/73

147 Uspenskij 68/64 
der Bevölkerung einzuwirken. Der Leser Basmakov hatte dem von ihm vorgeschlagenen Komitee folgende Aufgabengebiete zugedacht: Erarbeitung und Herausgabe von Literatur zu Sprachfragen, Grammatiken und stilistischen Handbüchern, Unterstützung wissenschaftlicher Institute bei der Herausgabe von Fachliteratur und Dokumenten, Erstellung von Texten für Hinweisschilder, Anschlagtafeln und Werbung und schlieBlich die Unterweisung der Bevölkerung im Verfassen von offiziellen Schreiben und Erklärungen.148 Ahnlich hatte bereits 1971 der Schriftsteller Šurtakov die Einrichtung eines Sprachzentrums angeregt, das die Bemühungen von Schriftstellern, Journalisten und Lehrern, die Sprachbeherrschung der Bevölkerung zu verbessern, koordinieren sollte. Surtakovs Vorschlag sah eine enge Zusammenarbeit eines solchen Zentrums mit den Massenmedien als Voraussetzung für eine effektive Durchsetzung der dort ausgearbeiteten Richtlinien in der Sprechergemeinschaft vor. 149

In einigen Beiträgen wird eine stärkere Kontrolle der Sprachpraxis gefordert. So wünscht sich der Leser Zadov eine Instanz, die Hinweisschilder, Reklametafeln und Anschläge auf ihre sprachliche Richtigkeit hin überwacht. 150 Die Leser Kałin und Lipatnikova wollen gar eine "Sprachmiliz" bzw. eine „Sprachpatrouille“ dafür aufstellen.151

Mehrfach wird danach verlangt, daß den Verlagslektoren bei der Bearbeitung von Manuskripten für den Druck größere Rechte eingeräumt werden. Gazarjan befürwortet beispielsweise die Einstellung eines „literaturnyj redaktor" in Verlagen, d.h. eines Lektors, der dafür zuständig ist, die sprachliche Form von für den Druck vorgesehenen Texten zu begutachten und gegebenenfalls aus eigenem Ermessen zu ändern. Nach Gazarjan soll er die „Wortparasiten" gnadenlos aus Manuskripten herausstreichen. 152 Sein Vorschlag wird 1973 von dem Leser Muchov unterstützt. Die Leser Vetkovskij - selbst Lektor -, Rubakin und Kašin äußern ähnliche Vorstellungen. 153

148 Vgl.: „Russkij jazyk . . “ 16/73

149 Surtakov $41 / 71$

150 Zador $92 / 64$

151 Lipatnikova 49/78, KaYin 35/67

152 Gazarjan $47 / 72$

153 Muchov 8/73, Vetkovskij $37 / 72$ und Rubakin 31/74, vgl. auch Kałin 35/67 
Die Verfasser von Beiträgen, in denen puristische Tendenzen anklingen, gehören überwiegend der Personengruppe der Laien an. Unter ihnen sind Arzte (Sakk, Davydov, Rubakin), Naturwissenschaftler (Blochin, Muchov) und Ingenieure (Čistjakov, Junker) ebenso wie Journalisten (Kurtynin, Zadov, Gazarjan) und Verlagslektoren (Vetkovskij, Levin). Aber auch Teilnehmer, bei denen man linguistische Grundkenntnisse voraussetzen kann, wie bei dem Anglistikdozenten Zluktenko oder dem Dozenten für das Fach Russisch Orlov, sind dem puristischen Lager zuzurechnen. Sprachreinigende Ambitionen hegen außerdem einige Schriftsteller, wie z.B. Antokol'skij, Roždestvenskij, Borisov, Alekseev, Baruzdin, Berezko, Tat'janið̌eva, Surtakov und Fonjakov.

\section{2. "Antinormalizatorstvo"}

Während die puristische Linie vorwiegend von Laien vertreten wird, sind es in erster Linie Schriftsteller und nur vereinzelt Laien, die dafür plädieren, der zunehmenden Standardisierung des Russischen Einhalt zu gebieten. Die Standardsprache bedeutet für sie eine nichterwinschte Einheitssprache, die jeglicher individueller Merkmale entbehrt.

Die Gegner der Sprachnormierung - Antinormalizatory - halten sprachlenkende Maßnahmen von seiten des IRJaz für unnötig, weil sie der russischen Sprache die Fähigkeit zuschreiben, aus eigener Kraft ihr schädliche Einflüsse abzuwehren:

Jazyk sam otbrasyvaet slova, $v$ kotorych ne nuzdaetsja, ne prinimaet togo, Zto emu Zuzdo po duchu." (Vinokurov 7/72)

,Jazyk samozatałivaetsja, otbrasyvaja vse izlišestva $i$ urodstva, izgonjaja modnoe i nanosnoe, otsylaja na pokoj ustarev̌̌ee $i$ usvaivaja vse plodotvornoe." (Atarov 35/71)

Hier wird Sprache zum selbstbestimmten, handelnden Subjekt, das aus sich heraus entscheidet, welche Elemente es als nützlich aufnimmt, welche als schädlich abweist. Immer wieder trifft man dabei auf den Vergleich der 
russischen Sprache mit einem alle fremden Elemente aufsaugenden und assimilierenden, mächtigen Meer:

,Jazyk - okean. I ne tak-to prosto zasorit' ego ščepołkami.“ (Vinokurov 7/72)

„Russkij jazyk - éto okean, kotoryj sam neplocho spravljaetsja so svoimi trudnostjami, sam otpravljaet na dno vse, čto segodnja ne nužno." (Abramov 47/72)154

Einige Antinormalizatory vertrauen deshalb darauf, daß sich die eigengesetzli. che Entwicklung des Russischen auch gegen lenkende Eingriffe durchsetz1 und beurteilen daher die Bemühungen von Sprachpflegern als sinnloses Unter. fangen:

„On (russkij jazyk - die Verf.) budet razvivat'sja po svoim zakonam, nezavisimo ot usilij tech, kto chotet napravit' ego v to ili inoe ruslo." (Zor'kin 38/71) 155

Andere warnen vor der Aufstellung und Propagierung von verbindlichen Nor men für den Sprachgebrauch, weil sie befürchten, daß dadurch die natürlich Evolution der russischen Sprache gehemmt werde, das Russische seine Leben digkeit verliere und absterbe.

„,Mne stranny vsjakie popytki ogradit' jazyk ot Zizni, pereseł' ego estestvennoe razvitie, tolknut' $v$ kakoe to zaranee opre delennoe ruslo." (Lanščikov 14/72)

Die genormte Standardsprache verwerfen sie als neutralisiert, farblos unc ausdrucksarm.156 Der Schriftsteller Abramov negiert die Existenz eine solchen Standardsprache. Für ihn stellt sie eine Abstraktion dar, weil sicl ihrer kein einziger Sprecher tatsächlich bediene. Die Verwendung eine normierten Sprache komme dem Genuß von destilliertem Wasser gleich:

„Na normativnom jazyke ne govorit ni odin čelovek - èto vse ravno, Zto pit' destilirovannuju vodu." (Abramov in: Kakoj nam nužen slovar', 23/72) 157

154 ähnlich: Borisova 20/76

155 ähnlich: Gecov 5/68, Solouchin 45/71, Leserbriefe in Red. 34/71

$156 \mathrm{Vgl}$ : Lipatov 34/71, Lev 14/72, Cudakov $41 / 73$

157 ähnlich: Levin 134/65, Civilichin $148 / 65$ 
Statt der von ihm als Abstraktion bezeichneten Standardsprache werde eine Nationalsprache verwendet, die er als ein Gemisch aus den verschiedensten in der Sprechergemeinschaft realisierten Varianten definiert:

„Literaturnyj jazyk - èto ponjatie abstraktnoe - esli chotite, daže fikcija. Ego voobsce (...) net, a est' obß̌cenacional'nyj jazyk, kotoryj sostoit iz raznych plastov, iz raznych slagaemych, i net ni odnogo čeloveka, kotoryj govoril by na Kistom literaturnom jazyke." (Abramov 47/72)

Andere Vertreter des Antinormalizatorstvo stimmen dem nicht zu. Sie stellen bereits Auswirkungen der Normierungsbestrebungen auf die Sprachpraxis der Bevölkerung fest. Weil sie sich viel zu sehr an vorgeschriebenen Normen festklammerten, verwenden ihrer Meinung nach große Teile der Bevölkerung eine ausdrucksschwache, nivellierte Durchschnittssprache - durchsezt von Klischees, leeren Phrasen. 158 Vinokurov widerspricht puristischen Behauptungen, die Bevölkerung weiche in ihrem Sprachgebrauch immer mehr von den kodifizierten Normen ab, vielmehr sei der Grad der Normentreue etwa in literarischen Texten eher gestiegen als gesunken.159 Im Gegensatz zu den Sprachreinigern betrachten aber die Antinormalizatory gerade diese Normentreue als eine Verschlechterung des Sprachniveaus in der Bevölkerung.

„Opasnost' bezlikogo, bescvetno-pravil'nogo, lišennogo vyrazitel'nosti jazyka - sej飞as glavnaja opasnost'." (Lipatov 34/71)

„Net, nado bojat'sja ne korjavosti vyraženija mysli (znatit mysl' truditsja, roß̌daetsja), a priglažennosti, obkatannosti pravil'nogo, no bezlikogo literaturnogo standarta." (Lev 14/72)160

Weniger gefährlich scheinen ihnen, wie im obigen Zitat angedeutet, kleine Ungereimtheiten und Holprigkeiten, die bei der Entwicklung neuer Sprachmuster hin und wieder nicht zu umgehen seien.161

Die russische Literatur von Pußkin bis Šolochov, schreibt Lev, sei voll von derartigen Unrichtigkeiten, für die man dankbar sein müsse.162 Gerade in 158 Rylenkov $96 / 64$, Soľ̌enicyn 131/65. Malov 9/66, Zilin 38/71, Zalygin 46/73,
Anašenkov $47 / 76$

159 Vinokurov $48 / 73$

160 ähnlich: Vinokurov 48/73, Gusev $18 / 76$

161 Borisova 29/71, Zalygin 46/73, Solov'ev $42 / 76$

162 Lev $14 / 72$ 
der gelungenen Abweichung von der Standardnorm zeige sich das individuelle Talent des Schriftstellers: „talant vsegda negramoten".163

Ursachen für eine derart nivellierte Sprachpraxis der Bevölkerung suchen die Laien unter den Antinormalizatory in den Lehrplänen des Russischunterrichts. Der Russischunterricht, so kritisieren sie, vermag die Schüler nicht in der Entfaltung ihrer stilistischen Fähigkeiten zu fördern, weil er sich auf stupide Wortschatzübungen, grammatische Analysen und ständige Diktate beschränke. 164 Sie halten es für falsch, den Schulerfolg einseitig an Rechtschreibefertigkeiten zu messen.165 Der Leser Nikiforov spricht gar von einer Fetischisierung der orthographischen Richtigkeit ("gramotnost' - ne feti'“"), die er dafür verantwortlich macht, daß das stilistische Können der Schüler unterentwickelt bleibe. 166

Die Schriftsteller unter ihnen sehen das Grundübel eher darin, daß die nichtstandardsprachlichen Varianten des Russischen aus dem legitimierten Sprachgebrauch ausgeschlossen werden. So sind regionale Varianten der russischen Standardsprache ebensowenig zugelassen wie Elemente aus Jargons und

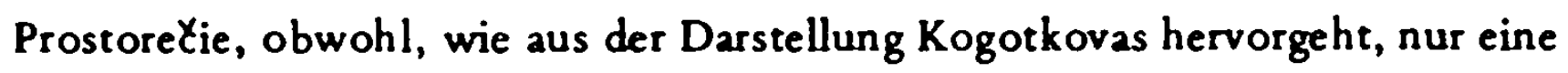
sehr kleine Sprechergruppe reinen Standard spricht.167 Auf diese Diskrepanz weist der Schriftsteller MoŽaev hin, als er Filins Bezeichnung der Dialektismen als „Fremdelemente“ (inorodnye èlementy) 168 für absurd erklärt, da die russische Bevölkerung zu achtzig Prozent aus Bauern bestehe. 169

Die Gegner der Normierung meinen, daß erst durch die Einbeziehung außerstandardsprachlicher Elemente, durch den Einfluß von Dialekten und Soziolekten, die Nivellierung der russischen Sprache wieder aufgehoben werden könne. Das Problem der russischen Sprache bestehe, so betonen sie, in ihrem

163 Gusev $18 / 76$

164 Zuravlev $54 / 64$

165 Plenkin 54/64, Nikiforov $16 / 78$

166 Nikiforov 16/78, ähnlich auch Tekučev $37 / 78$

$167 \mathrm{Vgl}$. auch S. 15

168 Filin $16 / 76$

169 Moźaev 23/76 
Mangel an Elementen aus der "Sprache des Volkes“.170 An der Auslegung des Begriffs "Sprache des Volkes" spalten sich die Antinormalizatory in zwei Lager.

Einige der Schriftsteller verstehen unter der „Volkssprache" die „gute alte Sprache des russischen Dorfes". Sie wollen also die Rückkehr zu einer Sprachform, von der sicher anzunehmen ist, daB sie seit geraumer Zeit nur noch von wenigen Dorfbewohnern der älteren Generation gesprochen wird1 71 - nämlich zum reinen, nicht durch anderssprachige Einflüsse berührten Dialekt.172

Die konservativen, auf Bewahrung alter Sprachzustände gerichteten Ambitionen dieser Linie des Antinormalizatorstvo treten besonders da zutage, wo Sprichwörter und Volkslieder als Muster für vorbildlichen Sprachgebrauch angegeben werden.173 Lipatov bedauert, daß alte Verwandtschafts- oder Münzbezeichnungen nicht einmal mehr im passiven Wortschatz der Bevölkerung vorhanden sind.174 SolŽenicyn schlägt sogar vor, veraltete, nicht mehr gebräuchliche Lexik durch besonders häufige Verwendung wieder zu neuem Leben zu erwecken. 175

Andere Antinormalizatory lehnen eine solche Aufwertung von Archaismen ab1 76 und befürworten stattdessen eine Orientierung an der tatsächlichen gegenwärtigen Sprachpraxis der Bevölkerung, und zwar an der aller sozialen Schichten und Regionen des Landes.

„Pisatel' otražaet to, Xto tvoritsja v živoj jazykovoj praktike millionov, i ètim tasto narułaet normu." (Abramov 47/72)177

170 z B.: Solzenicyn 131/65, Lipatov 34/71, Vinokurov 7/72, Abramov 47/72, Cudakov 41/73

171 Kogotkova 1970, S. 105

172 Vgl. 2.B.: Pokrovskij 28/69, Lipatov 34/71, Cudakov 41/73

173 Vgl.: Bokov $6 / 73$ oder Cudakov $41 / 73$ und $33 / 76$

174 Lipatov 34/71

175 Solženicyn 131/65; dieser Vorschlag wird unterstützt von Čivilichin $135 / 65$.

$176 \mathrm{Vgl}$.: Levin 134/65, Nazarenko $140 / 65$

177 Abramov bezieht sich hier, wie die meisten Schriftsteller in der Sprachrubrik vornehmlich auf den dichterischen Sprachgebrauch. 
Das Russische - so fordert Atarov - dürfe sich nicht völlig der expressiven Umgangssprache gegenüber verschließen. 178 Weder Prostoređ̌e noch Jargons und Fachsprachen sollen aus dem Sprachgebrauch - vor allem des Schriftstellers - ausgeschlossen werden:

"I poźtomu soveršenno nesostojatel'nymi i daže opasnymi predstavljajutsja mne popytki postavit' na puti prostorełija, naučnoj terminologii, gorodskich Žargonov i t.p.vsjačeskie zaslony i plotiny, daže vnedrit' centralizovannoe slovotvorkestvo." (Abramov 47/72)179

Diese Richtung des Antinormalizatorstvo spricht sich gegen eine unreflektierte Verherrlichung all dessen aus, was allgemein als Sprachgebrauch des einfachen Mannes aus dem Volk deklariert wird,180 die man bei einigen Vertretern des konservativen Lagers findet. 181 Anders als die sprachbewahrende Linie steht sie Neuprägungen positiv gegenüber. 182

3.3. Die Haltung der Linguisten in der Sprachrubrik der Literaturnają gazeta

Wie bereits erwähnt stehen die beteiligten Linguisten als Beobachter über der Auseinandersetzung in der Sprachrubrik und greifen nur ein, um als Sachverständige Fragen zu beantworten, Behauptungen anderer Beteiligter richtigzustellen oder eine ihrer Meinung nach in falsche Bahnen geratene Diskussion wieder auf den richtigen Weg zu bringen.

Sieht man von einzelnen Besonderheiten ab, die von der Thematik und dem Verlauf der vorangegangenen Erörterung abhängen, folgen die sprachwissenschaftlichen Artikel im großen und ganzen einem einheitlichen Schema.

Ein wesentliches Element ist die Standortbestimmung der offiziellen Sprachpolitik zwischen Purismus und Antinormalizatorstvo. Dabei wird der starren

$179 \mathrm{Vgl}$. auch : Rylenkov $92 / 64$ und Kolesnikov $30 / 73$

180 Abramov $47 / 72$

181 Vgl.z.B.: Bokov 6/73

182 2.B.: Vinokurov 7/72, Solov'ev $42 / 76$ 
Ablehnung jeglicher Modernisierungstendenzen im puristischen Lager eine ebenso eindeutige Absage erteilt wie der Laisser-faire Haltung des Antinormalizatorstvo.183 Obligatorisch folgt die Warnung vor dogmatischen unwissenschaftlichen Sprachurteilen, die beiden Richtungen vorgeworfen wird.184 In diesem Zusammenhang wird darauf hingewiesen, daß die Norm keineswegs als starres Gerüst aufzufassen ist, sondern als sich stetig verändernde Größe185 und daß einzelne Wörter oder Ausdrücke nicht an sich als falsch oder richtig bewertet werden dürfen, sondern erst in ihrem kontextuellen $\mathrm{Zu}$ sammenhang ${ }^{186}$. Ein aktives Eingreifen in die Sprache und den Sprachgebrauch der Bevölkerung könne und dürfe sich nur auf wissenschaftliche Erkenntnisse stützen. Folglich komme nur dem Linguisten zu, Urteile über Sprache zu fällen und zu entscheiden, welche sprachlenkenden Maßnahmen notwendig und angemessen sind.

Diese Abgrenzung der offiziellen Sprachpolitik als wissenschaftliche Disziplin gegenüber den als unwissenschaftlich verworfenen Ambitionen von Puristen und Antinormalizatory entspricht der Aufgabenstellung des IRJaz, wie sie in dem vom Institut herausgegebenen Sammelband Aktual'nye voprosy kul'tury rę. $\mathcal{C}_{i}$ (APKR) umrissen wird. Im Vorwort zu dem 1970 erschienenen Band heißt es über die Arbeit des Sektors für Sprachkultur am IRJaz:

„V osnove praktǐ̌eskoj dejatel'nosti sektora (...) ležala i ležit bor'ba na dva fronta: s purizmom is antinormalizatorstvom." 187

Ähnlich äußert sich in demselben Sammelband der Leiter der Abteilung für Sprachkultur, L.I. Skvorcov:

„Pozicija naučnoj normalizacii raspolagaetsja meždu poljarnymi točkami zrenija i ocenkami, odna iz kotorych svjazana so stichijnym, ili ,naučnym', purizmom, a drugaja s ubě̌dennym antinormalizatorstvom, appelirujušim neredko $k$ narodnym istokam, demokratižeskim ego osnovam."188

183 Vgl. vor allem: Grigor'ev $12 / 66$ und Birjukov 44/71

$184 \mathrm{Vgl}$. Skvorcov 80/64, Kapanadze/Krysin 5/68, Gorbałevic 47/69, Krysin 3/71

185 Gorbačevič 47/69,5/78, 39/78, Ctob slovom ... (Skvorcov) 52/78

186 Vgl. Kapanadze/Krysin 5/68, Filin 16/73, Kalinin $27 / 73$

187 .Predislovie", in: APKR 1970, S.6f

188 Skvorcov 1970, S. 100 f 
Die wörtliche Ubernahme dieser Feststellung in Skvorcovs 1980 erschienene Arbeit über theoretische Grundlagen der Sprachkultur zeigt, daß sich während des Beobachtungszeitraumes an der Haltung des IRJaz in dieser Hinsicht nichts geändert hat. 189

Bei einigen Laien-Beiträgen ist es sicherlich gerechtfertigt, den Verfassern Dilettantismus bei der Beurteilung von sprachlichen Problemen vorzuwerfen. Andererseits lassen die Beiträge der Linguisten größtenteils eine auch für Laien nachvollziehbare Aufklärung über die wissenschaftlichen Beurteilungskriterien vermissen. Meist erfolgt zwar der Hinweis auf die Relativität sprachlicher Richtigkeit und den dynamischen Charakter von Sprachnormen. Oder es wird das Kriterium der Zweckmäßigkeit genannt und auf die Notwendigkeit aufmerksam gemacht, bei der Beurteilung sprachlicher Fragen das Kommunikationsziel, den Adressaten und die Redesituation zu berücksichtigen.

Solche Erläuterungen, bei denen linguistische Fachausdrücke ohne weitere Erklärungen in den Raum gestellt werden, können aber dem Durchschnittsleser - geschweige denn dem „beruflich weit von der Philologie entfernten“ - kaum helfen, seine eigenen Vorurteile gegenüber bestimmten sprachlichen Äußerungen kritisch zu überdenken und gegebenenfalls abzulegen.

Der Anspruch des IRJaz an die Rolle von Sprachwissenschaftlern in Sprachdiskussionen wird denn auch in der vom Institut herausgegebenen Broschüre „Besedy o russkom slove" anders formuliert:

.Jazykovedy mogut i doľ̌ny opredelit' pričiny porłi jazyka, ukazat' sposoby bor'by s neju, opredelit' puti razvitija i obogaštenija jazyka."1 90

Um dieser Aufgabenstellung gerecht zu werden, bedürfte es solcher Artikel die in für Laien verständlicher Form schrittweise die Grundzüge der Sprach. politik einführen. Ansätze dazu finden sich in der Sprachrubrik aber nur selten, etwa bei Kalinin oder Gorbačevič. 191 
Gorbatevið kritisiert 1978 die Haltung der Linguisten in der Sprachrubrik. Auch er lastet einen Teil der Schuld für den Dilettantismus, mit dem die Bevölkerung in die Auseinandersetzung um Sprachfragen eingreift, den Linguisten an, weil sie dem breiten Leserkreis nur vereinfachte und dogmatische Belehrungen zugänglich machen:

„V složivšemsja položenii (diletantizme $v$ istolkovanii jazykovedð̌eskich problem) ottasti povinny sami jazykovedy. K sožaleniju, tonkaja metodika ich issledovanij, da i sam složnyj, dialektiŁ̌eski izmentivyj ob-ekt izučenija pered łirokim Łitatelem neredko predstajut v uproščennoj i daže dogmatičeskoj traktovke. Uvlekatel'naja dinamika razvitija jazyka, Zestkaja konkurencija starogo i novogo, ostraja bor'ba za vyživaemost' meždu otdel'nymi jazykovymi formami - vse èto, po suß̌̌estvu, ostaetsja v special'nych lingvistiteskich trudach. (...) Ne udivitel'no poétomu, čto umnyj i ljuboznatel'nyj sovremennik, ne udovletvorennyj podobnymi poučenijami, pribegaet $k$ zamančivomu, no uvy, samodel'no-kustarnomu sposobu poznanija istiny." (Gorbačevił 39/78)

Augenscheinlich vertraut das IRJaz allzu sehr darauf, daß die Informationen, die es in Form von populärwissenschaftlichen Broschüren veröffentlicht, von der breiten Masse der Sprachbenutzer tatsächlich rezipiert werden. Dies zeigt schon das Erstaunen, mit dem Kalinin 1971 feststellt, daß derartige Publikationen einem großen Teil der Diskussionsteilnehmer offensichtlich unbekannt sind:

„Nekotorye Citateli predlagajut sozdat' slovari nepravil'nostej". Stalo byt', ne vsem este izvestno tto dvumja izdanijami vysel slovar'-spravočnik Pravil'nost' russkoj re '‘', Zto tri goda nazad izdan ,Kratkij slovar' trudnostej russkogo jazyka', tto natinaja s 1967 goda vychodit nau $X_{n}$ opopuljarnyj Zurnal „Russkaja reł”“ i t.d." (Kalinin 35/71)

Ebenso wird die Bereitschaft des Durchschnittsbürgers, Handbücher und Wörterbücher zu Rate zu ziehen, erheblich überschätzt. Filin rät 1973 den Lesern, sooft wie möglich im Wörterbuch nachzuschlagen,192 und auch Kalinin 
meint, „Zto Zuustvo slova' - èto neobchodimost' vovremja navesti spravku v slovare".193 Filin scheint vorauszusetzen, daß jeder sowjetische Haushalt über ein Exemplar des OZegovschen Wörterbuches verfügt. 194 Bereits absurd mutet die Erwartung der LG-Mitarbeiterin Latynina an, daß nicht linguistisch vorbelastete Leser ein Wörterbuch der russischen Sprache des 11. - 17. Jahrhunderts mit Interesse lesen werden („odnako voz'mut v ruki vyšeď̌ij tom Slovarja russkogo jazyka XI - XVIl vv. i budut čitat' ego s interesom" "195).

Tatsächlich verhindert jedoch schon allein die zu geringe Auflage solcher Lexika oder Handbücher, daß sie von der breiten Masse benutzt werden können. 196 Während der Diskussion um die Orthographiereform beklagt zum Beispiel der Leser Sakk, daß die entsprechenden Handbücher zu Rechtschreibeproblemen längst vergriffen seien.197 An anderer Stelle räumt auch Filin ein, daß Wörterbücher in zu geringer Anzahl veröffentlicht werden. 198 Außerdem geben die Laien zu verstehen, $d_{a} \beta$ sie gar nicht bereit sind, Lexika zu Hilfe zu nehmen, um russische Texte lesen zu können:

„Neobchodimo, ttoby gramotnyj russkij čelovek mog Yitat' proizvedenija, napisannye na russkom jazyke, bez special'nogo slovarja, bez perevodYika." (Černuchin 38/71)

Die Artikel des Schriftstellers Lev Uspenskij ähneln inhaltlich denen der Linguisten. Wenn er auch an manchen Stellen das Interesse von Laien an der Verbesserung des Russischen lobend hervorhebt ${ }^{199}$, betont er doch wiederholt, $\mathrm{d} a ß$ es letztlich nur dem Linguisten zukomme, sprachliche Außerungen zu beurteilen, und nicht dem von seinem subjektiven Sprachgefühl ausgehenden Laien.200 Auch er beschreibt die Norm als veränderliche Größe 201 , relati-

193 Kalinin 29/76

194 „Russkij j2zyk ...“" 16/73

195 "Kakoj nam nužen slovar"“ 16/75

196 Das Schwierigkeitswörterbuch von Rachmanova, Trudnostirusskege jazyka (1974), etwa erschien in einer Auflage von 150000 Exemplaren, das von Gorbačevix, Trudnosti slovouporrebleniia (1974), nur in 40000 Exemplaren für über 120 Millionen Sowjetbürger russischer Sprache.

197 Sakk $37 / 64$

198 .Kakoj nam nužen slovar"“ $16 / 75$

199 Uspenskij 68/64, vgl. Zitat S. 35

$200 \mathrm{Vgl}$. Uspenskij $15 / 68$

$201 \mathrm{Vgl}$. Uspenskij 4/65, 23/72, $17 / 78$ 
viert die bei Laien meist vorhandene Vorstellung einer absoluten sprachlichen Richtigkeit 202 und fordert, den situativen Kontext einer Außerung zu berücksichtigen, bevor man sie dogmatisch als falsch ablehne. 203 Ohne die beiden Lager beim Namen zu nennen, grenzt auch er sich sowohl gegen puristische Tendenzen übereifriger Sprachreiniger als auch gegen die Laisser-faireHaltung der Normgegner ab. 204 
4. Zur konkreten Auseinandersetzung um Sprachgebrauch und Norm

Die Beiträge der Sprachrubrik enthalten konkrete Beispiele für Normabweichungen im Sprachgebrauch der Bevölkerung. Dabei lösen einige Besonderheiten der gegenwärtigen Sprachpraxis umfangreiche Diskussionen aus, während andere nur in Form von Fehlerlisten vorgetragen werden. Solche Meldungen, die sich in der Regel auf Abweichungen im Bereich der Grammatik beziehen, werden meist völlig isoliert von ihrem kontextuellen Zusammenhang vorgebracht, was mir deren Einordnung erheblich erschwerte, in manchen Fällen sogar unmöglich machte. Aus den Beiträgen selbst ging nämlich nur selten hervor, worin die Normverletzung besteht. So tauchte in Fehlersammlungen etwa rabotaet auf, also eine - isoliert betrachtet durchaus normgetreue Form. Um sie als "Fehler" erkennen zu können, muBte man wissen, $d_{2} B$ hier auf beliebte Wendungen wie kafe rabotaet angespielt wurde.

Um zu unterscheiden zwischen zufällig beobachteten Fehlern und solchen Normabweichungen, die in der Sprachpraxis weit verbreitet sind, stütze ich mich auf das von Gorbačevił herausgegebene Handbuch zu Zweifelsfällen der russischen Standardnorm, Trudnosti slovoupotreblenija i varianty norm russkoge literarurnogo jazyka. 205 Dabei gehe ich davon aus, daß hier verzeichnete Wörter als solche bekannt sind, die dem Sprachbenutzer Schwierigkeiten bereiten. Darüber hinaus werden hier typische Normabweichungen als zulässig, begrenzt zulässig oder aber nicht zulässig markiert. Dies gebe ich unter folgenden Kürzeln an:

Ta: Das Wort, für das eine Abweichung gemeldet wird, ist im Handbuch verzeichnet, nicht aber die Abweichung selbst.

Tb: Die Normabweichung wird verzeichnet als zulässige Variante.

Tc: Die Normabweichung wird verzeichnet als begrenzt zulässige Variante.

Td: Die Normabweichung wird verzeichnet als unzulässig. 
Diskussionen entzünden sich an lexikalischen Fragen, insbesondere an Dialektismen, Neuprägungen und Fremdwōrtern.

\subsection{Meldungen von Normverstößen im Bereich der Grammatik}

\subsubsection{Orthoepie}

Das Auftreten von Akzentvarianten im Sprachgebrauch behandeln zwei Beiträge von K. Gorbačevið (47/69 und 12/72), daneben die von Orlov (23/78) und Tolstichin (101/64). Nur am Rande erwähnt werden sie bei Junker (10/78), Kostinskij (31/78) und Uspenskij (129/64).

Beispiele für verbreitete Schwankungen in der Norm:

\begin{tabular}{|c|c|c|c|}
\hline Abweichung & Norm & Quelle & Trudnosti \\
\hline baržá & (bárža) & $\begin{array}{l}\text { Gorbačevið 47/69, } \\
\text { Uspenskij 129/64 }\end{array}$ & $\mathrm{Tb}^{206}$ \\
\hline fenomén & (fenómen) & Gorbačevił 47/69 & $\mathrm{Tb}$ \\
\hline mýslenie & (myšlénie) & Gorbačevie 47/69 & $\mathrm{Tb}$ \\
\hline petljá & (pétlja) & Gorbačevič 47/69 & $\mathrm{Tb}$ \\
\hline po vólnam & (po volnám) & Gorbačevið 47/69 & $\mathrm{Tb}$ \\
\hline premírovat' & (premirovdt') & Gorbačevið 47/69 & $\mathrm{Tb}$ \\
\hline zvónit & (zvonít) & Gorbačevič $47 / 69$ & $\mathrm{Tc}_{\mathrm{c}}$ \\
\hline pozvónit & (pozvonít) & Gorbatevič $47 / 69$ & $\mathrm{Tc}$ \\
\hline
\end{tabular}

206 Erwartungsgemäß stimmten bei den von Gorbałevit angeführten Beispielen ihre Bewertung als zulässige Varianten bzw. Normverletzungen mit deren Kommentierung in Trudnosti überein, da Gorbatevič Herausgeber des Handbuches ist. 
Beispiele für Normverletzungen:

\begin{tabular}{|c|c|c|c|}
\hline Abweichung & Norm & Quelle & Trudnosti \\
\hline alfávitnyj & (alfavitnyj) & Gorbačevǐ̌ 12/72 & $\mathrm{Td}$ \\
\hline bagrjanéc & (bagrjánec) & Gorbačevič $12 / 72$ & Td \\
\hline izdalí & (ízdali) & Gorbatevic $12 / 72$ & $\mathrm{Td}$ \\
\hline nádolgo & (nadólgo) & Gorbačevič $12 / 72$ & $\mathrm{Td}$ \\
\hline nepóXatyj & (nepočátyj) & Gorbačevit 12/72 & $\mathrm{Td}$ \\
\hline okb́n & (ókon) & Gorbačevič $12 / 72$ & $\mathrm{Td}$ \\
\hline perézityj & (perežítyj) & Gorbačevið 12/72 & $\mathrm{Td}$ \\
\hline provédennyj & (provedënnyj) & Gorbąevič $12 / 72$ & Td \\
\hline skréplennyj & (skreplënnyj) & Gorbað̌evič 12/72 & $\mathrm{Td}$ \\
\hline válovyj & (valovój) & Tolstichin 101/64 & $\mathrm{Td}$ \\
\hline
\end{tabular}

Beispiele für tatsächliche oder angebliche Homographe:

$\begin{array}{lll}\text { bronjá - brónja } & \text { Orlov 23/78 } & \text { Ta } \\ \text { jazykí(Sprachen) - jazýki (Zungen) } & \text { Orlov 23/78 } & \text { Td } \\ \text { kuártal (Quartier) - kuartál (Quartal) } & \text { Orlov 23/78 } & \text { Td } \\ & \text { Cistjakov 14/78 } & \\ \text { srédstua - sredstuá } & \text { Orlov 23/78 } & \text { Td }\end{array}$

Beispiele für Akzentabweichungen bei Termini von Fachsprachen:

centner (angeblicher Fachausdruck von Kolchosarbeitern) Orlov 23/78

dóbyča (Bergbau)

Orlov 23/78

Tolstichin 101/64 Tc (prof.)

izobrétenie (angeblich Schaffner-

iskrá jargon)

Orlov $23 / 78$

Td

kompás

Orlov 23/78

Tc

kraný

Orlov 23/78

Tc

Junker $16 / 78$

Tc

Kostinskij 31/78

pressá

Tolstichin 101/64 Tc

rúdnik

Orlov 23/78

Tc

sopló

Orlov 23/78

T: Norm

Der Leser Reznik bemängelt in seinem Artikel (18/71), daß die Betonungsangaben für geographische Namen von Lexikon zu Lexikon differieren. 
1978 beschreibt Gorbatevið eine Tendenz, nach der das graphisch bereits nicht mehr von $e$ unterschiedene $\ddot{e}$ auch als $e$ gesprochen wird:

maneur, ZelX', belesyj, bleknut', souremennyj (GorbaŁevið 5/78)

Umgekehrt hatte Kanaš (52/71), wohl um dieser Tendenz entgegenzuwirken, die konsequente graphische Differenzierung von $e$ und $\ddot{e}$ gefordert.

\subsubsection{Orthographie}

Zu Fragen der Rechtschreibung enthält die LG zwei Arten von Beiträgen, nämlich erstens die, die sich mit der 1964 geplanten Orthographiereform 207 auseinandersetzen, und zweitens solche, die übliche orthographische Fehler auflisten.

Auf die vornehmlich auf den Band 1964 beschränkten Artikel zur Orthographiereform will ich hier nicht näher eingehen, da sie an anderer Stelle bereits besprochen worden sind. 1969 haben Bukčina, Kalakuckaja und Cel'cova eine Broschüre 208 verfaßt, in der sie anhand der Reaktionen der Bevölkerung begründen, warum die geplante Reform nicht durchgeführt werden konnte. Die Autorinnen geben im Anhang ihrer Arbeit einen bibliographischen Uberblick über die damals in verschiedenen sowjetischen Zeitschriften veröffentlichten Stellungnahmen, in dem die LG-Beiträge jedoch nur lückenhaft erfaßt sind.209 Bei genauerer Betrachtung stellt sich heraus, daß hier in erster Linie der zweite Teil der Diskussion - die Aufsätze von Schriftstellern - und aus dem ersten Teil nur der Beitrag von Vinogradov verzeichnet werden, nicht aber die Leserbriefe, die die Diskussion in der LG eingeleitet hatten. Der Vollständigkeit halber seien an dieser Stelle die fehlenden Beiträge aufgeführt:

Sviridenko, „Ne zvuk okostenelyj" ", LG 25/64

Efimov, "Sila tradicii ili ...", LG 34/64

Sakk, "Ugroza . . . novoj reformy", LG 37/64

Plenkin, "Eto vse polumery", LG 54/64

Žuravlev, "Zlaja volYebnica grammatika", LG 54/64 
Die Leserbriefe, in denen übliche Rechtschreibefehler gemeldet werden, illustrieren, daß die Sprachbenutzer dort verunsichert sind, wo Aussprache und Schrift nicht miteinander übereinstimmen. Die angeführten Beispiele gehen auf vier Fehlerquellen zurück:

a) Nichtrealisierung von Doppelkonsonanten: verch, rasmejat'ja (Roskina 14/78)

b) phonetische Schreibweise bei Konsonantenverbindungen: metiki (Junker 16/78)

c) Nichtunterscheidung von stimmhaften und stimmlosen Konsonanten im Silbenauslaut:

špig

d) Verwechslung von $e / i$ und $o / a$ in unbetonten Silben: vintel' Uunker 16/78), Rodił̌̌ev, prinebrezitel'no (Povarcov 16/78), meofonija, filomentnyj (Petrova 11/74), izvenite (Fonjakov 44/78), salist arkestra felormonija (Fonjakov 43/73), perenisli, vateli, kokoj (kakoj), iz karoblja (Roskina 14/78)

Wie letztere, bei weitem häufigste Fehlerquelle zeigt, bereiten Akan'e und Ikan'e als Spezifikum der Standardsprache dem Gros der Sprachbenutzer erhebliche Schwierigkeiten.

\subsection{Morphologie}

Die gemeldeten Normabweichungen im Bereich der Morphologie betreffen in erster Linie das Substantiv:

Fehler in der Wahl des grammatischen Geschlechts werden bei folgenden Wörtern beobachtet:

\begin{tabular}{|c|c|c|c|}
\hline Abweichung & Norm & Trudnosti & Quelle \\
\hline $\begin{array}{l}\text { ket malosol'nyj } \\
\text { povidloj } \\
\text { manžetom }\end{array}$ & $\begin{array}{l}\text { keta } \\
\text { povidlom } \\
\text { manžetojl } \\
\text { manžetom }\end{array}$ & $\begin{array}{l}\mathrm{Ta} \\
\mathrm{Td} \\
\mathrm{Tb}\end{array}$ & $\begin{array}{l}\text { Uspenskij } 68 / 64 \\
\text { Cistjakov } 14 / 78 \\
\text { Lebedev } 14 / 78\end{array}$ \\
\hline preponom & preponoj & -. & Lebedev $14 / 78$ \\
\hline
\end{tabular}


Auf Bitten eines Lesers gibt die Mitarbeiterin des IRJaz, Rachmanova, 1977 Regeln für die Bestimmung des grammatischen Geschlechts bei kürzlich entlehnten Fremdwörtern - in erster Linie handelt es sich hierbei um nichtübersetzbare Fachausdrücke:

cece, kuasi, kivi-kivi, saljami, chindi, urdu, ralli

(Rachmanova 14/77)

Gorbałevił erläutert im selben Jahr Normveränderungen in der Genusbestimmung von Abkürzungswörtern:

TASS, rono, ZEK, VTEK

(Gorbatevie 34/77)

In drei Beiträgen wird der Gebrauch eines unüblichen Numerus bemängelt:

barrikada:

poisk:

pogody:

temperatury:
Bokov (92/54) meint, daß nur der Plural gebräuchlich sei;

Morozov will die Singularform nur als Jagdterminus verwendet wissen, nicht als Ausdruck für 'Suchen, Suche' (101/64)

Guljanickaja 5/68

Guljanickaja 5/68

Die meisten Fehlermeldungen stammen aus dem Bereich der Deklination. Die Leserin Gal' (22/78) führt ein Beispiel für das Deklinieren eines der Norm nach indeklinablen Fremdwortes an (drumja sal'tami). Uspenskij miBbilligt in einem Beitrag das Unterlassen der Flexion bei Ortsnamen auf ovo und ino (sižu ৩ Melichovo, Yivu ৩ Sofrino, Uspenskij 21/71). Umstritten ist, wie der Beitrag von Es'kova (29/71) zeigt, auch in linguistischen Kreisen die Frage, ob fremdsprachige Namen, bestehend aus Vor- und Familiennamen, bei der Deklination als Einheit aufgefaßt werden sollen ( $u$ Zjul' Verna, rasskazy Brèt Garta, proizvedenija Koman Dojla) oder aber einzeln flektiert werden müssen (Žjulju Vernu). Avilova und Derjagin (13/69) weisen erstere Möglichkeit, der Es'kova den Vorzug gibt, als eindeutig umgangssprachliche Erscheinung aus. In der Schriftsprache müßten bei ausländischen Personennamen in Ubereinstimmung mit den Gesetzen des Russischen beide Namensteile dekliniert werden. 
Ansonsten enthalten die LG-Beiträge Beispiele für Abweichungen in der Bildung einzelner Kasusformen:

\begin{tabular}{|c|c|c|c|c|c|}
\hline \multirow{4}{*}{$\begin{array}{l}\text { Kasus } \\
\text { Gen. Sg.: } \\
\text { Lok. Sg.: } \\
\text { Nom. Pl.: }\end{array}$} & \multirow{4}{*}{$\begin{array}{l}\text { Abweichung } \\
\text { brelka } \\
\text { votličae } \\
\text { klapaná }\end{array}$} & \multirow{4}{*}{$\begin{array}{l}\text { Norm } \\
\text { breloka } \\
\text { votličii } \\
\text { klápany }\end{array}$} & \multicolumn{3}{|c|}{ Trudnosti Quellen } \\
\hline & & & $\mathrm{Td}$ & \multicolumn{2}{|c|}{ Gorbatevic 12/72 } \\
\hline & & & & Povarcov & $16 / 78$ \\
\hline & & & Tc (prof.) & Junker & $16 / 48$ \\
\hline & & & & Kostinskij & $16 / 78$ \\
\hline & korrektorá & korréktory & Tc (razg.) & Uspenskij & $15 / 68$ \\
\hline & kolodcá & kolódcy & $\mathrm{Ta}$ & Prijma & $25 / 78$ \\
\hline & poršnjá & poršni & $\mathrm{Td}$ & Tolstichin 1 & $101 / 64$ \\
\hline & & & & Junker & $16 / 78$ \\
\hline & & & & Kostinskij & $31 / 78$ \\
\hline & regiljá & rígeli & - & Junker & $16 / 78$ \\
\hline Gen. Pl.: & jablonej & jablon' & Tc (obl.) & Gorbatevit & $12 / 72$ \\
\hline & kolikov & kolik & $\mathrm{Td}$ & Filimonov & $23 / 73$ \\
\hline & pozitok & požitkov & $\mathrm{Td}$ & Prijma & $25 / 78$ \\
\hline
\end{tabular}

Beispiele für Normabweichungen in der Formenbildung beim Verb:

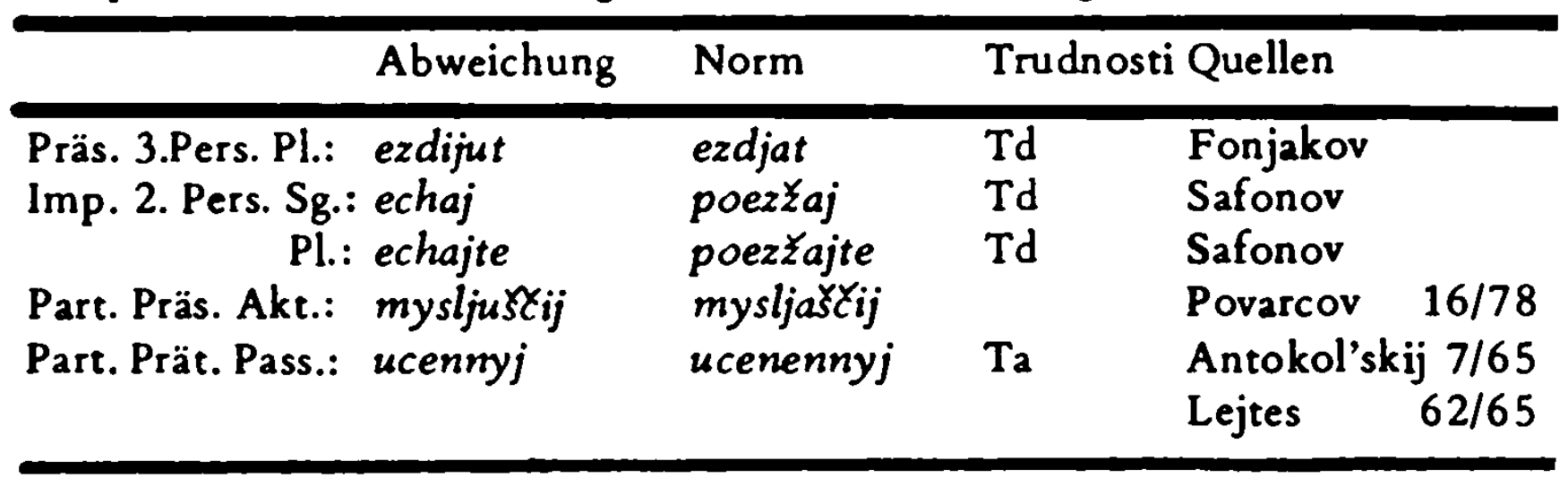

\subsubsection{Syntax}

Die in der LG vorgebrachten syntaktischen Normabweichungen beziehen sich fast ausschließlich auf den Gebrauch von Präpositionen. Beobachtet wird eine Tendenz zur präpositionalen statt unmittelbaren Rektion, aber auch die Verwendung falscher Präpositionen: 
Beispiele für präpositionale statt unmittelbarer Rektion:

Beispiel

Quelle

zafiksirovat' o čem

Lebedev

$14 / 78$

plan po dobyče,

programma po uveliteniju proizvodstua,

cysokie tempy po stroitel'stvu,

sredstua po rasprostraneniju opyta,

zavod po proizvodstur Zelezobetonnych

izdelij,

magazin po prodaže prodovol'stuennych tovarov

Abdullin $\quad 96 / 65$

oplačivat'za proezd

Lipatnikova $\quad 49 / 78$

Čistjakov

$14 / 78$

Sinel'nikov

$34 / 78$

Beispiele für den Gebrauch nicht normgerechter Präpositionen:

\begin{tabular}{|c|c|c|c|}
\hline nad & (für za): nabljudat' nad kem & Andreeva & $44 / 71$ \\
\hline 0 & (für na): o čem nadežda & Prijma & $25 / 78$ \\
\hline po & $\begin{array}{l}\text { (für dlja, za, o, v): } \\
\text { rešenie po oplate truda, } \\
\text { dlja okazanija pomošci po unedreniju, } \\
\text { voprosy po soderžaniju raboty, } \\
\text { literatura po peredovomu opytu; }\end{array}$ & Abdullin & $96 / 65$ \\
\hline na & (für za): sidet' na parte & $\begin{array}{c}\text { Borisov } \\
\text { Kapanadze/ } \\
\text { Krysin }\end{array}$ & $\begin{array}{l}2 / 68 \\
5 / 68\end{array}$ \\
\hline$v$ & (für po): $v$ adres & $\begin{array}{l}\text { Davydov } \\
\text { Alekseev u.a. }\end{array}$ & $\begin{array}{l}18 / 71 \\
21 / 71\end{array}$ \\
\hline
\end{tabular}

Der Leser Moiseev (96/65) tadelt die Tendenz zur analytischen GenitivBildung mithilfe der Präposition ot:

20 procentov ot plana, 30 procentov ot bjudzeta

Außerdem werden Beispiele für Nichtgebrauch des von der Norm vorgeschriebenen Genitivs nach Mengenangaben (skol'ko vremja - Andreeva 44/71) und in abhängigen Zahlenangaben (pochišcenie poltora - Sinel'nikov 34/78, suyYe trista pjat'desjat tysją - Demina 17/78) genannt. Sinel'nikov behaup- 
tet, daß derartige Unsicherheiten bei Zahlenangaben die verbreitetste Fehlerkategorie in den Medien sei.

\subsubsection{Semantik}

Ein großer Teil der vorgebrachten Normabweichungen geht auf die mangelnde Kenntnis der genauen Bedeutung eines Wortes zurück.

Beispiele:

\begin{tabular}{|c|c|}
\hline Wort & Kontext \\
\hline $\begin{array}{l}\text { autor } \\
\text { épicentr }\end{array}$ & $\begin{array}{l}\text { autor gola } \\
\text { kurortnye épicentry }\end{array}$ \\
\hline $\begin{array}{l}\text { dubl' } \\
\text { kokarda } \\
\text { krajnij }\end{array}$ & $\begin{array}{l}\text { edinstuennyi dubl' } \\
\text { v suoej zolotennoj kokarde } \\
\text { krajnij v očeredi }\end{array}$ \\
\hline $\begin{array}{l}\text { oblokotit'sja } \\
\text { obratno }\end{array}$ & $\begin{array}{l}\text { oblokotjas' na chobot orudija } \\
\text { Ty obratno Yichaeł'. } \\
\text { Casy obratno ostanovilis'. }\end{array}$ \\
\hline orbita & zavod vyšel na orbitu plana \\
\hline para & para dnej \\
\hline propiska & $\begin{array}{l}\text { propiska kluba, ovoščej i fruktov, } \\
\text { novych vid sporta }\end{array}$ \\
\hline $\begin{array}{l}\text { postroit' } \\
\text { potrebiteli } \\
\text { realizacija }\end{array}$ & $\begin{array}{l}\text { postroit' prud, ozero } \\
\text { postroit' mebel', taburetku } \\
\text { potrebiteli vagona } \\
\text { kartofel' otpravljaetsja } \\
\text { dlja realizacii (prodaza) }\end{array}$ \\
\hline
\end{tabular}

Borisov 2/68

Kalinin 21/75

Cistjakov 14/78

Gal' 22/78

Prijma 25/78

Td Alekseev 21/71

Russk. jazyk 16/73

Filimonov 27/73

Ta Sabsovič 33/76

Sakk,

Skvorcov 80/64,

Andreeva 44/71

Alekseev 21/75

Lipatov 34/71

Isakovskij 135/64

Borisov 2/68

Kapanadze/

Krysin 5/68

Alekseev 21/71

Seleznev 16/75

Skvorcov $40 / 75$

Isakovskij 135/64

Moiseev 96/65

Moiseev 96/65 
ne slučajno sjužet

unikal'nyj

urał̌at'sja za ščet
$U$ nich pjatero detej, i èto ne slutajno.

Smotrite nouju kinokartinu "Vystrel" po odnoimennomu sjužetu A.S. Puskina '̌est' unikal 'nych másin slutaj v swem rode unikal'nyj

On teper' vrašcaetsja vokrug matin

Chokkeisty pobezdajut za stet

bol'šoj skorosti i chorošej fizið̌eskoj

podgotoulennosti.
Karbovskaja 30/68

Guljanickaja 5/68

Davy dov 18/71

Kas'janova 35/71

Kašin 35/67

Hierzu gehören auch die offensichtlich beliebten Tautologien:

\begin{tabular}{lll}
\hline$v$ anfas & Tb & Borisova 20/76 \\
moja avtobiografija & Td & Russkij jazyk 16/73 \\
matYevaja ustreta & & Guljanickaja 5/68 \\
pamjatnyj suvenir & Td & Guljanickaja 5/68 \\
prejskurant cen & Td & Russkij jazyk 16/73 \\
gabaritnye razmery & & Seleznev 16/75
\end{tabular}

Häufig werden Paronyme verwechselt:

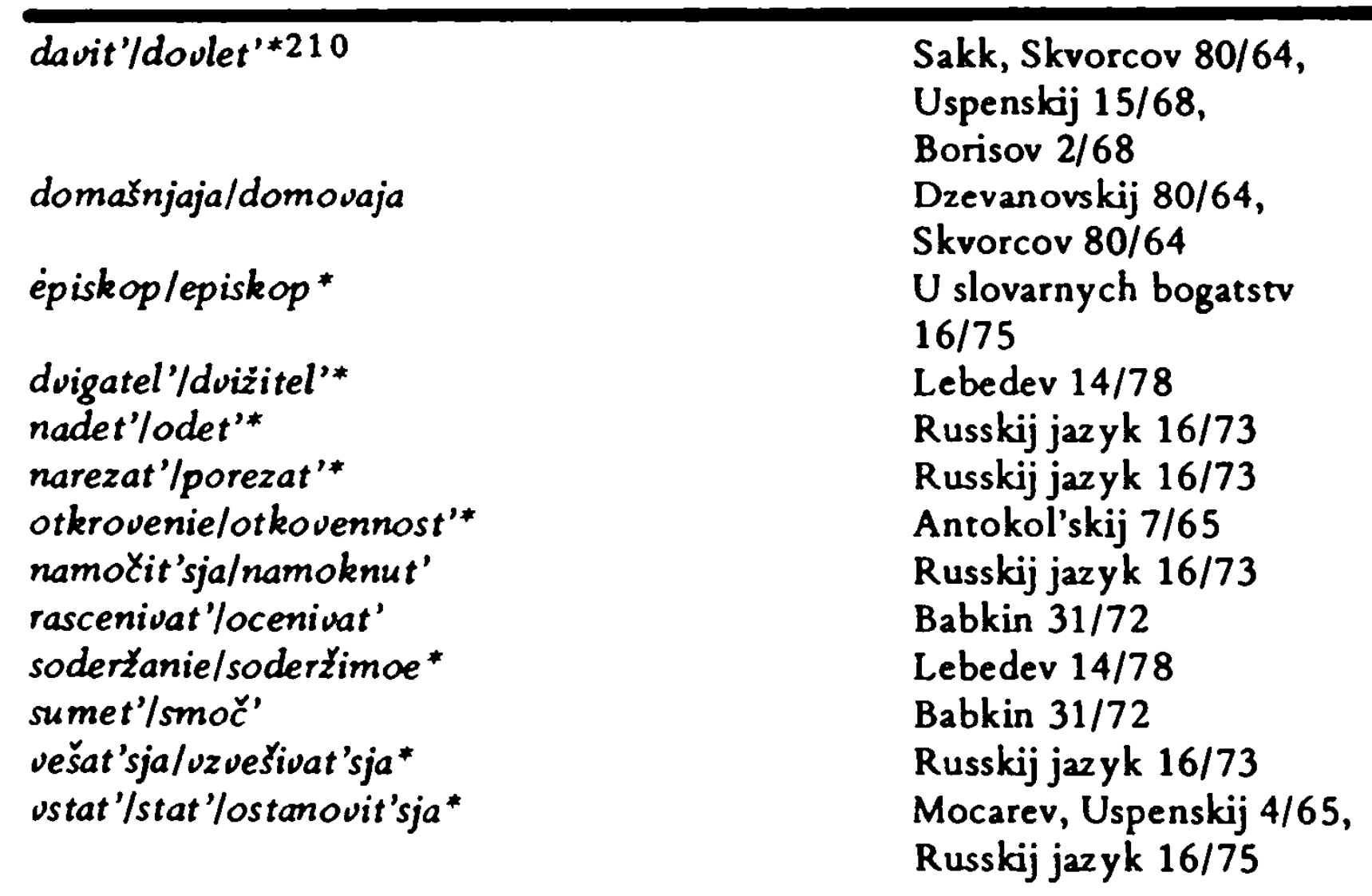

210 Die mit * versehenen Paronyme sind verzeichnet im Slovar' paronimov russkego jazyka. (Kolesnikov 1971) 
zakladyvat'/vykladyvat'

pereigrat'luyigrat'

podechat'/priechat'
Babkin 31/72

Guljanickaja 5/68

Borisov 2/68

Andreeva 44/71

Keineswegs als semantische Fehler, sondern als bewußte Abweichungen vom Standardsprachgebrauch sind dagegen folgende Ausdrücke aufzufassen:

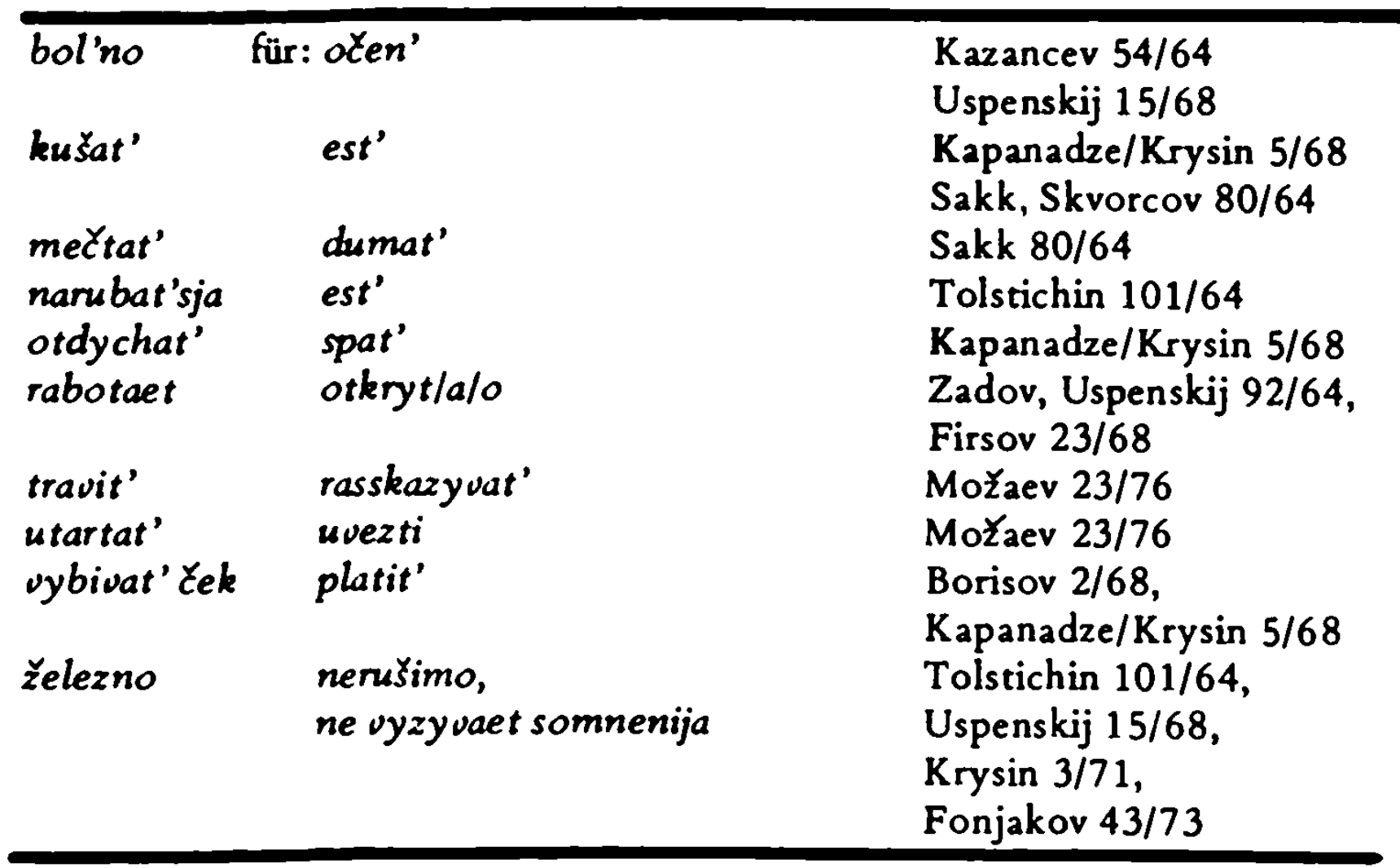

\subsubsection{Stilistik}

Neben einzelnen Stilblüten, also individuellen Normabweichungen, auf die hier nicht näher eingegangen werden soll, werden in der Sprachrubrik folgende stilistische Mängel kritisiert:

Karbovskaja und Uspenskij beanstanden den Gebrauch von Flickwörtern und beliebten Interjektionen:

vot èto, kak èto, ètogo togo (Uspenskij 21/71)

tak skazat', ne slučajno (Karbovskaja 30/68) 
Mehrere Beiträge erwähnen eine Tendenz, das Russische durch überflüssige Diminutisierung zu verniedlichen:

kraten'ko (Antokol'skij), privetik (Lejtes 62/65), biletik, bulocka, butylocka, ¿etvertinka kruglen'kogo, gazetocka, kilo kolbaski, konvertik, limontik, marołka, pesotek, plošadotka (Borisov 2/68), vidiki, manikjurtiki, pribor ${ }_{i k i}$, nastoe ${ }^{2} i$ (Kapanadze/Krysin 5/68), kolbaska, Caek, pivko, syrok (Russkij jazyk 16/73)

Rožanskij, Čukovskij (144/66) und Formanovskaja (14/77) behandeln modifizierte Phraseologismen. Während Rožanskij es generell ablehnt, phraseologische Ausdrücke zu verändern, befürworten Uspenskij und Formanovskaja dies als künstlerisches Stilmittel und bearistanden lediglich mißglückte Experimente.

Beispiele:

Rožanskij 144/66

On usegda iz vody čisty vychodit. (< vyjti suchim iz vody)

A ja otlil piljulju. (<otlit' puli/pozolotit' piljulju)

Kotoryj iz nego use Zily soset. ( < tjanut' Yily/krov'sosat')

$U$ nego sem' pjatnic v odnu subbotu. (< sem' pjatnic na odnoj

Prochorov znal, počem funt okopnych bloch. (< funt licha) nedele)

Formanovskaja 14/77

Tiše ede's' - dal' '̌e ne budeš' (dal 'Se budes')

Ne lomites' v zakrytye dueri (v otkrytye dueri)

Bragina und Sinel'nikov beobachten im öffentlichen Sprachgebrauch einen übermäßigen Hang zur metaphorischen Umschreibung. Besonders beliebt ist der auch im Schriftstelleraufruf und bei Davydov erwähnte Vergleich von wertvollen Gegenständen mit zoloto, dem ein entsprechendes Farbattribut hinzugefügt wird:

Cernoe zoloto: Erdöl, Kohle zelenoe, goluboe, beloe zoloto 
Als Beispiele für unpassende Metaphern werden genannt:

Metapher

Bragina 44/69

krylatyj aljuminij

pachari morja

poslednij akkord simfonii

gracii vystupili v boj

rentgenouskij analiz romana

kinochudoŽniki orkestrujut tonðajłie ot tenki cueta

geroinja fokusinet na sebe unimanie

కirocajsee polotno sozdano jarkimi mazkami

mažomoe zuranie, gamma suetlych tonov, polifonija

vengerskaja rapsodija

Sinel'nikov $34 / 78$

pachari zelenogo okeana

golubaja strada

kladovaja sbereženij

sladkij cholod

cholodnoe lakomstuo

klykastye

rogatye krasavicy
Gegenstand des Vergleichs

\author{
Metall \\ Arbeit von Fischern \\ Ringkampf \\ Ballettwet tbewerb
}

Musik

Gemälde

Fußballspiel einer ungarischen Mannschaft

Arbeiter in der Forstwirtschaft

Fischzucht

Sparkasse

Speiseeis

Speiseeis

Wölfe

Hirsche

Vielfach ist die Rede von erstarrten Wortverbindungen (Klischees):

belokrylye lajnery

neobozrimye gektary

lutYie peredoviki

neotemlemaja čast'

živoj interes

Castyj gost'

vemetrulis' mnogoètažnye korpusa

gorod suerkal steklom $i$ betonom

ego glaza s t Šcatel'no skryvaemoj
Baruzdin 127/65

Baruzdin 127/65

Baruzdin 127/65

Borisov 2/68

Borisov 2/68

Uspenskij 21/71

Uspenskij 21/71

Borisova 29/71

grustinkoj 
Ein besonders schädlicher Einfluß wird dem Stil von wissenschaftliciren und technologischen Fachsprachen zugeschrieben, den man als geschraubt und unnötig kompliziert empfindet:

Beispiele:

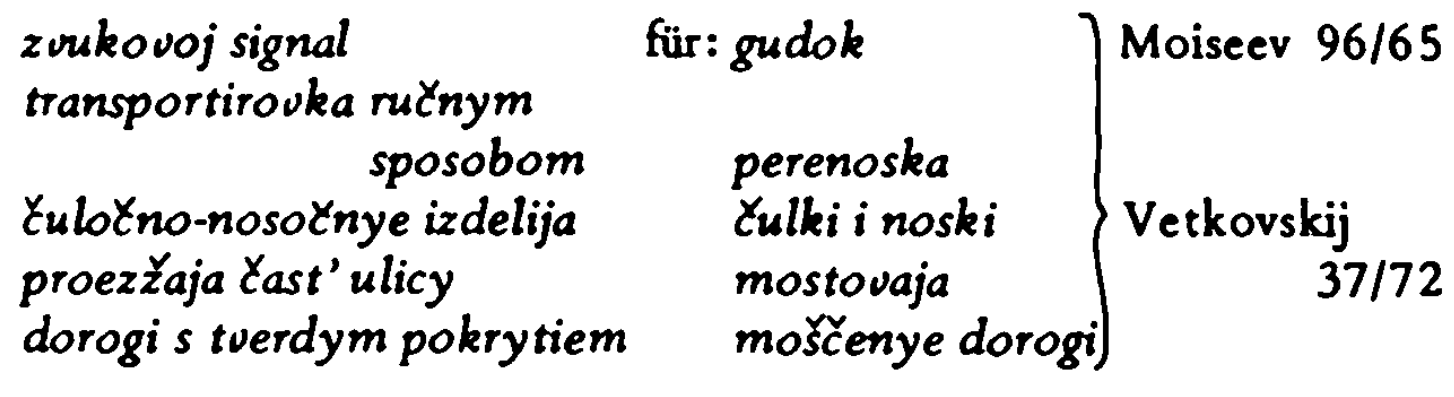

- apparat prednaznaten dlja ustanovki $v$ mestach s massovym poseš̌eniem naselenija (apparat ustanaulivaetsja $v$ ljudnych mestach) (Vetkovskij 37/72)

- 0 kuartalach s bol'Y̌oj plotnost'ju zastrojki (ט plotno zastroennych kuartalach) (Vetkouskij 37/72)

- otoplenie vagonov osứčestuljaetsja élektronagrevatel'nymi èlementami (otoplenie v vagonach elektriðeskoe) u. ä.

(Vetkovskij 37/72)

Gazarjan (50/72) und Blochin (8/73) kritisieren die von ihnen beobachtete Vorliebe für den Nominalstil, bei dem verbale Ausdrücke durch Verbalsubstantive auf enie/-anie und ,Ersatz"verben (osustestuljat'sja, proizuodit'sja u.ä.) wiedergegeben werden. 211

Als typische Bürokratismen (kanceljarit) werden folgende Ausdrücke benannt:

\begin{tabular}{|c|c|}
\hline $\begin{array}{l}\text { po Časti } \\
\text { so storony } \\
\text { s pomošcju } \\
\text { rabota po } \\
\text { v nastojaščij moment } \\
\text { v blǐajłem buduščem } \\
\text { na segodnjałnij den' } \\
\text { zapčasti } \\
\text { strojkontora } \\
\text { kombikorma }\end{array}$ & $\begin{array}{l}\text { Andreeva 44/71 } \\
\text { Gazarjan 50/72 } \\
\text { Poliš̌̌uk } 3 / 66 \\
\text { Atarov 35/71 }\end{array}$ \\
\hline
\end{tabular}


mesta obstego pol'zovanija

(fir: kuchnja, ubormaja, koridor)

meteorologičeskie osadki

metizy

(für: liven', grad, rosa, sneg)

(für: kastrjulja, guozd', utjug) kormodoby vajusčie brigady

4.2. Auseinandersetzungen um Fragen des Lexikons

\subsubsection{Neologismen}

In den Jahren 1964, 1971, 1975 und 1976 werden in der Sprachrubrik unter anderem Neologismen behandelt.

Einige Verfasser von Sprachbeiträgen stehen Neologismen prinzipiell skep tisch gegenüber. Sie halten Neuschöpfungen nicht nur für unnötig, sonderr auch für gefährlich, weil sie bereits existierende Wörter aus dem Sprachge brauch verdrängten.212 Dazu gehören sowohl Vertreter der puristischer Linie als auch sprachkonservative Antinormalizatory, denn beide Strömunger verbindet die Vorstellung, daß jede Weiterentwicklung der russischen Sprach eine „Verschlechterung", einen Verlust ihrer Russizität bedeute.

Hinter einer derart ablehnenden Haltung gegenüber jeglicher Sprachverände rung verbirgt sich die Unfähigkeit, von einmal verinnerlichten Normen z। abstrahieren und umzulernen. DaB sich dies nicht nur auf die Sprache be zieht, klingt bei dem Leser Pokrovskij an, der dem hastigen Lebensshythmu die Schuld dafür anlastet, daß "flatterhafte" Wörter auftauchten:

„Tut vinovat i neuderžimo ubystrjajuડ̌cijsja ritm Łizni. On prinosit s soboj novye i zatastuju bescretnye, bezlikie slova-motyl'ki, 
kotorye, pronikaja v chudožestvennuju literaturu, vytesnjzet iz starogo, uže složivł̌egosja jazyka jarkie samocvety slova." (Pokrouskij 28/69)

Die übrigen Beiträge unterscheiden sich dadurch, welche Art von Neologismen behandelt wird.

Zum einen geht es um Neuprägungen, die in Fachsprachen und im öffentlichen Sprachgebrauch entstanden sind:

a) Substantiva:

\begin{tabular}{|c|c|c|c|}
\hline Neologismus & Bedeutung 213 & Quelle & \\
\hline chorošist & $\begin{array}{l}\text { 'mit der Note chorošo bewer- } \\
\text { teter Schüler' }\end{array}$ & Rachm. / Form. & $11 / 77$ \\
\hline detsadovec & & Baruzdin & $127 / 65$ \\
\hline diCezagotouka & & Semenov & $7 / 64$ \\
\hline divizionka* & 'divizionnaja gazeta' & Filin & $17 / 76$ \\
\hline dojar & & Tolstichin & $101 / 64$ \\
\hline geologinja* & weibl. zu geolog & Alekseev u.a. & $21 / 71$ \\
\hline gurtoprav & & Tolstichin & $101 / 64$ \\
\hline kassirకa & 'Zenščina kassir' & Borisov & $2 / 68$ \\
\hline krugosvetka* & 'krugosvetnoe putešestvie' & Filin & $16 / 75$ \\
\hline moreprodukty* & $\begin{array}{l}\text { 'morskie produkty' } \\
\text { 'produkty morja' }\end{array}$ & $\begin{array}{l}\text { Semenov } \\
\text { Dzevanovskij } \\
\text { Skvorcov }\end{array}$ & $\begin{array}{r}7 / 64 \\
80 / 64 \\
80 / 64\end{array}$ \\
\hline nedopromyslenie & & Semenov & $7 / 64$ \\
\hline obezbolivanie & & Semenov & $7 / 64$ \\
\hline obilečivanie & & Semenov & $7 / 64$ \\
\hline ochotoustrojstwo & & Semenov & $7 / 64$ \\
\hline perepromyslenie & & Semenov & $7 / 64$ \\
\hline plovčicha & weibl. zu plovec & Borisov & $2 / 68$ \\
\hline podnevol'nik & 'podnevol'nyj čelovek' & Filin & $17 / 76$ \\
\hline
\end{tabular}

213 Sofern sie daraus zu erschließen war, wird hier die Bedeutung laut LG.Beitrag angegeben. Die mit Asteriskus versehenen Neologismen sind in Novyeslova iznakenija. 1971, aufgenommen, prilunenie verzeichnet das Russisch deutsche Neuwörterbuch von Friedrich/Geis, 1976 


\begin{tabular}{|c|c|c|c|}
\hline polborక̌ca & 'polovina tarelki borsca' & Uspenskij & $150 / 65$ \\
\hline pošiv & 'šit'e' & $\begin{array}{l}\text { Lipatov } \\
\text { Andreeva } \\
\text { Borisov } \\
\text { Firsov }\end{array}$ & $\begin{array}{r}34 / 71 \\
44 / 71 \\
2 / 68 \\
23 / 68\end{array}$ \\
\hline prilunenie & 'Mondlandung' & Uspenskij & $28 / 75$ \\
\hline prorabka & $\begin{array}{l}\text { 'pomešenie dlja prorabou na } \\
\text { stroitel'noj ploßtadke' }\end{array}$ & Alekseev u.a. & $21 / 71$ \\
\hline ręestroj & & $\begin{array}{l}\text { SolY̌enicyn } \\
\text { Lejtes }\end{array}$ & $\begin{array}{l}131 / 65 \\
148 / 65\end{array}$ \\
\hline rejsovik & 'Sofer rejsowj mašiny' & Filin & $17 / 76$ \\
\hline rozovod & & $\begin{array}{l}\text { Semenov } \\
\text { Tolstichin } \\
\text { Uspenskij }\end{array}$ & $\begin{array}{r}7 / 64 \\
101 / 64 \\
108 / 64\end{array}$ \\
\hline smel'stvo & 'smelost"' & Filin & $17 / 76$ \\
\hline sputnik & & Uspenskij & $28 / 75$ \\
\hline strigal' & & Tolstichin & $101 / 64$ \\
\hline subprodukty & & Uspenskij & $15 / 68$ \\
\hline technar'* & $\begin{array}{l}\text { 'specialist po techniČeskomu } \\
\text { obsluŽivaniju samoletov' }\end{array}$ & Uspenskij & $28 / 75$ \\
\hline tjaženie & & Uspenskij & $129 / 64$ \\
\hline zaryblenie & & $\begin{array}{l}\text { Tolstichin } \\
\text { Uspenskij } \\
\text { Lipatov }\end{array}$ & $\begin{array}{r}101 / 64 \\
108 / 64 \\
34 / 71\end{array}$ \\
\hline $\begin{array}{l}\text { zavodČanin * } \\
\qquad(\sim k a, \sim e)\end{array}$ & 'zavodskoj rabočij' & Alekseev u.a. & $21 / 71$ \\
\hline
\end{tabular}

b) Verben

\begin{tabular}{|c|c|c|c|}
\hline Neologismus & Bedeutung & Quelle & \\
\hline dubanit' & & Filin & $17 / 76$ \\
\hline kotegarit' & & Filin & $17 / 76$ \\
\hline matrosit' & & Filin & $17 / 7 \epsilon$ \\
\hline nedopereyypolnit' & & $\begin{array}{c}\text { Russkij jaz yk } \\
\text { Dagmar Christians - } 9783954792 \\
\text { PubFactory at 01/11/2019 05:07:27 } \\
\text { via free acc }\end{array}$ & $\begin{array}{l}\text { So3 } \\
\text { AM } \\
\text { ass }\end{array}$ \\
\hline
\end{tabular}


obiletit'

obiletit'sja

ozadarit'

prilunit'sja

skladirovat'

slesarit'

temperaturit' 'snabdit' biletami'

'postavit'zadaču'

'prizemlit'sja na lune'
Russkij jazyk

Russkij jazyk

Russkij jazyk

Skvorcov

Lipatov

Uspenskij

Filin

Filin
$16 / 73$

$16 / 73$

$16 / 73$

$40 / 75$

$34 / 71$

$84 / 64$

$17 / 76$

$17 / 76$

c) Adjektiva

Neologismus

Bedeutung

Quelle

muCnisto-konditer-

skij

polomojno-

poloter'nyj

posivotnyj

plat'evyj

platel'nyj

pal'tovyj

'platjanoj'

Uspenskij

$15 / 68$

sladimyj

slepimyj

sportsmednyj

volnitel'nyj

$\begin{array}{lll}\text { 'platjanoj' } & \text { Russkij jazyk } & 16 / 73 \\ & \text { Russkij jazyk } & 16 / 73 \\ & \text { Kalinin } & 35 / 71 \\ & \text { Kalinin } & 35 / 71 \\ & \text { Kalinin } & 35 / 71 \\ & \text { Kalinin } & 35 / 71 \\ \text { 'volnujuszij' } & \text { Kalinin } & 35 / 71\end{array}$

Filin

$16 / 73$

Russkij jazyk 16/73

Russkij jazyk 16/73

Russkij jazyk 16/73

Kalinin

$35 / 71$

Ihre Befürworter weisen auf die Notwendigkeit hin, daß der Veränderung der Realität auch durch die Schaffung neuer sprachlicher Muster Rechnung getragen werden müsse. Sogar Puristen wie der Leser Tolstichin halten es für selbstverständlich, daß vor allem im Produktionsbereich neue Wörter gebildet werden.

Ihre Gegner beanstanden einzelne Neologismen als mißglückte Wortbildungen. Selten begründen sie dabei, warum sie ihre Beispiele als bedenklich empfinden. Die Sprachwissenschaftler unterscheiden zwischen gerechtfertigten Neologismen und solchen, die entweder nicht im Einklang mit den Wortbildungs- 
gesetzen des Standardrussischen stehen, wie etwa chorołist, technar' (unproduktive Suffixe), zaryblenie (Substantiv als Grundlexem einer deverbalen Ableitung), volnitel'nyj (von volnovat') und platel'nyj (von plat'e) oder Dubletten darstellen (chorołist, smel'stvo). Andere Neuprägungen werden in die Grenzen des umgangssprachlichen Wortgebrauchs verwiesen, in dem sie entstanden seien: divizionka, krugosvetka, polborł̌a, podnevol'nik, dubanit', koðegarit', matrosit', slesarit', rejsovik.

Zum anderen stehen individuelle Neuprägungen vor allem im dichterischen Sprachgebrauch zur Debatte. Es werden zwar einige Beispiele für Okkasionalismen genannt:

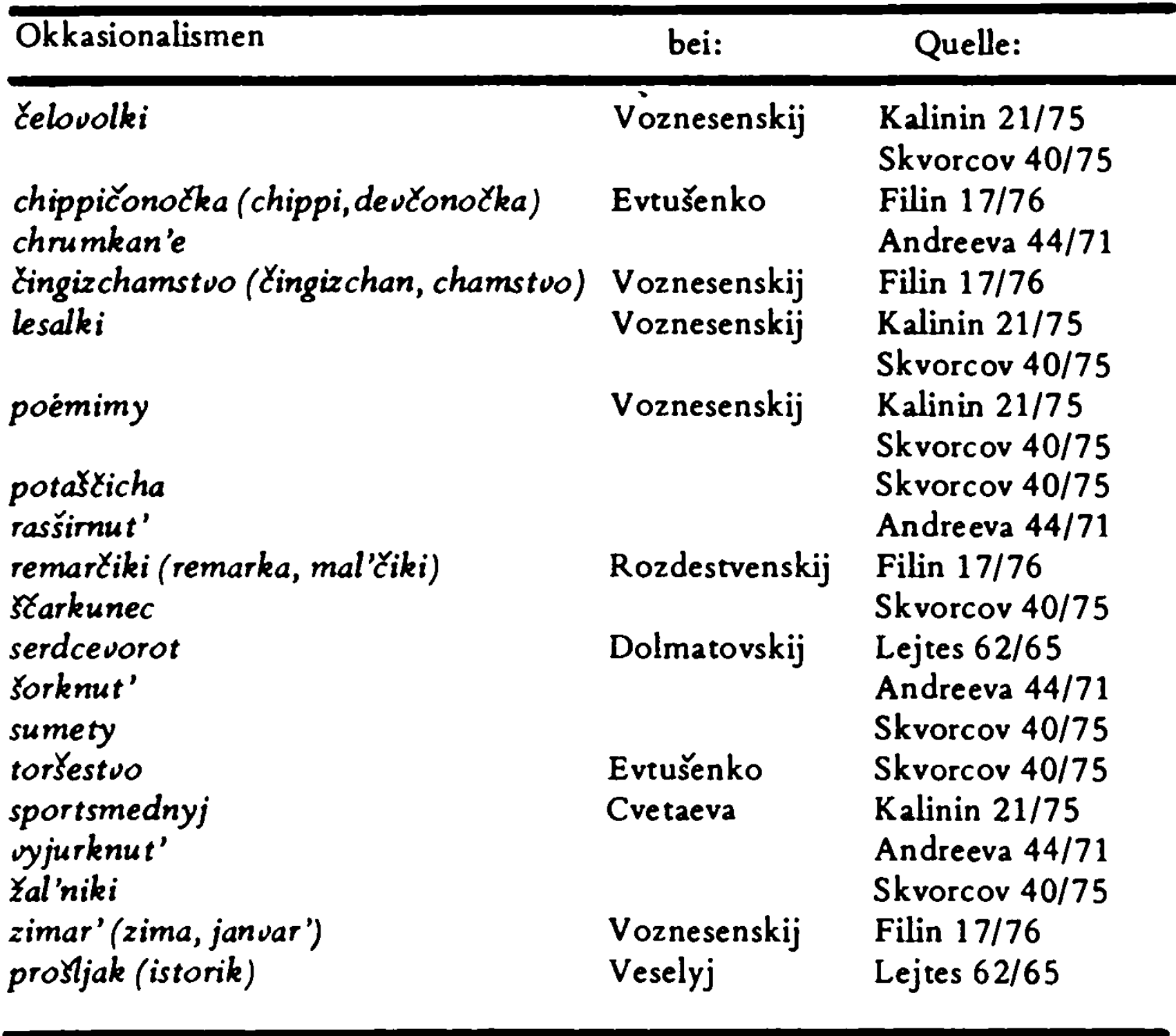

Eigentlich geht es hier aber weniger um konkrete Neuwörter als vielmehr um die Frage, ob dem Schriftsteller das Recht zugestanden werden sollte, die 
Realität in eigenen Worten zu beschreiben, oder ob er - wie Filin 1976 betont - auf die im Standard vorgegebenen Ausdrucksmittel beschränkt ist. 214

\subsubsection{Dialektismen}

Beiträge zu Dialektismen, also vereinzelt in den Standardsprachgebrauch aufgenommenen lexikalischen Elementen aus dem Wortbestand der Dialekte, sind in den Jahrgängen 1965, 1969, 1971, 1972, 1973, 1976 und 1978 zu finden.

Als Dialektismen werden genannt:

\begin{tabular}{ll}
\hline bososlepyj & Lipatov 34/71 \\
Capel'nik & Možaev 23/76 \\
gamozom & Možev 23/76 \\
gorod'ba & Lipatov 34/71, Babkin 31/72 \\
košel' & Rylenkov $96 / 64$ \\
kožuch & Lipatov 34/71 \\
pleten' & Lipatov 34/71 \\
pod-jaldykivat' & Levin 131/65 \\
prjaslo & Babkin 31/72 \\
proran & SolZenicyn 131/65, Levin 134/65 \\
raspadok & SolZenicyn 131/65, Levin 134/65 \\
skoren' & Lipatov 34/71 \\
skukožit'sja & Levin 134/65, Filin 17/76, MoZaev 23/76 \\
vir & Rylenkov 96/64 \\
zaplot & Babkin 31/72 \\
\hline
\end{tabular}

Im lexikalischen Bereich vollzieht sich nach der bereits eingangs zitierten Darstellung Kogotkovas eine zunehmende dialektale Beeinflussung der russischen Standardsprache durch die Aufnahme regionaler Lexik in die Massenmedien.215 Dabei hält die Verfasserin die Verwendung von Dialektwörtern im literarischen Sprachgebrauch für allgemein akzeptiert. Dem widerspricht aber die Auseinandersetzung über Dialektismen in der Sprachrubrik der LG, da sich diese ausschließlich an deren Verwendung bei Schriftstellern entzündet. An der Einstellung zu dialektalem Wortgut bildet sich unter den Diskussionsteilnehmern eine feste Front zwischen Gegnern und Befürwortern. 
Nicht nur bei Laien trifft man häufig eine negative Grundeinstellung gegenüber dem Dialekt an, die an den Vorurteilen deutlich wird, mit deren Hilfe man gegen die Verwendung von Dialektwörtern argumentiert.

Hier herrscht die Vorstellung, daß Dialektismen dem "Massenleser" nur schwer oder gar nicht verständlich seien, wie es Filin in einem Rückblick auf die Diskussion von 1976 in RR ausdrückt:

„... suß̌estvuet obక̌eprinjatyj literaturnyj jazyk i maloponjatnye ili vovse neponjatnye dialektizmy. Pisatel', esli on chocet byt' priznannym, nikogda ne dolZen zabyvat' o massovom Yitatele." 216

In den Beiträgen wird behauptet, die Bevölkerung könne dialektal gefärbte Texte überhaupt nur verstehen, wenn sie entsprechende Wörterbücher benutze: .Ja ne dumaju, tto pisatel' obogaščaet russkij jazyk, esli skvoz' ego tekst nado prodirat'sja so slovarem Dalja." (Korostyleva 46/73)

Bei diesem Argument wird von der Annahme ausgegangen, daß der Durchschnittsleser Nichtdialektsprecher sei, was nach Kogotkovas Darstellung über die Sprachverwendung in der russischen Bevölkerung aber nicht zutrifft. Danach ist nämlich die überwiegende Mehrheit aller Russischsprecher mit dialektalen Milieu verbunden.217

Vielfach wird in der LG mit Dialektismen archaische, nicht mehr gebräuchliche Lexik assoziiert, die den Sprecher als rückständig ausweist:

.I kogda pisatel' v opisanii rudnogo kraja, ego krasoty obrastaetsja k davno otŽivšemu, archaǐ̌eskomu rě̌eniju, $k$,slovesnym okamenelostjam', $k$ jazyku dedov, to étim samym, kak mne dumaetsja, on obednjact svoi vozmožnosti byt' vyrazitelem sovrcmennosti." (Gil'varg 28/69) 218

Uspenskij mahne in einem Beitrag zur Nachsicht gegenüber Dialektsprechern die es in entlegenen Winkeln des Landes immer noch gebe und denen mas

216 Filin 1977. 5.29

217 Kugorkova 1970. S. 105

218 Vigl duch Gorbunov $28 / 69$ 
ihre nichtstandardsprachliche Rede nicht vorwerfen dürfe, bis die Dialekte endgültig der Standardsprache ihren Platz überlassen hätten, was früher oder später $z$ wangsläufig geschehe.

„Gde-nibud' v gluši, da ne tol'ko v glułi, sochranilis' eł̌̌̌e ljudi, pol'zujuß̌̌iesja $v$ bytu ne literaturnym jazykom, a razliłnymi govorami i dialektami. Poka èto nabljudaetsja, bessmysleno uprekat' ich v nepravil'noj reci, ocenivaja ee po normam literaturnogo jazyka. U narodnych govorov svoi zakony, svoj slovar', svoi grammatičeskie osobennosti. Rano ili pozdno oni ustupjat mesto literaturnomu jazyku, a poka éto ne proizołlo, s nimi nel'zja ne stitat'sja." (Uspenskij 150/65)

Dieses bei Trägern der russischen Standardsprache auch heute noch verwurzelte Vorurteil, das den Dialekt schlichtweg als überkommene Sprachform abstempelt und dessen Verwendung als Zeichen von Rückständigkeit wertet $^{219}$, ist auch der sowjetischen Sprachwissenschaft nicht fremd.220 So begreift beispielsweise Filin den dialektal gefärbten Sprachgebrauch als „linguistischen Defekt":

„Nužno reYitel'no otlixat' literaturnye jazykovye normy (...), k polnomu ovladeniju kotorymi dolžen stremit'sja każyj kul'turnyj Čelovek, ot dialektnoj okrašennosti re $\chi_{i}$ otdel'nych nositelej literaturnogo jazyka (...), obš̌estvenno osoznavaemoi kak lingvistiYeskij defekt ..."221

Uberhaupt beschäftigt sich die sowjetische Linguistik mit dialektalen Sprachformen vorwiegend zum Zwecke der Aufzeichnung und Rekonstruktion historischer Sprachzustände:

„Die intensive Einwirkung der Standardsprache auf die Dialekte und Jargons sowie die Nivellierung und das allmähliche Verschwinden dieser Subsysteme der Ethnosprache veranlassen die Linguisten, diese im Rückgang befindlichen Erscheinungen zu erforschen und das Material, das in einigen Jahren nicht mehr der direkten Beobachtung zugänglich sein wird, zu fixieren." 222

219 Vgl. Kogotkova 1970, S. $143 f$

220 Vgl. dazu Girke/Jachnow 1974, S. 149 und dies. 1975, S. 13

221 Filin 1973, S. 6

222 Krysin 1976, S. 203 (disch. im Original), sehr deutlich auch bei Kasatkin 1967, S. 91 
oder:

„Vosproizvedenie na pis'me dialektnoj reči delo ne pisatelej, a lingvistov-dialekt ologov." 223

Insgesamt zielt die sowjetische intraethnische Sprachpolitik darauf ab, die Dialekte mehr und mehr zugunsten der Standardsprache als einheitlicher und verbindlicher Sprachform zu verdrängen. 224

Mit Ausnahme von Filin sind es in dem untersuchten Material allerdings ausschließlich Laien, die sich gegen die Verwendung von Dialektismen aussprechen.

Uneingeschränkt positiv stehen die Antinormalizatory dialektaler Lexik gegenüber, da sie ja die Hinwendung zum Dialekt - die Einbeziehung „aller Reichtümer des Russischen" (,vse bogatstva russkogo jazyka") - empfehlen, um der zunehmenden Standardisierung des Russischen entgegenzuwirken.225 Die verschiedenen Richtungen des Antinormalizatorstvo unterscheiden sich jedoch darin, welche Motivierung der generell positiven Bewertung von Dialektismen zugrunde liegt.

Die sprachkonservative Linie des Antinormalizatorstvo sieht in der Aufnahme dialektalen Wortguts in den literarischen Sprachgebrauch eine Möglichkeit zur Sprachbewahrung, zur Rettung der Dialekte vor dem drohenden Aussterben.226 Sie idealisieren den Dialekt als eine Quelle des echten, volkstümlichen, nicht durch fremde Einflüsse verdorbenen Russisch 227 und stellen ihm die Sprache der Stadt als supermodern, nivelliert und ausdrucksarm gegenüber. 228

In diesen Beiträgen ist die Befürwortung von Dialektismen meist mit einer Verdammung von Fremdwörtern 229 oder eindeutig sozialbedingter Varianten

223 Filin 1977, S. 24

$224 \mathrm{Vgl}$. Girke/Jachnow 1974, S. 77f, 149 und dies. 1975, S. 13

225 Vgl. z.B. Malov 9/66, Lipatov 34/71, Vinokurov 7/72, MoŽaev 23/76

226 Pokrovskij 28/69. Tjuleneva 28/69, Lipatov 34/71, Cudakov 41/73

227 Bokov 6/73, Cudakov 41/73, Tjuleneva 68/69

228 Čudakov $41 / 73$

229 z.B. bei SolZenicyn $131 / 65$ und Lipatov 34/71 
gekoppelt. Možaev beispielsweise setzt sich für Dialektwörter ein, warnt aber gleichzeitig vor Jargonismen und „anderen Wortparasiten“.230 Interessant ist dabei, daß er, wie Filin in einem Uberblick über die Diskussion von 1976 in RR nachweist, als "Wortparasiten" gerade typische Dialektismen aufgeführt hat:
„V to že vremja skukožit'sja (skorčit'sja, s-ežit'sja, smorštit'sja), tapel'nik (skovorodnik), gamozom (gur'boj) i dr., kotorye B. Možaev sčitaet ,slovami-urodcami' - tipižnye dialektizmy, v teદenie stoletij ustojčivo upotrebljavßiesja vsem naseleniem nekotorych mestnostej." 231

Diejenigen Antinormalizatory, die eine Orientierung an der tatsächlichen Sprachverwendung der Bevölkerung proklamieren, betrachten demgegenüber den Dialekt als nur eine der gegenwärtig tatsächlich gesprochenen Varianten der russischen Ethnosprache gegenüber dem ihrer Meinung nach kaum realisierten Standard.232 Die Aufnahme dialektalen Wortguts befürworten sie, wenn dies dem Idiolekt des aus dialektalem Milieu stammenden Schriftstellers entspricht, und um die Sprachpraxis der Bevölkerung realistisch wiedergeben zu können. 233 Dabei gehen sie nicht von der idealisierten Vorstellung eines reinen Dialektes aus, sondern - wie Abramov es darstellt von einem Gemisch der verschiedensten sprachlichen Schichten:

„Cego tol'ko ne ob-edinjaet ona (russkaja reč' v ee krestjanskom variante - die Verf.) v sebe segodnja! I korennoe starinnoe slovo, i dialektnye re enija i frazeologizmy, i naibolee populjarnye naučnoproizvodstvennye terminy, i reč' sovremennoj literatury, gazet, radio, televidenija... Da vsego, pǒ̌aluj, i ne perełislił’.“ (Abramov 47/72)

Aus den Aufsätzen in der LG geht hervor, daß das Bestreben, dialektales Wortgut aufzunehmen, unter sowjetischen Schriftstellern sehr populär ist. 234 Hier bestätigt das Material eine Tendenz, auf die bereits 1962 Panov hinge-

230 MoŽaev 23/76

231 Filin 1977, S. 24

232 Vgl. auch S. 49

$233 \mathrm{Vgl}$. dazu Abramov $47 / 72$ und Nersesov 33/70

234 Vgl.z.B. Solouchin $45 / 71$ 
wiesen hat.235 Einzelne Hinweise in den Artikeln lassen allerdings vermuten, daB Dialektwörter nicht immer nur deswegen in einen Text aufgenommen werden, weil sie entweder der Sprachverwendung des Schriftstellers entsprechen oder aber die Vermittlung des Inhalts an die Betroffenen durch Angleichung des Textes an deren Sprachgebrauch erleichtern sollen. Manchmal werden sie einem beliebigen Text als interessante sprachliche Besonderheiten aufgepfropft. So beobachtet Cudakov bei Schriftstellern die Tendenz, in ihren Texten unmotiviert Elemente der verschiedensten Dialekte zusammenzustellen:

„V literature poslednich let vse čaše vstre personaž, skažem, Żisljasčijsja vologodskim i nikogda - po sjužetu - severa ne pokidavsij, tem ne menee legko, bez zapinki upotrebljaet reženija srednerusskie, slova južnorusskich govorov $\mathrm{i}$ daže obnarǔ̌ivaet neožidannye poznanija $v$ sibirskich redkich dialektach." (Cudakov 33/76)

Možaev berichtet von einem Roman, in dem zur sprachlichen Abgrenzung der Dorfbewohner von den Städtern auch Wörter orthographisch unterschieden werden, deren Aussprache in Dialekt und Standardsprache identisch ist:

\begin{tabular}{|c|c|c|c|}
\hline$x_{\text {to }}$ & - & $\begin{array}{l}\text { für Dorfbewohner: } \\
\text { für Städter: }\end{array}$ & $\begin{array}{l}y_{\text {to }} \\
y_{\text {to }}\end{array}$ \\
\hline દego & - & $\begin{array}{l}\text { für Dorfbewohner: } \\
\text { für Städter: }\end{array}$ & $\begin{array}{l}\text { cevo } \\
\text { čego } 236\end{array}$ \\
\hline
\end{tabular}

Häufiger wird kritisiert, daß sich einige Schriftsteller nicht an ihrer eigenen Spracherfahrung orientieren, sondern sich aus Wörterbüchern klangvolle Ausdrücke heraussuchen.237

Während die Verwendung von Dialektismen im sonst standardsprachlichen Text bei Schriftstellern beliebt ist, scheint das Schreiben im Dialekt, also Dialektliteratur, in der Sowjetunion keine Rolle zu spielen. 238

235 Panov 1962, S. 5; vgl. dazu auch Brang 1973, S. 29

236 Mozaev 23/76

237 Vgl. z.B. Cudakov 33/76, Rylenkov $96 / 64$

238 Vgl. dazu Filin 1977, S. $23 \mathrm{f}$ 


\subsubsection{Fremdwörter}

Probleme fremdsprachlicher Lexik im russischen Standardwortschatz werden vorwiegend in den Beiträgen der Jahre 1971, 1973, 1974, 1977 und 1978 angesprochen. Dabei werden folgende Fremdworter erwähnt:

Liste der erwähnten Fremdwörter

Fremdwort

Quellen

agrochimija

agronom

grotechnika

atel'e

azboizobutilenoplastik

barmeny

barray

bestseller

biznes

bitl

bitnik

blaster

bojler

brojler

beki

cece

challi-galli

cheppening

chindi

chippi

chunta

detant
Uspenskij

Uspenskij

Uspenskij

Uspenskij

Lipator

Russkij jzzyk

Surtakov

Filin

Russkij jazyk

Fedorenko

Vladimirov

Filin

Vladimirov

$64 / 68$

$64 / 68$

$64 / 68$

$64 / 64$

$34 / 71$

$16 / 73$

$47 / 71$

$16 / 74$

$16 / 73$

$5 / 74$

$31 / 71$

$16 / 74$

Filin

$31 / 71$

$16 / 74$

Filin

$16 / 74$

Russkij jazyk

$16 / 73$

Filin

$16 / 74$

Vladimirov

$31 / 71$

Rachmanova

$14 / 77$

Filin

$16 / 74$

Filin

$16 / 74$

Rachmanova

$14 / 77$

Filin

$16 / 74$

Rachmanova /

Formanovskaja

$11 / 77$

Fedorenko 
Fremdwort Quellen

\begin{tabular}{|c|c|c|}
\hline diskretnost' & Fedorenko & $5 / 74$ \\
\hline displej & Filin & $16 / 74$ \\
\hline dizajner & Formanovskaja & $31 / 77$ \\
\hline dominanta & Fedorenko & $5 / 74$ \\
\hline dzajf & Petrova & $11 / 74$ \\
\hline$d z a z$ & Vladimirov & $31 / 71$ \\
\hline èkspander & Petrova & $11 / 74$ \\
\hline $\begin{array}{l}\text { eskaljacija } \\
\text { (anti-, kontr-, de-) }\end{array}$ & Fedorenko & $5 / 74$ \\
\hline fén & Ardabyvskaja & $84 / 64$ \\
\hline finis & Prijma & $25 / 78$ \\
\hline forvard & Vladimirov & $31 / 71$ \\
\hline galstuk & Filin & $16 / 74$ \\
\hline generacija & Russkij jazyk & $16 / 73$ \\
\hline golkiper & Vladimirov & $31 / 71$ \\
\hline granulirovanie & Uspenskij & $68 / 64$ \\
\hline ingibirovat' & $\begin{array}{l}\text { Ardabyvskaja } \\
\text { Uspenskij }\end{array}$ & $\begin{array}{l}84 / 64 \\
84 / 64\end{array}$ \\
\hline insajd & Vladimirov & $31 / 71$ \\
\hline interpersonalizacija & Fedorenko & $5 / 74$ \\
\hline istéblił̌ment & Fedorenko & $5 / 74$ \\
\hline kanalizacija & Russkij jazyk & $16 / 73$ \\
\hline$k \dot{e} t \dot{x}$ & Filin & $16 / 74$ \\
\hline kivi-kivi & Formanovskaja & $14 / 77$ \\
\hline kolgotki & Petrova & $11 / 74$ \\
\hline komp'juter & Filin & $16 / 74$ \\
\hline kondicija & Seleznev & $16 / 75$ \\
\hline konformizm (non-) & Fedorenko & $5 / 74$ \\
\hline kuasi & Formanovskaja & $14 / 77$ \\
\hline lamentacija & $\begin{array}{l}\text { Ardabyvskaja } \\
\text { Uspenskij }\end{array}$ & $\begin{array}{l}84 / 64 \\
84 / 64\end{array}$ \\
\hline lazer & Filin & $16 / 74$ \\
\hline linguist & Davydov & $18 / 71$ \\
\hline lobbi (lobbizm) & \multicolumn{2}{|c|}{$\begin{array}{c}\text { Filin } \\
\text { Dagmar Christians - 9783954792603 } \\
\text { Downloaded from PubFactory at 01/11/2019 05:07:27AM } \\
\text { via free access }\end{array}$} \\
\hline
\end{tabular}




mass medija
masstab (-nyj,
mazer
meditacija
mister Chit
motel'
najlon / nejlon
nokautirovat'
obligatomyj
plantacija

pobjuletenit'
pop-art
pop-muzyka
precizionnyj
preferencija
ralli
regbi
region
rev'ju
riforming
rok-n-roll
saljami
sal'to
sekuljarizacija
senaž
serijal
servis
smog
startovat'

Fedorenko

$5 / 74$

Babkin

$31 / 72$

Filin

$16 / 74$

Ardabyvskaja

$84 / 64$

Vladimirov

$31 / 71$

Fonjakov

$44 / 78$

Petrova

$11 / 74$

Vladimirov

$31 / 74$

Davydov

$18 / 71$

Lipatov

$34 / 71$

Atarov

$35 / 71$

Fonjakov

44/78

Laskov $109 / 64$.

Filin

$16 / 74$

Filin

$16 / 74$

Russkij jzzyk

$16 / 73$

Russkij jazyk

$16 / 73$

Filin

$16 / 74$

Vladimirov

$31 / 71$

Rachmanova /

Formanskaja

$11 / 77$

Fonjakov

$44 / 78$

Filin

$16 / 74$

Filin

$16 / 74$

Rachmanova

$14 / 77$

Fedorenko

$5 / 74$

Lipatov

$34 / 71$

Petrova

$11 / 74$

Filin

$16 / 74$

Fonjakov

$44 / 78$

Filin

$16 / 74$

Alekseev u.a.

21/71 


$\begin{array}{llr}\text { stekloepoplasty } & \text { Surtakov } & 47 / 71 \\ \text { stress } & \text { Filin } & 16 / 74 \\ \text { striptiz } & \text { Filin } & 16 / 74 \\ \text { subprodukty } & \text { Uspenskij } & 15 / 68 \\ \text { suSuar } & & \text { und 28/75 } \\ \text { suip-generator } & \text { Ardabyvskaja } & 84 / 74 \\ \text { suiter } & \text { Uspenskij } & 84 / 74 \\ \text { Yejk } & \text { Filin } & 16 / 74 \\ \text { tekstoamidoskoza } & \text { Vladimirov } & 31 / 71 \\ \text { terminal'nyj } & \text { Filin } & 16 / 74 \\ \text { transljator } & \text { Surtakov } & 47 / 71 \\ \text { trend } & \text { Davydov } & 18 / 71 \\ \text { tvist } & \text { Filin } & 16 / 74 \\ \text { unikal'nyj } & \text { Fedorenko } & 5 / 74 \\ \text { urdu } & \text { Filin } & 16 / 74 \\ \text { verbal'nyj } & \text { Davydov } & 18 / 71 \\ \text { vermisaž } & \text { Rachmanova } & 14 / 77 \\ \text { vobulator } & \text { Davydov } & 18 / 71 \\ & \text { Russkij jazyk } & 16 / 73 \\ & \text { Filin } & 16 / 74\end{array}$

Fremdwortpurismus spielt in der Sprachrubrik der LG kaum eine Rolle. Die Mehrzahl derjenigen, die sich zu Fremdwörtern äußern, halten es im Rahmen des internationalen Erfahrungsaustausches für notwendig, fremdsprachliche Lexik zu übernehmen. 239 Nur wenige allerdings sehen darin uneingeschränkt eine Bereicherung der russischen Sprache.240 Die meisten anderen befürworten Maßnahmen, die dem Zustrom von Fremdwörtern gewisse Beschränkungen auferlegen. Es soll nur Notwendiges, Unumgängliches entlehnt werden. 241 Vermieden werden sollen Fremdwörter in solchen Fällen, in denen 
ein gleich kurzes und ausdrucksstarkes russisches Aquivalent zur Verfügung steht. 242

Kritik an Fremdwörtern bezieht sich dabei in erster Linie auf deren nicht normgetreue Adaptierung. Petrova beschreibt 1974, daB aufgrund falscher Ubernahme mehrere orthographische oder orthoepische Varianten eines Fremdworts im Sprachgebrauch konkurrieren: nájlon - najlón -néflon oder espander - ékspander. 243 Hierzu gehören auch weit verbreitete Fremdwortentstellungen mit offensichtlich volksetymologischem Hintergrund wie poluklinika (Koroban 9/66), grejfrukt (Cistjakov 14/78, Lipatnikova 49/78) oder perekonstruirovat' (Fonjakov 43/73).

In einigen Beiträgen wird deutlich, daB in Fremdworrtern auch sonst typische Orthographiefehler, wie etwa die Verwechslung von ole und eli in unbetonter Silbe, gehäuft auftreten: vintel', salist arkestra felomonija, meofonija, filomentnyj. 244

Problematisiert werden in der Sprachrubrik ferner die Prinzipien, nach denen fremdsprachige Namen im Russischen wiedergegeben werden. Dabei plädiert man meist dafür, sich möglichst genau an der Lautung des Namens in der Originalsprache $z u$ orientieren, wenn es sich nicht um Namen handelt, die bereits anders - auch in Ubersetzung - im Russischen eingebürgert sind.245

Schwierigkeiten bereiten den Sprachbenutzem die Genusbestimmung bei Fremdwörtern und die Entscheidung, ob sie dekliniert werden müssen. 246

Andere Fehler entstehen dadurch, daß der Sprecher nur eine unklare Vorstellung von der Bedeutung eines Fremdworts hat, es aber dennoch benutzt, weil es gerade en vogue ist. So kommt es dann zu Paradoxa wie kurortnye

242 Uspenskij 84/64, Filin 16/74 und „Russkij jazyk ..." $16 / 73$

243 siehe Petrova 11/74

244 Vgl. Kap. 4.1.1. Orthographie, S. 65 f.

245 Vgl. Borovskij 7/69, Avilova/Derjagin 13/69, Bélza 13/69, Polkovnikov 20/69, Stasineviז 20/69, Kosinskij 20/69

$246 \mathrm{Vgl} . \mathrm{S} .67$ 
épicentry und autor gola oder den anscheinend beliebten Tautologien moja autobiografija, prejskurant cen und pamjatnyj suvenir. 247

Einige Artikel beziehen sich auf Fremdwörter als Elemente einer Fachterminologie, wobei die Kritik, die an ihnen geübt wird, eher der Ubernahme fachsprachlichen Wortguts in den allgemeinen Sprachgebrauch gilt als dem Umstand, daß diese Ausdrücke nicht russisch sind. 248

In der Sprachrubrik sind aber durchaus auch Aufsätze vertreten, deren Verfasser sich negativ zu Fremdwörtern äußern. Zum einen werden hier Fremdwörter aus der Befürchtung heraus abgelehnt, sie könnten das Russische überfremden, indem sie russische Elemente verdrängen. Diese Argumentation tritt am deutlichsten in dem Artikel von Solženicyn hervor ${ }^{249}$, ist aber auch bei Lipatov, Surtakov und sogar bei dem Linguisten Babkin zu finden. 250

Vereinzelt wird der Gebrauch von Fremdwörtern als Ausdruck der Schwäche der russischen Nation gegenüber dem Volk, aus dessen Sprache entlehnt wird, interpretiert. Dieses Argument ist ein Uberbleibsel aus der sowjetischen Sprachpolitik der fünfziger Jahre, die mit dem Fremdwortgebrauch eine „Kriecherei“ vor dem kapitalistischen System der USA und Westeuropas assoziierte. 251 Dies entspricht heute nicht mehr der Haltung der offiziellen Sprachpolitik. 252 Trotzdem klingt eine so begründete Aversion in einem Beitrag des Direktors des IRJaz, F. P. Filin an, der die Verwendung bestimmter Amerikanismen/Anglizismen zur Beschreibung sowjetischer Verhältnisse heftig kritisiert. Die Ubernahme des Ausdrucks smog dagegen rechtfertigt er mit der Behauptung, es könne für dieses Wort kein russisches Äquivalent existieren, da das Phänomen Smog in der Sowjetunion nicht vorhanden sei. 253

247 Vgl.S. 71

248 2.B. Ardabyvskaja 84/64, Surtakov 47/71

249 Soľenicyn $131 / 65$

250 Lipatov 34/71. Surtakov 41/71, Babkin

251 Keipert 1978, S. 288

$252 \mathrm{Vgl}$. Rachmanova/Formanovskaja 31/77

253 Filin $16 / 75$ 
Das Material in der LG liefert zwei weitere krasse Beispiele dafür, daß derartige Vorstellungen in der Bevölkerung immer noch fortleben. So mißbilligt der Anglistikdozent Zluktenko die Vorherrschaft englischer Termini in der internationalen Linguistik. 254 Lesenwert ist in dem Zusammenhang auch die Replik des Journalisten Vladimirov auf einen Artikel in der "Times", dessen Autor sich angeblich darüber lustig macht, daß die russische Sprache zu einem großen Teil aus Fremdwörtern, nämlich Anglizismen bestehe. Ahnlich wie Filin smog rechtfertigt, legitimiert Vladimirov die Ubernahme von Ausdrücken wie chippi, bitnik usw.255

Weniger auffällig, aber umso interessanter sind zwei Außerungen, die sich nicht auf Entlehnungen aus dem Amerikanisch/Englischen, sondern auf Ubernahmen aus dem Ukrainischen bzw. Weißrussischen als Sprachen von Völkern innerhalb der Sowjetunion und auf das Polnische als Sprache eines Verbündeten der UdSSR beziehen. So erwähnt Lev Uspenskij, daß in vielen Leserbriefen die Ubertragung des Suffixes -š̌̌ina, mit dem im Ukrainischen und Weißrussischen Benennungen von Gegenden von dem Namen ihres Zentrums abgeleitet werden (Poltaušcina $<$ Poltava), auch auf russische Bezirke beanstandet werde. Uspenskij läßt dabei durchblicken, daß ihm die Vorstellung, man könne mit diesem unrussischen Suffix auch die Bezeichnung Moskoustina ableiten, nicht behagt.256 Der Schriftsteller Kirsanov lehnt 1964 den Vorschlag der Orthographiekommission, die Buchstabenverbindung $c y$-durch $c i-z u$ ersetzen, ab, weil dann einige russische Wörter nicht mehr von ukrainischen zu unterscheiden seien. 257

Ein anderer bezeichnender Ausspruch fällt bei der Erörterung der Frage, wie fremdsprachige Eigennamen - und hier vor allem polnische - wiederzugeben sind. Den besonders von I. Bèlza unterbreiteten Vorschlag, sich dabei mög-

254 Zluktenko $18 / 71$

255 Vladimirov $31 / 71$

256 Uspenskij 21/71; Die vehemente Ablehnung des Suffixes šcina ist im übrigen wohl auf die häufig negativen Konnotationen (vgl.: inozem xina, turetčina) zurückzuführen, auf die an anderer Stelle der Schriftsteller Fonjakov aufmerksam macht: Fonjakov $44 / 78$

257 Kirsanov $117 / 64$ 
lichst genau an der Lautung des Namens in der Originalsprache anzulehnen, weist der Ingenieur Kosinskij entschieden zurück mit der Begründung:

„Uvaženie $k$ kul'ture drugich narodov, o kotorom spravedlivo

govorit I. Bèlza, vovse ne trebuet lomki jazykovych tradicij." (Kosinskij 20/69)

Es ist bedenkenswert, daß dies ein Leser sagt, der als Russe im tadżikischen Dułanbe lebt.

Aversionen gegenüber Fremdwörtern treten nicht allein im puristischen Lager auf, sondern sind auch bei einigen Antinormalisatoren und vereinzelt sogar bei Sprachwissenschaftlern zu finden. Von den Antinormalizatory sind jedoch nur diejenigen negativ gegenüber Fremdwörtern eingestellt, die der konservativen Richtung angehören.258 Für Solženicyn und Lipatov bedeuten Fremdwörter eine Bedrohung für die Volkstümlichkeit, die Echtheit des Russischen.259 Andere Antinormalizatory wie Atarov oder Borisova sehen die Aufnahme fremdsprachiger Lexik für eine Bereicherung des Russischen an und heißen ihre Assimilation für gut.

258 Fremdwortpuristische Tendenzen bei konservativen Antinormalizatory wie Solžnicyn und Jugov behandelt $H$. Keipert in dem bereits zitierten Aufsatz über puristische Tendenzen in der russischen Sprachpflege der Gegenwart. Vgl. Keipert 1978

159 Solženicyn $131 / 65$ und Lipatov 34/71 


\section{Die Bedeutung der Sprachrubrik für die Arbeit des IRJaz}

Vor der Beantwortung der Frage, welche Bedeutung der Sprachrubrik in der LG für die Arbeit des IRJaz zukommt, möchte ich an dieser Stelle die inzwischen gewonnenen Ergebnisse noch einmal knapp zusammenfassen.

Beim ersten Uberblick über das Material, das die Sprachrubrik der LG anbietet, drängt sich der Eindruck auf, hier seien in Themenwahl und Ausführung reichlich heterogene Artikel zusammengestellt. Einerseits waren es Meldungen von konkreten Normverstößen oder Fragen zu strittigen Problemen des Russischen, meist von Laien in Leserbriefen knapp vorgetragen und kommentiert von Sprachwissenschaftlern, oder anfangs von Uspenskij. Daneben standen umfangreiche, sich oft zu Diskussionsreihen fügende Artikel, in denen die literarische Spache und besonders deren Verhältnis zur Norm der Standardsprache behandelt wurden.

Hinsichtlich ihrer Einstellung zur Sprachpolitik des IRJaz lassen sich die Verfasser von Beiträgen für die Sprachrubrik - mit Ausnahme der beteiligten Linguisten, die als Mitarbeiter des IRJaz vorwiegend die Interessen des Instituts vertreten - zwei gegensätzlichen Lagern zuordnen. Auf der einen Seite stehen die Puristen, die sprachlenkende Maßnahmen von staatlicher Seite uneingeschränkt befürworten, denn ohne sprachlenkende Eingriffe - so meinen sie - sei die russische Sprache dem Verfall ausgesetzt, jegliche natürliche Entwicklung führe unweigerlich ins Chaos. Unzufrieden sind sie mit dem IRJaz, weil es sich gegenüber sprachlichen Modernisierungstendenzen allzu liberal verhalte. Seine konkreten Maßnahmen erscheinen ihnen zu dürftig, zu wenig verpflichtend und daher ohne die gewünschte Wirkung auf den Sprachgebrauch der Bevölkerung. Ihnen fehlt die Kontrolle, die erst eine Verpflichtung der Bevölkerung zu normgetreuem Sprachgebrauch gewährleiste, wobei sie der Norm keine Dynamik zubilligen wollen. Weil das IRJaz zu einer Sprachpolitik ihrer Vorstellung nicht fähig oder nicht gewillt ist, rufen sie zur Eigeninitiative normbewußter Sprachbenutzer auf. 
Das Lager der Antinormalizatory - vertreten durch eine konservative, sprachbewahrende und eine realistische Linie - setzt dagegen großes Vertrauen in die natürliche Sprachentwicklung. Während die einen sprachlenkende Maßnahmen für wirkungslos halten, weil sich die Eigengesetzlichkeit des Russischen allen Bemühungen zum Trotz durchsetze, befürchten andere von ihnen eine Hemmung des natürlichen Ablaufs und damit eine Verschlechterung der russischen Sprache.

Berühungspunkte haben Purismus und die konservative Linie des Antinormalizatorstvo dort, wo sie - beide auf Bewahrung tradierter Sprachzustände ausgerichtet - gegen Modernisierungstendenzen im Russischen protestieren. Die Zielrichtungen ihrer Angriffe unterscheiden sich jedoch wiederum insofern, als Antinormalisatoren das Russische vornehmlich vor fremdsprachigen Einflüssen bewahren wollen (Fremdwortpurismus), während für Vertreter des hier puristisch genannten Lagers eher ein innerer Purismus kennzeichnend ist. Von daher ist die Unterscheidung zwischen "Antinomalizatorstvo" und "Purismus", die hier in Anlehnung an die Definition der sowjetischen Linguistik gewählt wurde, nicht ganz zutreffend. Der eigentliche Gegensatz zwischen den beiden Lagern besteht darin, daß die einen eine strengere Kontrolle über die Einhaltung von Sprachnormen in der Bevölkerung fordern, als dies vom IRJaz vorgesehen ist, die anderen dagegen die Normierung und Kontrolle des Sprachgebrauchs ablehnen.

Die Sprachwissenschaftler treten beiden Lagern, deren unterschiedliche Haltungen sie als Varianten von unwissenschaftlicher und daher nicht legitimer Sprachkritik begreifen, als Vertreter einer wissenschaftlichen Sprachpolitik gegenüber.

Das Material in der LG entspricht also im großen und ganzen der Aufgabenstellung des IRJaz, das, wie mehrmals betont, einen Kampf an zwei Fronten führt, gegen übereifrige Normverfechter und gegen kategorische Normgegner. 260

260 "Predislovie". in: APKR 1970, S. 6f, Skvorcov 1970, S. 100f, ders. 1980, S. 112. siche auch S. $56 \mathrm{ff}$. 
Schon an dem umfangreichen Material, das allein in der LG veröffentlicht wird, wird jedoch deutlich, daß das IRJaz beide Strömungen erheblich unterschätzt. Skvorcov schreibt z.B. 1970 und unverändert auch 1980:

„Pervaja tołka zrenija (purizm - die Verf.) u nas faktiłeski schodit na net, vtoraja (antinormalizatorstvo - die Verf.) podderŽivaetsja rjadom pisatelej i $\mathbf{v}$ pervuju oðered' A.K. Jugovym." 261

Die Behauptung, der Einfluß des Purismus sei vernachlässigenswert gering, erweist sich angesichts der zahlreichen Leserbriefe mit eindeutig puristischen Anklängen bereits als unhaltbar. Aber auch der zweite Teil der Skvorcov'schen Aussage läßt sich nicht bestätigen, denn in der LG stehen eben nicht nur vereinzelte, sondern die Mehrheit der beteiligten Schriftsteller einer zunehmenden Vereinheitlichung des Russischen kritisch gegenüber.

Die beschriebene Zweigleisigkeit in der Aufklärungsarbeit des IRJaz hilft, die Heterogenität der unter der Sprachrubrik subsumierten Beiträge zu erklären. Auf diesem Hintergrund ist sie nämlich nichts Zufälliges, sondern Ausdruck dessen, daß die Auseinandersetzung mit den beiden unwissenschaftlichen Standpunkten durchaus auch formal in unterschiedlicher Art und Weise geführt wird. Schließlich tritt der Sprachwissenschaftler bei der Kommentierung von Leserbriefen Laien gegenüber, denen er aufgrund seines Wissens- und Autoritätsvorsprungs bei weitem überlegen ist. Die in der Regel als Schriftsteller bekannten Antinormalizatory aber haben der wissenschaftlichen Qualifikation der Linguisten ihre schöpferische Intuition entgegenzusetzen und besitzen außerdem in der LG als Organ des Schriftstellerverbandes praktisch ein Hausrecht.

Die Sprachrubrik, und hier besonders die Rubrik ,Jazyk i vremja", stellt also den Rahmen, innerhalb dessen die Auseinandersetzung auf zwei inhaltlich wie formal verschiedenen, einander kaum überschneidenden Ebene verläuft. Die eine entspricht dabei dem anfänglich und 1977 dominierenden Sprachdienstcharakter der Rubrik und besteht in einem Dialog zwischen Sprachbenutzer und dem IRJaz als normengebender Instanz. Die andere Ebene macht die zwi- 
schen Schriftstellern und Linguisten geführte Diskussion über das Verhältnis des Schriftstellers zur sprachlichen Norm aus.

\subsection{Der Dialog mit dem Sprachbenutzer}

Welche Bedeutung hat nun die Veröffentlichung von Leserbriefen in der Sprachrubrik der LG für die praktische Arbeit des IRJaz?

Die Zuschriften enthalten erstens - wenn auch nur in sehr kleinen Ausschnitten - Beschreibungen der tatsächlichen Sprachverwendung durch die Bevc̈lkerung. Hier werden Normabweichungen registriert und oft sogar die Sprechergruppen (Schriftsteller, Schüler) oder Kommunikationssituationen (Presse, Fachliteratur, Belletristik, Bekanntmachungen) genannt, in denen bestimmte Normabweichungen besonders häufig auftreten. 262 Solche Angaben helfen dem Institut bei der Beurteilung der Frage, bis zu welchem Grad die von ihm gesetzten Normen der russischen Sprache von der Sprechergemeinschaft befolgt werden. Es erhält so Anhaltspunkte für Schwachstellen in der Beherrschung der Standardsprache, an denen eine intensive Aufklärung nötig wäre. Auf die Wichtigkeit solcher Informationen weist Svarckopf hin:

„Poskol'ku kul'tura reti zakonomerno vkljutaet v sebja prikladnoj aspekt (...), normalizator krovno zainteresovan $v$ vyjasnenii stepeni togo, naskol'ko konkretnye nositeli jazyka vladejut literaturnymi normami (inate nevozmokna dejstvennaja propaganda norm literaturnogo jazyka). 263

In den Leserbriefen manifestieren sich aber auch die Vorstellungen der Sprachbenutzer von den Normen des Russischen. Hier zeigt sich, in wieweit dem Sprecher das gültige Normensystem bewußt ist. Es wurde schon an anderer Stelle erwähnt, daß sich viele Verfasser von Zuschriften an veralteten Normen oder an eigenen, nicht der Norm entsprechenden Sprachgewohnheiten orientieren. Die Leserbriefe geben somit dem IRJaz ein Feedback zu seiner Aufklärungsarbeit in der Bevölkerung. In der Sprachrubrik wurde u.a. deut- 
lich, daß die vom Institut herausgegebenen Broschüren und Handbücher zu Sprachfrazen nur ungenügend bekannt geworden sind und Wörterbücher nicht benutzt werden. Kalinin bemerkt:

„Iz Eitatel'skich pisem, iz statej (. . .) vidno (...), Žto my eక̌̌e malo propagandiruem chorołie knigi o jazyke, poleznye slovari, spraroxniki, posobija po kul'ture reči." (Kalinin 35/71)

Drittens ä:Bern die Laien ihre Einstellung zur Sprache, zur Kodifikation und zum Sprachgebrauch der Bevölkerung. Diese Außerungen bedeuten, wie bereits eingangs dargestellt, für den Sprachnormer wichtige Informationen für die Planung und Durchführung gezielter sprachpolitischer Maßnahmen:

„... praktiðeskoe osustestvlenie zadat kul'tury re $\chi_{i}$ trebuet izučenija jazykovogo opyta tech, k komu obrał̌̌ena jazykovaja politika, Ctoby znat', na kakie čerty jazykovogo 'ut'ja govorjašcich možro opirat'sja pri progagande kul'tury rexi, a s kakimi sleduet boro:'sja." 264

In diesem Sinne würdigt Babkin die Sprachrubrik der LG als nützliche Einrichtung:

„V zabote o dostoinstve, moß̌ci i Cistote russkogo jazyka 'Literaturnaja gazeta' pod rubrikoj 'Jazyk i vremja' na svoich stranicach vela oživlennyj, soderŽatel'nyj $i$, nesomnenno, ves'ma svoev:emennyj i poleznyj razgovor o tom, kak Zivet i razvivaetsja russkij jazyk $v$ nasu burnuju epochu. (. . .) Vyskazyvanija byli kritiłny, neredko samokritiłny, neuklonłivy i otkrovenny, a potomu sovsem netrudno, protitav podrjad vse opublikovannye gazetoj stat'i i zametki, ulovit', kakie Že, s tołki zrenija ułastnikov spora. reðevye nedostatki i poroki podležat osuždeniju i reXite.'nomu iskoreneniju." (Babkin 31/72)

Wie aus redaktionellen Anmerkungen hervorgeht, werden auch unveröffentlicht gebliejene Leserbriefe dem Institut weitergeleitet und dort vermutich ausgewertet. Aus solchen Außerungen hat das IRJaz 1965-1970 eine „kartoteka obš̌estvennogo mnenija“ erarbeitet. $265 \mathrm{Daß}$ die veröffentlichten Beiträge be:ücksichtigt werden, bestätigt neuerdings die kürzlich erschienene 
Arbeit des Leiters der Abteilung für Sprachkultur am IRJaz, L.I. Skvorcov, in der einige Artikel erwähnt werden. 266

Darüber hinaus wird dem Institut durch die Veröffentlichung der Leserbriefe und der ihm gebotenen Gelegenheit zu unmittelbarer Kommentierung die Möglichkeit eröffnet, auch die LG für die Propagierung seiner sprachpolitischen Maßnahmen zu nutzen und so einen weitaus größeren Leserkreis anzusprechen, als dies über populärwissenschaftliche Broschüren oder Handbücher möglich wäre. Dies unterstreicht z.B. Gorbałevið in der Diskussion von 1978:

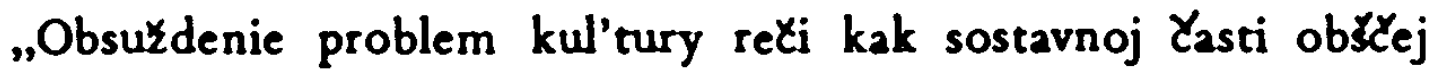
kul'tury čeloveka - zadata v ogromnoj mere prosvetitel'skaja. '̌irokaja Xitatel'skaja auditorija, znakomjas's tołkoj zrenija togo ili inogo avtora, sopereživaet, volnuetsja, negoduet, a znatit, vsem chodom diskussii vovlekaetsja $v$ aktivnyj process razmyłlenija, $i$ esli ugodno, priobstenija k kul'ture rodnogo jazyka." (Gorbačevit 39/78)

So wirdigt denn auch Skvorcov die Teilnahme von Sprachwissenschaftlern an Diskussionen in der LG267 als entscheidenden Beitrag dazu, die Vermittlung fundierter linguistischer Kenntnisse in der Bevölkerung zu intensivieren und auszuweiten. 268

5.2. Die Diskussion über das Verhältnis des Schriftstellers zur standardsprachlichen Norm

Die Auseinandersetzung über Wechselbeziehungen zwischen dichterischem Sprachgebrauch und den Normen der russischen Standardsprache nimmt

266 Skvorcov 1980, z.B. S. 132

267 Skvorcov spricht von der großen Diskussion, die in den Jahren 1971-1974 unter dem Namen .Jazyk i vremja" geführt worden sei. Eine solche zusammenhängende Diskussion hat es aber nicht gegeben, auch die Festsetzung der Grenzen 1971-1974 scheint willkürlich getroffen zu sein, da die Rubrik von 1971-1976 bestand.

268 Skvorcov 1980, S. 12 
unter den Sprachbeiträgen in der LG einen großen Raum ein. Sie hat nicht - wie der Dialog mit dem Sprachbenutzer - erst bei der Einrichtung einer speziellen Sprachrubrik 1964 Gestalt angenommen, sondern fand schon früher, nämlich 1934, in dieser Zeitung statt.269 Noch 1965 und 1966 verläuft sie außerhalb der Sprachrubrik und wird erst nach deren Konzeptionsanderung in sie eingegliedert.270 Sowohl ihre Thematik als auch die von den Diskussionsteilnehmern bezogenen festgefahrenen Fronten scheinen dem LG-Leser vertraut zu sein. So berichtet etwa Lanscikov:

„Ne v pervyj raz voznikaet $v$ petati spor na temu: dolžen li byt' jazyk pisatelja bezuprečnym s tołki zrenija literaturnoj normy, ili emu pozvolitel'ny kakie to ,vol'nosti'? Tradicionny i uČastniki spora: s odnoj storony - pisatel', napadajuszij na lingvistovnormalizatorov, s drugoj storony - jazykoved, trebujuscij ot pisatelja strogogo sobljudenija vsech pravil.“ (Lanక̌ikov 14/72)

Im Mittelpunkt der Diskussion steht also die Frage, inwieweit der Schriftsteller bei der Wahl seiner sprachlichen Ausdrucksmittel den Normen des Standardrussischen verpflichtet ist und inwieweit er seinen individuellsprachschöpferischen Ideen Ausdruck verleihen darf. Wie Lanščikov richtig bemerkt, erwarten Sprachwissenschaftler vom Schriftsteller angesichts der ihm zugedachten spracherzieherischen Aufgabe eine besonders strikte Befolgung standardsprachlicher Normen. Hier und da werden ihm allerdings im Rahmen des Uberschaubaren gewisse stilistisch oder inhaltlich motivierte Normabweichungen zugestanden: die Bildung neuer Wörter und Wortverbindungen, sofern sie den Wortbildungsmöglichkeiten des Standardrussischen nicht widersprechen und nicht reine Dubletten sind271, das Abwandeln von erstarrten Phraseologismen 272 und zur Personencharakterisierung die Aufnahme vereinzelter dialektaler oder umgangssprachlicher Lexik. 273

Elemente aus der "Sprache des Volkes" und individuelle stilistische Besonderheiten dürfen dabei den standardsprachlichen Charakter literarischer

$269 \mathrm{Vgl}$. dazu S. 18 mit Anmerkung 30. Weitere Schriftstellerartikel zu diesem Thema in der LG erwähnt Grigor'ev 1961.

$270 \mathrm{Vgl}$.S. 22

271 Siehe Skvorcov 40/75

272 Cukovskij 144/64; Formanovskaja $14 / 77$

273 Vgl. dazu z.B. Kasatkin 1967, S. 88 
Texte nicht beeinträchtigen, da sonst die immer wieder geforderte Allgemeinverständlichkeit nicht mehr gewährleistet sei. 274

Die Antinormalisatoren nun können einer rein edukatorischen Aufgabe nichts abgewinnen. Sie wollen sich die Möglichkeit nicht nehmen lassen, die nicht immer normgerechte Sprachpraxis der Bevölkerung, über die sie schreiben, realistisch wiederzugeben, statt das Auseinanderklaffen von geforderter Norm und tatsächlichem Sprachgebrauch zu kaschieren.275 Deshalb fordern sie die Enttabuisierung dialektaler und soziolektaler Sprachelemente - wenn auch meist nur auf literarischem Gebiet. Daruber hinaus nehmen sie in der Tradition anerkannter Klassiker das Recht für sich in Anspruch, aktiv an der Weiterentwicklung des Russischen teilzuhaben, auch wenn nicht all ihren sprachschöpferischen Experimenten Erfolg beschieden ist. 276

Besonders bei der Aufnahme außerstandardsprachlicher Lexik in literarische Texte geraten Schriftsteller in Konflikt mit der Instanz des „literaturnyj redaktor", einem verlagseigenem Korrektor, der die sprachliche Form von Manuskripten vor der Drucklegung auf ihre Ubereinstimmung mit den Normen des Standardrussischen berpruft und gegebenenfalls eigenmächtig verändert. Kritische Erwähnung findet diese Instanz in den Beiträgen von Rylenkov (96/64), Malov (9/66), Birjukov (9/66), Vinokurov (7/72 und 47/73), Lev (14/72), Abramov (47/72), Dik (5/68) und Gladilin (32/74). Hier werden die Korrektoren als dogmatische Verfechter sprachlicher Normen charakterisiert:

.Redaktor - èto jarostnyj storonnik normy, 22 nemnogimi iskljurenijami èto vsegda purist." (Abramov 47/72)277

Malov und Rylenkov nennen Beispiele für Wörter, die von Korrektoren beanstandet wurden. Gladilin beschreibt, wie einer seiner Romane dermaßen verändert worden sei, daß nach der Uberarbeitung ein ungehobelter

274 Vgl. dazu auch S. 82

275 Levin 134/65, Kolesnikov 30/73, Možaev 23/76, Nersesov 33/76, Vanšenkin 23/78, Abramov $47 / 72$.

276 Vinokurov 48/73, Gusev 18/76, Žirmunskaja 27/76, Solov'ev 42/76, Vaň̌enkin $23 / 78$

277 ähnlich auch: Birjukov $12 / 66$, Vinokurov $7 / 72$ 
Soldat in der Sprache eines Akademikers redete, eine andere Person gar ganz gestrichen worden sei, weil sie sich im Manuskript nicht der Standardsprache bedient hatte. Malov und Vinokurov (7/72) befürchten, daß die Sprachdiskussionen von 1965/66 bzw. 1971/72 einer verstärkten Zensur literarischer Texte Vorschub leisten könnten. Die Rigorosität, mit der einige Korrektoren diesen Berichten zufolge in Texte vornehmlich noch unbekannter Autoren eingreifen, führt nach Meinung der Antinormalisatoren zu einem überängstlichen Sprachverhalten bei Schriftstellern. Deren Verunsicherung äußert sich z.B. in der von Uspenskij, Kron und Beljarev erwähnten Tendenz, alles, was außerhalb des Standardwortschatzes liegt oder im übertragenen Sinn zu verstehen ist, mit Anführungsstrichen abzusichem.278

Weitaus schlimmere Folgen befürchten die Antinormalisatoren, wenn Schriftsteller aus Angst, Normen zu übertreten, keine neuen, originellen Sprachmuster mehr hervorbringen, sondern, sich am Ublichen orientierend, ständig abgegriffene Klischees reproduzieren:

„Pisatel'stvo - éto vsegda risk. Plocho, esli iz-za stracha ostupit'sja pisatel' stanet Curat'sja jazykovoj paradoksal'nosti, složnych i prichotlivych jazykovych figur, razgovornoj ,prixudlivosti'.“ (Vinokurov 48/73) 279

Nicht umsonst prangern sie in ihren Artikeln immer wieder eben jene klischeehafte Sprachverwendung an, die selbständiges Denken überflüssig macht oder gar blockiert:

„Knižnaja reł' v nesravnenno bol'Sej stepeni, ð̌em Živaja, pol'zuetsja gotovymi soð̌tanijami slovi celych fraz. I esli rebenok priuðaetsja govorit' tol'ko gotovymi ,blokami', to skol' pagubno vlijaet èto na obrazovanie u nego netrivial'nogo sposoba myslenija $i$ pravil'nych ponjatij o tom, ¿̌to znatit myslit'!" (Čudakov 41/73)

"Slovesnye ,modeli", gotovye bloki iz ul'trasovremennych slov i ponjatij sposobny soobకtit' illjuziju intellektual'nosti, sverchsovremennosti, togda kak na dele osvoboždajut mozg ot vsjareskoj raboty." (AnaY̌enkov 47/76) 
Die daraus entstehende glatte, normgerechte Literatur (Eistopisanie280, gladkopis'281 krasnoretie 282) biete zwar keinerlei AnlaB zu Beanstandungen, sei dafür aber langweilig und entbehre jegticher Merkmale individueller Wirklichkeitsverarbeitung. 283

In dieser erst später der Sprachrubrik untergeordneten Auseinandersetzung, die in erster Linie von Schriftstellern und Linguisten getragen wird, dominieren eindeutig die Antinormalizatory. Die eingangs aufgeworfene Frage, wessen Bedürfnissen die LG mit ihrer Sprachrubrik entspricht, muB also für die beiden Ebenen der Auseinandersetzung unterschiedlich beantwortet werden. Auf der Ebene des Dialogs zwischen dem normengebenden Institur und dem Laien-Sprachbenutzer kommt sie primär den Interessen des IRJaz nach. In der Diskussion um den dichterischen Sprachgebrauch dagegen steht sie den Antinormalizatory als Forum zur Verfügung, ihre mit wesentlichen Prinzipien der „offiziellen“ Sprachpflege des IRJaz nicht abereinstimmenden Ansichten zum Ausdruck zu bringen, was nicht zuletzt aus dem Hausrecht resultiert, das die Antinormalizatory als Schriftsteller in der LG genießen. 


\section{Resïmee}

Die Sprachrubrik der LG wurde 1964 im Zusammenhang mit der systematschen Einbeziehung der Massenmedien in die Sprachpolitit des IRJaz eingerichtet. Begonnen als unregelmäBig erscheinende Sprachecke zur Beantwortung oder Kommentierung einzelner, an die Redaktion der Zeitschrift gesandter Leserzuschriften, die in erster Linie der Schriftsteller Lev Uspenskij vornimmt, entwickelt sie sich ab 1968 unter zunehmendem Einflub des IRJaz zu einem festen Bestandteil der LG. Dabei tritt der anfangs prägende Sprachdienstcharakter der Rubrik, der sich in deren ursprünglichem Namen ,Sluzba russkogo jazyka" widerspiegelt, allmāhlich in den Hintergrund und macht mehr und mehr zusammenhängenden Diskussionen Plazz.

Sprachbeiträge werden von Schriftstellern, Linguisten und Laien verfabt. Nur die ersten beiden Personengruppen stehen sich unter vengleichbaren Voraussetzungen als Diskussionspartner gegenüber. Während von Schrifustellern verfabte Aufsätze in der LG als Organ des Schriftstellerverbandes auch die Diskussionen über Sprache dominieren, wird den Linguisten von der Redattion eine immense Autorität als Sachverständigen emgeräumt. Von beiden Gruppen nicht als ernstzunehmende Gesprächspartner akzeptiert stehen die zahlreichen beteiligten Leser mit ihren Zuschriften. Sie haben wenig Einflub auf den Verlauf und das Ergebnis der Auseinandersetzungen. Erwünscht ist ihre Teilnahme nur dann, wenn sie beobachtete Normabweichungen aufzählen oder Fragen stellen, die dann von Linguisten beanţwortet werden kōnnen. Kritik am Sprachgebrauch von Schriftstellern oder an der Arbeit des IRJaz wird mit dem Hinweis auf die Inkompetenz von Laien zurückgewiesen.

Die Sprachrubrik der LG spiegelt die Situation wider, in der sich die offizielle Sprachpolitik in der Sowjetunion auch nach eigenen Angaben befindet: zwischen übereifrigen Verfechtern und kategorischen Gegnern der Sprachnorm. Beide Strömungen werden von ihr als unwissenschaftich abgetan und fälsch. licherweise verharmlost. Wohl deshalb fehlt in der wissenschaftlichen Literatur eine eingehende Beschreibung der beiden konträren Standpunkte. In dieser Hinsicht bot das LG-Material reichlich Informationen. Es ermöglicht, 
die Vorstellungen von Sprache, die den beiden Richtungen zugrunde liegen, herauszuarbeiten und die Argumentationsweise ihrer Vertreter zu illustrieren.

Dabei ergab sich, daß die meisten Teilnehmer nur äußerst vage Vorstellungen daruber hatten, was Sprache im gesellschaftlichen Leben leistet. Auffällig war der stereotype Charakter ihrer Sprachurteile, der vermuten läBt, daß diese Einstellungen kollektiv erlernt sind. Interessant wäre es, zu untersuchen, woraus diese Vorstellungen resultieren und in wiefern sie darauf zurückgefuhrt werden können, daß, wie Gorbałevił es andeutet, der Bevölkerung in Sprachfragen nur unzureichende, allzu vereinfachte Antworten gegeben werden, oder aber, wie oftmals in den LG-Beiträgen, ihre Erklärungen zu wenig auf die linguistischen Vorkenntnisse von Laien abgestimmt sind. Dafür müBten sowohl Lehrbücher für den Schulunterricht und populärwissenschaftliche Broschüren des IRJaz analysiert werden, als auch die zahlreichen von Schriftstellern verfaßten Sprachbücher, die offensichtlich einen großen EinfluB auf die Bevölkerung haben.

Puristische Ansichten wurden vor allem von Laien vertreten, bei denen es sich - soweit dies aus den jeweiligen Angaben zu Beruf und Wohnort der Verfasser zu ermitteln war - um einen Personenkreis handelt, von dem eine überwiegende Verwendung der Standardsprache zu erwarten ist. In erster Linie von Schriftstellern vorgebracht wird die Position des Antinormalizatorstvo, bei dem zwei Richtungen unterschieden werden müssen: eine sprachbewahrende, konservative Linie, die sich durch Fremdwortaversion und Idealisierung dialektaler Sprachformen auszeichnet, und eine Linie, deren Vertreter sich am tatsächlichen Sprachgebrauch der Bevölkerung orientieren.

Viele Beiträge in der Sprachrubrik behandeln konkrete Beispiele für Normabweichungen, die in der gegenwärtigen Sprachpraxis der Bevollkerung zu beobachten sind. Die vorwiegend in der Form von Fehlerlisten vorgebrachten Normverletzungen im Bereich der Grammatik wurden von mir - soweit dies möglich war - systematisiert. 
Diskussionen entzündeten sich vor allem an Problemen des Lexikons. Besonders die Frage, ob der Schriftsteller dialektale Elemente in seine literarische Sprache aufnehmen darf, war sehr umstritten. Viele Teilnehmer, darunter auch Sprachwissenschaftler, außerten eine negative Einstellung gegenüber dem Dialekt, der als Sprachform rückständiger Dorfbewohner abgelehnt wurde. Diese Vorstellung scheint bei russischen Standardsprechern tief verwurzelt zu sein. Befürwortet werden Dialektismen ausschlieBlich von den Antinormalizatory, teils jedoch im Bestreben, alte Sprachzustände aufrechtzuerhalten (konservative Linie). Der Fremdwortpurismus spielt in der LG nur eine sehr unbedeutende Rolle, markante Xußerungen gegen Fremdwörter blieben auf Ausnahmen beschränkt.

Festgestellt werden konnte, daB die Auseinandersetzung in der LG auf zwei verschiedenen Ebenen verläuft. Die eine Ebene entspricht dabei dem anfänglichen Sprachdienstcharakter der Rubrik und stellt einen Dialog zwiechen Sprachbenutzer und normengebender Instanz dar. Eine Zusammenarbeit der Redaktion mit dem IRJaz garantiert dabei, daB Leserbriefe an das Institut zur Einsicht und Kommentierung weitergeleitet werden, und rāumt dem IRJaz die Möglichkeit ein, die LG als Publikationsorgan zu nutzen, um so auf breite Leserkreise EinfluB nehmen zu können. Die Auswertung der Leserzuschriften bietet dem Institut wichtige, für eine gezielte Durchführung sprachlenkender MaBnahmen notwendige Informationen.

Auf einer anderen Ebene liegt die Auseinandersetzung zwischen Schriftstellern und Linguisten um das Recht des Schriftstellers auf freie Auswahl seiner sprachlichen Ausdrucksmittel. Während Linguisten und Laien von den Schriftstellern einen besonders normgetreuen Sprachgebrauch erwarten, wollen diese die Sprachpraxis der Bevölkerung mitsamt den üblichen Normverstößen realistisch wiedergeben und auch selbst sprachschöpferisch tätig werden. Ihre Kritik gilt zum einen den verlagseigenen Korrektoren, weil sie Abweichungen vom Standardsprachgebrauch oft kategorisch ablehnen und eigenmächtig durch ähnliche, aber nicht unbedingt treffende Standardwörter ersetzen. Sie tadeln aber auch Schriftsteller, die aus Unsicherheit oder Opportunismus eine geglättete, normgerechte und daher keinerlei Anlab zu Beanstan- 
dungen bietende Literatur produzieren, die ohne jegtiche individuelle Wirklichkeitsverarbeitung nichtssagend bleibe. 


\section{DOKUMENTATION}


M. Semenov: „Vo kuznice..."“

In der Nummer 7 der LG von 1964 befindet sich ein feuilletonistischer Aufsatz von $M$. Semenov über neuere Wortschöpfungen im Russischen. Dieser Beitrag verläßt nicht den Rahmen einer bloßen Aufzählung von Semenovs Meinung nach zu beanstandenen Neologismen:

moreprodukty, rozovod, ochotoustrojstvo, dilezagotovki, nedopromystenie, perepromystenie, obezbolivanie, obile $X_{i v a n i e ;}$

Außerdem bemängelt Semenov Abbreviaturen zur Bezeichnung von Behörden:

- 1-j MOLMI: Pervyj Moskouskij ordena Lenina medicinskij institut

- Privet delegatam KADI, MADI i ChADI! (Kieuskij, Moskouskij iCharkouskij autodorožnyj institut)

1. Sviridenko: „Ne zvuk okostenelyj"

Mit dem Brief des Lesers Sviridenko aus Kant beginnt in der LG eine Diskussion um die 1964 geplante Orthogr aphiereform.

Sviridenko sieht die Ursache für stilistische und inhaltliche Mängel in Schulaufsätzen darin, daß im Schulunterricht der Vermittlung von orthographischen Regeln zuviel Zeit und Energie gewidmet werde. Die Lehrerschaft warte ungeduldig auf die Ergebnisse der Kommission, die an der Vereinfachung der russischen Rechtschreibung arbeite. Derzeit seien die Lehrer damit beschäftigt, den Schülern Regeln beizubringen, die oft weder durch die Aussprache noch durch logische Folgerichtigkeit abgesichert seien. Sviridenko hält es für wichtig, daß die Probleme der Orthographiereform nicht allein von Linguisten entschieden, sondern auch von Lehrern und Schriftstellem diskutiert werden. Nach Sviridenko erhoffen sich die Lehrer von der Kommission eine Vereinfachung der Trennungsregeln und der Regeln für den Gebrauch von Großbuchstaben, die Vereinheitlichung der Wiedergabe von unbetonten Vokalen, die Reduzierung der Vielfalt von Lautwechseln und die Abschaffung von Doppelkonsonanten im Wortstamm. 
Eine weitere Ursache für den mangelhaften Sprachgebrauch bei Schulem sei Schriftstellem, Literaturwissenschaftlem und Publizisten anzulasten, die die Schulbücher in einer grauen Sprache verfaBten. Er erinnert daran, daB L. Tolstoj seinerzeit vorbildliche Schulbücher und didaktische Erzählungen geschrieben habe. AuBerdem benōtige man dringend ein Lehrbuch der Stilistik für die fönfte bis zehnte Klasse, das unter Mitwirkung von Pädagogen und Schriftstellern zusammengestellt werden müsse.

Sviridento beschlieBt seinen Brief mit der Aufforderung an Schriftsteller, Wissenschaftler und Pädagogen, zu dem Thema Orthographiereform Stellung zu nehmen.

A.l. Efimor: "Sila tradicii ili...."

Efimov berichtet über den Verlauf der Diskussion innerhalb der Orthographiekommission. Er erwähnt, daB im November 1962 in der Abteilung für Literatur und Sprache der Akademie der Wissenschaften eine Kommission zur Verbesserung der russischen Orthographie gebildet worden sei, die aus wissenschaftlichen Mitarbeitern, Fachkrāften für den Bereich der russischen Sprache, Lehrern, Pädagogen, Psychologen und Vertretern der Volksbildung bestünde. Innerhalb der Kommission sei umstritten, welches Prinzip bei der Festlegung der Rechtschreibung zugrunde zu legen sei. Einige Kommissionsmitglieder vertreten nach Efimov das Prinzip der Angleichung der Schrift an die Aussprache, andere dagegen hielten an dem historischen Prinzip fest.

Efimov ist der Ansicht, dab die Beseitigung der Doppelkonsonanten keinen Verlust für das Russische bedeute. Die Diskussion darum könne jedoch erst dann abgeschlossen werden, wenn durch empirische Untersuchungen nachgewiesen sei, da in russischen Wörtern keine langen Konsonanten realisiert werden.

Er hālt es für erforderlich, auch die Aussprachenorm zu überarbeiten. In der Auseinandersetzung um die Beziehung zwischen Rechtschreibung und Aussprache werde fälschlicherweise die Aussprachenorm als unverletzbar vorausgesetzt. Tatsächlich sei jedoch 2.B., obwohl die Norm gonjat, choronjat vorschreibe, eine andere Aussprache, nämlich gonjut, choronjut verbreiteter. Gelänge es, diese überall anzutreffende Realisierung zur Norm zu erheben, wäre auch das leidige Problem der elf unregelmäBigen Verben gelōst, die Millionen von Schülern auswendig lernen müßten, obwohl nicht einmal Erwachsene sie beherrschten. 
Unbestritten zu einer Erleichterung der Rechtschreibung führe der Verzicht auf den "mjagkij znak" nach den Zischlauten $Z, \zeta, \xi$ (molodež, neseY, obižełsja, splos, noC, sprjač, stričsja). Hier sei der "mjagkij znak" ohnehin nur ein überliefertes Zeichen für eine früher vorhandene Weichheit der bereits im 14. Jahrhundert erhärteten Konsonanten $\check{z}$ und $\zeta$. Die Markierung des femininen Genus durch den „mjagkij znak" sei redundant, da es bereits durch Prädikat und Attribut ausreichend markiert werde.

Bevor man die Schreibweise von zusammengesetzten Adjektiven (zusammen oder mit Bindestrich) festlege, müsse überprüft werden, wie häufig solche Adjektive in der zeitgenōssischen Presse und Literatur vorkommen. Derzeit herrsche völlige Unordnung bezüglich der Schreibweise von Adjektiven:

$\begin{array}{lll}\text { večnozelenyj } & \text { aber: } & \text { temno-rusyj } \\ \text { mašinostroitel'nyj } & \text { aber: } & \text { matina-traktomyj }\end{array}$

Den in der Kommission erörterten Vorschlag, die Präfixpasre raz-/ras-, bez-l bes- usw. einheitlich auf eine Form zu beschränken (raz-, bez-), verwirft Efimov. Er sieht darin einen zu starken Eingriff in die Sprache, durch den viele Wörter, deren Präfixbestandteil nicht mehr als solcher zu erkennen sei, eine neue Schreibweise erhalten müBten: voztok, iztok, beztolox'.

Als weniger umstrittene Vorschläge, deren Annahme er für wahrscheinlich hält, nennt Efimov die endgültige Aufgabe des "tverdyj znak" und seine Ersetzung durch den "mjagkij znak" (ad'jutant, s'ezd), die Angleichung der Schreibung an die Aussprache in Lehnwörtern wie Zuri (zjuri), parašut (parašjut) und die Anderung der Buchstabenverbindung cy in ci. Letztere MaBnahme werde sich nach Uberzeugung von Wissenschaftlern nicht in Richtung auf eine Erweichung des $c$ auf die Aussprache auswirken. Trotz der Unbestrittenheit dieser Vorschläge sei jedoch auch hierzu die Meinung der LG-Leser für die Kommission interessant und nützlich.

Außerdem spricht Efimov sich gegen die ständige unqualifizierte Kritik von Laien an dem Urteil von Fachkräften auf dem Gebiet der Orthographie aus.

LG 37/64 (26.3.1964)

SPOR IDET

S. 3

S. Sakk: „Ugroza . . . novoj reformy“

Der Arzt S. Sakk aus Dagestan zweifelt am Nutzen der Orthographiereform, da die Regeln zur Rechtschreibung erst 1956 überarbeitet worden seien und schon jetzt, nach zehn Jahren, erneut einer Änderung bedürften. Er glaubt nicht daran, daß allein die Reform der Rechtschreibung das Niveau der Sprachbeherrschung verbessern könne. Derartige Eingriffe in die Sprache, wie sie von der Kommission vorgeschlagen werden, machen es seiner Meinung 
nach eher schwieriger, richtig zu schreiben. Dadurch, daB die Orthographieregeln ständig wechselten, werde die Bevölkerung nur verunsichert. Sakk kritisiert, da $B$ die Reform von 1956 nicht konsequent genug durchgeführt worden sei. Man habe nicht dafür gesorgt, daB die neuen Regeln zugänglich gemacht wurden. Der Mehrheit seien sie immer noch unbekannt. Augenblicklich könne man sie unmöglich kaufen, da sie in viel zu geringer Auflage veriegt worden seien.

Sakk schlägt vor, die 1956 erstellten Regeln zu überarbeiten, einige wirklich unnōtige oder unverständliche Regeln zu beseitigen und dann neu herauszugeben. SchlieBlich müsse man diese Neuauflage allen Bürgem der UdSSR über Presse und Rundfunk bekannt machen, ausreichend viele Exemplare drucken und dafür sorgen, daß sie jederzeit im Verkauf vorrätig seien. AuBerdem solle regelmäBig in der Radiosendung "Besedy o russkom slove“ über Anderungen in der Orthographie informiert werden. Sakk wünscht ausdrücklich eine Antwort von führenden Wissenschaftlern auf seinen Brief.

\section{N. Plenkin: „E்to vse polumery"}

N. Plenkin, beruflich in der Lehrerausbildung tätig, teilt ebenfalls nicht die hohen Erwartungen Sviridenkos an die Orthographiereform. Er meint, sie werde nicht bedeutend zur Verbesserung des Sprachgebrauchs von Schülern beitragen. Viel eher benōtige man ein neues Lehrbuch der russischen Sprache.

Plenkin bemängelt, da $B$ viele Jahre lang die Lemfortschritte der Schüler, entsprechend ministerieller Instruktionen und Schriften zur Methodik, allein an der Anzahl der in den schriftlichen Arbeiten unterlaufenen Orthograhie- und Interpunkrionsfehler gemessen worden seien, während stilistische Fehler überhaupt keine Beachtung gefunden hätten. Er hält einen neuen Lehrplan, der den bis jetzt vernachlässigten lexikalischen Bereich berücksichtigt, für dringend erforderlich. In einem neuen Lehrbuch müsse seiner Meinung nach neben der Grammatik und der Orthographie auch die Lexik, Stilistik und Akzentologie behandelt werden.

\section{I. Žuravlev: ,Zlaja volšebnica grammatika“"}

1. Zuravlev macht die Lehrer für russische Sprache und Literatur für die mangelnde Sprachbehertschung von Schülern verantwortlich. Er wirft ihnen vor, sie versteckten hinter ihrem ständigen Gerede über die Schwierigkeiten der russischen Orthographie nur ihre eigene Unzulänglichkeit. Er übt Kritik am Russischunterricht, der durch die Stupidität von Wortschatzübungen, Diktaten und endlosen grammatischen Analysen die Legende von den unüber- 
windbaren Schwierigkeiten bei der Erlernung der russischen Sprache hervorgerufen habe. AuBerdem verwandle die Frage-Antwort-Methode den Unterricht in einen "bezgramotnyj dialog" zwischen Lehrern und Schülern, der zu Denkfaulheit und Stammelei führe. Ohne daB die Unterrichtsmethode verbessert werde, könnten die Probleme der Sprachkultur auch durch noch so viele Orthographiereformen nicht gelöst werden. Er fordert, daB russische Sprache und Literatur als Einheit und nicht wie bisher getrennt unterrichtet werden, zusaztzlich müsse die Lehrerausbildung verbessert werden. Erst dann verschwinde die panische Angst vor der Grammatik, und die orthographischen Schwierigkeiten träten in den Hintergrund.

\section{Uspenskij: Dorogie moi bold'ycildi"}

Lev Uspenskij kommentiert füfzehn Leserbriefe, die an die Redaktion der LG eingesandt wurden. Er gibt dabei zunächst einen Uberblick uber die Leserbriefverfasser: darunter befänden sich drei Pensionäre, vier Schüler, ein Offizier im Ruhestand, eine Tertilarbeiterin, ein Fabrikangestellter, ein Mitglied des Schriftstellerverbandes. Uspenskij weist darauf hin, dab eine derartige $\mathbf{Z u}$ sammensetzung noch vor fünfzig oder hundert Jahren unvorstellbar gewesen sei, da sich damals nur einige wenige Schriftsteller und ein paar Sprach wissenschaftler um die russische Sprache gekümmert hätten. Heute dagegen sorge sich das ganze Volk darum, da richtiges Sprechen und Schreiben für Millionen zu einer Notwendigkeit geworden sei.

Sprachbesorgte („,bolel'sciki za jazyk“) äußerten vielfach den Wunsch nach einem gesamtrussischen Amt zur Bewahrung der Reinheit der russischen Sprache. Verständlicherweise verfügten sie jedoch nicht immer über eine ausreichende Qualifikation auf sprachwissenschaftlichem Gebiet, so daB ihre Forderungen oft unangemessen seien und ihre Ratschläge nicht ohne weiteres akzeptiert werden könnten.

Der Leser Sapolov aus Chabarovsk spreche sich beispielsweise gegen griechisch-lateinische und französische Fremdwörter vor allem in der Landwirtschaft aus: agrotechnika, granulirovanie, agrochimija. Uspenskij antwortet ihm mit einem Zitat von V. Belinskij, in dem dieser zwar den unnötigen Fremdwortgebrauch kritisiert, gleichzeitig aber auch auf die Notwendigkeit eines internationalen Austausches von Begriffen und daher auch von Wörtern hinweist. Außerdem wird erwähnt, daB Fremdwörter nicht in jedem Fall weniger verständlich seien als russische Wörter. So sei einem Bauern das Lehnwort kučer geläufiger als das russische Wort voznica. Uspenskij schlägt vor, das Fremdwort vorzuziehen, wenn es treffender, küzer und ausdrucksstärker sei als das russische Pendant: agronom statt polezakonnik oder pole- 
Zivotno-restenevod. Er vertritt die Ansicht, daB die Sprache selbst entscheide, welche Fremdwörter dem Russischen nützlich und welche unnōtig seien: nüzliche Fremdwörter werden seiner Meinung nach adaptiert, während unnōtige ("Barbarismen“) sich gar nicht über längere Zeit in der Sprache halten kỏnnten.

Einem anderen Leser, der sich über das Vordringen des Ausdrucks atel'e statt masterskaja beschwert, antwortet Uspenskij, atel'e sei gerechtfertigt in Verbindungen wie suejnoe atel'e, galanterejnoe atel'e, nicht aber in der Verbindung parovozoremontnoe oder vodoprovodnoe atel'e.

In einem weiteren Leserbrief wird nach Uspenskij der Gebrauch von Schablonen und Flickwōrtern bemāngelt:

Beispiele: vot èto, kak éto, ètogotogo, vedut sev (statt sejut); zakontili sev (statt otsejalis')

pjat' Celovek rebjat;

Was die Forderung nach einem Sprachdienst betrifft, so verspricht sich Uspenskij weniger Erfolg von einem Amt mit Kontrollfunktion als von einer kontinuierlichen Arbeit an der Verbesserung der Sprachkultur. Ein Kontrollorgan, das die Sprache auf Hinweisschildern oder Werbetexten überwacht, hält er fưr angebracht, um solche Mängel zu vermeiden wie:

- V prodate sol'bez prodauca paket 7 kopeek.

- ket malosol'nyj

- Yvinoj Špig

- plat'evaja than', pal'tovaja tkon';

Abschliebend bemerkt Uspenstij, da in der Bevölkerung der tiefe Wunsch danach bestehe, grammatisch richtig zu sprechen und zu schreiben. Er begrüßt es, daB sich so viele Sprecher um ihre Sprache kümmern.

V.V. Vinogradov: „Kul'tura reči i orfografija“

Die Fragen der Sprachkultur, so schreibt Vinogradov, gewinnen bei der Entwicklung der sowjetischen Gesellschaft immer mehr an Bedeutung. Er sprich von wachsenden sozialen Anforderungen, die an die Norm und die Realisation der vielfältigen Stile der Standardsprache herangetragen werden. Von allen Seiten höre man Klagen über Verunstaltungen des Russischen und das Unvermögen der Sprecher, sich der vielschichtigen Möglichkeiten der russischen Sprache zu bedienen. Bemängelt werde die Flachheit und Leblosigkeit des offentlichen Sprachgebrauchs. Zeitungen und Zeitschriften veröffentlichten immer wieder Aufrufe zur Verbesserung der Sprachkultur. Fast in jeder 
Zeitungsausgabe könne man Normverletzungen und stilistische Fehler entdecken.

Beispiele für Stilfehler:

- čudesnyj aéroport so usemi mezdunarodnymi unernimi dannymi;

- Na stene doma - ego gorel'ef, mudraja, tak chorošo znakomaja nam po žizni golova poeta

Beispiele für falsche Bildhaftigkeit:

- Pesnja žavoronka razbivaetsja na tajusčie bryzgi muzyki.

- Veterok produvaet bluzku, oblepljaja grud'.

Als vorrangige Aufgaben bei der Verbesserung der Sprachkultur nennt Vinogradov die Entwicklung der Fähigkeit zu konzentriertem Lesen, die Erziehung zum Sprachgefühl und die Vermittlung eines Verständnisses für die feinen Unterschiede $\mathbf{z w i s c h e n}$ den verschiedenen Stilen der Standardsprache. Die Sprachnormen müßten der Bevölkerung bekannt gemacht werden. Der Kampf um die Verbesserung der Sprachkultur müsse geplant und im Einklang mit den Gesetzen der zeitgenössischen Standardsprache durchgeführt werden. Wichtig sei dabei, daB sich daran nicht nur alle Philologen und Russisten, sondern auch Schriftsteller, Schauspieler und überhaupt alle Vertreter der russischen Intelligenz sowie alle Liebhaber des russischen Wortes beteiligen. Weiter hält Vinogradov wissenschaftliche Untersuchungen zur Sprachentwicklung, zur Wortbildung, zur Semantik und Phraseologie des Russischen für unumgänglich. Schließlich kritisiert er die Schriftstellerorganisationen, Philologenverbände und auch Leser dafür, da sie die gegenwärtige Literaturproduktion zu selten an ihrer sprachlichen Form messen.

Anschließend geht Vinogradov auf die Diskussion um die bevorstehende Orthographiereform ein. Er äußert die Ansicht, daB eine sichere Sprachbeherrschung die Aneignung orthographischer Normen und grammatischer Regeln erleichtere. Folglich sei es die Hauptaufgabe, die allgemeine Sprachkultur zu erhōhen. Die Rechtschreibung sei zweitrangig. Eine absolute Sicherheit in der Orthographie sei nicht erreichbar, deswegen dürfe man sich orthographischen Fehlern gegenüber nicht übermäßig streng verhalten. Die Orthographie sei für die schriftliche Form der Sprache dasselbe wie die Orthoepie für die mündliche Form. Wenn man also in den Aussprachenormen Schwankungen und Varianten zulasse, müsse man dies auch für die Rechtschreibung akzeptieren. 
LG 72/64 (18.6.1964)

(O čem nam pišut)

S. 1

R. Ponomarev: (Leserbrief ohne Titel)

Der Leser Ponomarev schlägt der LG vor, eine ständige Rubrik mit dem Titel "Služba tistoty russkogo jazyka" einzurichten, die seiner Meinung nach sowohl für Leser als auch für Schriftsteller von großem Nutzen sei.

\section{LG $80 / 64$}

Die Redaktion der LG berichtet, daß sie viel Leserpost zu sprachlichen Fragen erhalte. Sie nimmt den Vorschlag Ponomarevs auf und eröffnet die Rubrik "Sluzba russkogo jazyka", die unter der Verantwortung der Schriftsteller K.I. Cukovskij und L.I. Uspenskij geführt werden soll.

\section{S. Sakk: „Slova-sornjaki“"}

Der Leser Sakk beklagt sich über gängige, aber seiner Meinung nach falsche Wortverwendungen:

- kušat': A segodnja bez appetita kuگaju.

- mě̌tat' : A my š̌enoj mętali, と̌to vy ne pridete!

Ja mettaju zdes' musormyj jałčik postavit'.

- dovlet': On dovleet nad podčinennym

$V$ ètoj sem'e žena dovleet nad mužem.

- obratno : Ja obratno poobedal. Ty obratno tichaes'.

Sakk hält es für erstrebenswert, des öfteren im Rundfunk Vorträge und Gespräche zu Sprachproblemen zu übertragen. Solche Sendungen interessierten die Hörer und würden von ihnen mit großem Erfolg genutzt.

\section{Ju. Dzevanovskij: „Slovoprodukty“}

Ein zweiter Brief befaßt sich mit der sprachlichen Form von Hinweisschildern und Bekanntmachungen. Dzevanovskij beanstandet: domovaja (statt domănjaja) kuchnja, koževye izdelija, moreprodukty. Derartige Wortschöpfungen übten auf den Sprachgebrauch von Schülem, aber auch von Erwachsenen einen schädlichen Einfluß aus, da solche Hin weisschilder besonders ein prägsam seien.

\section{L.L Skvorcov: (NaY kommentarij)}

Skvorcov, der die Leserbriefe beantwortet, bezeichnet den von Dzevanovskij beanstandeten Ausdruck domovaja kuchnja als sprachlich einwandfrei. Er weist auf die notwendige Unterscheidung hin zwischen Sprachverschmutzung, 
zu der er Kanzleiausdrücke, erstarrte Floskeln (moreprodukty) und Vulgarismen wie obratno und kuSat' zāhlt, und Bedeutungsverschiebungen wie bei zoprosto und doulet', die man nicht voreilig kategorisch ablehnen dürfe. Er warnt davor, sich bei Urteilen über die Sprache auf den eigenen, subjektiven Geschmack zu verlassen.

\section{LG 84/64 (16.7.1964) SLUŽBA RUSSKOGO JAZYKA S. 3}

\section{E. Ardabyrskaja: „Sušuar i ingibitor"}

Die Leserin Ardabyvskaja miBbilligt die Verwendung von Fremdwörtem. Besonders bei der Ubersetzung von technologischer Fachliteratur komme es häufig vor, daB Fremdwörter, für die fast immer gleichwertige russische Ausdrücke zur Verfügung ständen, in das Russische eingeführt werden. Entlehnungen wie ingibirovat', meditacija, lamentacija oder etwa fèn und sutuar tragen ihrer Meinung nach wenig zur Bereicherung der russischen Sprache bei.

\section{P. Kazancev: "Objazany, no...“}

Kazancev ist der Auffassung, da2B, wenn er als einfacher Drechsler keinen Ausschub produzieren dürfe, erst recht denjenigen, die mit dem lebendigen Wort zu tun haben, keine Fehler unterlaufen dürften. Redakteure und Lektoren, die in Verlagen arbeiteten, hätten den Ruf, "gramotnejłie iz gramotnejłich" zu sein. Obwohl sie aber dazu verpflichtet seien, Manuskripte in die grammatisch richtige Form zu übertragen, tauchten immer wieder Fehler in Druckerzeugnissen auf, wie z.B. bol'no statt olen' oder tridcatišesticentnerovyj.

\section{Uspenskij: „Kommentarij““}

L. Uspenskij äußert den Eindruck, daB in den Leserbriefen zur Rubrik „Služba russkogo jazyka" oft viel Lärm um nichts geschlagen werde. Im Falle von ingibirovat' sei ein komplexer Begriff durch einen einfachen, international verständlichen Terminus benannt worden, der wohl kaum außerhalb des Fachgebietes angetroffen werde. Keinesfalls könne man ihn mit dem russischen zamedlit' gleichsetzen. Auch die Fremdwörter lamentacija und meditacija hält er für ungefährlich, da sie auBerhalb von Fachliteratur höchstens in ironischem Kontext auftauchten. Die auch seiner Meinung nach kuriose Bildung sušuar von frz. sechoir werde man kaum außerhalb eines Frisiersalons hören.

Zu Kazancevs Kritik an bol'no in der Bedeutung von oten' bemerkt Uspenskij, $\mathrm{daB}$ dies als Nebenbedeutung angelegt und daher keineswegs falsch sei, wenn man es auch als Archaismus betrachten müsse und es daher nicht in jedem 
Kontext verwenden kōnne. Bandwurmwörter wie tridcatišesticentnerovyj solle man möglichst vermeiden, weil sie kaum auszusprechen seien.

\section{LG 92/64 (4.8.1964) SLUŽBA RUSSKOGO JAZYKA S. 2}

\section{Bokov: "Sokrovennoe“"}

Viktor Bokov begrüBt, daB in der LG eine Auseinandersetzung über Sprachkultur geführt wird. Seiner Meinung nach trägt jeder ein wenig dazu bei, die russische Sprache zu verderben. Schriftstellern, Kritikern, Dramaturgen, Wissenschaftlern, Schauspielern und Moderatoren in Rundfunk und Fernsehen spricht er die Pflicht zu, die russische Sprache vor jeglicher Entstellung zu schützen. Er kritisiert einen 1963 erschienenen Gedichtband, der folgende Fehler enthalte:

- barrikada (Verwendung im Singular)

- vyezžajut sejalki i traktory

- u suete utra krasujut sazency

N. Rubcov: "Monomachova papacha"

Der Ingenieur Rubcov reiht Beispiele für seiner Meinung nach falschen Wortgebrauch zu einem Sketch aneinander.

\section{Ja. Zadov: ,Jazyk ulicy"“}

Der Journalist Zadov beschwert sich über sprachliche Unzulänglichkeiten auf Hinweisschildern und in der Werbung (Beispiele: rabotoet statt otkryt (a/o); dni $i$ Casy priema otdela). Er hält eine Instanz für notwendig, die Hinweisschilder und Werbetexte auf ihre sprachliche Richtigkeit kontrolliert.

\section{Uspenskij: „Kommentarij““}

Uspenskij schreibt in seinem Kommentar zu dem Leserbrief von Zadov, daß die Ausdrücke rabotaet masterskaja/kafelatel'e keinesfalls als Fehler angesehen werden dürften, da rabotat' über die Nebenbedeutung 'dejstvovat', 'funkcionirovar" verfüge. Man könne aber rabotat' nicht in jedem $F_{2}$ all in dieser Bedeutung verwenden. Für falsch hält er die Kombination stadion rabotaet oder kladbišce rabotaet. Bei restoran und kafe zieht er die Konstruktion restoran otkryt, kafe otkryto vor. 


\section{N. Rylenkov: „lz rodnikovych glubin“}

Der Beitrag von Nikolaj Rylenkov bezieht sich vorwiegend auf die literarische Sprachverwendung. Er ist der Ansicht, daß ein Dichter nur dann über das erforderliche Sprachgefühl verfügt, wenn er alle sprachlichen Reichtümer seines Volkes kenne. Nie habe die Sprache der Poesie eine derartige Bereicherung erfahren wie in der Sowjetzeit, wo sie sprachliche Besonderheiten aus allen Gesellschaftsschichten und Regionen des Landes aufgenommen habe.

Rylenkov kritisiert den Gebrauch von Exotismen ("slovesnaja èkzotika“) bei jungen Schriftstellern, die mit aufgeschnappten Wörtern prahlen wollten. Die Verwendung solcher Wörter trage keineswegs zur Verschönerung der Sprache bei, sondern mache sie geschraubt, unglaubwïdig und ungenau. Er spricht sich dagegen aus, daß Schriftsteller, statt von ihrer eigenen sprachlichen Erfahrung auszugehen, auf Wörterbücher als Quelle zurückgreifen. Dabei beruft er sich auf Julian Tuwim.

Er mißbilligt das Verhalten von Verlagslektoren. Unter ihnen gebe es nicht wenig Puristen, die jedes ihnen unbekannte Wort anzweifelten.

Beispiele:

utrennik : Dieses angeblich nicht in Wörterbüchern fixierte Wort sei im Verlag nur durch Hinweis auf einen Beleg bei Bunin durchgesetzt worden.

vir : Der Lektor habe es durch omut ersetzen wollen.

košel' : sei als Dialektismus beanstandet worden.

Ein solches Vorgehen ermuntere den Schriftsteller nicht gerade dazu, frische, lebendige und ausdrucksstarke Wörter zu suchen, sondern desorientiere ihn eher. Darin liege auch die Ursache dafür, daß heutzutage eine umfangreiche Alltagslyrik produziert werde, die ebenso grammatisch richtig wie farblos sei.

\section{LG 101/64 (25.8.1964) SLUŽBA RUSSKOGO JAZYKA S. 2}

A. Morozov: "... a poisk prodolžaetsja“"

Der Schriftsteller Morozov beanstandet die Verwendung von poisk im Singular. Sowohl bei Ušakov als auch im zehnbändigen Akademie-Wörterbuch sei allein die Pluralform als zulässig angegeben während der Gebrauch des Singulars nur auf einige wenige Fachjargons (Jagd, Bergbau, Militär) beschränkt bleibe. Morozov akreptiert den Gebrauch von poisk im Singular nicht als Ergebnis einer natürlichen Sprachentwicklung. Von einer echten Sprachentwick- 
lung kōnne man nur dann reden, wenn sie eine Bereicherung für die Sprache bedeute, nicht aber im Falle eines blinden Austauschens des richtigen Wortes durch ein zweifelhaftes. Auch bei noch so ausgedehnter Verbreitung bleibe ein Fehler ein Fehler.

\section{A. Tolstichin: „Bez krajnosti“}

Der Leser Tolstichin hālt das Bemühen um Bewahrung der russischen Sprache vor "Kesselstein und RuB" für eine der wichtigsten anstehenden Aufgaben. Als nicht tolerierbar bezeichnet er Vulgarismen und Argotismen wie Zelezno narubalsja borš̌̌a oder ne temni mne mozgi und Akzentfehler wie porక̌njá, pressá, válovyj, dóbyta, die man hōchstens in der Belletristik zur Personencharakterisierung zulassen kōnne.

AuBerdem befaßt sich Tolstichin in seinem Brief mit Neologismen im terminologischen Bereich. Dabei geht er davon aus, da die Auffüllung des Wortbestandes durch die sich ständig weiterentwickelnde Produktionstätigkeit des Menschen bestimmt werde und daher jedes neue Wort aufgrund objektiver Erfordernisse entstehe. Deshalb hätten sich notwendige Termini wie strigal', dojar, zaryblenie, gurtoprav und rozovod auch gegen den Willen der Normverfechter durchgesetzt. Die Gegner von terminologischen Neuschōpfungen stellten diese zu Unrecht als Wortparasiten hin, wobei sie mit absurden Analogieschlüssen argumentierten: wenn es schon zaryblenie und rozovod gebe, müsse man auch zazverenie und georginovod zulassen. Sie übersähen dabei, $\mathrm{d}_{2} \mathrm{~B}$ es niemandem einfallen würde, ein Wort zu bilden, ohne daB es die Produktionsbedingungen erforderten.

\section{LG 108/64 (10.9.1964) SLUŽBA RUSSKOGO JAZYKA S. 2}

\section{Uspenskij: ,,Rozovod? $\mathrm{D}_{2}$ - Zaryblenie - gm, gm ....}

Uspenskij, der auf Tolstichins Brief antwortet, hält nicht jeden Neologismus für gerechtfertigt. Als verfehlt bezeichnet er z.B. die Vorschläge Chlebnikovs für Luftfahrttermini (letoba für aviacija oder letavicalletica für lettica). Den Ausdruck rozovod akzeptiert er aufgrund des Vorhandenseins analoger Bildungen (sadovod, polevod. pticevod). Zaryblenie jedoch verstoße gegen die Wortbildungsregeln, da die Ableitung von Abstrakta auf enie nur deverbal und nicht direkt vom Substantiv aus möglich sei. Uspenskij hält es für unwahrscheinlich, daß dieses Wort in die Standardsprache eingeht. Ferner äuBert er sich mißbilligend über den Ausdruck skladirovat'. 


\section{LG 109/64 (12.9.1964) SLUŽBA RUSSKOGO JAZYKA S. 2}

\section{B. Laskin: „Rasstaz na zakaz"}

Ahnlich wie der Leser Rubcov schreibt Laskin eine Kurzerzählung, die vorwiegend aus in Leserbriefen bemängelten Wörtern und Redewendungen besteht.

\section{LG 112/64 (19.9.1964) SLUŽBA RUSSKOGO JAZYKA S. 2}

\section{S. Vasil'ev: „Gde ovsjug, gde zlak?“}

Der Schriftsteller Sergej Vasil'ev begrüBt die Einrichtung der R'ubrik „SluŽba russkogo jazyka" und den Einsatz derer, die sich freiwillig dafür zur Verfügung stellen, die Sprache von Unkraut zu säubern. Er warnt jedoch davor, alles sprachlich Ungewöhnliche ohne Unterschied zu behandeln und damit auch die lyrische Ausdrucksweise als falschen Sprachgebrauch abzustempeln, wie es einige Leser praktizierten.

LG 115/64 (26.9.1964)

(,Za“i ,protiv")

S. 2

\section{Udalov: „Esli už mesti, tak Kisto“}

V. Udalov aus Luck begrüßt die Orthographiereform. Die Veröffentlichung der Reformvorschläge* habe ihn sehr gefreut, da diese Reform der Lehrerschaft kaum vorstellbare Möglichkeiten eröffne. Die Zeit, die sonst für die Vermittlung schwieriger, verwirtender Regeln aufgewendet werden müBte, könne man jetzt dafür nutzen, die stilistischen Fähigkeiten der Schüler zu verbessern. Nur den Vorschlag der Kommission, nach $c$ einheitlich $i$ (statt $y / i)$ zu schreiben, hält er für unangebracht, da dies nicht der Aussprache von -cy- entspreche.

\section{N. Zadornov: "Doč cigana s'ela ogurci“"}

Zadornov befürchtet, daß bei der Einführung der neuen Rechtschreiberegeln Millionen von Leuten, die die russische Sprache bereits beherrschen, umlernen müssen. Dies bereite der Bevölkerung viel zu große Schwierigkeiten. Er 
spricht sich für eine breite Erōrterung der Kommissionsvorschläge aus, an der sich Pädagogen, Lehrer und Journalisten beteiligen sollen. Er räumt ein, dab viele der alten Orthographieregeln unvollständig seien, dafür seien die neuen fast alle strittig. Er ermahnt die Wissenschafter, die Energien und die Zeit der arbeitenden Bevölkerung nicht unnötig zu vergeuden.

\section{P. Zimin: „Sem'raz otmer”.}

Der Leser Zimin hält die geplante Orthographiereform für einen Versuch, die Sprache künstich zu modernisieren. Er miBbilligt die Beseitigung des "mjagkij znak" nach Zischlauten, die einheitliche Schreibung von $-c i$ für $-c y-1$ ci- und das Ersetzen des "tverdyj znak" durch den "mjagkij znat", da sich diese MaBnahmen auf die Aussprache auswirkten. Er befürwortet, daB sich möglichst viele Leute an der Diskussion des Projektes beteiligen.

\section{B. Kogan : „I tak i èdak?“}

Der Leser Kogan aus Tałkent bezweifelt, daB die geplante Reform die russische Orthographie verbessern könne. Er bemängelt vor allem die Inkonsequenz der Kommission, wenn sie vorschlägt, die Doppelkonsonanten in Fremdwörtern zu vereinfachen, sie aber dann in Wörtern wie summa, gamma oder wanna beibehalten will. AuBerdem spricht er sich gegen die Wiedergabe der Buchstabenverbindung $-c y$ - als -ci- und $e$ als $O$ aus.

\section{S. Kirsanov: „Vopreli bukve i duchu“}

Der Schriftsteller Semen Kirsanov sieht keine Notwendigkeit zur Reform der russischen Rechtschreibung. An den Vorschlägen zur Verbesserung der Orthographie kritisiert er deren Widersprüchlichkeit. In einigen Vorschlägen sei eine Tendenz zur phonetischen Transkription zu spüren, während bei anderen die Aussprache völlig ignoriert werde. Einerseits beharrten die Verfasser auf der historischen Bedeutung des $y$, und $z$ war auch in so unpassenden Fällen wie bei predynfarktnyj, während sie sie an anderen Stellen übersähen (ogurci statt ugurcy). Kirsanov mißbilligt die Beseitigung des .,mjagkij znak" nach Zischlauten, weil er das feminine Genus bei Substantiven markiere, bei Verben den Infinitiv kenndich mache und außerdem zur Unterscheidung von Minimalparen beitrage (plar - plat'!). Die Schreibweise ogurci, chlopci, golubci lehnt er ab. weil dadurch russische Wörter nicht mehr von ukrainischen zu unterscheiden seien. Der Vorschlag, bei zajac das ja durch e zu ersetzen, sei nicht gerechtfertigt, da das ja in zajac deutlich zu hören sei. 


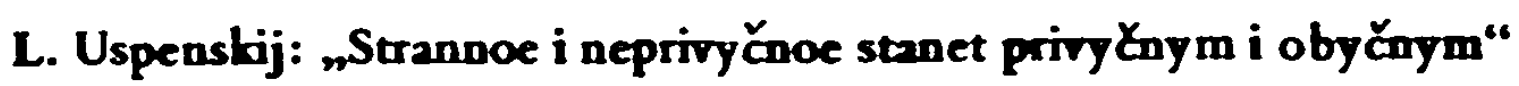

Uspenskij vergleicht den Widerstand der Bevölkerung gegen die neuen Rechtschreiberegeln mit den Protesten gegen die Reform von 1918. Es sei damals ebenso ungewöhnlich gewesen, den "tverdyj znak" am Wortende zu tilgen, wie heute den "mjagkij znak" nach Zischlauten. Daran und an die Ersetzung des "tverdyj znak" durch den ,mjagkij znak" werde man sich gewöhnen. Er hebt hervor, daB zum ersten $\mathrm{Mal}$ eine Orthographiereform auf demokratischem Wege durchgeführt werde. Während die Sprachwissenschaftler bisher der Bevölkerung immer neue Regeln vorgeschrieben hätten, kōnne jetzt die gesamte Bevölkerung ihre Meinung zu den Kommissionsvorschlägen äußern und dadurch bestimmen, ob sie angenommen oder abgelehnt werden. Dies garantiere, daß die derzeitige Reform die beste aller möglichen Reformen werde.

\section{A. Spasoloukockij: "Beregite russkij jaryk!“}

In diesem Aufsatz werden folgende Vorschläge der Reformkommission beanstandet:

- Fortfall des „mjagkij znak" nach Zischlauten,

- Vereinfachung von Doppelkonsonanten in Lehnwörtern,

- Ersatz des "tverdyj znak“ durch den „mjagkij znak“"

- o statt $\ddot{e}$ nach Zischlauten unter der Betonung

$-c i-$ für $-c y$ -

\section{Kondyrev: „Edva bi éto blagotvorno"}

In einem kurzen Beitrag erklärt Lev Kondyrev, daB er die jetzige Orthographiereform im Gegensatz zu der von 1918 für unnōtig hält, ja sogar befürchtet, daB sie der russischen Sprache eher nicht wiedergutzumachenden Schaden zufügt.

\section{Leonov: „Prošu slova“"}

Auch Leonov sieht keinen Sinn in der jetzigen Orthographiereform, die nicht die erste innerhalb einer Generation sei. Er bedauert, daB die Vorschläge der Reformkommission nicht namentlich unterschrieben wurden, und vermutet, daß man zur Erörterung dieser wichtigen Angelegenheit keinen einzigen Schriftsteller eingeladen habe. Leonov fordert auch die Leser auf, sich dafür einzusetzen, daß die Vorschläge der Kommission nicht verwirklicht werden. 
Abschließend kündigt er an: „.. . esli vmesto ich (ogurcov - d.Verf.) vyrastut ogurci, to ja ne stanu est' takich ogurcej."

\section{Sklorskij: „Reforma pravil'na“"}

Viktor Sklovskij dagegen hält die Reform für richtig, meint aber, sie müsse vorsichtig durchgeführt werden, da sie den Sprachbenutzer sonst verwirre. Ein den neuen Regeln angepaßtes Wort mute zunächst falsch an, bis man sich an die neue Schreibweise gewōhnt habe.

\section{Inber: "Davajte podumaem chorošen'ko“}

Die russische Orthographie ändert sich nach Vera Inbers Meinung viel zu oft. Die Reform von 1918 sei gerechtfertigt gewesen, niemand beklage mehr den Verlust des Jat' oder des "tverdyj znak" am Wortende. Aber bereits 1956 habe man sich nur mit Mühe daran gewöhnen kōnnen, da $B$ in einigen Wörtern verboten wurde, $-c y$ - zu schreiben (pancir'). Noch schwerer falle es heute, ogurci zu akzeptieren. Nur einzelne Vorschläge der Kommission findet sie sinnvoll und nützlich.

\section{Maksimova: "Usvaivat' pravila budet legče“"}

L. Maksimova, wissenschaftliche Mitarbeiterin am IRJaz, geht in ihrem Beitrag auf die Argumente ein, die in Leserbriefen gegen das Weglassen des "mjagkij znak" nach Zischlauten vorgebracht werden.

Es sei nicht richtig, meint Maksimova, zu behaupten, der Verzicht auf den „mjagkij znak" verändere die Aussprache der Zischlaute. Die Standardnorm lasse bei $\check{c}$ und $\tilde{c}$ nur eine weiche, bei $\not{Z}$ und $\zeta$ nur eine harte Aussprache zu. Lediglich einige Dialekte zeichneten sich durch eine harte Aussprache von $\not$

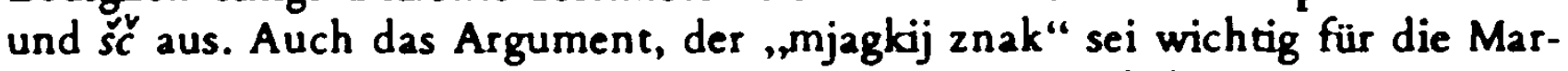
kierung des femininen Genus bei Substantiven, sei unhaltbar, da das Russische auch maskuline Substantive auf "mjagkij znak“ kenne (kon', golub'). Weiter erläutert Maksimova, warum der "mjagkij znak" in Formen wie $m y \zeta^{\prime}{ }^{\prime} u$, noč 'ju, $\zeta^{\prime} j u$ oder $\chi^{\prime} j a$ auch nach den neuen Regeln nicht wegfallen soll. Hier habe der "mjagkij znak" eine Trennungsfunktion. Er kennzeichne, daß auf den Konsonanten $z$ wei eigenständige Laute, nämlich $j$ und ein Vokal, folgten.

Maksimova ist der Úberzeugung, daß die neuen Regeln vor allem den Schülern helfen werden. 


\section{G. Serebrjakova: „Ostorołno!“}

Für die Schriftstellerin Galina Serebrjałova sind die Vorschläge zur Orthographiereform AnlaB zur Beunruhigung, weil eine solche Reform Millionen Sowjetbürger zum Umlernen nōtige. AuBerdem werde sich die Veränderung der Rechtschreibung verheerend auf die Lyrik auswirken.

\section{Smirin: ",Logika' uproščenija i živaja logika jazyła"}

Der Historiker Smirin hält nur einzelne Vorschläge der Kommission für annehmbar. Er wendet sich besonders gegen die Reduzierung der Vokalwechsel ir Wortstämmen, da dies gegen den logischen Aufbau der russischen Sprache verstoße. Smirin malt die Konsequenzen aus, die die vorgeschlagene Reform nach sich ziehen werde. Er befürchtet, eine Verzögerung in samtlichen Verlagsarbeiten, da die Verlagsangestellten zunāchst einmal umgeschult werden müßten. Wörterbücher müßten überarbeitet werden, da einige Wörter nach der neuen Schreibweise an anderer Stelle eingeordnet werden müBten als nach der alten. AuBerdem müBten sämtliche Werke der Klassiker neu ediert werden. Dieser Aufwand lohnt sich nach Smirins Meinung vor allem deshalb nicht, weil die neuen Regeln keine wirkliche Vereinfachung der Orthographie mit sich brächten.

\section{M. Šaginjan: "Ne vtljučajas' v spor"}

Mariètta Saginjan übt Kritik am Verlauf der Diskussion um die Orthographiereform. Leserbriefe werden ihrer Meinung nach nur scheinbar gleichberechtigt veröffentlicht. Tatsächlich folge aber meist ein belehrender Kommentar von einem Mitarbeiter des IRJaz. In vielen Beiträgen der an der Diskussion beteiligten Linguisten* vermißt sie einen Ausdruck der Anerkennung gegenüber den kritischen Leserbeiträgen und die geringste Einsicht, da Fehler habe. Ihrer Meinung nach ist es nicht allein Sache der Linguisten, über eine Verbesserung der Orthographie zu entscheiden.

Die Schriftstellerin ist der Ansicht, daB die Ursachen für die mangelhafte Sprachbeherrschung der Bevölkerung nicht in der Orthographie des Russischen zu suchen sind, sondern eher in der Schulausbildung. In den vorrevolutionären Gymnasien habe man wesentlich intensiver die Werke der Klassiker gelesen, heute jedoch hielten Fernsehen und Kino die Schüler vom Lesen und

Sie bezieht sich nicht nur auf die Diskussion in der LG, sondern auch auf die in anderen Zeitungen. 
Schreiben ab. Auf eine, von ihr zum jetzigen Zeitpunkt als verfehlt bezeichnete, Umstellung der Orthographie müßten immense finanzielle Mittel und viel Zeit aufgewandt werden, die man für wichtigere Aufgaben einsetzen könnte.

\section{LG 129/64 (29.10.1964) SLUŽBA RUSSKOGO JAZYKA S. 2/3}

L. Uspenskij: "TjaY̌enie begemota iz bolota"

Bevor Uspenskij auf drei Leserbriefe eingeht, erinnert er daran, da $B$ die Sprache über verschiedene Stilebenen verfüge, was gewöhnlich von den Verfassern der Zuschriften nicht berücksichtigt werde.

Einem Leser, der die Verwendung der Termini tjałenie, bryzgal'nyj und sotetonnoe (lecenie) beanstandet, antwortet er, dies seien Professionalismen, die in der allgemeinen Standardsprache nicht vorkämen. Tjaženie beurteilt er wegen seiner ungewöhnlichen Bildungsweise als unschönen Ausdruck und legt den Medizinern nahe, ihn aufzugeben. Auch von soletannoe (letenie) zeigt er sich wenig begeistert und schlägt daher vor, dafür lieber ein Fremdwort zu übernehmen.

Uspenskij unterstützt einen weiteren Leser, der Akzentfehler beklagt (nefteprówd, benzoprówod, musoropróvod).

Schließlich geht er auf die Frage ein, ob der Akzent bei barža auf der ersten oder auf der zweiten Silbe liege. Er bezeichnet beide Varianten als heute nahezu gleichberechtigt, wobei bárža eine leichte buchsprachliche, baržá eher eine umgangssprachliche Färbung aufweise. Bei den Akzentvarianten váchter/ vachtér dagegen sei die letztere Variante sehr viel stärker als ProstoretieElement ausgewiesen als barzá, so daB ihre Verwendung nur in der alltäglichen Umgangssprache angebracht sei.

\section{LG 135/64 (14.11.64) SLUŽBA RUSSKOGO JAZYKA S. 2}

M. Isakorskij: „Mokno li postroit' ozero?“

M. Isakovskij beanstandet sprachliche Mängel in den Medien. Gerade weil langst nicht alle Zeitungsleser und Rundfunkhörer ibre Muttersprache tadellos beherrschten, halte er es für sehr schädlich, wenn in Radiosendungen oder in der Presse sprachliche Fehler auftauchten. Die Bevölkerung übernähme dann diese Fehler, da sie sich nicht vorstellen könne, daß in den Medien Fehler unterlaufen können. Das verwirre die Bevölkerung und füge der Sprachwissencchaft großen Schaden zu. 
Beispiele:

$\begin{array}{ll}\text { - trudit'sja für rabotat' : a) traktor truditsja; } \\ \text { b) tunejadcy trudjatsja plocho; } \\ \text { - stroit'/postroit' } & \text { : a) postroit'prud, ozero; } \\ & \text { b) postroit' taburetku, mebel'; } \\ \text { - para } & \text { : a) para als unbestimmte Mengenan- } \\ & \text { be: para nedel', para Yagov, para } \\ & \text { rublej; } \\ & \text { b) para für duojka }\end{array}$

Obwohl in der Presse schon viel über den falschen Gebrauch von para geschrieben worden sei, habe sich diese Untugend wie eine Epidemie verbreitet.

\section{LG 144/64 (5.12.64)

\section{A. Rožanskij: „Obnovlenie s uš̌̌rerbom“}

Der Beitrag des Moskauer Philologen Rožanskij beschäftigt sich mit modifizierten phraseologischen Ausdrücken. Nach Meinung des Verfassers dürfen die einzelnen Bestandteile von Phraseologismen nicht verändert werden, da sonst der ganze Ausdruck zerstört werde. Als Beispiele für mißglückte Veränderungen solcher Redewendungen nennt er:

- On usegda iz vody tistyj vychodit. (< vyjti suchim iz vody)

- ... a ja otlil ... piljulju. (< otlit' puli und pozolotit' piljulju)

- ... kotoryj iz nego use Zily soset; ( < tjanut' žily und krov' sosat')

- U nego sem' pjatnic v odnu subbotu; (< sem' pjatnic na odnoj nedele)

- Prochorov znal, počm funt okopnych bloch. (< funt licha)

\section{K. Čukovskij: „Na tu že temu“}

Cukovskij, der das von Rožanskij angeschnittene Thema aufnimmt, ist auch der Ansicht, daß ein Phraseologismus durch Veränderung eines sciner Bestandteile zerstört werde. Dies sei aber nicht immer als Zeichen für schlechten Sprachgebrauch zu werten. Vielmehr müsse man unterscheiden $z$ wischen den Fällen, in denen durch unachtsamen Umgang mit der russischen Sprache phraseologische Ausdrücke verunstaltet werden, wie in den von Rožanskij angeführten Beispielen, und solchen, wo das Aufbrechen phraseologischer Einheiten als Stilmittel angewendet wird, was in der Literatur durchaus legitim sei. 
Beispiel:

Ona

ir muchi delaet slona

i posle

prodaet slonouruju kost'.

(V. Majakovskij)

Čukorskij regt an, die Leser sollten sich zu den von Roł̌anskij aufgeführten Beispielen äubern. Er hält z.B. den Ausdruck sem' pjatnic u subbotu für eine gelungene Umgestaltung eines abgegriffenen Sprachklischees. 


\section{Mocarev: „Modnye slovęki“"}

Der Lehrer 1. Mocarev kritisiert die Verwendung von ustat' anstelle von stat' und ostanovit'sja. Für falsch hält er ebenso den Gebrauch des von ihm als Modewort bezeichneten Ausdrucks ponatalu anstelle von snatala und unatale. Er fordert Lev Uspenskij zu einer Stellungnahme auf.

\section{Uspenskij: „Ne tak-to prosto“}

Uspenskij räumt zwar ein, er sei selbst von den erwähnten Verwendungen nicht begeistert, weist aber darauf hin, daß man sie nicht als Fehler ansehen könne. Vielmehr seien beide Beispiele Ausdruck der Weiterentwicklung der Sprache im ständigen vorwärtsgerichteten Kampf zwischen Varianten. In der Sprache sei alles der Veränderung unterworfen, so auch die Bedeutung und die Funktion des Wortes. Für ustat' statt stat' finde man Belege bereits bei Tolstoj und Aksenev, für ustat' anstelle von ostanovit'sja schon bei Blok.

Ponatalu verzeichne bereits das 4-bändige Akademie-Wörterbuch, das als Beleg eine Stelle bei Saltykov-Šedrin angebe. Zwar trage dort das Wort noch das Stilmerkmal "razgovornoe"; ein Wort jedoch, das heute noch als umgangssprachlich gelte, könne morgen schon als standardsprachlich anerkannt werden.

Uspenskij mahnt anschließend zu Vorsicht bei dem Urteil daruber, was in der Sprache gut, was schlecht sei.

P. Antokol'skij: „Smotret' v koren'!““

Der Schriftsteller P. Antokol'skij sieht die Ursache für schlechten Sprachgebrauch in den Mängeln des Russischunterrichts. Seiner Meinung nach wird in der Mittelschule zu wenig Aufmerksamkeit auf das wichtigste Schulfach, nämlich den muttersprachlichen Unterricht gelegt. Solange hier keine Änderung erreicht werde, müsse man damit rechnen, daß das Niveau der Sprachverwendung niedrig bleibe und sogar weiter sinken werde. Er fordert eine ausreichende Anzahl an Unterrichtsstunden für den muttersprachlichen 
Unterricht und ein umfangreiches Programm zum Studium der muttersprachlichen Literatur.

Als sprachliche Mängel erwähnt er:

- priboleju, pripozdaju, pristimu

- ucennye tovary

- zachoronenie

- pamjatnye podarki

- kraten'ko, dumaetsja, pereživat' (ohne Akk. Erg.)

- privetik

- otkrovenie (statt: otkrovennost')

\section{LG 37/65 (23.3.65) SLUŽBA RUSSKOGO JAZY
L. Uspenskij: „Otvet zarubežnym bolel'ščikam“"}

L. Uspenskij kommentiert Leserbriefe aus dem Ausland. Er kritisiert dabei einen in Düsseldorf lebenden Russen, weil dieser in seinen Urteilen über das zeitgenössische Russisch von dem Sprachzustand Anfang der 20er Jahre ausgehe.

Ein Russischlehrer aus der BRD weise auf Fehler im Lehrbuch von Vogt hin. Seinen Angaben zufolge hilft ihm die Rubrik "Služba russkogo jazyka" bei seinen Unterrichtsvorbereitungen.

Ein weiterer Leser aus der DDR kritisiere den Ausdruck čustvo loktja als fehlerhafte Entlehnung aus dem Deutschen.

\section{A. Lejtes: „Vozmožnosti slova“}

A. Lejtes beginnt seinen Beitrag mit einer Aufzählung von Beispielen für Idiosynkrasie bei Schriftstellern*, um dann zu erklären, daß man sich in der Sprachkultur nicht auf solche Gefühlsurteile stützen dürfe. Antokol'skij wirft er vor, seine Beispiele basierten auf eben solcher Idiosynkrasie. Ucennyj sei weder eine Neubildung noch sonstwie als sprachlich falsch zu bezeichnen, $\mathrm{da}$ es bereits bei Dal' angegeben und in modernen Wörterbüchern ebenfalls,

- Dieser Artikel wird im Zusammenhang mit dem Begriff Idiosynkrasie erwähnt in den Beiträgen von Svarckopf und Kostomarov zu Sprachbewertungen: Kostomarov/ Švarckopf 1966 und Svarckopf 1970 sowie bei Skvorcov 1967a. 
wenn auch als fachsprachliches Wort, verzeichnet sei. Lejtes hält es für wichtig, das starke Eindringen von fremdsprachlicher Lexik und besonders Technizismen in die Standardsprache zu untersuchen. Dabei dürfe man jedoch nicht losgelöst vom Kontext einzelne Wörter als ästhetisch oder unästhetisch beurteilen. Gerade die Sprache der sowjetischen Poesie habe gezeigt, daß auch die trockensten Technizismen in einem poetischen Kontext stilistisch angemessen sein könnten.

Dies gelte jedoch nicht für ,mißgestaltete" Wörter, die jeden poetischen Kontext zerstören, wie z.B.:
prosljak
(für: istorik)
bei A. Veselyj
serdcevorot
bei E. Dolmatovskij

Der Ausdruck privetik ist nach Lejtes linguistisch nicht zu beanstanden, er rufe allerdings Assoziationen an gewisse Bürger hervor, für die das Wort typisch sei, weil sie es ständig verwendeten. X̂hnlich habe z.B. Paustovskij seine Romanfiguren durch Ausdrücke wie volnitel'no, na polnom ser'eze und na intime charakterisiert.

Lejtes behauptet, daß sich Urteile über sprachliche Probleme oft auf dilettantischem Niveau befänden. Weit zurückliegende lexikalische Entwicklungen akzeptiere man ohne Anzweifelungen (prelestnyj, prozor), vergesse aber, $\mathrm{da} B$ die Lexik auch in der Gegenwart ständig Veränderungen unterworfen ist. (Beispiel: Bedeutungsänderung von perezivat'.) Außerdem könnten einige Leute nicht zwischen gesetzmäßigen und ungesetzmäßigen Sprachentwicklungen unterscheiden.

Der Verfasser findet es wichtig, neben dem rein linguistischen auch die sozialpsychologischen Aspekte des Auftretens von Neubildungen oder des Verschwindens von Ausdrücken zu berücksichtigen. Unter Sprachdienst versteht er nicht nur den Kampf für die Reinheit der Sprache, sondern das beständige Bemühen darum, daß die Sprache zu jeder Zeit den vielfältigen Anforderungen der Gegenwart entspricht.

\section{LG 96/65 (14.8.65) SLUŽBA RUSSKOGO JAZYKA S. 2}

\section{Z. Moiseev: „Prilipčivaja bolezn': kanceljarit"}

Moiseev beginnt seinen Brief mit einem Zitat von Čukovskij über die Gefährlichkeit des amtssprachlichen Stils (kanceljarit). Bürokratische Wendungen beherrschten viele Zeitungsartikel, Dissertationen, Reden, technologische Abhandlungen und seien oft sogar in alltäglichen Gesprächen zu finden. 
Als Beispiele für die Durchdringung des Sprachgebrauchs mit amtssprachlichen Wendungen führt er an:

- potrebiteli uagona

- Obespexivajte vysokij uroven' podgotovki ugonov pod pogruzku!

- Elektriteskoe oborudovanie imeet vzrywobez opasnoe ispolnenie.

- rubil'nik v otkrytom/zakrytom ispolnenii

- vlagonepronicaemyj (statt: nepromokaemyj)

- zurkowj signal (statt: gudok)

- Kartofel' zatarenmyj (nasypannyj) u mełki orprauljaetsja dlja realizacii (prodazi).

- v magazinach s maloj plostad'ju torgowgo zala

- Genitiv-Konstruktionen mit ot: 20 procentov ot plana, 30 procentov ot bjudzeta

Femer kritisiert er Termini wie perepromysd, ruslootišenie, dnooxiłzenie, beregootistenie oder obustrojstwo, deren Vorkommen in Büchern oder Broschüren er deshalb fữ gefährlich hält, weil sie dadurch zur Norm erhoben und dann von zehn Millionen Menschen verwendet werden könnten. An die Mitarbeiter des IRJaz richtet er die Frage, ob sie nicht merkten, was in Fachverlagen der russischen Sprache angetan werde. Er fordert, daB in den terminologiegebenden Kommissionen in wissenschaftlichen Forschungseinrichtungen neben Fachleuten auch Sprach wissenschaftler mitarbeiten.

\section{R. Abdullin: „Po ili o?“}

In derselben Ausgabe bemängelt der Leser R. Abdullin die Ausweitung von po als Universalpräposition anstelle von dlja, $0, z a, v$ :

- reśenie po oplate truda

- dlja okazanija pomošči po medreniju

- dannye po čislennosti

- woprosy po soderzaniju raboty

- literatura po peredowmu opytu

Konstruktionen mit po treffe man auch dort an, wo eine unmittelbare Verbrektion vorliege, jegliche Präposition also unnötig sei:

- plan po dobyče

- programma po uveliteniju proizvodstua

- vysokie tempy po stroitel 'stou

- sredstu po rasprostraneniju opyta

- zavod po proizwodst m Yelezobetonnych izdelij

- mugazin po prodaye prodovol'stuennych tovarov 


\section{A. Kron / L. Uspenshij: "Kavyčli i Kakby Kegonery dli““}

Unter dieser polemisierenden Uberschrift veroffenticht die LG 123 zwei Beiträge über den übermäBigen Gebrauch von Anführungastrichen. Ihre Verfasser, Aleksandr Kron und Lev Uspenskij, sprechen von einer Tendenz, jedes Wort, das in übertragener Bedeutung gebraucht wird oder das nicht zum Standardwortschatz gehört, in Anführungsstriche einzuschließen. Uspenskij ist der Meinung, der Leser kőnne selbst feststeßen, ob ein Ausdruck wörtlich oder im übertragenen Sinne zu verstehen sei. Er hofft, da 8 viele Leser durch Zuschriften an die LG ihre Meinung zu diesem Problem aubern und so unterstützen, da der Anführungsstrich-Manie, die eher ein Zeichen dafür sei, daB man die Verantwortung für das Geschriebene micht äbernehmen wolle, endlich ein Ende gesetzt werde.

V.V. Vinogradov: ,Zametki o stilistike sovremennoj sovetskoj literatury"

Die Redaktion stellt in dieser Ausgabe einen Artikel von Vinogradov über stilistische Tendenzen der zeitgenössischen sowjetischen Literatur, den sie als in einigen Punkten strittig bezeichnet, zur Diskussion.*

Vinogradov fordert vom sowjetischen Schriftsteller nicht nur das Wissen um die Feinheiten der verschiedenen Stile des Russischen, sondern auch deren aktive Beherrschung. In Diskussionen über Sprache sei ein grober Themenkomplex immer wieder behandelt worden, aber leider vorwiegend Verletzungen der russischen Standardnorm, wie vermeintlich oder tatsächlich falscher Wortgebrauch oder die Verwendung von Dialektismen und Vulgarismen. In diesem Sinne hätten sich beispielsweise die Schriftsteller F.V. Gladkov, K.I. Cukovskij, A. Jugov, A. Morozov, B. Timofeev oder L. Uspenskij für die Richtigkeit und Reinheit der russischen Sprache eingesetzt. Dabei sei jedoch der stilistische Aspekt vernachlässigt worden.

Als negative Tendenzen in der zeitgenössischen sowjetischen Literatur nennt er verschiedene Stilformen, die mit sprachlichen Mängeln, wie der Verwendung von abgegriffenen Klischees, der Uberladung von Texten mit Fachtermini und der Imitation bäuerlicher Sprache einhergingen.

- Vinogradov spricht in seinem Beitrag vor allem literaturwissenschaftliche Aspekte an, die, weil sie für die vorliegende Untersuchung nicht relevant sind, hier nicht wiedergegeben werden. Einige det nachfolgenden Diskussionsbeiträge greifen nur diese Aspekte auf und werden deshalb ebenfalls nicht berürksichtigt. 
Eine grundlegende Aufgabe der Sprachkultur besteht nach Vinogradov darin, zu entscheiden, wie die Reichtümer der russischen Sprache in der Belletristik ästhetisch und zielgerichtet eingesetzt werden können und welche Elemente dieses unerschöpflichen Sprachvorrats in die Standardsprache aufgenommen werden können.

LG 127/65 (26.10.65)

(Pisatel' Citaet pottu)

S. 2

\section{S. Baruzdin: „Kaleten'e slovom“}

Der Schriftsteller Sergej Baruzdin befaßt sich in diesem Beitrag mit der sprachlichen Form von Kinderbüchern. Er bemängelt sowohl die Verwendung von "erniedrigenden" statt diminutiven Namensformen, wie Vas'ka, Van'ka, Małka, Zen'ka, als auch den Gebrauch von Klischees, wie belokrylye lajnery, neobozrimye gektary korolevy polej oder luCYie peredoviki. Als schlecht bezeichnet er den Ausdruck detsadovec.

Alle Leute, die mit Kindern zu tun haben, also Eltern, Erzieher, Lehrer und auch Autoren und Herausgeber von Kinderbüchern, sollten über ein sicheres Sprachgefühl verfügen. Er bedauert, daß so viele Bücher erscheinen, die die erwähnten Mängel aufweisen.

\section{A. Jugov: „Okean za rešetkoj“"}

A. Jugov, der sich auf den Beitrag von Vinogradov bezieht, wendet sich gegen die Verdammung von nichtstandardsprachlicher Lexik. Er hält das "Wörterbuch des Volkes" für verbindlicher als das seiner Meinung nach nur für Ausländer konzipierte Wörterbuch von S.I. OŽegov oder das vierbändige Akademiewörterbuch, das aus dem Tolkovyi slovar' von Dal' über die Hälfte an Wörtern als nichtstandardsprachlich ausgesondert und viele weitere mit

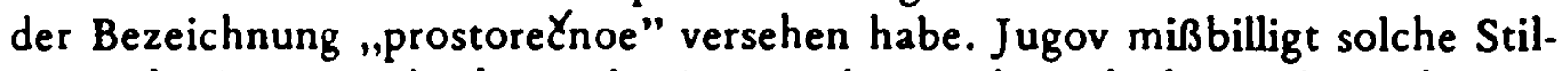
vermerke in Wörterbüchern, da sie von dem Gebrauch des so bezeichneten Wortes abschreckten.

In den letzten zehn bis zwanzig Jahren tauchten immer mehr Bücher und Heftchen über Sprachkultur auf, die alle die Sprache der Schriftsteller und Journalisten von Prostorě̌ie-Elementen, Slavismen und Archaismen reinigen wollten. Jugov fordert von der Sprachwissenschaft, daß sie sich darauf beschränkt, die Sprache zu untersuchen und zu beschreiben, statt sie zu reglementieren. 
Den von Vinogradov verwendeten Begriff "prostorečno-dialektnyj" verwirft Jugov als unwissenschaftlich, da das Prostoreと̌ie eine überregionale, dem ganzen Volk gemeinsame Erscheinung sei. Er tritt für die Aufnahme von Prostoretie-Elementen in die Standardsprache ein und sieht sich damit in der Tradition führender Schriftsteller und Sprachwissenschaftler wie Buslaev oder Sachmatov. Buslaev habe bereits vor mehr als hundert Jahren betont, daß sich die ältesten und wesentlichen Merkmale der russischen Sprache im Prostoreð̌ie eher als im Sprachgebrauch der Gebildeten bewahrt hätten. Was Archaismen und Provinzialismen angeht, so spricht Jugov - ebenfalls mit einem Verweis auf Buslaev - der Wissenschaft das Recht ab, vorzuschreiben, wie viele und welche Elemente der Dialekte in den Standard aufgenommen werden sollten. Dies könne allein das Sprachgefühl des Einzelnen entscheiden.

LG 131/65 (4.11.65)

SPOR IDET

S. 2

A. Solženicyn: „Ne obyčaj degtem క̌xi belit', na to smetana“

Solæenicyn kritisiert zunächst den Ton und die sprachliche Form von Vinogradovs Artikel. Die angeführten Beispiele (proran, raspadok) bezeichnet er als falsch.

Nach Solženicyns Meinung hat die russische Schriftsprache bereits seit der petrinischen Zeit ständig unter gewaltsamen Zerstörungen gelitten. Die Schuld dafür lastet er der gallophilen Schicht der Gebildeten und unachtsamen Ubersetzern und Publizisten an. Betroffen davon seien sowohl der Wortschatz als auch der grammatische Bau und die Struktur des Russischen. Der Wortschatz sei ständig ärmer geworden, wobei verlorengegangene Elemente durch meist völlig überflüssige Fremdwörter ersetzt worden seien.

Im grammatischen Aufbau des Russischen hätten sich nur solche Strukturen erhalten können, die denen in (west)europäischen Sprachen ähnelten. Solzenicyn beklagt das Verschwinden von typisch russischen Merkmalen, wie z.B. der Möglichkeit, von Verben feminine und maskuline Substantive abzuleiten. Stattdessen bilde man neutrale Substantive auf enie/-anie:

$\begin{array}{llll}\text { statt } & \text { ubyv' } & : & \text { ubyuanie } \\ \text { statt } & \text { nagramozdka } & : & \text { nagramoźdenie } \\ \text { statt } & \text { sochrana } & : & \text { sochranenie } \\ \text { statt } & \text { prinorouka } & : & \text { prinoravlivanie } \\ \text { statt } & \text { peretask } & : & \text { peretaskivanie }\end{array}$

Als unrussisch bezeichnet er ferner die Zusammensetzung von zwei oder drei Substantiven wie in rečestroj und das Vorhandensein einer Vielzahl von Abstrakta. 
Er bedauert, daß die russische Bildungsweise von Adverbien (uperevert, upriporodoch, dotonka, obukon) und die Möglichkeit, Verben durch Präfigierung zu verändern, in Vergessenheit geraten sei. Verben wie ostegnut', rasklonit', uklonit' seien ungebräuchlich geworden.

Außerdem richtet sich Solženicyn gegen die unzähligen Fremdwörter, die sich in der russischen Sprache festgesetzt hätten.

Seiner Ansicht nach ist der Wortbestand der mündlichen Rede trotz der Aufnahme einer Vielzahl von wissenschaftlichen und technischen Termini und Jargonismen besorgniserregend geschrumpft. Es werde immer nur eine geringe Anzahl von ständig wiederholten Wörtern verwendet. Dieser Zustand bedürfe dringend einer Veränderung. Dabei schreibt er den Schriftstellern die Aufgabe zu, den Wortbestand dadurch wieder zu erweitern, daß sie aus dem Gebrauch gekommene Wörter bewußt verwenden, um sie so in die Sprache zurückzuholen und zu reaktivieren. In diesem Sinne empfiehlt er die Verwendung von Wörtern wie:

vyšatnut', prisatnut' (zu ošatnut', ołatnut'sja), doumevat', prizevat 'sja, peremknut', predmestnik, slistnut', perevil 'nut'

F. Levin: „Kto chočet posadit' derevo..."

Levin wendet sich in erster Linie gegen Vinogradovs Kritik an Dialektismen in der Belletristik. Seiner Meinung nach sind dialektale Elemente notwendig zur Więdergabe des Lokalkolorits und zur Charakterisierung der handelnden Personen durch ihren Sprachgebrauch. Man könne sich unmöglich vorstellen, $\mathrm{da}$ die Helden bei Čechov eine normierte (destillierte) Sprache verwendeten.

Trotz Fernsehen und Presse höre man auf dem Dorf immer noch dialektale Wörter und Ausdrücke und seltsam entstellte „Barbarismen“. Auch Gor'kij habe sich nicht dagegen ausgesprochen, daß Personen in literarischen Texten durch ihren Sprachgebrauch charakterisiert werden. In seiner Kritik an Panferov wegen der Verwendung von skukožit'sja und podjaldykivat' habe er sich lediglich gegen die Verschmutzung des Russischen durch Provinzialismen gerichtet.

Was die ständigen Angriffe gegen Elemente aus Dialekt und Prostore gehe, müsse man überhaupt lernen, zu unterscheiden $z$ wischen dem gerechtfertigten Protest gegen die Verunreinigung der Sprache einerseits und andererseits der Bereicherung der Standardsprache durch Wörter und Ausdrücke aus

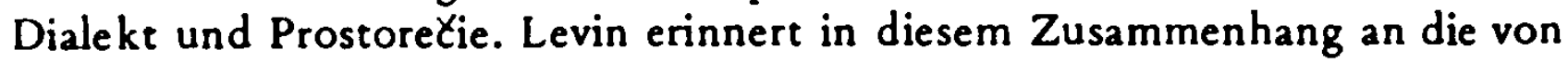
ihm als puristisch bezeichneten Angriffe gegen Klassiker wie Puškin, Nekrasov, Majakovskij, Zošcenko und Aksenov. 
Anders als Solłenicyn sieht er keinen Sinn darin, Archaismen wie nagramozdka, ubyv' und peretosk, die weder im mündlichen noch im schriftlichen Sprachgebrauch verankert seien, zu neuem Leben zu erwecken.

Die Wörter raspadok, proran, lajner, bul'dozer, samosual und skreper bezeich ne Vinogradov zu Unrecht als unverstāndliche Provinzialismen. Die letzten fünf Wörter seien jedem regelmäBigen Zeitungaleser vertraut, proran allgemeinverständlich und raspadok könne man bei jedem Schriftsteller aus dem Uralgebiet und Sibirien finden.

Die LG 134/65 veröffentlicht Auszüge aus acht Leserbriefen - kurze Statements, die kaum eigene Gedanken in die Diskussion einbringen, sondern eher die Nützlichkeit einer solchen Erörterung, wie sie unter "Spor idet" geführt wird, betonen. Darüber hinaus werden in einem Leserbrief die Sprachtlischees als Hauptfeinde der russischen Sprache angeprangert. Derselbe Leser, Dozent an einer pädagogischen Hochschule, weist darauf hin, daB zwar viel über die Gleichgüligkeit der Schriftsteller gegenüber der Sprache geredet werde, man sie aber andererseits auch ständig in der Auswahl ihrer kïnstlerischen Mittel einschränke. Ein anderer Leser (Redakteur) sieht in den Fachtermini, die häufig an unpassenden Stellen verwendet würden, das Hauptïbel des derzeitigen Sprachgebrauchs.

V. Nazarenko: „Chudožnik ili pisar'?a"

Vadim Nazarenko bedauert, daß Vinogradov offen gelassen habe, ob sich seine Ausführungen auf die gesamte Standardsprache oder nur auf die Sprache der Literatur beziehen.

Die häufig geführten Auseinandersetzungen um die Sprache der Schriftsteller betrachtet er als wenig nutzbringend. Ein Schriftsteller dürfe sich nur an seiner eigenen - auf individueller Lebenserfahrung gewachsener - Sprachpraxis orientieren. Deshalb hält er die Ratschläge, diese oder jene Wörter in die schriftstellerische Praxis einzubeziehen, für zwecklos und weist daher Solzenicyns Vorschlag zur Retrung des Wortbestands als unnatürlich zurück. Ein Schriftsteller, der genau weiß, worüber und wofür er schreibt, kenne keine sprachlichen Probleme. 


\section{A. Lejtes: „Sobor a ne summa kamnej“}

Der Titel des Aufsatzes von Lejtcs bezieht sich auf dessen Vorwurf gegenüber Vinogradov, dieser habe in seinem Artikel isolierte Zitate angehäuft, ohne zu berücksichtigen, in welchem Kontext sie stehen.

Lejtes erklärt sich nicht einverstanden mit SolŽenicyns Behauptung, die russische Sprache habe sich seit der petrinischen Zeit zusehens verschlechtert, denn allein dic Bereicherung des Russischen durch das Sprachschaffen Puskins widerspreche ihr. Solženicyns Abwertung der Abstrakta auf eniel-anie bezeichnet er als nicht überzeugend, zumal sie Solženicyn selbst in „SluČaj na stancii Kreðetovka" zurecht mit Vorliebe verwendet habe.

Er betont, daß sprachliche Außerungen nur hinsichtlich ihrer kommunikativen $Z$ weckmäßigkeit bewertet werden dürfen. Dies gelte auch für die Beurteilung des Wortbestandes und der stilistischen Besonderheiten zeitgenössischer literarischer Texte.

\section{V. Čvilichin: „Replika v spore“}

Vladimir Civilichin, den Vinogradov in seinem Artikel kritisiert hatte, rechtfertigt die Sprache seiner Erzählung ,.Élki-motalki“ damit, daß sie, aus der Sicht des Helden konzipiert, nur in Anlehnung an dessen Sprachgebrauch verfaßt werden könne.

Wic Solženicyn hält auch Čivilichin es für unumgänglich, fast vergessene, kaum noch gebräuchliche Lexik wieder zu reaktivieren. Seiner Meinung nach muß es möglich sein, auch dialektale Elemente, die in keinem Wörterbuch verzeichnet sind, in literarische Texte einzuflechten.

Dic Schriftsteller Michail Alekseev, Viktor Astafev, Vasilij Belov und Vladimir Cybin lobt er dafür, daß sic, weil sie die Gefahr einer „Destillierung“" der russichen Sprache erkannt hätten, zur Sprache des Volkes als der reinen Quelle \&urückgekehrt seien.

\section{LG $150 / 65$ (21.12.65) SLUŽBA RUSSKOGO JAZYKA S. 2 \\ L. Uspenskij: „Polboršřu? Ničego strašnogo!•}

1)em Artikel von Uspenskij geht ein Auszug aus einem Leserbrief aus Lugansk voraus, in dem sich der Verfasser über die Vermischung von Russisch und I Hrainisich in der Ukraine beschwert. 
In seiner Antwort erinnert Uspenskij zunächst daran, daB es in den entlegenen Winkeln immer noch Personen gebe, die nicht die Standardsprache verwendeten, sondern verschiedenen Dialekte. Diesen Menschen könne man nicht falschen Sprachgebrauch vorwerfen, da Dialekte ihre eigenen Normen und grammatischen Besonderheiten hätten. Er ist überzeugt davon, daB die Dialekte früher oder später der Standardsprache ihren Platz überlassen müssen; bis dahin müsse man sie aber akzeptieren.

In der Alltagssprache, wo die Normen nicht so streng befolgt wirrden wie in der Standardsprache, sei der Ausdruck polborł̌a für polovina tarelki boršta nichts Ungewöhnliches, in der Standardsprache könne man ihn aber ebenso wie ähnliche Abkürzungen (polbedy, polgorja, polbutylki, polustof) nicht zulassen.

Die Vermischung von urkrainischen und russischen Elementen im mundlichen Sprachgebrauch dürfe man nicht verurteilen, im schriftlichen Sprachgebrauch sei jedoch nur reines Russisch oder reines Ukrainisch erlaubt.

\section{Sergin: „SluKat' reX' narodnuju““}

Sergin beschreibt in seinem Aufsatz die Entwicklung der russischen Standardsprache als stetige Annäherung der ursprünglich slavisch-bulgarischen Literatursprache an die Volkssprache. Die ersten Einflüsse des mündlichen Sprachgebrauchs der Bevölkerung auf die Literatursprache setzt er zur Zeit Ivan IV. an. Im 17. Jahrhundert sei dann der Protopop Avvakum besonders für die Volkssprache eingetreten. Sergin setzt hier den von Avvakum verwendeten Begriff „Prostorečie" mit dem heutigen linguistischen Terminus gleich. Später hätten besonders Lomonosov und Puskin der russischen Sprache den Weg bereitet. Vom zeitgenössischen Schriftsteller erwartet Sergin die Einbeziehung der Alltagssprache, wie sie in der Fabrik oder auf der Kolchose zu hören sei. 


\section{J2. Poliš̃uk: „Bantiki fel'etona“}

Jan Poliscuk beklagt, daB die Feuilletons in Zeitungen von Archaismen und Slavismen getränkt und von Bürokratismen übersättigt seien.

Beispiele für Archaismen und Slavismen:

oko, sej, licezret', otvetstvovat', glagolet, poeliku, vozymelo;

Beispiele für Bürolkatismen:

- predvkusenie poluCit' voznagrazdenie za ispolnenie,

- No ispolnenie postanovlenija,

- na segodnjařnij den',

- imeetsja u naličii,

- $v$ Časti snabŽenija

Die Verwendung von Archaismen und Bürokratismen hält er nur dann für angebracht, wenn dies zur Typisierung von Personen oder zur Wiedergabe des Lokalkolorits im literarischen Text notwendig ist und solche Elemente nicht nur als $F$ arbtupfer fungieren.

F. Malov: „Poščadim koromyslo“

Fedor Malov meint $z w a r, d a B$ Vinogradov ein wichtiges Thema angeschnitten habe, befürchtet aber, dieser Artikel gebe den Verlagstektoren Gelegenheit, gegen gut die Häfte des Wortbestandes litarischer Texte ein Veto einzulegen.

Malov, der die Beiträge von Šergin, Jugov und Solłenicyn unterstützt, hält es nicht für besorgniserregend, wenn dialektale Elemente in einen literarischen Text einfließen. Für gefährlich betrachtet er im Gegenteil die hochmütige Verachrung, die Ubernahmen aus dem reinen, gesunden Prostore $Y_{i e}$ entgegengebracht werden. Er kritisiert, daß ein Verlagslektor Ausdrücke wie:

ostoZ e, koromyslo, tyn, sternja, kalitka, toporiste, Yadut, oblogi beanstandet. Gerade das Prostorečie und die Dialekte stellen seiner Meinung nach ein unermessliches Material zur Bereicherung der russischen Sprache zur Verfügung. Als Vorbilder für die Aufnahme von Elementen aus der Sprache 
des Volkes in literarische Texte nennt er Tolstoj, Gor'kij, Bunin, Serafimovit, Kasatkin, Capygin, Siłkov, Sejfullina, Babel', Zoß̌cenko und Pod-jačev.

Malov beklagt den heutigen standardisierten Sprachgebrauch, der keine individuellen Besonderheiten mehr aufweise. Der Einflub der Medien habe verursacht, daB selbst Bauern, die weder lesen noch schreiben können, buchsprachlich reden. Er warnt davor, daB die russische Sprache ihres lebendigen Inhalts beraubt werde.

\section{Koroban: "Pritiny i sledstvija“"}

V. Koroban aus KiYinev ist der Meinung, es sei im Rahmen eines Zeitungarartikels sinnvoller, über stilistische Verunstaltungen zu sprechen, die den Wert eines literarischen Werkes mindern, als wie Vinogradov stilistixche Tendenzen in der sowjetischen Gegenwartsliteratur beschreiben zu wollen, was ohne grobe Vereinfachungen gar nicht zu bewerkstelligen sei.

Er britisiert in erster Linie die Imitation dialektalen Sprachgebrauchs (anziner, poluklinika).

F. Birjukov: „Bliže k živomu slovu“"

Der Sprachwissenschaftler Birjukov zählt in seinem Aufsatz Ursachen für die von Vinogradov beschriebenen Tendenzen in der zeitgenössischen Literatur auf.

Zum einen stellen seiner Meinung nach sowohl Schriftsteller als auch Verlagslektoren niedrigere Anforderungen an die Sprache literarischer Texte als früher. Die literarische Sprache sei nivelliert und am Zeitgeschmack orientiert.

Er bedauert, daB es seit Gor'kij keine Sprachdiskussionen mehr gegeben habe. Im Unterschied zu damals, wo die Kritik auch vor bedeutenden Schriftstellern wie Panferov, Gladkov oder ViY̌nevskij nicht haltmachte, betrachte man heute Schriftsteller allzu schnell als unantastbar. AuBerdem vernachlässige die Literaturkritik die sprachliche Form literarischer Texte.

SchlieBlich kritisiert Birjukov die Haltung der Linguistik gegenüber der lebendigen Umgangssprache. Ebenso wie viele Verlagslektoren bei der Korrektur literarischer Texte nur solche Wörter durchgehen ließ̧en, die im Wörterbuch von Ušakov verzeichnet sind, erlaubten auch viele Linguisten den Schriftstellern nur die Verwendung von Wörtern, die von ihnen als, ,allgemeinverständlich" eingestuft werden. Seiner Meinung nach ist es an der Zeit, daß sich die Linguistik den Erfordernissen des Lebens annähert. Hierzu könnte z.B. die 
Zeitschrift Voprosy jazykoznanija beitragen, indem sie nicht nur allzu spezialisierte Probleme behandele, sondern auch Fragen aufgreife, die sich auf die Entwicklung der Umgangssprache oder auf stilistische Probleme der Sprache der Literatur, der Publizistik und der Wissenschaft beziehen.

\section{Grigor'ev: „I poétam nužno znat' lingvistiku“}

Grigor'ev, wissenschaftlicher Mitarbeiter des IRJaz, ist der Ansicht, die Linguistik habe sich, mit Ausnahme von Vinokur, Vinogradov und Bachtin, bislang zu wenig um die Sprache der Literatur gekümmert.

Im weiteren kritisiert er die von Nazarenko erhobene Behauptung, ein Schriftsteller, der genau wisse, worüber und wofür er schreibe, kenne keine sprachlichen Probleme. Damit beweise Nazarenko, daß ihm der Inhalt eines literarischen Textes wichtiger sei als dessen sprachliche Form, und vertrete damit dieselbe Position wie die Schreiberlinge, gegen die er sich ereifere.

Die Puristen, die in der Sprache keine Neuerungen dulden, die ihrem persōnlichen Geschmack nicht entsprechen, seien im Unrecht. Weitaus mehr irrten jedoch Jugov und alle Antinormalisatoren, die in der Norm eine Erfindung von heutigen Senkovskijs, Kačenovskijs oder Greł's sāhen. Nur auf objektive Kriterien gestützt dürfe man über Sprachfragen urteilen.

Grigor'ev fordert, eine allgemeinverständliche Theorie der poetischen Rede auszuarbeiten und ein Wörterbuch zur zeitgenōssischen Sprache der Literatur zu erstellen.*

Bereits seit 1960 arbeitet Grigor'ev an einem Projekt zur Erstellung eines Wörterbu. ches der russisch-sowjetischen Poesie: vgl. Grigor ev 1965, 1973 und 1979. 


\section{V.V. Vinogradov u.a.: (ohne Tited)}

In der LG 23/67 nehmen führende sowjetische Sprachwissenschaftler Stellung zu der in der Zeitschrift Nedelja abgedruckten Erzählung "Tam gde rastut rododendrony, gde igrajut patefony, gde ulybki na ustach “* von V. Aksenov. Ihren Angaben zufolge sind die Helden aus Aksenovs Erzählung zwei Moskauer Schwätzer, die bereits seit sieben Jahren an der Herausgabe eines Wörterbuches arbeiten. Beiden fehlt eine eigene Weltanschauung, dafür zeichnen sie sich durch eine grobe Belesenheit aus. Die Schwżtzer, von denen einer Spezialist für den Buchstaben U,der andere für $O$ ist, heißen USakov und Ožegov.

Die Unterzeichner des Briefes beschweren sich darüber, daB Aksenov mit seiner Erzählung die großen sowjetischen Sprachwissenschaftler OŽegov und Ušakov, deren Verdienste um die Lexikographie nicht allein in der Sowjetunion, sondern auf internationaler Ebene anerkannt seien, lächerlich mache. Unterschrieben haben den Briet neben V.V. Vinogradov R.I. Avanesov, S.G. Barchudarov, F.P. Filin, L.S. Kuznecov, V.D. Levin, A.A. Reformatskij, V.J. Sidorov, Ju S. Sorokin, G.V. Gornung, S.K. Šaumjan, J.F. ProtZento, L.I. Skvorcov, V.A. Redkin und S.S. Vysotskij. 


\section{A. Semenov (Leserbrief ohne Titel)}

Der Leser Semenov aus Barnaul beanstandet eine Reihe von Betriebs- und Fabriknamen:

- Brak: Bamaul'skij rezino-azbestovyj kombinat

- Transmas, Sibẻlektrotjažmał, DorožmaY, Altajsel'maš, Rostsel'maY, TaYsel'may;

- ChBk, GRO, KChB, VRZ;

- Pivobezalkogol'nyj zavod;

Er erinnert daran, daß in den ersten Jahren der Sowjetmacht die Arbeiter ihren Fabriken noch liebevolle Namen gegeben hätten wie Krasnyj putilovec, Bol'ševik, Elektrosila, Serp i Molot. Da die Arbeit in der Sowjetunion eine fröhliche Angelegenheit sei, müßten seiner Meinung nach auch die Fabriken und Betriebe fröhliche Namen tragen.

LG 31/67 (2.8.67)

S. 5

\section{Safonov: "Echajte!“"}

Safonov mißbilligt die immer weiter um sich greifende Imperativbildung echaj, echajte von echat', die unrussisch sei und schrecklich klinge. Nicht allein Grammatiker und Bücherwürmer, sondern das ganze russische Volk habe entschieden, daß der Imperativ von echat' poezžaj(te) lautet.

K. Barykin: „Skoraja lingvističeskaja otvečaet“"

Barykin berichtet über den kurz zuvor in der Abteilung für Sprachkultur des IRJaz eingerichteten telefonischen Sprachdienst, den jeder Sowjetbürger anrufen kann, wenn er Fragen zur russischen Sprache hat.

Nach Barykin wird von dem Sprachdienst rege Gebrauch gemacht. Oft werde er aber völlig unnötig mit den banalsten Fragen behelligt, die sich die Anrufer 
mit einem Blick ins Wörterbuch hätten selbst beantworten können. Viele Anrufer seien zu faul, im Wörterbuch nachzuschlagen. Manchmal entwickele sich aus einem solchen Telefongesprāch aber auch eine Zusammenarbeit $z$ wischen IRJaz und dem Anrufer, wie bei dem Folkloristen Dubrovin, der Material über aussterbende Mundarten der Handwerker aus dem Bezirk Ul'janov gesammelt habe.

Barykin würdigt den Telefondienst als sehr nürzliche Einrichtung, die man aber für Fragen in Anspruch nehmen solle, die, weil sie auch unter Linguisten noch diskutiert werden, nicht in Handbüchern beantwortet werden, so z.B., wenn man nicht sicher sei, ob es moe rodnoe Cili oder moja rodraja Cili buten müsse.

Er schlägt vor, das telefonische Sprachbüro solle ein eigenes Nachrichtenorgan herausgeben, das auf die eingetroffenen Fragen kurze qualifizierte Antworten gibt und in hoher Auflagenzahl der Bevölkerung zugänglich gemacht wird.

Einen bescheidenen Beitrag leiste der Telefondienst auch bei der Prognostizierung sprachlicher Veränderungen. So zeigten die Fragen der Anrufer mitunter, welche noch nicht in den Wörterbüchern erfaBten Ausdrücke so häufig gebraucht werden, da B sie demnāchst in orthographische und erklärende Lexika aufgenommen werden müssen.

LG $35 / 67(30.8 .67)$

\section{Kałin: (Leserbrief ohne Titel)}

Der Leser Kałin erinnert daran. daB in einer Sprachdiskussion einmal der Vorschlag gemacht worden sei, eine Sprachmiliz einzurichten. Ihn wundert, daB die Verlagslektoren, die doch für die Kontrolle des gedruckten Wortes zuständig seien, verunstalteten Wörtern grünes Licht geben. Ein solcher störender Ausdruck sei za ščet, verwendet in der Bedeutung von blagodarja:

- ObsluŽivanie na avialinijach ulučśitsja za šcet stroitel'stua novych i rekonstrukcii starych aérodomov.

- Chokkeisty pobeždajut za ščet bol'šoj skorosti $i$ choroł̌ej fiziteskoj podgotoulennosti.

\section{A. Beljarev: (Leserbrief ohne Titel)}

Der Arzt Beljarev lobt die unermüdlichen Bemühungen der LG um die Reirheit der russischen Sprache. Er kritisiert aber. daß auch in der LG manchmal 
unnötige Anführungsstriche gesetzt werden, obwohl sie selbst bereits Artikel veröffentlicht habe, in denen die Anführungstrich-Manie aufs Korn genommen werde.*

Beispiel: Jablonevyj cuet "s-edali" tumany, komi "podrezali" morozy, pčelosem'i ,zivut".

Der Verfasser dieser Zeilen meine offensichtlich, ohne die Anführungsstriche glaube der Leser, Wolken hätten Zähne und ernährten sich ausschließlich von Apfelfarbe.

LG 39/67 (27.9.67)

POČTA REDAKTORA

S. Kipnis: (Leserbrief ohne Titel)

S. Kipnis aus Moskau unterstützt Barykins Vorschlag, ein linguistisches Bulletin herauszugeben, das auf Fragen zur russischen Grammatik, die dem telefonischen Sprachdienst gestellt werden, kurze qualifizierte Antworten gibt. Kipnis verspricht sich von einem solchen Bulletin, wenn es auf einfachem, billigen Papier gedruckt und in hoher Auflage verlegt werde, großen Nutzen.

Beljarev meint hier vermutlich die Artikel: Kron/Uspenskij $123 / 65$. 


\section{LG 2/68 (10.1.68) SLUŽBA RUSSKOGO JA
L. Borovoj: "Mnogoe v nemnogom"}

L. Borovoj behandelt in seinem Artikel charakteristische Tendenzen in der zeitgenössischen Sprache der Belletristik. Im Englischen und in anderen groben Weltsprachen habe sich eine Tendenz herausgebildet, in Sätze ohne grammatische Unterordnung ganze Ketten von durch Bindestriche verbundene Wörter einzufügen.

Beispiel: On uže opjat' byl bossom i govoril den'gi-moi-poetormu-delajtekak-uam-prikazano tonom.

Dieses Phänomen sei sowohl in der russischen Umgangssprache als auch in der Belletristik wiederzufinden.

Volkssprachlich:

Vot priechal - raspleti kosa, vot priechal - poterjaj krasu;

Belletristik:

Už Mar'i - zažgi snega, zaigraj ovaržki

Smotris' - on, kak i drugoj, gibok, tonok, master sdelat' suoj padam-do-nog

I na nich nachoditsja pokupatel', na ètich V-Natural'nuju-Velicinu-

Kotou-S-Rusalot 'imi Glozami (Arsenij Tarkouskij)

Da diese Wendungen einen Bruch mit den Normen der Syntax bedeuteten, sei im Ausland seinerzeit eine stürmische Kontroverse über die Bindestrichtechnik (ajfenizacija) entbrannt. Heute jedoch lasse die Norm sie im Englischen und anderen Sprachen in gemäBigter Form bereits zu.

Borovoj kritisiert die Nichtbeachtung von Interpunktionsregeln bei einigen Schriftstellern und besonders bei A. Vesely, der auf sämtliche Satzzeichen verzichte.

Ein anderes Charakteristikum des zeitgenössischen Sprachgebrauchs sieht er in der Verkürzung von Äußerungen mithilfe von Formeln wie količestvo perechodit $v$ kačestvo und $k$ to $k$ čemu. die of in den trivialsten Zusammenhängen gebraucht würden.

Immer häufiger werde in der Belletristik die Sprache der Wissenschaft verwendet. Dies hält Borovoj nur dann für gerechtfertigt, wenn damit eine Romanfigur als Wissenschaf tler charakterisiert werden soll. Diese Motivation liege aber meist nicht vor. 


\section{Borisov: "Letajte samoletami!"}

Der Schriftsteller Leonid Borisov beklagt sich über sprachliche Mängel der Werbung. Als Beispiel führt er den seiner Meinung nach grammatisch falschen und daher Lächerlichen Werbeslogan der Aéroflot "Letajte samoletami!" an und kritisiert, dab Skvorcor ihn in einem Aufsatz in Russkaja rec' als völlig richtig und den Standardnormen des zeitgenössischen Russische entsprechend bezeichnet habe.*

Im weiteren bringt er zahlreiche Beispiele für falschen Sprachgebrauch im Alltag.

in der Presse: potiv, plouticha, para (in Fällen, wo dua, due stehen müBte, es sich also nicht um Pazre handelt), autor gola, skol'niki sidjat na partacb;

auf dem Bahnhof: grałdane passałiry na platforme... proizvoditsja posadka na poezd;

in Kaufhäusern: platel'nye otdely, platel'nye Skafy (statt platjanye skafy)

izobrazitel'naja produkcija prinimaem predwaritel'nye zakazy

ja $k$ vam čerez poll'asika podojdu

ja k nemu včera podechal, a ego ne bylodoma

vybivat' ček (statt platit')

kassirša (statt Ženšćcina-kassir)

Borisov stellt zudem eine Tendenz zur Verniedlichung der Umgangssprache fest (,jazyk sacharijnyj, sladen'kij, susal'nyj"):

limontik, bilerik, Četvertinka kruglen'kugo, plošcadocka, butylołka, kilo kolbaski, gazetocka, pesołek, bulołka, konvertik, marokka

Geringschätzung gegenüber der Sprache habe dazu geführt, daß Schablonen in der Sprache der Belletristik, vor allem in der Ubersetzung aus Fremdsprachen, auftauchten:

neotemlemaja ćast', Živoj interes, jauno (für besspomo und seine Synonyme). tut (statt siju sekundu, tottas, nemedlenno), objuzatel'no (statt nepremenno), prezde usego (auch in Fällen, wo richtiger wäre: voper'ych, snatala, sperva, samoe glaunoe)

Außerdem mißbilligt Borisov den ständigen Gebrauch der Ausdrücke požaluj, dovelos; ve eti dni und volnujušcij. 
L. Kapanadze / L. Krysin: „Možno li s-est' tri tarelki?“

L. Kapanadze und L. Krysin, beide wissenschaftliche Mitarbeiter am IRJaz, betrachten die Tendenz zur Verniedlichung - von ihnen als Krankheit des Sprachgebrauchs bezeichnet und auf Gleichgültigkeit gegenüber der eigenen Sprache oder Hang zu Schönrednerei zurückgeführt - ebenso wie Borisov als ernstzunehmendes Problem des gegenwärtigen Russisch:

„No ne men'šee zlo - vse èti mešťanskie vidiki, manikjurtiki, priborčiki, nastoečki ili gipertrofirovanno vežlivye otdychat' (vmesto spat'), kušat' (vmesto est') i t.d."

Anders als Borisov beurteilen sie Ungenauigkeiten in der Umgangssprache, zu denen sie den Slogan „Letajte samoletami!" zählen. Völlig gerechtfertigt sei dabei die Konstruktion mit Instr. sg.: neben echat' poezdom, plyt' parachodom, dobirat'sja tramuaem auch letet' samoletom. Erst der Gebrauch des Instr. pl. (samoletami) mache die gewohnte, normale Konstruktion zu einer unnatürlichen, fast außerstandardsprachlichen. Umgekehrt sei in dem Ausdruck doechat' lošad'mi nur der Instr. pl., nicht aber der Instr. sg. gebräuchlich. Die von Borisov beanstandete Konstruktion sidet' na parte verteidigen die Verfasser als ebenso zulässig wie sidet'za partoj, da parta die Bedeutung ,stol + skam'ja" trage. Auch der Satz ja uybila ček za sto grammov (statt ja platila za sto grammov) bietet für sie keinen Grund zur Beanstandung. Para dnej charakterisieren sie als eine umgangssprachliche, der niederen Stilebene angehörende Wendung. Nichtsdestoweniger bezeichne para aber nicht nur "zwei voneinander abhängige Gegenstände", wie Borisov meine, sondern auch „einige gleichartige Gegenstände”. Unter Linguisten vermute man, daß die zweite Bedeutung unter dem Einfluß des deutschen Ausdrucks ein paar (,einige") entstanden sei.

Als eindeutigen Fehler bezeichnen die Verfasser dagegen buchsprachliche Elemente im alltäglichen Sprachgebrauch, wie beispielsweise amtssprachliche Wörter oder zeitungssprachliche Floskeln in Gesprächen:

Beispiele: Nado ne upustit' nalicija solnca. Ach, èta palatka uže ne funkcioniruet?

Abschließend warnen Kapanadze und Krysin vor dogmatischen Urteilen (richtig / falsch) in bezug auf Sprache und betonen die Notwendigkeit, unter anderem die Stilebene, das Kommunikationsziel, den Adressaten und die Redesituation bei der Beurteilung zu berücksichtigen. 


\section{Dik: „IKčite košku“}

In einem feuilletonistischen Aufsatz über die Entstehung eines Leitartikels und dessen Zensur durch den Verlagslektor kritisiert der Schriftsteller I. Dik die Schablonenhaf tigkeit der Zeitungssprache.

\section{A. Gecov: (Leserbrief ohne Titel)}

A. Gecov aus Moskau wirft Borisov vor, er habe, um die Wendung letajte samoletami als falsch darzustellen, zu unangemessenen Analogieschlüssen gegriffen. Analogien seien in bezug auf Sprache zwar nützlich, aber aufgrund der Eigengesetzlichkeit der Sprache, wie er mit folgenden Beispielen belegt, nicht immer beweiskrāftig:

na kuchne
na lestničnoj kletke
na Kavkaze
idu lesom

na kuchne

na lestničnoj kletke

no Kavkaze aber nicht:

aber nicht: aber:

aber nicht: na komnate

na kletke tigra

$\checkmark$ Krymu

kupajus' rečkoj

\section{G. Guljanickaja: (Leserbrief ohne Titel)}

Die Leserin G. Guljanickaja aus Leningrad hat die Artikel zur russischen Sprache mit Interesse gelesen und ergänzt die Liste der dort vorgebrachten sprachlichen Mängel durch eigene Beispiele:

Sportsprache: - kommanda pereigrala sopemikov (statt vyigrala)

- matCevaja ustreלa

Medien: - pamjatnyj suvenir

- pogody, temperatury

Beliebt sei in der letzten Zeit das Wort sjužet, das oft völlig falsch verwendet werde:

Smotrite nouriju kinokartinu "Vystrel" po odnoimennomu sjužetu AS. Puškina.

\section{LG $15 / 68(10.4 .68)$ \\ L. Uspenskij: „Jazyk, jazyka, jazyku“"}

Uspenskij fühlt sich in Leserbriefen zu seinen Artikeln von zwei Seiten angegriffen: Die einen beschimpften ihn als Konservativen, als Reaktionär, weil er nicht begeistert sei von Ausdrücken wie skladirovat', subprodukty (statt votrocha), mućnisto-konditerskie izdelija. Man werfe ihm vor, er wolle den sprachlichen Fortschritt unterbinden. Von anderer Seite werde er wiederum 
als "Liberaler" oder sogar "Sprachanarchist" hingestellt, weil er weder gegen die Variante korrektorá (statt korréktory) noch gegen Jargonismen wie Zelezno oder do lampocki einschreite.

$\mathrm{Zu}$ seiner Verteidigung führt er an, daB viele heute standardsprachliche Ausdrücke ursprünglich aus Jargons stammen:
oxkoutiratel'stuo
Falschspielerargot
dourư̌ničestvo
kurolesit', erunda
Bettlerjargon
Seminaristensprache

Heute fiele es auch dem strengsten Verlagslektor nicht ein, diese Wörter aus einem Text zu streichen.

Auch die beliebte Verwendung von doulet' für tjagotet', natimat' stört ihn nicht, denn schließlich hätten auch andere Wörter einen erheblichen Bedeutungswandel erfahren, wie etwa izumlenie von "sumasšestvie" zu "sil'noe udivlenie".

Uspenskij hält nichts davon, daB Laien über Sprache urteilen. Er sieht in ihnen eine ,riesige Armee aufrichtiger Eiferer für die Sprache, die sich unaufhörlich in den Kampf gegen deren Zerstörung, Verunreinigung und Entstellung stürzen und deren nahen Untergang beweinen". Die meisten von ihnen betrachteten Sprache als ein einheitliches, sich immerfort nach denselben ewigen Gesetzen entwickelndes Gebilde. Nur der Sprachwissenschaftler wisse, da $B$ man vor Beurteilung einer sprachlichen AuBerung den situativen Kontext, in dem sie stehe, berücksichtigen müsse. Der Laie dagegen verlange von einem Diamanten zum Glasschneiden (Umgangssprache) den Glanz eines Brillanten (Sprache der Literatur) und von dem Brillanten, daB er Glas zerschneide.

\section{Azbel': „O nauke i ce jazyke“}

Der Physiker M. Azbel hält eine spezielle Wissenschaftssprache für nōtig, auch wenn dies die Allgemeinverständlichkeit wissenschaftlicher Texte verhindere. Die Fachsprache vergröBere die Kompaktheit der Information und erweise sich daher als sehr nützlich. Schon um eine einfache mathematische Formel in der Alltagssprache wiederzugeben, müsse man ganze Bücher schreiben. Demgegenüber wende sich die Alltagssprache und die Sprache der Literatur an die Phantasie des Lesers, der desto mehr Raum bleibe, je weniger konkrete Information geboten werde. Der Gebrauch der 
alltäglichen Sprache führe zu einer gewissen Ungenauigkeit und Mehrdeutigkeit der Informationsübermittlung, was in der Literatur möglich und notwendig, in der Wissenschaft aber unzulässig sei. Ergebnisse der Wissenschaft, die für die Allgemeinheit wichtig sind, sollten nur von Wissenschaftlern selbst in eine allgemeinverständliche Form gebracht werden, wie ja auch Gedichte von Lyrikern übersetzt wirden.

\section{G. Ly Xinskij: „Sư̌čestvuet li takaja problema?"“}

Lyscinskij, Rektor des Elektrotechnischen Instituts von Novosibirsk, befürwortet ebenfalls die Ausbildung einer eigenen Wissenschaftssprache und nimmt in Kauf, daB sie nur Eingeweihten verständlich ist. Er hält es für begrüBenswert, daB Elemente der wissenschafulichen Sprache in die Sprache der Belletristik und die Allagssprache eingehen.

Fachsprachliche Termini sollten seiner Meinung nach ständig präzisiert und vereinheitlicht werden. Dafür sei ein terminologischer Dienst erforderlich, der in der UdSSR in Form von akademischen Fachkommissionen bestehe.

Lystinskij räumt ein, es gebe auch schlechte Beispiele für wissenschaftliche Fachliteratur. Niemand denke jedoch daran, die Sprache der Literatur zu reformieren, nur weil einige Schriftsteller schlechte Romane verfaBten. Die Sprache der Wissenschaft sei völlig gesund und bedürfe keiner Behandlung.

\section{Rodinov: "Ėto delo samych ư̌enych"}

Der Direktor des Verlages „Nauka” Rodionov entkräftet das Argument, die Wissenschaftssprache sei dem Durchschnittsleser nicht verständlich, mit dem Hinweis darauf, daß die Vorstellung von einem Durchschnittsleser falsch sei. Mit der Differenzierung der Wissenschaft habe sich auch eine Differenzierung des Lesers ergeben. Wissenschaftliche Arbeiten werden für einen Leserkreis geschrieben, der bereits mit den Fragestellungen des betreffenden Fachgebietes vertraut sei, dessen Terminologie kenne und daher auch dessen Sprache verstehe.

\section{B. Dickson: ,Zatem tak govorit'?““}

Dieser Beitrag ist eine gekürzte Ubersetzung eines in der englischen Zeitschrift New Scientist erschienenen Aufsatzes zur Sprache der Wissenschaft. Der Verfasser B. Dickson geht davon aus, daß die Unverständlichkeit wissenschaftlicher Fachsprachen für die Allgemeinheit nicht daran liegt, daB zuviele Fachausdrücke verwendet werden, sondern daB ihr Stil zu kompliziert sei. Dies zeigt er am Beispiel einer Unterhaltung $z$ wischen Vater und Sohn, wobei der Sohn alltägliche Fragen stellt, auf die der Vater im Stil eines wissenschaftlichen Vortrags antwortet. 


\section{O. Fursov: „Učti!”}

Der Leser Firsov aus Leningrad ist besorgt um die zunehmende Verwendung sprachlicher Klischees, von ihm sogar bei bedeutenden Mitgliedern des Schriftstellerverbandes, und nicht nur bei der Charakterisierung von Romanfiguren, beobachtet.

Beispiele:

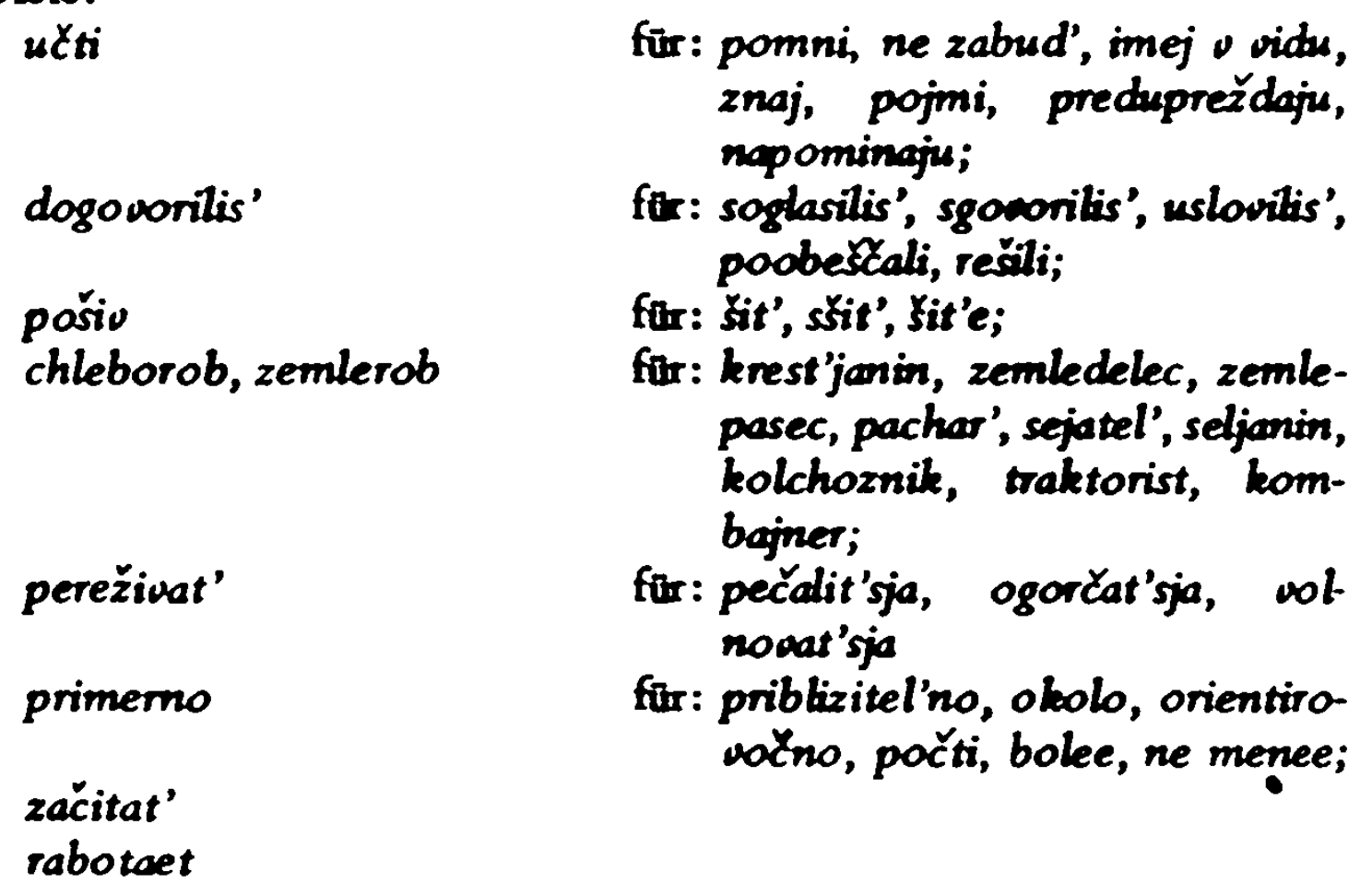

AbschlieBend ruft er alle Schreibenden auf, die russische Sprache vor unschönen und fremden Ausdrücken zu bewahren.

N.A. Es'kova: , ¿̌jul' Vermu ili Žjulju Vemu?"

Der Beitrag von Es'kova beschäftigt sich mit der Frage, wie fremdsprachige Namen im Russischen zu deklinieren sind. Die Verfasserin bezieht sich dabei auf eine Bemerkung V.P. Danilenkos in RR Nr. 2/68*, der sich darüber beschwere, $\mathrm{d}_{2} B$ in einem Zeitungsartikel der Dativ Žjul' Vermu statt Žjulju Vernu verwendet worden sei, was für ihn als offensichtlicher Fehler gelte. 
Es'kova vertritt demgegenuber die Auffassung, daB es sich hierbei nicht um ein Zeichen von Ungebildetheit handele, sondern um eine Tendenz, die A.V. Superanskaja bereits 1957 beschrieben habe*. Bei im Russischen sehr gebräuchlichen fremdsprachigen Namen beginne man, die Verbindung von Vorname und Name als eine Einheit zu betrachten, von der nur das letzte Element, also der Familienname, dekliniert werde, obwohl die Vornamen einzeln oder in Verbindung mit anderen Familiennamen durchaus dekliniert werden:

rasskazy Brèt Garta, proizuedenija Konan Dojla, u Zjul'Vema (aber: u Zjulja Moka)

Diese Tendenz wird laut Es'kova von Verlagslektoren bekämpft, wobei man sich auf DE. Rozental'** berufe, der die Deklination von Vornamen auf Konsonant vorschreibe, unabhängig davon, ob sie einzeln oder in Verbindung mit dem Familiennamen stehen. Als Resultat dieser Vorschrift verwende man in anderen Kasus als dem Nominativ nur noch den Familiennamen. Die Verfasserin betrachtet ihren Beitrag als Hinweis auf die Notwendigkeit einer linguistischen Untersuchung dieses Problems.

\section{LG 30/68 (24.7.68) SLUŽBA RUSSKOGO JAZYKA S. 12}

V. Karbovskaja: „Nu propalo . . . čto Že izmenilos?“"

V. Karbovskaja beklagt das allmähliche Verschwinden des „schönen flüssigen Russisch", was daher rühre, daB heutzutage Telegrammstil und Stammelei (kosnojazytie) in der Sprachmode als letzter Schrei gelte. Dies kōnne man sogar bei talentierten Schriftstellern beobachten, die, sobald sie uber die Jugend schreiben, in deren Jargon verfielen. Die Jugendlichen wiederum kopierten den Sprachgebrauch von Romanfiguren. Karbouskaja kritisiert vor allem den ständigen Einschub der Interjektionen oj und nu (,Nukan'e") und des Ausdrucks tak skazat', worin sie den Ansatz zu einer "faulen" Sprache sieht. Außerdem bemängelt sie die semantisch ungenaue Verwendung von ne slučajno:

Ve sluçajno noś zavod uyšel na pervoe mesto.

$U$ nich pjatero detej, $i$ èto ne slučajno.

Eine Ursache für die Verschlechterung der Sprachkultur liege darin, daß Kinder in der Schule nicht mehr lernten, frei mit ihrer Sprache umzugehen. Kinder sollten schon in der Familie an den richtigen Sprachgebrauch gewöhnt werden. Andernfalls müsse die Schule diese Aufgabe übernehmen. 
Sie bedauert, daB die Jugendlichen sich kaum noch mit Literatur beschäftigten. Manche läsen gar nicht, fischten sich stattdessen aus fremdem Sprachgebrauch Unanständigkeiten heraus und gingen dann ihr Leben lang mit Schmutz im Mund einher und verstreuten ScheuBlichkeiten. Auf solche Leute kann man ihrer Ansicht nach nur mit Hilfe von Gesetzen einwirken. Es sei beschāmend, daß man Gerichte einschalten müsse, um die Sprache von Schmutz zu reinigen. Sie hält es für besser, wenn dies rechtzeitig durch die Erziehung in der Schule und durch die Autorität des Lehrers geschehe.

\section{LG 51/68 (18.12.68) SLUŽBA RUSSKOGO JAZYKA S. 4}

\section{V.1. Borkovskij / L. Latynina: ,Znat' i ljubit'“}

Die LG-Kortespondentin A. Latynina interviewt den Chefredakteur von RR, V.I. Borkouskij. Sie beginnt mit der Frage nach der Bilanz aus den ersten zwei Erscheinungsjahren von RR. Borkorskij antwortet, man habe die ersten zwei Jahre dafir gebraucht, den Charakter und die Linie der Zeitschrift festzulegen. Dies sei jetzt abgeschlossen. Man verfüge über einen festen Kreis von Autoren, Lesern und Korrespondenten und habe zusätzlich Rubriken eingerichtet, mit deren Hilfe die Leser stärker zur Mitarbeit herangezogen werden sollten. Im letzten Heft habe man beispielsweise die Leser aufgefordert, sich an einer kollektiven Untersuchung des sprachlichen Stils in Periodika zu beteiligen. Auf zahlreichen Leserkonferenzen in verschiedenen Städten habe die Redaktion die Bestätigung dafür erhalten, daB sie den richtigen Weg eingeschlagen habe.

AnschlieBend fragt Latynina nach dem Aufgabengebiet von RR. Borkovskij definiert RR als eine Zeitschrift, die die Sprachwissenschaft der breiten Offentlichkeit nahebringe. Das Material in RR basiere im Unterschied zu gewissen in anderen Zeitschriften veröffentlichten Beiträgen von Schriftstellem auf exakten linguistischen Untersuchungen. Die Uberlegungen der Schriftsteller zu Sprache seien 2 war oft sehr interessant, aber nicht immer qualifiziert und beweiskräf tig.

Auf die Frage nach dem Leserkreis von RR teilt Borkovskij mit, laut Umfrageergebnissen setze er sich aus Technikern, Lehrern Studenten, Schülem, Propagandisten und Verlagsangestellten zusammen.

Anschließend kūndigt Borkovskij an, daB sich die nächstfolgende Ausgabe der Zeitschrift besonders mit der Sprache von Filmschauspielern beschäfrigen werde. Obwohl das Kino eine große Rolle in der Entwicklung der Sprachpraxis spiele, sei die Schauspielersprache bemerkenswert arm und fehlerhaft. $\mathrm{Zu}$ diesem Problem sollten sich unter anderem Drehbuchautoren äuBern. 
Latynina pflichtet Borkovskij bei, daß die Sprache der Filmschauspieler arm sei, sicht darin jedoch ein künstlerisches Mittel zur Charakterisierung der Helden. Borkovskij, der ihren Einwand nicht akzeptiert, meint, der Sprachgebrauch von Filmhelden richte sich nach literarischen Schablonen. Er betont in diesem Zusammenhang jedoch ausdrücklich, daß RR keine Normen aufstellen, sondern lediglich die Umgangssprache stilistisch kommentieren wolle.

Abschließend fordert er alle an der Problematik Interessierten auf, RR zu lesen.

\section{N. Nikonov: "Genij i Vinegret“}

Der Aufsatz von Nikonov über sowjetische Vornamen ist eine Kurzfassung eines 1969 vollständig in RR erscheinenden Artikels*. Die Verringerung der Vielfalt von Vornamen, die in der Presse häufig beklagt werde, hält der Verfasser für weniger besorgniserregend als Namensentstellungen und Phantasienamen. Namensentstellungen führt er auf mangelnde Bildung der Bediensteten in Standesämtern zurück. In einem Rayon des Verwaltungsbezirkes Kujbysev seien zum Beispiel neben der richtigen noch zwei falsche Schreibarten des Namens Vjąeslav gebräuchlich: Vetislav und Večjaslav. Als Beispiele für. Phantasienamen nennt er Ojušminal'da (Abkürzung von Otto Jur'e vic S̈midt na l'dine), Lagsmivara (für: Lager' Smidta v Arktike). Ähnlich phantastische Namen seien vorwiegend in den zwanziger Jahren als Protest gegen traditionelle Normen in Mode gekommen: Pjat'včet (pjatiletka v Cetyre goda), Elektrofina, $\dot{E}$ mbrion, Vinegret, heute jedoch selten geworden. Nikonov lehnt besonders Vornamen ab, von denen man schwer Vatersnamen ableiten könne.

Er kritisiert aber auch, daß in der Presse Vornamen nach subjektivem Geschmack akzeptiert oder abgelehnt würden. Objektive Beurteilungskriterien können seiner Meinung nach nur durch wissenschaftliche Untersuchungen gewonnen werden. Er erwähnt, daß man in der Sowjetunion damit begonnen habe, solche Untersuchungen in interdisziplinärer Zusammenarbeit von Linguisten, Soziologen, Historikern und Ethnologen durchzuführen. An der Allunionskonferenz über Personennamen hätten zusätzlich auch Angestellte von Standesämtern teilgenommen.

\section{N. Curmaeva: „Ostroumnyj - bystroumnyj"}

Curmaeva beschreibt hier die Geschichte des Wortes ostroumnyj. Auch dieser Beitrag ist ein Vorgriff auf einen 1969 in RR erschienenen Aufsatz.**

- Nikonov 1969

- Čurmaeva 1969 


\section{Ja. Bororskij: „Ž̈roe slovo i normalizatory"}

Borovskij versteht die Norm als systematisches Erfassen der sprachlichen Fakten in ihrer stetigen Veränderung und Weiterentwicklung. Keinesfalls sei die Norm als ein der Sprache von auBen auferlegtes Schema zu betrachten. Bezeichnungen wie ,literatumoe", "razgovornoe" und "prostoretie" lehnt er ab, da sie auBerhalb eines bestimmten Kontextes wenig verständlich seien und nur die Verwendung des so bezeichneten Wortes eingrenzten. Der Verfasser beruft sich dabei auf ein Zitat von V.A. Zukovskij in dem Buch Sud'by rodnogo slova von A. Jugov*.

Für die Arbeit von Sprachpflegern gilt seiner Meinung nach die Devise „Prežde vsego - ne vredit'", die besonders den Autoren und Behörden ans Herz zu legen sei, auf deren XuBerungen man sich aufgrund ihrer Autorität verlasse, auch wenn sie nicht durch überzeugende Argumente abgesichert sind. Der Akademie der Wissenschaften wirft er vor, sie greife in einigen ihrer Veröfentlichungen ohne ausreichende Begründung in die Sprache ein. So empfehle sie zum Beispiel, bei fremdsprachigen Personennamen nach russischem Muster auch die Vornamen zu deklinieren.

Bei der Wiedergabe polnischer Eigennamen herrsche im Bol'కoj_pol'skorusskij_slovar' (1967) ein großes Durcheinander: statt daB die polnischen Suffixe -n'sk, niski, -ów konsequent durch ihre russischen Entsprechungen -nsk, -nskij, -ov ersetzt werden, fände man neben Minsk Min'sk-Mazovecki, neben Krakov Tarnuv. Wenn das Kriterium der Richtigkeit in der möglichst genauen Annäherung an die Lautung in der Herkunftssprache bestehe, könne man gleich dazu übergehen, sich bei der Flexion polnischer Namen am polnischen Paradigma zu orientieren: (polonez Ogin'skégo).

\section{LG 13/69 (26.3.69) SLUŽBA RUSSKOGO JAZYKA S. 6 •}

\section{N. Avilova / V. Derjagin: „Nužna li ėta zaščita?“}

Die Sprachwissenschaftler N. Avilova und V. Derjagin verteidigen in ihrer Antwort auf den Artikel von Borovskij die Verweise auf Stilzugehōrigkeit 
in Wörterbüchern. Kein einziges Wörterbuch komme ohne kurze Hinweise auf den Verwendungsbereich und die stilistische Nuancierung der einzelnen Lexeme aus, kaum jemand aber leite aus diesen Hin weisen irgendwelche Verbote ab. Vielmehr sei dies ein Verfahren zur wissenschaftlichen Beschreibung der lebendigen Sprache. Die stilistischen Bewertungen seien keine Hirngespinste einiger Sprachwissenschaftler, sondern ergäben sich aus der Analyse von Textkorpora, d.h. Texten von Schriftstellern, Journalisten, Wissenschaftlern und Personen des offentlichen Lebens, die von ihren Zeitgenossen als Autoritäten anerkannt würden.

Was die Deklination ausländischer Personennamen betrifft, so sei bereits 1968 eine Diskussion darüber geführt worden. Die Verfasser verweisen auf einen Beitrag von N.A. Es'kova, "Žjul' Vemu ili Žjulu Vemu" in der LG 29/68 und auf einen Aufsatz in RR 5/68. Damals habe man den Unterschied zwischen Umgangs- und Standardsprache nicht berücksichtigt. Während man umgangssprachlich ebenso gut Zjul' Vermu und Mark Tveru sagen kōnne wie Pal Palytu oder Mar' Vanne, sei es im Standardsprachgebrauch, wie sprachwissenschaftliche Untersuchungen bewiesen hätten, angemessener, bei ausLandischen Personennamen in Übereinstimmung mit den Gesetzen des Russischen beide Namensteik zu deklinieren.

Zur Schreibweise polnischer Namen verweisen sie auf einen Artikel von L.P. Kalakuckaja und V.E. Staltmane, „Pol'skie i cerskie familii porrusski" in RR*.

\section{Bèza: „V pylu polemiki“}

1. Bèlza, stellvertretender Vorsitzender der Gesellschaft für polnisch-sowjetische Freundschaft, tritt dafür ein, sich bei der Wiedergabe ausländischer Eigennamen möglichst genau an deren Lautung in der Originalsprache zu orientieren. Dieses Prinzip sei eigentlich die Norm, in der Praxis werde aber immer wieder davon abgewichen. Dieses Problem harre schon lange einer Lösung auf höchster Ebene, nämlich der Entscheidung von seiten einer linguistischen Kommission. Gestützt auf deren Empfehlung müsse dann ein entsprechendes wissenschaftlich fundiertes Handbuch erstellt werden, in dem die für die sowjetische Gesellschaft charakteristische Achtung gegenüber der Kultur anderer Vollker zum Ausdruck komme.

LG 20/69 (14.5.69) SLUŽBA RUSSKOGO JAZYKA

V. Grigorjan: „Č́to sčitat' normoj?““

V. Grigorjan wirft die Frage auf, worin ,richtiges Sprechen" bestehe und wie 
die russische Sprache aussähe, wenn alle Sprecher sich an die von Sprachpflegem erarbeiteten Regeln hielten.

Sprachenthusiasten verstünden unter "richrigem Sprechen" allein die Fähig keit, aus einer Reihe von Möglichkeiten, einen Gedanken auszudrücken, die einzige Möglichkeit auszuwählen. Heutzutage erscheinende Bächer, Artikel und Broschüren zur Sprachkultur erinnern seiner Meinung nach häufig an die sprachnormenden Bestrebungen von Schrifustellern und Gelehrten vor Puskin. Besonders Karamzin und sein Gegner Siskor aber seien von der falschen Annahme ausgegangen, es gebe in der Sprache einerseits Zulassiges und andererseits Elemente, die entfernt werden müBten, da sie die Sprache "verschmutzten". Ahnliche Ansichten wirden auch heute vertreten. Grigorjan selbst orientiert sich an Pußkin: "Istinnyj vkus sostoit ne $\nabla$ bezoťetnom otverženii takogo-to oborota, no v Euvstve sorazmernosti i soobraznosti." Er ist der Uberzeugung, daB sich das Prinzip "tak govorjat" in der Sprache durchsetzt, auch wenn die "Neokaramzinisten" sich dagegen wehren. Dies sei in Betracht zu ziehen, bevor man gegen ein Wort vorgehe, das zwar als nichtstandardsprachlich gilt, aber im Sprachgebrauch lebendig ist.

AbschlieBend widerspricht sich Grigorjan selbst, indem er fordert, gegen "offensichtiche Entstellungen" der Sprache einzuschreiten.

\section{B. Polkomikov: „Vezde nư̌na mera"}

B. Polkonnikov aus Moskau begrübt, daB die LG das Problem der Wiedergabe fremdsprachiger Eigennamen im Russischen, das schon lange einer Losung bedürfe, aufgenommen hat. Auch er hält das von Bèlza angeregte Handbuch für dringend notwendig. Dem Vorschlag von I. Bèlza, sich möglichst genau an der Lautung in der Originalsprache zu orientieren, stimmt Polkovnikov allerdings nicht uneingeschränkt zu. Er hält es zum Beispiel für falsch, die bereits gewohnten Bezeichnungen Velikij Bar'ernyj Rif und Novyj JuŽnyj Uèl's durch Gréjt Bèrrier Rif und N'ju-Saus-Ü̈ls zu ersetzen oder bekannte Städtenamen wie London, Vena, Rim zu verändern. Bei der Wiedergabe ausländischer Personennamen sollte seiner Meinung nach das Prinzip der Annäherung an die Lautung in der Originalsprache jedoch befolgt werden, sofern dies nicht in scharfem Widerspruch zur lebendigen russischen Sprachpraxis stehe.

\section{Stasinevič: "Neobchodim spravǒ̌nik“"}

Der Chemiker D. Stasinevið aus Moskau unterstützt den Vorschlag, ein Handbuch zur Schreibung ausländischer Eigennamen zu erstellen. Er führt auberdem einige Beispiele für die falsche Schreibung ausländischer Namen an: Moissan statt Mluassan; Grasov statt Grassgof; Scilard statt Silard. 


\section{J. Koainskij: "Ne putanica, a tradicija"}

J. Kosinskij, Ingenieur aus Dusanbe, spricht sich gegen eine Orientierung an der Lautung in der Originalsprache aus, da dies seiner Meinung nach einen Bruch mit sprachlichen Traditionen bedeutet. Die Achtung gegenüber der Kultur anderer Völker dürfe nicht so weit gehen, daB Sprachgewohnheiten angetastet wirden.

LG 28/69 (9.7.69)

"Tol'ko li ,slovesnye okamenelosti"?"

In dem Vorspann zu einer Auswahl von Leserbriefen über Dialektismen und Archaismen in der Belletristik erwähnt die Redaktion, daB diesen Leserbrie fen eine Kritik des Schriftstellers Sergej Nibitins an V. Romanov vorausging, der in einer Rezension dem Schriftsteller Fedor Malov vorgeworfen hatte, sein Buch ,Na Prykše" sei überladen mit dialektalen Ausdrücken.

Drei der Leserbriefe unterstützen Romanovs Position. Der Leser V. Gorbunov aus Sevłenko (Kazachstan) hält es für falsch, leblose erstarrte Wörter zu neuem Leben zu erwecken. Er spricht von einem natürlichen, gesetzmäBigen Verschwinden von Wörtern aus der Sprache, die durch gleichwertige neue ersetzt werden. Er verweist auf XuBerungen von Gor'kij und Lunačarskij zu Dialektismen und hält Diskussionen über Dialektismen in der Belletristik von Zeit zu Zeit für notwendig.

G. Galachov aus Jarcevo schreibt, er glaube gern, daß für Philologen und Schriftsteller die Lektüre Dal's schon für sich einen GenuB bedeute, nichtsdestoweniger verfolgten literarische Werke andere Ziele, als ,selbstgedrehte Wörtchen" (samovitye slovečki) zu sammeln. Für den Leser sei es unangenehm, wenn er ständig seine Lektüre unterbrechen müsse, um unbekannte Wörter im Lexikon nachzuschlagen.

S. Gil'varg hält die russische Standardsprache für vielfältig genug, um alle Gedanken und Gefühle vollständig ausdrücken zu können. Ein Schriftsteller der überlebte archaische Ausdrücke verwendet, vermindert ihrer Meinung nach damit seine Fähigkeit, die Gegenwart zu beschreiben. 
Positiv über die Verwendung von Dialektismen äuBern sich A. Pokrovskij und N. Tjuleneva, die darin eine Möglichkeit zur Bewahrung von alten Sprachzuständen sehen.

Wie Pokrovskij ausführt, verursacht der heutige hastige Lebensrhythmus einen raschen Sprachwandel, bei dem neue farblose und "leichtlebige" Wörter (slova-motylki) entstehen, die, wenn sie in belletristische Werke eindringen, die klaren "Wortedelsteine" (jarkie samocuety slova) aus der festgefügten Sprache herausbrechen. Sogar in anspruchsvollen Buchern breite sich eine primitive, farblose, supermoderne Sprache aus, die die Eleganz, die Schönheit und den Wohlklang des Russischen vemissen ließe. Daher sei Malovs Buch nützlich, weil es den Leser wieder mit dem unschätzbar reichen Wortgut der Dialekte vertraut mache.

A. Spirin: „Kak roždaetsja pogovorka?““

A. Spirin erläutert die Herkunft einiger russischer Redensarten (bit'baklu $\}_{i}$; lipa vekovaja; očertja golovu; u čerta na kuliðłach).

Wie die LG-Redaktion anmerkt, hat der Autor in jahrelanger Sammeltätigkeit 15000 Sprichwörter und Redensarten des Russischen zusammengetragen.

\section{LG 44 /69 (29.10.69) SLUŽBA RUSSKOGO JAZYKA S. 4}

A. Bragina: "Metafory podlinnye, metafory ložnye“"

A. Bragina beanstandet die falsche Verwendung von Metaphern in den Medien. Beispiele:

- krylatyj aljuminij ... vychodit iz ognevych kupelej $(\rightarrow$ Metall zum Flugzeugbau)

- pachari morja ... ne mogut oslabit' trudowgo nakala $\leftrightarrow$ Arbeit von Fischern)

- poslednij akkord simfonii $(\rightarrow$ Ringkampf)

- devjatyj val spartakiady

- gracii vystupili v boj $(\rightarrow$ Ballettwettbewerb)

- rentgenouskij analiz romana

- (kinochudožniki) orkestrujut tončajšie ottenki cueta

- (geroinja) fokusiruet na sebe unimanie

- Yirotajsee polotno sozdano jarkimi mazkami ( $\rightarrow$ Musik) 
- oy slysite matomoe zurtanie . . gamma suetlych tonov ... polifonija ( $\rightarrow$ ein Gemälde)

- na pole razygryuaetsja vengerskaja rapsodija ( $\rightarrow$ FuBballspiel einer ungarischen Mannschaft)

- kinoretisser ovestestuil $i$ zazemlil roman

Dies seien keine Metaphern mehr, sondern schlicht und einfach Fehler. Man müsse lernen, gute von schlechten Metaphern zu unterscheiden, und zwar nicht nur im Bereich der Belletristik, sondern vor allem auch in der Sprache der Massenmedien.

\section{LG $47 / 69$ (19.11.69)

K. Gorbačevič: "Bárža ili baržá?"

K. Gorbąevi飞 beantwortet eine Leserzuschrift, in der der Ingenieur Tarasov aus Moskau kritisiert, da in dem Wort fenomen immer noch die Betonung, für den russischen Sprecher ungewohnt, auf der 2 weiten Silbe vorgeschrieben sei. Er verweist darauf, daB sich auch der Akzent des Wortes muzyka im Lauf der Zeit verschoben habe. Seiner Meinung nach ist die allgemeine Verbreitung einer nicht im Wörterbuch fixierten Betonung keineswegs als Anzeichen von Unwissenheit zu werten, sondern als ein ProzeB der Sprachentwicklung.

Gorbačevič erklärt, daB Streitgespräche über Akzentfragen von Jahr zu Jahr heftigere AusmaBe annähmen, weil sich die Akzente im Russischen von einer Generation zur nächsten ändern:

Beispiele für Akzentverschiebungen:

$\begin{array}{ll}\text { bárža } & \text { oder } \\ \text { pétlja } & \text { oder } \\ \text { po wlnám } & \text { oder } \\ \text { mýslenie } & \text { oder }\end{array}$

barzá
petljá
po vólnam
myšlénie

An zwei Beispielen will er die allmähliche Veränderung der Betonungsnorm verdeutlichen:

\section{1. premirovát' oder premírovat'?}

Während alle zeitgenössischen Wörterbücher premirovát' vorschreiben, hätten Untersuchungen des Sprachgebrauchs gezeigt, daB viele Sprecher premírovat' vorziehen. Die Ursache dafür sieht Gorbačevił in der Akzentverschiebung bei den Verben auf -irovat'. Während 1847 im Slovar' cerkovnoslovjanskogo i russkogo jaz yka noch ausschlieBlich die Betonung auf der letzten Silbe festge- setzt sei, lasse das Akademiewörterbuch von 1895 bei vielen Verben dieses 'Typs bereits zwei Varianten zu (akkompanírovat', angažírovat', balansírovat'). Bei Ožegov befinde sich der Akzent der angegebenen Verben auf dem 
Anfangsvokal des Suffixes. In der letzten Ausgabe von D.E. Rozental' Kul'tura re $X_{i}$ gelte premúrovat' als zulässige Variante.

2. zuonít oder zuónit, pozvonít oder pozvónit?

Alle Wörterbücher schreiben laut Gorbačevið zwonít, pozvonít vor, und auch ihn persōnlich stört die Betonung zubnit. Trotzdem hält er die zweite Akzentvariante nicht für falsch, da in den letzten hundert Jahren eine große Anzahl von zweisilbigen Verben auf -it' (varit', gruzit', darit', kurit') eine Akzentverschiebung zur Wurzel hin erfahren hätten. Moskauer Wissenschaftler hätten aufgrund der Ergebnisse einer Untersuchung aber die Verwendung der Varianten zuonit/zuonit die zweite als zulässig anerkennen müssen, und es sei offensichtlich, daB sie sich zur standardsprachlichen Norm entwickele.

Gorbałevið warnt abschließend davor, sich bei Urteilen aber die Sprache von Gefühlen oder Stimmungen leiten zu lassen. Vielmehr müsse man die Gesetze der Sprachentwicklung kennen und die tatsächliche Sprachpraxis untersuchen und berücksichtigen. Nötig sei vor allem ein neues zeitgenössisches akzentologisches Wörterbuch des Russischen. 


\section{LG 3/71 (13.1.71) \\ L. Krysin: „Spory i normy“"}

L. Krysin beschreibt einen Disput unter zwei Freunden, der durch eine Zeitungsnotiz über den Jugendslang (Železno, potrjasno, diko povezlo, zakadrit') ausgelöst wurde. Während der eine Gesprächspartner den Gebrauch der erwähnten Jargonismen als Ausdruck dafür erklärte, daß sich die Jugend als Antwort auf den normentreuen Durchschnittsstil von Lehrbüchern, Zeitungsartikeln und Rundfunksendungen einen eigenen, ausdrucksstarken und der Erwachsenenwelt nicht ohne weiteres verständlichen Jargon schafft und dies als normale Erscheinung darstellt, spricht sein Gegenüber von schmutzigen Wörtern aus der Diebes- und Gaunersprache.

Krysin führt diesen Streit als Beispiel dafür an, wie Sprachbenutzer ihren subjekiven Geschmack für allgemeingültig erklären und von ihrem Sprachgefühl auf die Normen des Russischen schließen. Dieses Vorgehen hält er für unberechtigt, weil jemand, der seine Sprache beherrsche, deswegen noch nicht ihre Strukturen und Gesetze kenne, wie etwa ein Sprachwissenschaftler.

Jeder Mensch sei darauf bedacht, das im Augenblick seinen kommunikativen Bedürfnissen erfüllende Sprachsystem möglichst zu erhalten. Solche bewahrenden Tendenzen seien wichtig, um einen Traditionsbruch zu verhindern. Ohne ständige Erneuerungsprozesse aber würde die Sprache erstarren und könnte den Anforderungen der Gesellschaft nicht länger gerecht werden. Von diesem Konflikt $z$ wischen bewahrenden und erneuernden Tendenzen, dem wesentlichen Prinzip der Sprachentwicklung, spürten Laien nur dessen oberflächliche Erscheinungen. Sie sähen nur das einzelne Neuwort und urteilten ohne Kenntnis der Sprachentwicklung darüber, ob dieses Wort nützlich oder schädlich für die Sprache sei. Dabei stünden sich die unterschiedlichen Sprachgewohnheiten und -vorlieben der einzelnen Sprecher, u.a. auch sozial und biosozial bedingt, gegenüber. Alte Menschen etwa halten eher an dem fest, wie man früher gesprochen habe, während Jugendliche mit Vorliebe sprachliche Neuerungen aufgriffen. Krysin betont, daß solche geschmacksorientierten Sprachbewertungen nicht weiterhelfen. Die Sprache stelle eine objektive Gegebenheit dar und habe ihre eigenen Entwicklungsgesetze. Dies bedeute jedoch nicht, daß man sie sich selbst überlassen dürfe. Krysin befürwortet eine wissenschaftliche auf detaillierten theoretischen und experimentellen Forschungsarbeiten basierende Sprachlenkung. Als Untersuchung, die diesen Anforderungen entspricht, nennt er Panov, M.V. Russkaja fonetika. 


\section{LG 18/71 (28.4.71) SLUŽBA RUSSKOGO JAZYKA S. 6}

\section{Davydov: „.. . ne v stroku“}

Der Arzt V. Davydov aus Taganrog bedauert in seinem Brief, daB die Rubrik „Sluł̌ba russkogo jazyka“, die einige Jahre lang ein ziemlich regelmäßiger Bestandteil der LG gewesen sei, nicht mehr erscheint, obwohl nach wie vor in den Medien sprachliche Mängel aufträten.

Beispiele:

- v adres kogo statt po adresu oder Dativobjekt

- ständiger Gebrauch von zoloto + Farbattribut: neft' $\rightarrow$ Cernoe zoloto, ugol' $\rightarrow$ Cermoe zoloto

- ständige, meist falsche Anwendung des Adjektivs unikal 'nyj: šest' unikal 'nych mašin slučaj v swem rode unikal'nyj

Diese Nachlässigkeit im Umgang mit Wörtern sei eine Mißachtung des Lesers, Zuschauers und Zuhorers.

Ju. Zuktenko: „Tajny ,bilingva““

Ju. Zluktenko kritisiert die Durchsetzung linguistischer Texte mit fremdsprachigen Termini, von denen der Verfasser behauptet, sie seien oft selbst erfunden.

Beispiele:

$\begin{array}{lrr}\text { - obligatomyj } & \text { statt } & \text { objazatel'nyj } \\ \text { - verbal'nyj } & \text { statt } & \text { glagol'nyj } \\ \text { - terminal'nyj } & \text { statt } & \text { konetnyj } \\ \text { - linguist } & \text { statt } & \text { jazykoved }\end{array}$

Die Ursache dafür liegt seiner Meinung nach darin, da dieser Stil als „,wissenschaftlich" gelte, wobei man sich gern auf die sprachliche Form der Artikel in Voprosy jazykoznaniją berufe. Zluktenko sieht keine Berechtigung dafür, daß ein international gültiger Bestand an Termini, der die Kommunikation unter Wissenschaftlern verschiedener $L$ änder erleichtern soll, einseitig aus englischen Termini geschaffen wird. Es werfe ein schlechtes Licht auf die Linguisten, die bei der Aufstellung und Verbesserung terminologischer Systeme für andere Fachbereiche mitwirkten, aber sich nicht im mindesten um ihr eigenes terminologisches System kümmerten, das sich in einem chaotischen Zustand befinde.

P. Reznik: ,Ja z2, no..."

Der Leser P. Reznik aus Stavropol führt an einigen Beispielen vor, daß in rus- 
sischen Wörterbüchern ein Wirrwarr in Bezug auf die Betonungsangaben für ausländische geographische Namen herrsche.

Beispiele:

Slovar' russkoj transkripcii . Slovar' udarenij dlja rabotnikov geografieskich nazvanij:

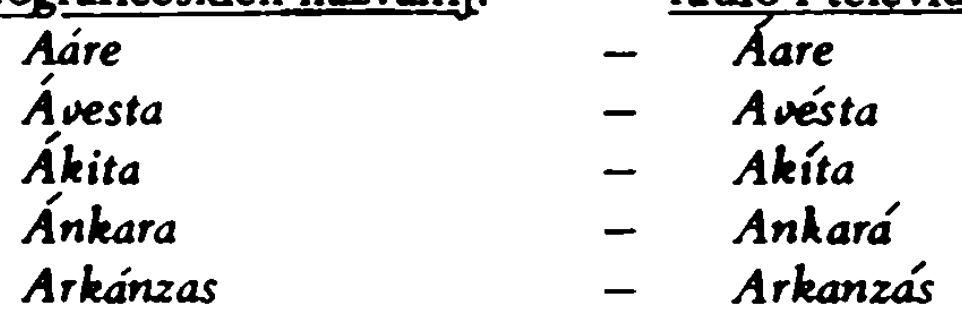

\section{LG 21/71(19.5.71) SLUŽBA RUSSKOGO JAZYKA S. 6}

M. Alekseev/S. Baruzdin/G. Berezko/V. Koževnikov/L. Tat'janičeva: "Zaslon-slovesnoj Y̌eluche."

Am 19.5.71 erscheint ein Aufruf zum Kampf gegen schlechten Sprachgebrauch, der von den Schriftstellern M. Alekseev, S. Baruzdin, G. Berezko, V. Koževnikov und der Schriftstellerin L. Tat'janiževa unterzeichnet ist.

Die Verfasser bedauern, daß Artikel, in denen besorgt die Verschmutzung des mündlichen und schriftlichen Sprachgebrauchs angesprochen werde, leider oft erst dann in der Presse veröffentlicht werden, wenn es bereits zu spät sei, wenn das sprachliche "Unkraut" (sornjaki) sich nur noch schwer „vertilgen" (vypolot') lasse. Hätten 2.B. die Medien schon vor mehreren Jahren darauf hingewiesen, daB die Verwendung von krajnij statt poslednij unangebracht sei, gäbe es heute nicht so viele Leute, die diese Wörter verwechseln.

Nach eigenen Angaben wollen die Schriftsteller mit dem Aufruf „.. . pobudit' sobrat'ev po peru - pisatelej, žurnalistov, rabotnikov radio i televidenija obšximi silami ogradit' russkij jazyk ot urodlivych slovoobrazovanij, kołujuł̌xich iz gazety v gazetu, iz peredači v perdału."

Sechs sprachliche „,Sünden“, werden aufgezählt, die es zu bekämpfen gilt:

1. "amtssprachlich-bürokratische" Wörter und Wendungen (v adres statt Dativobjekt)

2. Ausweitung des Anwendungsbereichs von Wörtern mit urspringlich eng begrenzter Bedeutung:

startovat'

propiska

propisyuat'sja $(\rightarrow$ futbol startoval, startujut zavody, strojki, brigady)

(propiska kluba)

$(\rightarrow$ maxiny, knigi, samodejatel'. nye kollektivy) 
3. „nachlässig bürokratische Wortschöpfungen": zavodčane, zavodXanin, zavodXanka

4. Klischees: beloe, Cemoe, zelenoe, goluboe zoloto

5. unangemessene Verwendung von wissenschaftlichen Termini: orbita ( $\rightarrow$ zavod, trest, strojkal vysla na orbitu plana)

6. mißgestaltete, durch keinerlei sprachliche Normen legitimierte Wortbildungen: plovcicha, geologinja, prorabka

Die Verfasser räumen ein, daß die Schriftsteller dabei nicht ganz unschuldig seien, da diese oft erst über die direkte Rede von Romanfiguren solche falschen Ausdrücke bekannt machten (s kakogo ty goda?). Die angefürten Mängel seien nur die auffälligsten von Hunderten von Argernissen in der russischen Sprache. Die Leser werden ermuntert, eigene Beispiele zusammenzutragen.

\section{Uspenskij: „Moroz krepěal ....“}

L. Uspenskij befaßt sich mit der Sprache der russischen Presse und richtet sich daher vorwiegend an Personen, die in Zeitungen veröffentlichen oder an Rundfunk- und Fernsehsendungen mitarbeiten.

Eine der Todsünden des Zeitungsstils sei die Neigung, Klischees zu verwenden. Er unterscheidet zwei Arten von Klischees, die schmückenden und die „bürokratischen". Als Beispiele für erstere führt er an:

castyj gost' $v$ knižnych magazinach; wentruk podtjanut strojnyj; vametnulis' nad Ob'ju mnogoétaz'nye korpusa;

Als bürokratische Floskel, die kein lebendiges Wort mehr enthalte, bezeichnet er die Formulierung

litevoj stet promystlennikov polnitsja chorołimi trudovymi uspechami.

Der amtssprachliche Stil breite sich in der Alltagssprache wie ein Geschwür aus, was u.a. in dem typisch bürokratischen komplizierten, von verbalen Abstrakta auf eniel-anie überladenen Satzbau zutage trete.

Uspenskij entdeckt daneben "Agrammatismen" in der Zeitungssprache. So tendiere man dazu, Ortsnamen auf ovol-ino nicht zu deklinieren (Zivu $v$ Sofrino, sižu v Melichovo). Viele Leute, die sich um die Reinheit der russischen Sprache sorgten, beklagen nach Uspenskij die Ubertragung des ukrainisch-weißrussischen Suffixes -stina, das zur Bezeichnung von Gegenden um ein Zentrum diene (poltaušcina < Poltava), auf russische Bezirke: Saratouština, Pskoustina. Auch die Bezeichnung Priirtyš'e, eine Analogiebildung nach dem Muster Povolž'e, Pridneprov'e, hält Uspenskij für unzulässig. Die alten Benennungen für Flußnamen legitimierten nicht dazu, für jede beliebige Gegend an einem FluB analoge Namen zu bilden. 
Abschließend legt Uspenskij den Journalisten ans Herz, mit der Sprache vorsichtiger und genauer umzugehen.

\section{LG 25/71 (16.6.71) SLUŽBA RUSSKOGO JAZYKA S. 5}

M. Kurtynin: „Esli ty Zurnalist ...“

Wie M. Kurtynin berichtet, ist der Schriftstelleraufruf von den Leningrader Journalisten aufmerksam gelesen worden und habe darüber hinaus in den Zeitungsredaktionen und Rundfunk- und Fernsehanstalten großes Interesse hervorgerufen. Er sei gerade zur rechten Zeit verfaßt worden, denn die dort angesprochenen Probleme lägen schon lange auf der Hand.

Anders als vor zehn oder zwanzig Jahren habe man sich heute auf einen intelligenten Leser mit breiter Allgemeinbildung einzustellen, den man nicht in einer primitiven, von Klischees, amtssprachlichen Elementen und „Wortunkraut" durchsetzten Sprache anreden könne. Die Bemühung um Sprachkultur gehöre vielmehr zu den Berufspflichten des Journalisten.

Die Zeitungsleser protestierten gegen einen derartigen Sprachgebrauch, wie die riesige Flut an Briefen zeige, die durch leider zu selten in Zeitungen veroffentlichte Artikel zur russischen Sprache hervorgerufen werde.

Nach Kurtynins Information haben die Leningrader Journalisten schon mehrmals auf Konferenzen über sprachliche Schlampigkeit und Floskeln gesprochen, wären dem Problem aber nicht mit der gebotenen Härte begegnet. Sein Verband werde den Schriftstelleraufruf auf der nächsten Vorstandssitzung diskutieren, später müsse dann eine Konferenz aller Leningrader Redaktionen stattfinden. Besonders in den Ausbildungsstätten für Journalisten müsse routinemäßig an der Verbesserung des Sprachgebrauchs gearbeitet werden.

Die LG habe mit der Veröffentlichung der Artikel über Sprachkultur einen äußerst wichtigen Beitrag geleistet. Kurtynin fordert die Redaktion auf, sich diesem Problem ständig zu widmen. Die Rubrik "Služba russkogo jazyka“ solle ein ebenso regulärer Bestandteil der LG werden wie andere feste Rubriken.

\section{LG 29/71 (14.7.71) SLUŽBA RUSSKOGO JAZY
G. Silina
(telefonisch übermittelter Bericht ohne Titel)}

G. Silina berichtet über die von Kurtynin bereits angekündigte Konferenz aller ' eningrader Journalisten unter dem Thema „Kak my pišem, kak my govorim": 
Unter Kurtynins Vorsitz seien etwa 150 Teilnehmer, Beschäftigte bei Presse, Rundfunk und Fernsehen, wissenschaftliche Mitarbeiter des Instituts Jazykoznanija AN SSSR und Dozenten des Lehrstuhls für russische Sprache an der Leningrader Universität, zusammengekommen. Es seien Reden gehalten worden von Ju. Otkupšxikov (dr.fil.nauk), J. Slivker (Mitglied des Redaktionskollegiums der "Leningradskaja pravda“), K. Gorbatevit (wissenschaftlicher Mitarbeiter am Institut Jazykoznanija AN SSSR), K. Rogova (Dozentin an der LGU) und N. Mazendzinova (Redakteurin des Leningrader Rundfunks). Nach Silina waren Floskeln, mißgestaltete Wörter und Wortverbindungen sowie zweifelhafte Neologismen, die die Norm der russischen Sprache verletzen, Gegenstand der Konferenz. Die Versammelten hätten beschlossen, den Dialog über den Sprachgebrauch nicht nur sporadisch, sondern regelmäßig zu führen. Er werde auf Redaktionskonferenzen unter Teilnahme von Schriftstellern und Sprachwissenschaftlern fortgeführt.

\author{
"Idet leturka"
}

Die LG-Redaktion informiert über bisherige Reaktionen auf den Schriftstelleraufruf.

Bei einigen Zeitungen werde auf Redaktionskonferenzen aufmerksamer die sprachliche Form des veröffentlichten Materials untersucht. Die Redaktion der "Lesnaja promyłlennost"“ habe auf den Aufruf hin eine Sonderkonferenz einberufen. Die "Sovjetskaja Sibir"“ melde, in Novosibirsk werde ebenfalls eine Konferenz aller Zeitungen der Stadt durchgeführt. Daneben plane man ein Preisausschreiben für die beste publizierte Ausgabe der Zeitung, bei der Schriftsteller und Linguisten als Jury fungieren sollen.

Auch beim „Ural'skij raboxij" habe eine Sonderkonferenz unter Vorsitz des Leiters des Lehrstuhls für Stilistik der Ural-Universität stattgefunden.

\title{
M. Borisova: „Muki slova“
}

Maja Borisova äußert sich als Schriftstellerin zu dem Aufruf. Dabei vertritt sie die Auffassung, daß in der Lyrik kleine Ungereimtheiten in der Sprache nicht stören, sondern die Individualität des Dichters vermitteln. Gedichte beeinflussen ihrer Meinung nach den Sprachgebrauch des Lesers weitaus weniger als die Presse. 
Da die Medien hauptsächlich der Ubermittlung von Informationen dienten, sei sprachliche Originalität hier völlig fehl am Platz. Oft werden, so schreibt Borisova, Informationen in Form von feststehenden Redewendungen weitergegeben, die man jedoch nicht als Klischees bezeichnen dürfe. Borisova nennt sie zeitungssprachliche Idiome, die es dem Journalisten erlaubten, nicht erst nach passenden Wörtern zu suchen, wenn es auf die schnelle, genaue Wiedergabe von Fakten ankäme. Es lohne sich nicht, über Floskeln wie obed prošel $\checkmark$ teploj, druZestuennoj obstanouke zu polemisieren, da sie an ihrem Platz eine Funktion erfülten. Eine Einkleidung der Information in eine poetische Ausdrucksweise würde eher die Aufmerksamkeit des Lesers vom Inhalt der Information ablenken.

Als echte Klischees beurteilt Borisova vorwiegend in Essays auftauchende Formulierungen wie:

gorod suerkal steklom i betonom;

ego glaza s tščatel 'no skryvaemoj grustinkoj.

Auf den Leser wirkten sie wie ein Signal zum Abschalten der Aufmerksamkeit. $\mathrm{Zu}$ solchen Floskeln würden paradoxerweise oft ursprünglich originelle Wendungen, die dann in einer Flutwelle alle Zeitungen ergriffen.

Die Ursache für sprachliche Mängel sieht die Verfasserin darin, daß der Journalist beim Schreiben nicht den Leser berücksichtigt, den er ansprechen will.

\section{LG 31/71 (28.7.71) SLUŽBA RUSSKOGO JAZYKA S. 6}

N. Vladimirov: „V svoi vorota"

Vladimirovs Artikel richtet sich gegen einen in der "Times" erschienenen Bericht des Moskauer Jimes"Korrespondenten David Bonavia. Laut Vladimirov hat Bonavia in seinem Beitrag das russische Volk lächerlich zu machen versucht, weil es ein Gemisch aus Russisch und entstelltem Englisch spreche (régbi, suitery, mister Chit, biznes, bitniki, džaz, nokautirovat').

Vladimirov pflichtet Bonavia bei, daß die russische Sportsprache viele Termini entlehnt habe, betont aber, daß diese erstens nicht nur englischer Herkunft seien und dies zweitens nicht bedeute, daß die russische Sprache zur Bildung eigener Termini unfähig sei. Der Sport entwickle wie jede Form des Spiels seine eigene Sprache. Jeder der entlehnten Termini könne mit Leichtigkeit übersetzt werden, dann aber verliere der Sport den spielerischen Aspekt gegenüber anderen Beschäftigungen. Englische Sportausdrücke seien im Russischen bereits seit den $30 \mathrm{er}$ Jahren üblich, sie beschränkten sich vor- 
wiegend auf das Gebiet des Fußballs: beki, chavbèki, insajdy, forvardy, golkipery. Nur einige von ihnen seien auch heute noch gebräuchlich, andere haben man inzwischen ersetzt, wie z. B. golkiper durch das "ritterliche" uratar.

Außerdem habe Bonavia behauptet, die Russen hätten mit Entlehnungen wie džaz, bitnik, chippi die kulturelle Dekadenz der Amerikaner übernommen. Damit habe er versucht, seinen Lesern weiszumachen, es gäbe in der UdSSR ebenso viele Beatniks wie Fußballer. Vladimirov wirft Bonavia vor, er wisse genau, daß in der UdSSR die Ausdrücke bitnik und chippi eben deshalb keine russischen Entsprechungen haben, weil die von ihnen bezeichneten Phänomene in der UdSSR nicht existierten, die Ausdrücke also nur zur Beschreibung westlicher Zustän de benutzt würden.

"Priglašenie k razgovoru“"

Mit einer Vorbemerkung zu einer neuen Artikelserie eröffnet die Redaktion die Rubrik ,Jazyk i vremja". Hier wird berichtet, daß auf den Schriftstelleraufruf hin Hunderte von Leserbriefen in der LG-Redaktion eingetroffen seien, die dann kurz kommentiert werden. Einige Leser hätten darauf hingewiesen, daß die angeschnittenen Fragen nur einen kleinen Aspekt der Problematik der russischen Standardsprache ausmachten. Als viel gefährlicher schätzten sie die Nivellierung der Sprache ein, gegen die sich Schriftsteller, Linguisten und alle, denen am Schicksal der russischen Sprache gelegen sei, einsetzen müßten.

Andere Leser beklagten die Ubersättigung der Wissenschaftssprache mit Termini und Fremdwörtern, die sich leider mehr und mehr standardsprachliche Rechte erkämpften.

Die Redaktion berichtet aber auch von Briefen, in denen der Sinn einer Behandlung sprachlicher Probleme in der Presse stark angezweifelt werde. Diese Leser verträten die Ansicht, die Sprachentwicklung liefe spontan im Volk ab und jegliche Versuche, dagegen einzuschreiten, seien zum Scheitern verurteilt.

Beispielsweise beschuldige der Naturwissenschaftler K. Mal'cev die Verfasser des Aufrufs, sie urteilten nach subjektiven Maßstäben und gäben Geschmackswertungen ab. Eine unvoreingenommene Betrachtung von Sprachdiskussionen zeige, daß die Sprache sich völlig unabhängig von deren Ergebnissen oder von Meinungen einzelner Teilnehmer en twickle.

Verabsolutierung eigener sprachlicher Vorlieben zu objektiven Wertmaßstäben für die Richtigkeit des Sprachgebrauchs wirft auch der Ingenieur Krivcov 
den Schriftstellern vor. Urteile über die Sprache dürften nur aufgrund objektiver Tatsachen gefällt werden. Im Zeitungsstil sei die Verwendung von Klischees völlig gerechtfertigt, da nur so eine Information in möglichst knapper Form weitergegeben werden kann.

Aus den sehr unterschiedlichen Leserbriefen zieht die LG-Redaktion den Schluß, es sei unumgänglich, die sprachlichen Probleme weiter zu diskutieren. Sie fordert Leser, Schriftsteller und Linguisten dazu auf, zu den angesprochenen Fragen Stellung zu beziehen.

\section{Lipatov: "Slovo v opasnosti“"}

V. Lipatov beklagt, daß intelligente Leute Wörter wie kožuch, skoren', prjaslo, bososlepyj, gorod'ba, pleten' nicht mehr verstünden, und lastet dies nicht zuletzt den Verfassern von Wörterbüchern an, die diese Wörter mit Hilfe von Zusätzen wie "oblastnoj“ aus dem Standardwortschatz verbannten. Er begrüßt den Schriftstelleraufruf und unterstützt den Kampf gegen die „Wortmißgeburten" (slova-urodcy), für die er eigene Beispiele an führt:

- zaryblenie, senaž, oysli na orbitu plana, rezerv begutestua po časti krasoty;

- ékrany mira - vgosti k nam! spartakiadnyj deržite łag!

- Jargonelemente: brjanku po telefonu, tolkat' rečugu, otkolot' chalmu

Mehr Sorgen als solche sprachlichen Kuriositäten bereitet ihm jedoch die Tatsache, daß die Sprache immer mehr an Ausdrucksstärke und Volkstümlichkeit einbüße. Neologismen bedeuten seiner Meinung nach nicht unbedingt eine Bereicherung des russischen Wortschatzes. Als schlechte Beispiele nennt er den ständigen Gebrauch von pošiv statt šit'e, plantacija statt pole und atel'e statt masterskaja. Ebenso falsch sei prilunit'sja für prizemlit'sja na lune. Viele alte russische Bezeichnungen dagegen seien unter dem Einfluß des Bürokratismus in Vergessenheit geraten: šurin (brat Zeny), dever' (brat muža), pjatialtynnyj, semišnik.

Heute liege die Hauptgefahr im unpersönlichen farblos-richtigen ausdrucksschwachen Sprachgebrauch. Besonders Schriftsteller trügen Verantwortung dafür, daß alle Reichtümer der russischen Sprache bewahrt und in ihren Werken vermittelt werden, denn gerade die Belletristik forme den Sprachschatz der Heranwachsenden. 


\section{N. Atarov: „Zamutilis' li vody?"“}

N. Atarov wirft Lipatov vor, seine Behauptungen widersprächen dem, was 2.B. durch das Buch Kornej Cukovskijs Zivoj kak Zizn' allgemein bekannt sei.

Der Warnung vor der Verarmung der russischen Sprache setzt Atarov die Ubernahme anderssprachlicher lexikalischer Elemente wie z.B. aus den Turksprachen und den westlichen Sprachen entgegen, die dem von Natur aus starken Russischen nicht geschadet, sondern es nur verbessert hätten.

Den Vorwurf Lipatovs gegenüber den Herausgebern von Wörterbüchern weist Atarov entschieden zurück. Bezeichnungen wie "oblastniteskij" und "prostoretie" hätten lediglich die Funktion, auf den Hauptverwendungsbereich der jeweiligen lexikalischen Elemente hinzuweisen.

Atarov vertritt die Auffassung, die Standardsprache dürfe sich gegenüber der lebendigen, expressiven Umgangssprache nicht völlig verschließen.

Anders als Lipatov steht Atarov wissenschaftlichen Termini positiv gegenüber. Es bedeute grade einen Fortschritt in der Entwicklung des Russischen, daß es heutzutage auch für die Kommunikation im Wissenschaftsbereich genügend ausgerüstet sei, was PuYkin noch vermißt habe. Pußkin habe zwar geraten, wissenschaftliche Termini möglichst ins Russische zu übersetzen, um das Russische auch auf diesen Funktionsbereich vorzubereiten, er habe sich aber immer gegen die puristischen Bestrebungen der Siskovisten und anderer fortschrittsfeindlich Gesinnter gewandt. Eine Uberladung des Russischen mit Fachtermini brauche man nicht zu befürchten, denn die Sprache werde selbst mit allem Uberflüssigen fertig.

Der Gebrauch des Fremdworts plantacija statt pole sei nicht an sich falsch. In der Verbindung kofejnaja, tabačnaja, citrovaja plantacija sei pole ebenso fehl am Platz wie plantacija in dem Ausdruck russkoe pole.

Die tatsächlichen Gefahren für die russische Sprache habe bereits Kornej Čukovskij beschrieben: „meščanskoe beskul'tur'e" "naša len', son mysli“", "kanceljarit".

Einige Beispiele für Bürokratismen im alltäglichen Sprachgebrauch:

statt:

liven', grad, rosa, sneg : meteorologičeskie osadki

statt:

kuchnja, ubornaja, koridor : mesta obš̌ego pol'zovanija

statt:

kastrjulja, guozd', utjug: metizy 


\section{ferner:}

\section{strojkontora, zapcasti, kombikorma}

Aus der Amtsprosa gelange all dies über die Presse in die Standardsprache und verlange Aufnahme. Dagegen müsse man kämpfen. Unnötig sei es aber, gegen Fremdwörter, seltene Prostorečie-Elemente oder kurzlebige Jargonausdrücke vorzugehen. Die Sprache reinige sich aus eigener $\mathrm{Kraft}$, indem sie alles Úberflüssige und allen Schmutz abstoße, das Modische und Fremde verjage, das Veraltete ablege und alles Fruchtbringende aufnehme.

\section{A. Kalinin: "Naprasnye strachi"}

A. Kalinin verwirft Lipatovs Einschätzung, Fremdwörter gefährdeten die nationale Grundlage der russischen Sprache. Wie bereits Lenin betont habe, solle man Entlehnungen bekämpfen, die ohne zwingende Notwendigkeit verwendet werden und deshalb die Lektüre des Textes erschwerten. Bei vielen Leuten, die an Fremdwörtern Anstoß nähmen, könne man oft schwerwiegendere Mängel im Sprachgebrauch beobachten.

Aus Leserbriefen und Artikeln, in denen zum Ausdruck komme, daß deren Verfasser glauben, irgendwelche sprachlichen Mängel zum ersten Mal festgestellt zu haben, folgert Kalinin, daß die umfangreiche Literatur zur Sprachkultur nicht genügend verbreitet worden ist. So sei anscheinend weder die Existenz des Handbuchs Pravil'nost' russkoj reti und des Kratkij slovar' trudnostej russkogo jazyka noch die seit 1967 regelmäßig erscheinende Zeitschrift Russkaja re '́ bekannt.

LG 38/71 (15.9.71)

L. Zor'kin : „Nado li sporit'?“"

Der Naturwissenschaftler Zor'kin bezweifelt, daß die derzeitige Diskussion überhaupt einen Einfluß auf die Entwicklung des Russischen ausübt. Stattdessen bewirke sie, daß man nicht mehr unbefangen schreiben könne.

Klischees hält er für notwendig zur Verkürzung der Informationsübermittlung. Statt sie generell zu verdammen, solle man lieber ihren Gebrauch festlegen und dadurch einschränken.

Zor'kin sieht keine Veranlassung zur Sorge um die russische Sprache. Die Probleme, die Lipatov und Atarov ansprechen, bezeichnet er als erfunden und falsch. Weder das Verschwinden einiger Prostorečie-Elemente und Dialektismen, noch das Auftreten von Klischees und Termini, nicht einmal Jargon-Elemente, könnten die russische Sprache beeinträchtigen. Sie werde sich nach 
ihren eigenen Gesetzen entwickeln, und zwar unabhängig von den Bemühungen derer, die sie in die eine oder andere Richtung zwängen wollen.

\section{Cernuchin (Leserbrief ohne Titel)}

L. Černuchin aus Obninsk unterstützt das Vorgehen gegen unnötige Wortschöpfungen und „WortmiBgeburten". Gewisse Schriftsteller trügen in hohem Maße zur Verunreinigung des Russischen bei, denn durch sie fänden Ausdrücke wie cuvicha, s privetikom, do lampočki, prošnymut'sja, połamat' und ähnliche Wörter aus Jargons Aufnahme in Bücher und Zeitschriften. Ein Russe müsse russischsprachige Werke ohne Fachwörterbuch und Ubersetzungshilfen lesen können.

\section{P. Avrachov (Leserbrief ohne Titel)}

Der Leser Avrachov, Spezialist für Sprengarbeiten aus Krivoj Rog, geht davon aus, daß es unmöglich ist, Wörter aus dem allgemeinen Sprachgebrauch auszumerzen. Für jedes Wort fänden sich Anhänger und Gegner.

Es schade nicht, wenn einer seiner Kollegen mangelhaft spreche, da dies nur von wenigen Leuten gehört werde. Die Schriftsteller aber, deren Werke in Hunderttausenden von Exemplaren veröffentlicht werden, sollten nicht supermodern, sondern flüssig und gut, eben russisch schreiben.

\section{V. Žilin (Leserbrief ohne Titel)}

V. Žilin aus Gubkin bekräftigt Lipatovs Behauptung, die Sprache verarme und verliere ihren volkstümlichen Charakter.

Er meint, für den Satz

Po zernu my opredelilis' $k$ urounju prołlogo goda, a po moloku segodnja opredeljaemsja po devjat' kilogrammov na korouru.

(Hervorhebungen im Original)

hätte ein Zeitgenosse Puškins einen Dolmetscher benötigt.

\section{Kas'janova (Leserbrief ohne Titel)}

Als nicht volkssprachlich, sondern als Elemente einer "Lakaiensprache" bezeichnet die Leserin V. Kas'janova aus Moskau folgende Formulierungen:

my obchochotalis'; ja nedostojna, ¿̌tob na menja kričali; on teper' uraščaetsja vokrug masin; pravil'nyj morjačok; vot siž $i$ usju dorogu vojuju s preplatel'scikami; propesolat teper' votk.

Sie erinnert an Gorkij's Vorbild, der die Sprache als bedeutendste Waffe der Kultur angesehen habe, weil sie den Menschen zu Menschenwürde und gegenseitiger Achtung erziehe. 


\section{R. Chodi-Zadè : S tołki zrenija istorizma“}

Als Teilnehmer, dessen Muttersprache nicht Russisch ist, greift der Philologe R. Chodi-Zadé aus Dušanbe in die Diskussion ein. Seiner Meinung nach teilten auch die anderssprachigen Bewohner der Sowjetunion die Sorge um die Reinheit der russischen Sprache, da das Russische als Kommunikationsmittel zwischen den Nationalitäten fungiere. Die russische Sprache sei reich und stark in ihrer nationalen Grundlage und beeinflusse daher in positiver Weise (,,blagotvorno") die Entwicklung vieler Nationalsprachen. So habe das TadZ̈ikische einerseits durch den industriellen Fortschritt, aber auch durch den Kontakt mit der führenden russischen Kultur eine deutliche Bereicherung des Wortschatzes erfahren.

In der derzeitigen Diskussion stoße man leider oft auf polemische Behauptungen, die einer wissenschaftlichen Fundierung entbehrten. Vielfach werde die Problematik zu vereinfacht dargestellt.

V. Petuskov: „Pravil'no li my govorim?“

V. Petuškov rezensiert eine 1971 erschienene Publikation von K.S. Gorbačevič, Izmenenie norm russkogo literaturnogo jaz yka.

Im Unterschied zu vielen Handbüchern zur Sprachkultur, die, wie meist schon Titel wie "Govori pravil'no" oder "Govorite pravil'no" nahelegten, in erster Linie belehrenden Charakter hätten, stelle das Werk von Gorbačevǐ die standardsprachliche Norm als eine dialektisch widersprüchliche und komplexe Erscheinung dar. Tatsächlich sei die Norm zunächst auf die Erhaltung der Stabilität einer Sprache ausgerichtet. Die Sprache aber ändere sich und damit auch die Normen. Die Norm für die mündliche Variante der Standardsprache gründe sich vorwiegend auf die Autorität berühmter Schriftsteller. Daß es absurd ist, Aussagen über die heutige Aussprachenorm durch den Verweis auf die unanfechtbare Autorität der Klassiker abzusichern, will Petułkov an einem Beispiel erläutern:

Nekotorye pljujüt na normy literatumoj reči. Nam, mol, use pozvoleno, my sem'jami tak govorim, nas tak i pochoronjät. Ja vzdrognúl ,uslyšav takoe, no ne stal vystupat' protiv . . . (Unterstreichungen und Betonungszeichen im Original)

Die heutzutage als falsch geltenden Betonungen der unterstrichenen Wörter seien bei den Klassikern zu belegen. Die Standardsprache sei vorwiegend eine Schriftsprache. In der mündlichen Variante verfüge sie über mehrere Spielar- 
ten: den „polnyj stil' ${ }^{\prime \prime}$ für Reden und Auftritte vor groBem Publikum und im Rundfunk, der sich durch möglichst genaue Aussprache (zdra(v)sturite Aleksandr Aleksandrovic) auszeichne, den gewöhnlichen Gesprächsstil (zdras'te Al'san Al'sany C) und das schnelle Sprechen (zdras' San SanyC).

Außerhalb der Grenzen der Standardsprache breite sich unüberschaubar das sogenannte Prostore sem Maße deren Bewegung und deren Normensystem bestimme, obwohl es ihr per definitionem entgegenstehe.

J.P. Jakubinskij habe Ende der 20er Jahre, gefragt, ob man portfel' auf der ersten oder $\mathbf{z}$ weiten Silbe betonen müsse, folgende Auskunft gegeben:

portfél'-predmet, kuda kladut dokumenty, a v pórtfel' ložut dokumenty. S portfélem chodjat, a s pórtfelem chodjut.

Die Verwendung der Präpositionen v oder na in den Verbindungen igrat' v (na) teatr, snimat'sja v (na) studii, slutit' vo (na) flote sei funktionalstilistisch verteilt: $v$ sei standardsprachlich vorgeschrieben, in professionalen Argots werde jedoch na vorgezogen.

Petułkov ist der Ansicht, daß eine ebenso strenge Normierung wie bei der technischen Fachsprache für die Standardsprache den Tod bedeute. Nach Gorbað̌evið̌ liefe unentwegt eine Konkurrenz unter Varianten ab, die man nicht unterbinden könne. Das bedeute jedoch nicht, da $\beta$ man gar nicht in den SprachentwicklungsprozeB eingreifen könne oder dürfe. Man müsse dabei nur die relative Eigenständigkeit der Sprache und die Veränderbarkeit des Normensystems berücksichtigen. Für wichtig hält Petułkov die Beschäftigung mit der mündlichen Variante der Standardsprache. Die allmählich beginnende Erforschung der Umgangssprache müsse gefördert werden.

V. Roždestvenskij: „Osnovanija dlja trevogi est'!“"

Wie der Titel des Aufsatzes zeigt, meint der Schriftsteller V. Rozdestvenskij, es gebe durchaus Anlaß zur Sorge um die russische Sprache. Man könne weder von einem an sich schlechten, noch von einem an sich guten Wort sprechen, denn die Wörter seien alle gleichwertig und erst ihre Kombination mit anderen lexikalischen Elementen könne bewertet werden. Gerade bei jungen Schriftstellern könne man aber beobachten, daß sie noch zu unvorsichtig mit den Wörtern umgingen. Entweder sie hielten sich zu sehr an Vorbilder, ahmten nur nach, oder aber sie wollten um jeden Preis etwas Neues hervorbringen. 


\section{N. Andrijasvin (Leserbrief ohne Titel)}

Der Leser N. AndrijaSvin wirft Lipatov Subjektivismus und Kategorismus in seinen Urteilen über den Sprachgebrauch vor. Der von der LG begonnene Dialog über "Sprache und Zeit" könne aber nur dann zu dem gewünschten Ziel führen, wenn die Teilnehmer tatsächlich die Komplexität der vor ihnen stehenden Aufgaben anerkennten und nicht mit emotionalen Einstellungen operierten, sondern mit einem echten Verständnis für die Entwicklung der Sprache.

\section{G. Tarnaruckij (Leserbrief ohne Titel)}

Der Journalist G. Tarnaruckij aus Abakan teilt Lipatovs Sorge um die russische Sprache, stimmt aber mit dessen Hang zu archaischer Lexik nicht überein. Er betrachtet den Dialog in der LG ebenfalls als positiven Schritt zu einer Verbesserung der Sprachkultur.

\section{E. Seliverstova (Leserbrief ohne Titel)}

Der Brief von E. Seliverstova aus Kurgan richtet sich hauptsächlich gegen den Beitrag von L. Zor'kin. Es sei falsch, sich mit dem heutigen mündlichen und schriftlichen Sprachgebrauch abzufinden, wie es Zor'kin tue, der dazu aufrufe, auf die natürliche Entwicklung der Sprache zu vertrauen. Darauf, daß ein solches Verhalten zur Verschmutzung der Sprache führe, hätten bereits Lenin und Gor'kij aufmerksam gemacht. Sie hält es für dringend notwendig, daß Diskussionen über die Sprache in Literaturzeitungen geführt werden. Derartige Auseinandersetzungen seien stets nützlich.

\section{Andreeva: „Moj drug, moe vtoroe 'ja”“ (Pis'mo v redakciju)}

V. Andreeva hat nach eigenen Angaben lange im Ausland gelebt und daher die Veränderungen, die die russische Sprache in den letzten Jahren erfahren hat, besonders deutlich gemerkt. Einige Veränderungen ordnen sich ihrer Ansicht nach harmonisch in das Sprachsystem ein, andere dagegen müsse man kritisieren:

zautra ja $k$ vam podedu, pošiv, doklady začityuajutsja

Auch sie beobachtet eine gefährliche Tendenz zur Verarmung der Sprache, die aus Gleichgültigkeit und Leichtfertigkeit entstehe. Beispiele aus der Moskauer Umgangssprache sollen ihre Aussage belegen: 
ja nabljudaju nad nim; לto vy na menja ogorčaetes'; Casy obratno ostanovilis'; skol'ko vremja; èto ichnee delo; pervaja popaułaja na glaza masina; lekcii kontrolirujutsja so storony partkoma; ja priłel po Zasti iskusstva; po idee, on dolŽen sejťas obedat'.

Für noch schwerwiegender hält sie unmotivierte Neuschöpfungen bei Schriftstellern:

raş̌irnul glaza; on vyjurknul iz domu; Yorknul po ulicu; moroznym chrumkan'em, zadripannaja papada; udul iz u ǔilišča.

Gegen Verschmutzung und Entstellung der Sprache müsse man mit der Waffe in der Hand vorgehen, als Waffe solle dabei die Feder des Schriftstellers dienen.

F. Birjukov: „O kristallach slov, o slovesnoj pyli“"

Der Sprachwissenschaftler Birjukov geht davon aus, daß die Sprache eine lebendige, schöpferische Kraft darstellt. Zusammen mit dem Neuen, das sie bereichere und noch ausdrucksstärker mache, sammle sich aber auch allerlei "Sprachschmutz" an. Daher sieht er einen Meinungsaustausch, wie er derzeit in der LG stattfindet, für nützlich und notwendig an.

Birjukov unterstützt Atarov in dessen ablehnender Haltung gegenüber puristischen Bestrebungen. Künstliche Barrieren störten nur die freie Entwicklung der Umgangssprache. Atarov habe jedoch ein zu groBes Vertrauen in die Selbsterhaltungskraft der Sprache. So sei z.B. an Fremdwörtern neben Nützlichem auch viel Unnötiges, der Sprache schadendes Material entlehnt worden. Bereits Petr I sei dagegen eingeschritten, indem er für Úbersetzungen Vorschriften angefertigt habe. So habe er sich bei seinem Gesandten über dessen Fremdwörtergebrauch beschwert:

„V reljacijach tvoich upotrebljaes' ty zelo mnogo pol'skie idrugie inostrannye slova i terminy, za kotorymy samogo dela vyrazumet' nevozmožno; togo radi upred' tebe reljacii suoi k nam pisat' use rossijskim jazykom, ne upotrebljaja inostrannych slov i terminov."

Lomonosov, Fonvizin, Sumarokov und Krylov hätten zu ihrer Zeit der Flut von Fremdwörtern ebenfalls nicht teilnahmslos gegenübergestanden. Sie hätten das Notwendige, Unumgängliche entlehnt, aber vor allem in der eigenen Sprache nach neuen Ausdrucksmitteln gesucht und sie gerade dadurch gefestigt und vervollkommnet.

Ohne aktives Eingreifen der mit Recht besorgten Gesellschaft werde die Sprache nicht gereinigt. Sprachkultur müsse aber systematisch gelehrt werden. Birjukov kritisiert die Einschränkung des Literatur- und Sprachunterrichts in 
der Schule. Sogar Schüler, die später Schriftsteller oder Journalisten werden wollten, brächten ständig die Bedeutung einzelner Wörter durcheinander.

V. Solouchin: „Okean rodnoj rełi“"

Solouchin meint, daB weder durch Streitgespräche noch durch Dekrete grundlegende sprachliche Probleme gelöst werden könnten. Die Sprache existiere unabhängig davon, ob Wörter richtig oder falsch ausgesprochen werden. Trotzdem hält er das von der LG initiierte Gespräch für nützlich.

Der Verfasser beschreibe Sprache als eine aus vielen verschiedenen Ebenen bestehende Einheit. In der Realität ließen sich die einzelnen Ebenen nicht deutlich voneinander abgrenzen, weil sich der Sprache Menschen bedienten, die man nicht streng bestimmten Kategorien zuordnen könne. So kämen amtssprachliche Elemente in Romanen vor, Wörter aus den verschiedensten Jargons tauchten in Zeitungsartikeln auf und zeitungssprachliche Ausdrücke wiederum gelangten in Vorträge. Es erfordere ein ausgeprägtes Sprachgefühl, Bildung und Kultur, damit kein derartiges Durcheinander entstehe, wie oft in der zeitgenössischen Alltagssprache auf der Straße, in Geschäften, auf Versammlungen und sogar im Radio.

Solouchin führt den Begriff des Sprachklimas einer Gesellschaft ein, das durch den Ideolekt der einzelnen Sprecher, deren Bildung, Erziehung und Alter geprägt werde. Wenn die Gesellschaft in den SprachprozeB eingreife, hänge das Resultat von den Sprachgewohnheiten und Vorlieben, der Bildung und dem kulturellen Niveau derjenigen ab, die die Regelungen vornehmen.

Als wichtiges Mittel zur EinfluBnahme auf den Sprachgebrauch betrachtet Solouchin die Belletristik. In letzter Zeit klage man oft über eine Nivellierung der Sprache der Literatur, die dadurch farblos, standardisiert und mittelmäßig werde. Der Leser gewöhne sich an den mittelmäßigen Stil und es falle ihm dann schwer, ein gutes, aber sprachlich kompliziertes Werk zu lesen. Um dem abzuhelfen, müsse man das Sprachklima der Gesellschaft ändern. Er habe jedoch keine Vorstellung darüber, wie das geschehen sollte.

Einige Schriftsteller betrachteten als eine Gegenmaßnahme dazu, sich stärker der Volkssprache zuzuwenden, worunter sie jedoch nicht die Sprache der Fabrikarbeiter sondern bäuerliche Sprachformen, Dialekte und Mundarten, verstünden. Hierbei sei die Gefahr, in das andere Extrem abzugleiten, was tatsächlich auch vorkomme. 
Solouchin nennt Lermontov, Puškin, Tolstoj und Čechov als Vorbilder in der angemessenen Aufnahme von umgangssprachlicher Lexik, Archaismen und Dialektismen. Leskov bezeichnet er bezüglich seines Sprachgebrauchs als einmalige Ausnahme, der jedoch nicht alle Schriftsteller nacheifern dürften.

A. Jugov, in dem Solouchin einen Vorkämpfer für die Reinheit der Sprache sieht, befürchte grundlos, daß Zusätze wie "prostorečnoe", „oblastnoe" und „,razgovornoe" in Wörterbüchern den Schriftsteller von einer Verwendung des jeweiligen Lexems abschrecken sollten. Wörterbücher haben nach Solouchins Meinung überhaupt keinen Einfluß auf die Sprache des Schriftstellers.

LG $47 / 71(17.11 .71)$

JAZYK I VREMJA

S. 6

S. Surtakov: „Selucha i jantarnoe zerno“"

In der LG 47/71 meldet sich der Schriftsteller Surtakov zu Wort. Seiner Meinung nach darf man die russische Sprache nicht als Einheit betrachten, sondern muß zwischen Volkssprache, Standardsprache und Informationssprache unterscheiden. In der Informationssprache sei ein immenser Zuwachs an lexikalischen Mitteln sicher als vorteilhaft zu beurteilen, da sie lediglich der möglichst umfassenden Information des Lesers diene.

In der Sprache der Literatur, die den Menschen das Schöne vermitteln solle, könne man es kaum als Bereicherung ansehen, wenn unzählige Termini wie stekloépoplasty, tekstoamidoskoza, asboizobutilenoplastik aufgenommen werden. Surtakov fragt sich, was noch an Russischem übrig bleibe, wenn Tag für Tag neue Termini eingeführt werden.

Zu Atarovs Beitrag bemerkt er, daß derzeit in weitaus bedeutenderem Ausmaße als in allen früheren Entlehnungsepochen Fremdwörter ins Russische eindrängen. Man müssen schon ein sehr großer Optimist sein, wenn man meinte, die Sprache werde damit aus eigener Kraft fertig. Noch betrüblicher sei es, daß mit dem Auftreten von farblosen Termini, amtssprachlichen Ausdrücken, Neologismen, Barbarismen und anderen „Ismen" viele lebendige russische Wörter verdrängt würden.

Heftig kritisiert Surtakov die "Theorie der natürlichen Sprachentwicklung“, ohne die keine einzige Sprachdiskussion bisher ausgekommen sei. Die Behauptung einiger Diskussionsteilnehmer, die Sprache werde vom Volk geschaffen, könne heutzutage, wo das Volk überhaupt keine Beziehung mehr zu der Unmenge neuer Wörter habe, nicht mehr aufrechterhalten werden. Kormodobyuajuščie brigady seien am Büroschreibtisch entstanden, asboizobutilenoplustik habe man im Labor erfunden. Einzelne Neuwörter 
wurden nach Surtakov in erster Linie über deren Aufnahme in die Medien verfestigt. Unter diesen Umständen sei fraglich, ob das gehäufte Auftreten eines sprachlichen Phänomens als Zeichen für seine Verankerung im Volk oder nicht eher als Folge des heutigen Informationsapparates anzusehen sei.

Šurtakov schlägt vor, ein Sprachzentrum einzurichten, das die Bemühungen von Journalisten, Schriftstellern und Lehrern um die Verbesserung des Sprachniveaus der Bevölkerung koordinieren solle. In einem solchen Zentrum, das trotz der Existenz des Institut russkogo jazyka notwendig sei, sollen nach Surtakov Lehrer, Journalisten und Schriftsteller mitarbeiten. Hier solle die Entscheidung darüber fallen, welchen der neuen Wörter Bürgerrechte einzuräumen seien, welche auf Fachsprachen beschränkt bleiben sollen. Surtakov betont, daß die Arbeit des Sprachzentrums nur dann effektiv sein könne, wenn es in engem Kontakt mit den Massenmedien wie Zeitungen, Rundfunk und Fernsehen stehe.

LG $52 / 71(22.12 .71)$ JAZYK I VREMJA

S. 8

V. Kanaక̌ ,,Toð̌ki nad $\ddot{e}^{\prime \prime}$

V. Kanaš fordert in seinem kurzen Beitrag, daß $e$ und $\ddot{e}$ wieder in allen Texten graphisch unterschieden werden. 


\section{E. Vinokurov: „So slovom šutki plochi“"}

E. Vinokurovs Beitrag bezieht sich auf die 1971 von Lipatov eingeleitete Diskussionsreihe (LG 34/71). Er resümiert, da $B$ in der erwähnten Diskussion vorwiegend Neologismen sowie Termini und Bürokratismen in der Zeitungssprache bemängelt worden seien.

Bezüglich Neologismen vertritt er die Auffassung, es sei unnatürlich, alle neuen Wörter, die mit neuen Erscheinungen und Begriffen des 20. Jahrhunderts aufkommen, auszumerzen. Termini werden seiner Meinung nach berechtigterweise gebraucht, umso mehr, als schon Pußkin und Lermontov Begriffe aus der Physik in ihre literarischen Werke aufgenommen hätten. Die Zeitungssprache zu verändern hält Vinokurov für unsinnig, da sie ihrer vordringlichen Aufgabe, der Informationsübermittlung, durchaus gerecht werde.

Was die Sprache der Literatur betrifft, so gehe es nicht darum, sie von fremden Elementen zu reinigen, sondern darum, alle "Schätze der russischen Sprache" in sie aufzunehmen. Wichtigstes Auswahlkriterium sei dabei der Geschmack. Vinokurov spricht von dem ,Zauber", der einem Wort anhaftet, das sich von der "neutralen" Norm losgerissen habe. Er ist überzeugt von der Kraft der Sprache zur Selbstreinigung.

\section{K. Gorbačevið̌: „Vol'nost'? Skoree ołibka"}

K. Gorbað̌evið hebt hervor, daß in den Diskussionen über Sprache häufig die Frage im Mittelpunkt stand, ob die Einhaltung der standardsprachlichen Norm für den Schriftsteller verbindlich sei oder ob Verletzungen der standardsprachlichen Regeln neue Regeln hervorbrächten. Bei der Beantwortung dieser Frage kristallisierten sich unter den Teilnehmern zwei Fronten heraus, nämlich einerseits die der erbitterten Puristen, die jede beliebige Abweichung von der durch Wörterbücher legitimierten Norm ablehnten, und andererseits die der eifrigen Gegner jeglicher Sprachnormierung, die dazu tendierten, die gesamte russische Lexikographie der „Versklavung des Schriftstellerhandwerks" zu beschuldigen. In Vinokurov sieht er einen überzeugten Vertreter letzterer Position. Dessen Aufruf, alle "Reichtümer der Sprache" einzubeziehen, tarne nur die Forderung nach Legitimierung von Normverstößen. 
Im folgenden gibt Gorbał̌evið Beispiele für Normverletzungen bei zeitgenössischen russischen Schriftstellem.

In der Lyrik sei besonders auffallend, daß orthoepische Regeln nicht beachtet würden:

$\begin{array}{lll}\text { okón } & \text { statt } & \text { ókon } \\ \text { izdalí } & \text { statt } & \text { ídali } \\ \text { bagrjanéc } & \text { statt } & \text { bagrjánec } \\ \text { nádolgo } & \text { statt } & \text { nadólgo } \\ \text { alfávitnyj } & \text { statt } & \text { alfavitnyj }\end{array}$

Falsche Betonungen träten gehäuft in den Passivformen des Verbs auf: nepóCatyj, provédennyj, peréžityj, skréplennyj

Zwar sei auch das Akzentsystem Veränderungen unterworfen - so habe zu Puškins Zeiten noch muzýka gegenüber dem heutigen múzyka als Norm gegolten - aber diese Veränderungen folgten bestimmten Gesetzmäßigkeiten, die man nicht ohne Notwendigkeit mißachten dürfe.

Die Zunahme von Normverletzungen in literarischen Werken bezeichnet GorbaYeviX als besorgniserregend. Er befürchtet, junge Schriftsteller könnten mit der Zeit auf einem Recht zu grammatischer Unrichtigkeit beharren, da schon heute einige von ihnen die Grammatik angriffen:
brelok
- Gen.Sg.
brelka
(statt breloka)
jabloni
- Gen. Pl.
jablonej
(statt jablon')

Die oft vertretene Ansicht, eine fehlerfreie Sprache sei neutral und wenig ausdrucksstark, weist er als falsch zurück.

A. Lanščikov: „Ne pokułajas' na normu... .“

A. LanłŁikov äußert sich allgemein zu Sprachdiskussionen. Die Auseinandersetzung um die Frage, ob die Sprache des Schriftstellers streng normgetreu sein müsse oder ob "Freiheiten" erlaubt seien, werde bereits seit längerer Zeit auf den Seiten der LG geführt. Als traditionell bezeichnet er die Positionen der Teilnehmer: auf der einen Seite stünden die Schriftsteller, die sich auf die normierenden Linguisten stürzten, auf der anderen Seite die Sprachwissenschaftler, die von den Schriftstellern die strenge Einhaltung der Normen forderten. Von daher böten die Artikel von Vinokurov und Gorbačevič nichts aufregend Neues. Vinokurovs Aufsatz zeuge aber eher von einem Verständnis für das Wesen der Sprache als der des Sprachwissenschaftlers Gorbačevič, der sich der lebendigen Sprache gegenüber mißtrauisch verhalte. 
Wenn es gelänge, alle Spuren von Unrichtigkeit aus der Muttersprache auszumerzen, so meint Lanščikov, dann erreichte man tatsächlich eine verbesserte, vervollkommnete Sprache wie z.B. das Lateinische. Wie das tote Lateinische höre dann die Sprache auf, auf Veränderungen der Wirklichkeit zu reagieren, sie bliebe in ihrer Entwicklung stehen. Eine Sprache sei aber nur lebendig, solange sie sich verändere, wobei sie sich durchaus nicht an standardsprachlichen Normen vergreife.

Lanłxikov warnt vor allen Versuchen, die Sprache in ihrer natürlichen Entwicklung $\mathrm{zu}$ behindern oder sie in eine festgelegte Richtung zu drängen. Leider seien die Linguisten nicht die einzigen, die auf der Notwendigkeit sprachlicher Reglementierung beharrten. Im folgenden geht Lanščikov auf den 1971 von dem Schriftsteller Surtakov unterbreiteten Vorschlag, ein Sprachzentrum einzurichten, ein.

Derartige Vorschläge ließen sich zum Glück nicht verwirklichen, denn sonst gäbe es bald zwei verschiedene russische Sprachen: das echte, lebendige von vielen Millionen Einwohnern verwendete Russich und die Sprache des Sprachzentrums, gesprochen von weniger als hundert Schriftstellern, Journalisten und Sprach wissenschaftern.

\section{F. Lev: „ל̌cto my ostavim detjam?““}

F. Lev wirft Gorbačevič eine puristische Haltung vor. Man dürfe nicht jede Abweichung von der Norm als Fehler ansehen. Die russische Literatur von Puškin bis Solochov sei voll von derartigen Unrichtigkeiten, für die man den Autoren dankbar sein müsse. Er setzt grammatische Richtigkeit eines Textes mit Ausdrucksschwäche, Neutralität gleich.

Besonders bei Kinderbüchern sei zu beobachten, daß sie in einer normentreuen Sprache verfaßt würden, die jeglichen eigenen Stils en tbehrten. Er kritisiert die für Kinder angefertigten Nacherzählungen der Werke Tolstojs und Gor'kijs, die zwar grammatisch ein wandfreier als die Originale seien, aber vom Stil Tolstojs oder Gor'kijs nichts mehr spüren ließen. Lev kritisiert, daß heutzutage Kinder, weil sie über die Medien mit der Sprache der Erwachsenen konfrontiert werden, viel zu früh lernten, schriftsprachlich zu reden. Dies hemme die Entwicklung ihrer Denkfähigkeit. Gerade Holprigkeiten im Ausdruck zeigten, wie Gedanken entstehen, wie daran gearbeitet werde. Wenn aber fertige Wortblöcke vorhanden seien, brauche man nicht so viel Energie auf das Denken zu verwenden. Daher sei Holprigkeit im Ausdruck viel weniger gefährlich als eine allzu geschliffene, richtige, aber farblose Standardsprache. 
„Kakoj nam nư̌en slovar'?“

Anläßlich des Treffens von Linguisten und Schriftstellern zur Planung eines neuen Akademie-Wörterbuchs führt die LG ein Gespräch mit F.P.Filin, A. Babkin und F. Proťenko als Sprachwissenschaftlern und F.A. Abramov und L. Uspenskij als Schriftstellern.

Im Verlauf der Diskussion begründet Babkin die Notwendigkeit einer Neufassung des Akademie-Wörterbuchs damit, daß der Wortschatz der russischen Sprache heutzutage ungewöhnlich schnell an Umfang gewinne, weshalb das vorhandene 17-bändige Wörterbuch bereits als veraltet gelten müsse. Das Stichwort der "Bereicherung des russischen Wortschatzes" nimmt Abramov auf, um sich gegen die unberechtigte Verwendung von technologischer Terminologie im allgemeinen Sprachgebrauch auszusprechen. Er plädiert dafür, wissenschaftlich-technische Termini nicht in das Wörterbuch aufzunehmen, weil man sie damit zu einem Bestandteil der Standardsprache mache. Filin hält es für eine nicht zu ändernde Tatsache, daß die Fachterminologie in den allgemeinen Sprachgebrauch eingegangen ist. Gleich, ob man dies nun als eine gute oder eine schlechte Entwicklung betrachte, müsse das Wörterbuch dem Rechnung tragen.

Abramov bezweifelt, daß es eine Standardsprache gibt; er hält sie für eine Fiktion, da niemand die normierte Sprache verwende. Er wirft den Sprachwissenschaftlern vor, sie setzten zwischen Umgangssprache und Standardsprache eine viel zu scharfe Grenze an. Seiner Meinung nach soll ein Wörterbuch den tatsächlich üblichen Sprachgebrauch widerspiegeln und nicht das, was man gerne sehen möchte.

Uspenskij wehrt sich gegen den vielbeschworenen Antagonismus zwischen Schriftstellern und Linguisten: kein Sprachwissenschaftler betrachte die Norm als ein der Sprache aufgezwängtes Gerüst, das sie an der Entwicklung hindern soll. Vielmehr sei die Norm eine veränderliche Größe. Er schlägt vor, Laien an der Erstellung des Wörterbuchs zu beteiligen und verweist darauf, daß 1958 "massenweise" von der Bevölkerung angefertigte Wortlisten im Institut jaz ykoznanija eingetroffen seien. Babkin dagegen bezweifelt, $d a ß$ eine Mitarbeit der Bevölkerung ohne vorherige linguistische Ausbildung möglich sei. 
A. Babkin: „Nastojaక̌Čemu slovu - nastojał̌cee mesto“"

A. Babkin lobt die Redaktion der LG dafür, daß sie unter der Rubrik, Jazyk i vremja" rechtzeitig ein inhaltsreiches, lebendiges und nützliches Gespräch über die derzeitige Entwicklung der russischen Sprache ermöglicht hat. Die Beiträge der Teilnehmer beurteilt er als kritisch und offen. Die erwähnten sprachlichen Mittel ließen sich beim Durchsehen der Artikel leicht herausgreifen, verurteilen und „ausrotten“.

Als Todsünde bezeichnet Babkin semantische Ungenauigkeiten, wie sie häufig durch falsche Präfigierung von Verben (zakladyuat' statt vykladyuat', rascenivat' statt ocenivat') oder auch durch die Verwechslung von sumet' und smoč' aufträten.

Babkin verweist auf die von Paustovskij festgestellten Signale für die Verarmung einer Sprache. Dabei nennt er zuerst die Úberladung der Sprache mit Fremdwörtern. Obwohl, so Babkin, der unnötige Gebrauch von Fremdwörtern von allen Diskussionsteilnehmern ausnahmslos kritisiert werde, träfe man trotzdem immer wieder auf nichtberechtigte Fremdwörter. Ein zweiter Mangel bestehe im falschen Wortgebrauch:

$$
\begin{gathered}
\text { maštab, masYtabnyj, masštabnost' } \\
\text { statt } \\
\text { veličina, bol'šoj, ogromnyj }
\end{gathered}
$$

In Dialektismen und Regionalismen sieht Babkin keine Gefahr für die Standardsprache. Er unterstützt den Aufruf der Derevenకtiki (einer Schriftstellergruppe), ,im Meer der bäuerlichen Sprache nach den Perlen des Russischen zu tauchen." Die Verarmung der heutigen Massenliteratur, über die mit Recht von vielen geklagt werde, entstehe durch deren Orientierung an der Umgangssprache.

Babkin hält nichts von Laien, die sich dazu berufen fühlen, an der Normierung der Sprache mitzuwirken ("normalizatory").

Die stilistischen Anmerkungen in erläuternden Wörterbüchern kritisiert er als oft veraltet. Gerade darin begründe sich auch die Notwendigkeit einer Uberarbeitung des Akademie-Wörterbuchs. So sei es verwirrend, kovat als "veraltet" und ,regional" zu bezeichnen, oder etwa prjaslo, gorod'ba, zaplot mit dem Vermerk ,oblastnoe“ zu versehen, als werde nicht jeder Zaun sogar in Leningrad so benannt.

In Artikeln unter der Rubrik ,Jazyk i vremja" habe man schon des öfteren dazu aufgerufen, die russische Sprache von Krankheiten zu bewahren. Leere Worte nützten jedoch gar nichts. Als positives Beispiel führt Babkin ein Komitee in der Georgischen SSR an, das sich um die Reinheit und Richtigkeit 
der georgischen Sprache bemühe, und schlägt vor, ein ähnliches Komitee auch für die russische Sprache zu gründen.

LG $37 / 72(13.9 .72)$

JAZYK I VREMJA

S. 5

M. Vetkovskij: „Vchod osuščest vljaetsja Yerez kalitku“"

Der Verlagslektor M. Vetkovskij beschwert sich über den unnötig komplizierten sprachlichen Stil wissenschaftlicher und technologischer Fachliteratur.

Statt apparat ustanavlivaetsja v lijudnych mestach

hieße es dort:

apparat, prednaznaten dlja ustanovki $v$ mestach $s$ massovym

posesteniem naselenija

statt $v$ plotno zastroennych kuartalach:

- kuartalach s bol'Soj plotnost'ju zastrojki

statt otoplenie v vagonach èlek triceskoe:

otoplenie vagonov osuక̌cestuljaetsja élektronagrevatel'nymi

élementami

Derartige Konstruktionen verderben seiner Ansicht nach die russische Sprache. Vetkovskij beruft sich dabei auf Paustovskij, der ebenfalls auf deren Gefahr hingewiesen und zu ihrer Beseitigung aufgerufen habe.

Gleichzeitig kritisiert Vetkovskij einen Artikel von G. Solganik, in dem die Entwicklung zur Terminologisierung der Sprache als positiv beurteilt werde. Nur zu knappen Wiedergaben komplizierter Sachverhalte hält Vetkovskij Termini für nötig, keinesfalls dürften jedoch elementare Begriffe durch Termini ersetzt werden.

Als schlecht beurteilt er z.B.:

vodoobespecennost'

rusloočiš̌enie

lesopokrytaja plołtad'

doma uysokoj ètažnosti für

für

für

für obespeไennost' vody oxisčenie rusla pokrytaja lesom ploščad' mnogoe tažnye doma

Auch erziele man durch Verwendung von Termini keinesfalls immer eine kürzere Ausdrucksweise, wie es Befürworter von Termini behaupten:

ohne Termini:

mostovaja

gudok

moščenye dorogi

perenoska

čulki i noski mit Termini:

proezžaja Cast' ulicy

zunkovoj signal

dorogi s tverdym pokrytiem

transportirouka ručnym sposobom

čuloŁ̌no-nosočnye izdelija 
Immer seltener höre man heutzutage die Wörter rezervuar, čan und bak, da sie ständig durch das Modewort emkost' ersetzt würden. Außerdem sei eine Vorliebe für das Verb osuščestuljat'sja zu beobachten, das in den letzten Jahren allgemein als Ersatz für andere Verben verwendet werde.

Durch ihre starke Verbreitung übe die technologische Fachliteratur einen immensen Einfluß auf den allgemeinen Sprachgebrauch aus. Deswegen müsse ihre sprachliche Form in den Verlagen einer Kontrolle unterworfen werden.

\section{A. Babkin: „Bogatstva russkoj reči“"}

A. Babkin greift noch einmal in die Diskussion ein, um Leserbriefe zu der Artikelserie, die von der LG-Redaktion an ihn weitergeleitet wurden, zu beantworten.

Dem Eindruck eines Lesers, die russische Intelligenz würdige ihre Muttersprache nicht, widerspricht Babkin. Zwar seien auch heute noch Tadel wegen unnötigem Fremdwortgebrauch angebracht, aber die Mehrheit der Sprecher, und zwar auch der nicht muttersprachlich Russischsprechenden, bemühe sich, das Russische in seiner lexikalischen Vielfalt richtig zu beherrschen. Babkin stellt ein starkes Interesse der Leser an den veröffentlichten Artikeln fest. Nicht nur Schriftsteller, Wissenschaftler und Lehrer verfaßten Leserzuschriften, sondern auch Nichtphilologen, die ernsthaft um das Schicksal des Russischen besorgt seien. Sie alle verbinde das Wissen um die hervorgehobene Rolle des Russischen als Verständigungsmittel zwischen den Nationalitäten der Sowjetunion und auf internationaler Ebene.

Vielfach äußerten die Leser den Wunsch nach einem Wörterbuch, das neben Worterklärungen auch Hinweise darüber gibt, wo und wie das jeweilige Wort $\mathrm{zu}$ verwenden ist. Ebenso beklagten sie, daß viele bereits seit längerer Zeit gängige Ausdrücke nicht in den Wörterbüchern registriert werden. Babkin weist dann nochmals auf die geplante Uberarbeitung des Akademie-Wörterbuchs hin, das vollständiger und vielseitiger als die vorherigen Ausgaben sein und den heutigen Sprachgebrauch widerspiegeln werde.

\section{LG $47 / 72(22.11 .72)$ \\ F. Abramov: ,Jazyk na kotorom govorit vremja"}

Dem Interview mit dem Schriftsteller F. Abramov ist ein Leserbrief vorausgeschickt, dessen Verfasser wissen möchte, ob Abramov, dessen Sprachver- 
wendung nicht immer den Normen entspreche, bewußt von den Normen abweiche.

Im Interview wird Abramov zunächst gefragt, wie er die momentane Sprachentwicklung beurteile und welche Beziehung $z$ wischen Standardsprache und dichterischer Sprache bestehe.

Für den zweiten Teil der Frage verweist Abramov nur auf Gor'kij und Tolstoj und geht dann auf die gegenwärtige Entwicklung des Russischen ein: Weil die Standardsprache heutzutage über die Medien auch in die entlegensten Dörfer gelange, vereinige die ländliche Variante der russischen Sprache heute ursprüngliches altes Wortgut, Dialektismen, Jargonismen, populäre wissenschaftliche Termini und Elemente der zeitgenössischen Sprache der Literatur und der Medien in sich. Die Synthese aus all diesen Sprachschichten ergebe eine besondere nationale Sprachform, die ungewöhnlich ausdrucksstark sei. Die städtische Sprache sei hingegen in bedeutendem Maße nivelliert worden.

Abramov ist der Ansicht, man dürfe keine Angst vor Entwicklungsprozessen in der Sprache haben, sondern müsse sich in sie einfühlen, weil sie die Veränderungen des menschlichen Lebens widerspiegelten. Er verwirft nicht jede Sprachnormierung; wendet sich aber dagegen, daß Schriftsteller in der Auswahl ihrer sprachlichen Mittel eingeschränkt werden. Er negiert die Existenz einer Standardsprache, da kein einziger Sprecher die reine Standardsprache verwende. Stattdessen gebe es eine aus verschiedenen Schichten bestehende Nationalsprache ( ,obక̌tenacional'nyj jazyk").

Nicht in der Verunreinigung der Standardsprache liege das Problem des zeitgenössischen Russisch, sondern im Mangel an Elementen aus der Sprache des Volkes. Darunter verstehe er auch Prostore $X_{i e,}$ städtische Jargons und Fachsprachen. Es sei falsch und gefährlich, solche sprachlichen Elemente mit allen Mitteln abzuwehren und eine zentralgelenkte Wortschöpfung einzuführen.

Nach eigenen Aussagen orientiert sich Abramov in seinen literarischen Werken am zeitgenössischen mündlichen Sprachgebrauch, mit Vorlieben an dem der Dörfer des Nordens.

Obwohl er eine Ausrichtung der Literatur an der Volkssprache befürwortet, hält er nichts davon, gegenüber allem, was die sogenannten ,einfachen Leute aus dem Volk" von sich geben, in Ehrfurcht zu versinken.

Auch Abramov ist überzeugt von der Selbsterhaltungskraft des Russischen und sieht in Verlagslektoren eifrige Verteidiger der Norm, die mit wenigen Ausnahmen immer Puristen seien. 
S. Gazarjan: „Skol'ko vesit slovo?“

Der Journalist S. Gazarjan behauptet in seinem Leserbrief, daß ein technologisches Fachbuch durchschnittlich zu 7\% aus überflüssigen Wörtern bestehe. Als solche bezeichnet er folgende Ausdrücke:

osušcestuljat'sja, proizuodit'sja

s pomose 'ju, rabota po

Er kritisiert Konstruktionen wie:

okazyuajut pomo ̌̌́'/ulijanie statt: prinimat' ućastie

pomogajut/vlijajut

učastvovat'

Statt der einfachen Wörter sejYas, teper', skoro verwende man $u$ nastojał $Y_{i j}$ moment, v nastojastee vremja, v blizajకem budustem.

Um diese sprachlichen Mängel zu beheben, schlägt Gazarjan vor, derartige „Wortparasiten" tabellarisch aufulisten und am Schreibtisch der Verlagslektoren anzubringen mit der Aufforderung an die Lektoren, sie gnadenlos aus den Texten herauszustreichen. Besser noch wäre die Einstellung eines "literaturnyj redaktor", der von dem Geld bezahlt werden solle, das man auf diese Weise an Papier spare. 


\section{Bokov: „Rodnoe slovo, bogatstvo naše"}

Der Schriftsteller V. Bokov geht zunächst auf die Sprache der russischen Literatur ein, wobei er sich hauptsächlich gegen einen schlechten und langweiligen, weil durchschnittlichen, Stil wendet. Als Beispiel für guten Stil nennt er die Werke Prǐ̌vins, Šolochovs und Bloks, ferner Sprichwörter und Volkslieder.

Anschließend kritisiert Bokov Bürokratismen auf Hinweisschildern (perechod na peresadku, russkij Čaj), bei der Benennung von Städten (Novokujbyšeusk statt Novokujbyకev) und in Redewendungen (dobroj noti! statt spokojnoj noti!).

Den Sprachgebrauch einfacher Leute bewertet Bokov dagegen positiv, er sei originell (koni statt losadinye sily) und lebendig.

LG $8 / 73(21.2 .73)$

JAZYK I VREMJA

(Čitateli sporjat)

Die folgenden drei Leserbriefe schließen an eine Diskussion von 1972 an. Die damalige Problemstellung - Mängel in der Sprache der wissenschaftlichtechnischen Fachliteratur - wird im Vorspann von der Redaktion kurz referiert.

M.A. Blochin: „Ne pridetsja li menjat' grammatiku?“

M.A. Blochin, Direktor des Physikalischen Instituts der Universität Rostov, beklagt den zunehmenden Gebrauch von "Wortparasiten" (slova-parazity) wie osuščestuljat', proizuodit' und imejuščiesja und die damit verbundene Substantivierung von verbalen Ausdrücken. Diese Wörter überschwemmten nicht nur die wissenschaftlich-technische Fachliteratur, sondern verunreinigten auch Zeitungen, von wo aus sie in den mündlichen Sprachgebrauch eindrängen. Sie seien $\mathrm{zwar}$ russisch, würden aber in der unrussischen Funktion von Hilfsverben verwendet, wo sie die Flexion von Verben übernähmen. Im Russischen dagegen gebe es Flexionsendungen, die diese Aufgabe erfüllten. $\mathrm{Nach}$ Blochins Meinung verändern derartige Konstruktionen die Struktur der russischen Sprache. Wenn die Massenmedien nicht stärker darauf achseten, 
müsse man bald die russische Grammatik umarbeiten. Dann aber könne die junge Generation weder Puskin noch Tolstoj, ja nicht einmal mehr Solochov verstehen.

Abschließend fordert Blochin die Veröffentlichung einer Stellungnahme von seiten des sowjetischen Kultusministeriums und des Instituts für Sprachwissenschaften der AN SSSR zu diesem Problem.

\section{G. Solganik: „Gnev - plochoj sovetnik“"}

G. Solganik hält eine Bewertung von 1. Proizuoditsja otistka trub ot ržavtiny als schlecht und 2. Truby otišzajutsja ot ržautiny als richtig für unzulässig. Vielmehr bestünden zwischen beiden Ausdrücken erhebliche Unterschiede bezüglich ihres Inhalts, der stilistischen Nuancierung und ihres Anwendungsbereichs.

Die Verwendung von Konstruktionen mit halbabstrakten Verben und deverbalen Substantiven zur Kennzeichnung eines wissenschaftlichen Terminus (1.) in Abgrenzung zur Beschreibung eines konkreten Vorgangs (2.) sei in der wissenschaftlich-technischen Literatur unumgänglich. Eine solche Tendenz zur Terminologisierung, die auf die Präzisierung der wissenschaftlichen Sprache abziele, könne aber, wie jede Tendenz, auch zu Extremen führen. So wäre ein Satz wie Vchod osusčestuljaetsja čerez kalitku falsch, da hier ein alltäglicher, konkreter Vorgang gemeint sei. Seiner Meinung nach geht es also nicht darum, irgendwelche angeblich schlechten Wörter (wie osušCestuljat'sja) aus dem Sprachgebrauch auszumerzen, sondern darum, sie richtig anzuwenden. Oft ignoriere man in Urteilen über die technische Fachsprache deren spezifische Merkmale. Daraus leiteten sich dann Abschaffungs- und Verbotsempfehlungen $a b$, die eine Verarmung der wissenschaftlichen Sprache bewirkten.

\section{A Muchov: „Pora rěsat'!“}

Der Leser A. Muchov bemerkt ein besonders starkes Anwachsen von terminologischen Ausdrücken und fragt, ob man nicht ohne sie auskommen könne. Er unterstützt den 1972 von Gazarjan unterbreiteten Vorschlag, in den Institutsverlagen Sachverständige zur Kontrolle des sprachlichen Ausdrucks der Veröffentlichungen (,literaturnyj redaktor") zu beschäftigen. Vor allem aber müsse das Verantwortungsbewußtsein all derjenigen angehoben werden, die beruflich in irgendeiner Weise mit dem gedruckten Wort zu tun haben. 
F.P. Filin: „Russkij jazyk - problemy real'nye i mnimye“

Die erste Frage Latyninas betrifft die bereits erwähnte Diskussion über Konstruktionen mit deverbalem Substantiv und Hilfsverb in der Sprache der technischen Fachliteratur. Zu Blochins Brief stellt Filin richtig, daß die von ihm genannten Konstruktionen der russischen Sprache keineswegs fremd seien, wie dieser behauptet hatte. Die Ausdrücke imeetsja, proizuodit'sja, osuščestuljat'sja mit Verbalnomen seien nicht an sich schlecht. Ob solche Konstruktionen in einem Text angebracht sind oder nicht, sei eine Frage des Funktionalstils, wie es bereits Solganik in seinem Brief ausführlich erklärt habe.

Man müsse unterscheiden $z$ wischen der allgemeinverwendeten schriftlichen Standardsprache („obł̌eprinjatyj pis'mennyj literatumyj jazyk”) und der jeweiligen Fachsprache. Jede sprachliche Varietät habe ihre besonderen Charakteristika. Dies alles werde in sprach wissenschaftlichen Werken erläutert, vor allem in Wörterbüchern, die jeder Leser sooft wie möglich zu Rate ziehen solle. Filin räumt $z$ war ein, daß nicht jeder die Möglichkeit habe, das 17-bändige Akademiewörterbuch zu benutzen, dafür sei aber das Wörterbuch von Ožegov jedem zugänglich.

Andere Beschwerden, die nach Latynina häufig von Lesern vorgebracht werden, beziehen sich auf die Terminologie in der populärwissenschaftlichen Literatur.

Vor allem kritisiere man die Vorherrschaft der Fremdwörter. Als Beispiele dafür werden erwähnt:

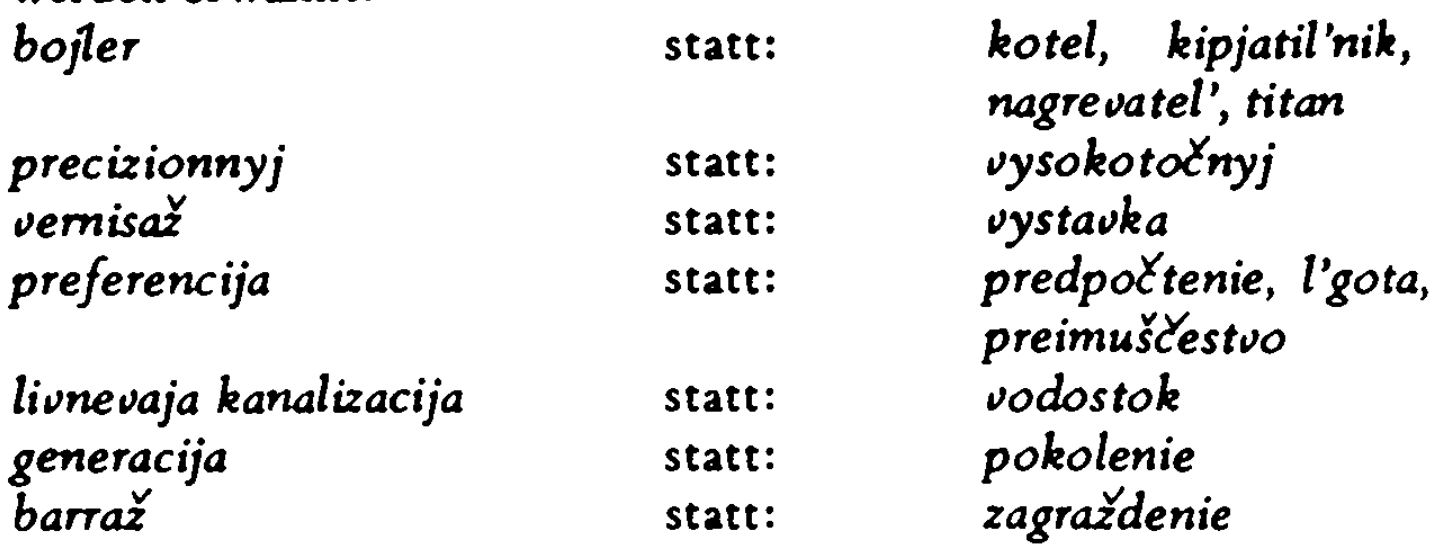

Filin antwortet darauf, man könne nicht mit Verboten gegen Fremdwörter vorgehen. Im übrigen betreffe dieses $P$ hänomen nicht nur die russische $\mathrm{Sprache.}$ So habe der französische Staat unter de Gaulle vergeblich versucht, das Eindringẹ englischer Wörter ins Französische zu verhindern. 
Jeder Wissenschaftsbereich verfüge über eine eigene Terminologie, auf die das Institut russkogo jazyka keinen Einfluß habe. Die Untersuchung und Verbesserung des terminologischen Systems sei vielmehr die Aufgabe der jeweiligen Fachspezialisten. Linguisten sollten sie dabei mit theoretischen Arbeiten zur Wortbildung beraten.

In den Leserbriefen finden sich nach Latynina auch Klagen über eine Verunreinigung der russischen Sprache durch Elemente aus der Umgangssprache. Beispielsweise werden genannt:

- obiletit'

- ozadaxit' (Postavit' zada'u')

- Verwechslung von stat'

$\begin{array}{lll}\text { narezat' } & - & \text { porezat' } \\ \text { nadet' } & - & \text { odet' } \\ \text { veSat'sja } & - & \text { vzuełivat'sja } \\ \text { namoXit'sja } & - & \text { namoknut' }\end{array}$

Ferner registierten sie eine Tendenz zur unnötigen Diminutivbildung(kolbaska, čaek, pivko, syrok). Bemängelt würden auch Elemente aus Prostore Jargons. Hierbei führten die Leser teilweise Beispiele an, die schon bei Cukovskij*, Timofeev** und in linguistischen Abhandlungen erwähnt werden. Latynina folgert daraus, daß diese Werke in der Bevölkerung nicht ausreichend bekannt sind.

Einige Leser forderten energischere als nur aufklärende Maßnahmen. Des öfteren wurde von ihnen vorgeschlagen, Komitees oder Gesellschaften der russischen Sprache zu gründen, die dann eine Kontrolle über die Redekultur ausüben könnten. Als Hauptargument für die Einrichtung solcher Komitees werde die Unfähigkeit der wissenschaftlichen Institute, den Sprachgebrauch wirksam zu beeinflussen, angegeben. Der Journalist BaYmakov aus Ussurijsk habe darauf hingewiesen, daß sich in der UdSSR schon eine beachtliche Zahl von Sprachgesellschaften gebildet hätten, die sich als sehr nützlich erwiesen. Bašmakovs Vorschlag weise der Sprachgesellschaft folgende Aufgabenbereiche zu: Herausgabe und Verbreitung von Literatur zur Sprachpflege; Erstellung von Handbüchern zur Grammatik und Stilkunde; Unterweisung der Bevölkerung im Abfassen von Erklärungen und offiziellen Briefen; Unterstützung der Mitarbeiter in Behörden bei der Herausgabe von Fachliteratur und Dokumenten; Erstellung von Texten für Aushängeschilder und Reklametafeln. 
Filin erinnert daran, daß derartige Forderungen bereits 1971 von Surtakov in der LG erhoben worden sind.* Er hält solche Komitees für funktionslos, da man per Gesetz auf die Sprachpraxis weder einwirken könne noch dürfe. Außerdem zeugten die Vorschläge von der Inkompetenz ihrer Verfasser. Schließlich gebe es bereits ein dem IRJaz angeschlossenes Konsultationsbüro, das Verlagen, Redaktionen und jeder Einzelperson, die irgendwelche sprachlichen Fragen habe, offenstünde. Wichtiger, als die Bevölkerung im Abfassen von offiziellen Schreiben zu unterrichten, sei es, sie zum freien Umgang mit der russischen Sprache anzuleiten. Dies könne aber nicht durch Verbote wie: "Man darf nicht krajnij, moja autobiografija oder prejskurant cen sagen!" erreicht werden, sondern nur durch die Anhebung des allgemeinen Bildungsniveaus.

Latynina weist darauf hin, daß dazu die Medien viel beitragen könnten, wenn dort konsequent richtig gesprochen würde. Außerdem befürwortet sie die sprachliche Kontrolle von Hinweisschildern, Plakaten und Bekanntmachungen. Bezeichnungen wie polomojno-polotemoe atel'e, połivotnaja masterskaja hält sie für unzulässig. Filin erwidert, solche Bezeichnungen beruhten auf dem neuen Selbstverständnis der einzelnen Berufszweige, man müsse sich daher an sie gewöhnen.

Abschließend stellt Latynina die Frage, welche Maßnahmen zur Verbesserung der Orthographie unternommen werden. Viele Leser drängten darauf, daß das in den 60 er Jahren begonnene Projekt zur Orthographiereform weitergeführt werde.

Filin sieht gegenwärtig keinen Anlaß dazu, tiefgreifende Veränderungen am orthographischen System des Russischen vorzunehmen. Eine Rechtschreibung, die keine Mühe macht, gäbe es nicht. Zwar sei es für den Schreibenden am einfachsten, so zu schreiben, wie er spricht. Dadurch werde aber aufgrund unterschiedlicher Aussprachegewohnheiten das Lesen erschwert. Disziplin in der Rechtschreibung bedeute eine Erleichterung der Verständigung. Dabei verweist Filin auf das Englische, wo trotz schwerwiegender Diskrepanz zwischen Orthographie und Aussprache keine Reform durchgeführt worden sei. Man dürfe nicht leichtfertig mit den Traditionen brechen, um die Orthographie zu vereinfachen. Sinnvoller ist es seiner Meinung nach, die Aneignung der Rechtschreiberegeln zu erleichtern. Daran arbeite das IRJaz zur Zeit. Für 1974 plane man, ein umfassendes orthographisches Wörterbuch sowie Handbücher und Broschüren zu verschiedenen Fragen der Rechtschreibung herauszugeben.

- Surtakov $47 / 71$ 


\section{LG 22/73 (30.5.73) ČITATEL' SPORIT S PISATELEM}

\section{B. Procerov: „Naǔ̌no-techniłeskij stil'?““}

Der Leser B. Procerov tadelt die Verwendung von Technizismen in der Belletristik. Der heutige Leser ziehe einen literarischen Text vor, der statt in einem "wissenschaftlich-technischen Dialekt" in der zeitgenössischen Standardsprache geschrieben sei.

Der Verfasser wirft den technischen Termini vor, sie verunreinigten die russische Sprache, weil sie bereits in den mündlichen Sprachgebrauch vorgedrungen seien, wo sie oft nur die Funktion hätten, die Gelehrtheit des Sprechers unter Beweis zu stellen.

LG 27/73 (4.7.73)

JAZYK I VREMJA

S. 6

M. Filimonov: (Čitatel' nedoumevaet)

Der Lehrer Filimonov listet in seinem Brief Beispiele für Normabweichungen auf:

- krajnij (v očeredi)

- schodit'(s tramuaja)

- skazat' kak projti na takuju-to ulicu

- podskazat'

- mesjačnik po zaščite ptic

- vypolnjat' pravila

- chochotat'do kolikov

Besonders stören ihn Fehler in der Belletristik, da er in der literarischen Sprachverwendung einen vorsichtigen Umgang mit den Sprachnormen für geboten hält. Er fragt, von wem man sonst die Sprache lernen solle, wenn nicht vom Schriftsteller.

\section{A. Kalinin: „Ne edinoj merkoj“}

A. Kalinin, Dozent für Journalistik an der Moskauer Universität, bedauert, daß in Diskussionen über Fragen der Sprachkultur üblicherweise die stilistische Differenzierung der Standardsprache unberücksichtigt bleibe. Er weist darauf hin, daß ein und dieselbe sprachliche Erscheinung in einem Redestil deutlich als Fehler, in einem anderen Kontext aber als normal empfunden werden kann.

Im weiteren erläutert er die Verschiedenheit von Funktionalstilen, indem er die Sprache der Literatur der Umgangs- und Zeitungssprache gegenüberstellt. 
Dabei sei jedoch der Unterschied nicht derart kraß anzusetzen, wie es die Imaginisten in ihrem Manifest ${ }_{n}$ Počti deklaracija" behauptet hätten, die der Sprache der Literatur die Merkmale Bildhaftigkeit, Reinheit der Sprache und Harmonie zugeordnet, die Zeitungssprache andererseits als barbarisch, nicht bildhaft und arhythmisch abqualifiziert hätten. Der heutige Zeitungsstil habe bereits viel von der Expressivität des Gesprächs und der Bildhaftigkeit der Belletristik übernommen. Umgekehrt fänden ebenso zeitungssprachliche Ausdrücke Aufnahme in die Belletristik.

Kalinin findet es erfreulich, $\mathrm{da} B$ in der letzten Zeit bei vielen Lesern das Interesse an ihrer Sprache gewachsen sei, da der Kampf um die Reinheit der eigenen Sprache nur mit vereinten Kräften geführt werden könne.

\section{LG 30/73 (4.7.73) \\ NAUČNO-TECHNIČESKAJA LITERATURA - CELOVEK - LITERATURA}

M. Kolesnikov: „Novye obrazy - novyj jazyk“"

Der Beitrag von M. Kolesnikov über Technizismen in der Belletristik steht im Zusammenhang mit einer Artikelserie über die literarische Verarbeitung der wissenschaftlich-technischen Revolution.

Kolesnikov geht davon aus, daß es im Zeitalter der technologischen Revolution unumgänglich sei, auch komplizierte technische Vorgänge in literarischen Werken zu beschreiben, da der Arbeitsplatz einen wichtigen Bestandteil im Leben des Menschen darstelle. Folglich seien Technizismen in der Sprache der Literatur notwendig. Er beruft sich dabei auf Untersuchungen von Soziologen, die ergeben hätten, daß bei einem Vermeiden der technischen Termini Texte über soziale und wissenschaftliche Problematik erheblich an Verständlichkeit einbüßten. Kolesnikov sieht in Technizismen Wörter und Begriffe, die mit dem alltäglichen Leben eng verbunden sind und daher die Sprache nur bereichern können. Die Frage, ob dem Leser ein Text, in dem Technizismen vorkommen, verständlich sei, bejaht er mit dem Hinweis dar auf, $\mathrm{d} a ß$ der Leser selbst diese Sprache aktiv verwende. Leider stünden aber einige Kritiker, die überkommenen Vorstellungen verhaftet seien, fest auf dem Postament der Norm; jeder neue Begriff, der in literarische Werke eingeführt we rde, rufe bei ihnen einen stürmischen Protest hervor.

Positiv erwähnt Kolesnikov den Prozeß der allmählichen Assimilierung von Fremdwörtern, die bald völlig integriert sein werden. 


\section{A. Čudakov: „と̌ivoe slovo i kanony chrestomatij“}

Čudakov befaßt sich mit der Auswahl von muttersprachlichen Texten für den Schulunterricht und tadelt dabei, daß meist Texte bevorzugt werden, die in einem streng normgetreuen, neutralen buchsprachlichen Stil gehalten sind. Er vermißt in ihnen das "lebendige Wort der Volkssprache". Die Standardsprache, so argumentiert er, werde den heranwachsenden Kindern früh genug über die Medien vermittelt. Die lebendige Volkssprache lernten sie dagegen meist erst nach der Gewöhnung an die Standardsprache kennen, so daß sie keine echte Beziehung mehr zu ihr aufbauen könnten. Zur Verbesserung schlägt er vor, an Stelle von zeitgenössischen Texten von Journalisten eher Auszüge aus Werken von Tolstoj, Aksakov oder Prišvin aufzunehmen und auch Sprichwörter und Scherzverse einzubeziehen. Nur so könne der bereits erhebliche Unterschied zwischen der Sprache des Kindes in der Schule und beim Spiel wieder aufgehoben werden.

Cudakov kritisiert ferner die Anpassung von Texten aus früheren Epochen an die zeitgenössische Sprache (z.B. werde bei Tolstoj plat'e durch odezda ersetzt), die man mit Verständnisschwierigkeiten der Schüler rechtfertige. Tatsächlich hätten jedoch psycholinguistische Untersuchungen gezeigt, daß Kinder weit mehr begreifen, als allgemein angenommen werde. Wichtig sei vor allem, daß das Kind in seinem ersten Buch nicht mit einer sterilen, vereinfachten Sprache konfrontiert werde, sondern mit dem lebendigen Wort der Folklore und berühmter Dichter.

Der Sprachunterricht müsse neu durchdacht werden. Früher, als die Schule eine von Dialekten umgebene Insel der Standardsprache gewesen sei, habe sich der Spachunterricht sinnvollerweise auf die Vermittlung der Standardsprache konzentriert. Heute, wo es fast gar keine reinen Dialekte mehr gebe und der größte Teil der Kinder bereits im sterilen sprachlichen Milieu der Stadt aufwachse, müsse die Schule vordringlich die lebendige Sprache lehren.

LG 43/73 (24.10.73)

JAZYK I VREMJA

S. $6 / 7$

I. Fonjakov: „Sadis', MaŠn'ka, pjaterka!“”

Der Beitrag des Schriftstellers I. Fonjakov behandelt das Niveau der Sprachverwendung in der Schule, an Universitäten, bei Schriftstellern, in sonstigen Publikationen und auf Hin weisschildern. 
Fonjakov ist der Ansicht, daß bei Schülern und Studienanfängern durchweg ein zu niedriges sprachliches Niveau feststellbar sei. Neben Stilblüten wiesen Schulaufsätze eine große Zahl von grammatischen und orthographischen Fehlern auf. Häufig sei beispielsweise die Verwechslung von ola und $e / i$ in vortonigen Silben anzutreffen (sein Beispiel: salist arkestra felormonii). Die Tatsache, daß Examensarbeiten von Philologiestudenten of orthographisch zufriedenstellend seien, sei allein darauf zurückzuführen, daß sie in der Schule gelernt hätten, nur solche Wörter in Aufsätzen zu verwenden, von denen sie wïßten, daß sie sie richtig schreiben könnten. Bei einem Diktat müsse man zu 50\% mit mangelhaften Ergebnissen rechnen. Aufsätze enthielten dagegen eher stilistische Unsauberkeiten.

Trotz Auswahl bei der Aufnahme von Studenten gelangten noch viele nicht mit den literatursprachlichen Normen vertraute Schulabgänger in die Universitäten. Solch ein Student könne sein Diplom erhalten, ohne seinen Sprachgebrauch im geringsten verbessert zu haben. Die Einschätzung, wonach nur Philologen und speziell Russischlehrer und Schriftsteller sich um ein hohes sprachliches Niveau bemühen müßten, lehnt Fonjakov strikt ab. Schlechter Sprachgebrauch ist für ihn ein Indiz für unterentwickelte Denkfähigkeit.

Im weiteren geht der Verfasser auf sprachliche Mängel in der Belletristik ein. Als Beleg führt er "Fehler" in Texten von Astafev an:

- polegat' (bezogen auf eine Person)

- oruźejnyj (statt ružejnyj) ogon'

- chlopalis' Zelezno plaśč-palatki pod vetrom statt: chlopali slouno Keleznye pod vetrom

- gorlo ego porezanno dergalos', vyžimal slezy i klejkuju sljunu

- skol'ki zuezd suetilis'

- parovozno pychtit (statt pychtit kak parovoz)

- razljubeznyj (statt očen' ljubeznyj)

In Publikationen der großen Verlage müsse man heutzutage alle möglichen Fehler entdecken: z.B. diskussirovat', umerకtuil, perekonstruiroval (statt rekonstruiroval). Diese, so Fonjakov, besorgniserregenden Erscheinungen seien in einer von ihm durchgeführten Umfrage folgendermaßen begründet worden:

Angesichts der Bemühungen um die Entwicklung der Technologie werde der Sprache und der Literatur nur noch wenig Aufmerksamkeit geschenkt. Die Zahl der Unterrichtstunden im Fach Russisch sei zu gering bemessen, die Klassen mit 40 - 50 Schülern überfüllt. Der Sprachunterricht sei zu theore tisch ausgerichtet. Ein weiterer Grund werde im schlechten Einfluß des Fernsehens gesehen, der dazu führe, daß die Kinder nur noch wenig lesen und schreiben.

Abschließend kritisiert Fonjakov, daß die bei vielen vorhandene Sorge um die russische Sprache of in falsche Bahnen gerate. So habe man zu viel 
Zeit und Mühe im unnötigen Kampf gegen die Fremdwörter verloren. Zur zeitgenössischen Sprache gehöre industrija ebenso selbstverständlich wie promyšlennost'.

LG $46 / 73(14.11 .73)$

S. Zalygin: „O ,kul'ture vyvesok' i urokach stilistiki“"

Der Schriftsteller S. Zalygin weist die Vorwürfe Fonjakovs gegenüber Astafevs Stil entschieden zurück, indem er Belege für die Anwendbarkeit der von Fonjakov als Fehler bezeichneten Ausdrücke anführt. Er räumt ein, daß stilistische Unreinheiten auch bei Schriftstellern vorkommen. Man müsse aber unterscheiden zwischen Mängeln, die beim Bestreben, neue Wörter und Wortverbindungen $z u$ bilden, entstünden, und denen, die auf der allzu starken Orientierung an Normen und Traditionen beruhten. Während im ersten Fall auch stilistisch gute Ergebnisse erzielt werden könnten, sei letzteres Vorgehen völlig perspektivlos. Zalygin wirft Fonjakov vor, dieser erhebe seinen subjektiven Geschmack zum Maßstab für sprachliche Richtigkeit.

\section{B. Korostyleva: „Bagrjanaja zol'?“"}

Die Lehrerin B. Korostyleva teilt Fonjakovs Sorge um das Sprachniveau von Schülern, sie stimmt aber nicht mit ihm überein, daß es sich in den letzten Jahren katastrophal verschlechtert habe, sondern stellt eine Tendenz zur Verbesserung fest, die aber nicht schnell genug fortschreite.

Die Schuld für die sprachlichen Unzulänglichkeiten der Schüler werde zumeist den Lehrkräften angelastet. Das sei aber nur bedingt gerechtfertigt. Den Russischunterricht hält sie insofern für unzureichend, als hier den Schülern vorwiegend Regeln zur Orthographie und zur Interpunktion eingepaukt werde, obwohl viel wichtiger sei, bei ihnen ein Sprachgefühl zu entwickeln, damit sie die Regeln selbständig anwenden könnten.

Andererseits werde das Sprachgefühl des Schülers, der bereits die Grundzüge der russischen Sprache beherrsche, stärker durch die Sprachverwendung der Eltern, Freunde, vor allem aber der Medien ausgebildet. Besonders die Medien verhielten sich in ihrer Sprachverwendung nicht gerade vorbildlich. Korostyleva kritisiert deren schematisierte Ausdrucksweise und das Vorkommen von Normverletzungen wie fanaty statt fanatiki. 
Was die Belletristik anbelangt, so beklagt sie den freien Umgang einiger Schriftsteller mit grammatischen Formen.

Beispiele:

- Spixki est'/ tabak naidem/ bol'sevik/ taptat' idem!

- bagrjanaja zol'(zola)

Von Schriftstellern und Journalisten erwartet sie ein ausgeprägtes Verantwortungsbewußtsein in bezug auf ihren Sprachgebrauch, da sie das Sprachgefühl eines großen Bevölkerungsteils beeinflußten.

E. Vinokurov: „Čistopisanie ili bol'šaja literatura?"“

E. Vinokurov, der ebenfalls aut Fonjakovs Artikel antwortet, meint, der Grad der Normtreue von literarischen Texten sei nicht etwa abgesunken, sondern im Gegenteil gestiegen. Eben diese Durchschnittlichkeit und Neutralität literarischen Stils bewirkt seiner Meinung nach eine Verschlechterung der Sprachkultur der Bevölkerung. Der Künstler müsse neue Formen entwickeln und von Schablonen abweichen. Das damit verbundene Risiko hätten große russische Schriftsteller (PuY̌kin, Tolstoj, Gogol', Esenin) nie gescheut. Heutzutage aber tendiere man immer mehr zu einer Standardisierung der Sprache.

Vinokurov hält es für falsch, den Verlagslektoren bei der Bearbeitung literarischer Vorlagen zu viel Macht einzuräumen. Man solle eher dem Sprachgefühl des Schriftstellers vertrauen.

\section{Nikolaev: „E் to volnuet vsech“}

Der Ingenieur Nikolaev resümiert in seinem Leserbrief, daß sich in der Diskussion zwei verschiedene Einstellungen zur Sprache der Belletristik gegenüberstünden. Einige Teilnehmer gestünden dem Schriftsteller uneingeschränktes Recht zu sprachlichen Experimenten zu, während andere jegliches Abweichen von der Standardsprache als Verletzung der Norm strikt ablehnten. Er schlägt vor, sich in dieser Frage an den Aufrufen Gor'kijs zum Kampf für die Reinheit und Richtigkeit der russischen Sprache zu orientieren. 
A. Kalinin: „Kak slovo naše otzovetsja“"

A. Kalinin faßt Ergebnisse einer Untersuchung von Schulbüchern für das Fach Literatur zusammen. Dabei wirft er den Autoren vor, sie zählten vorwiegend Plattheiten und Phrasen auf, meist ohne Belege für ihre Aussagen anzufuhren. Die Verwendung von umgangssprachlichen Elementen werde einmal als positiv und dann wieder als negativ gewertet. Kalinin verzeichnet eine negative Einstellung der Schulbuchautoren gegenüber Dialektismen. Sie gingen davon aus, da $B$ die Verwendung von Dialektwörtern einen Text unverständlich mache. Um nun aber die dialektale Lexik bei einem Dichter wie Nekrasov zu erklären, setzten sie dem negativ belasteten Begriff "Dialektismus" den positiv bewerteten Begriff "volkssprachliches Wortgut" (,narodnaja leksika“) entgegen.

Abschließend geht Kalinin auf Fonjakovs Beitrag ein. Er erwähnt, daß die von Fonjakov bemängelte Schreibung diskussirovat' in zeitgenössischen Wörterund Handbüchern neben diskutirovat' als standardsprachlich anerkannt werde. Zur Anhebung des sprachlichen Niveaus bei Schülern sei es erforderlich, daB in jedem Unterrichtsfach bei den schriftlichen Arbeiten auch der sprachliche Ausdruck bewertet werde.

1. Klenickaja: „Ne nado zubrę̌li!!“

Abschließend meldet sich noch einmal eine Lehrerin für das Fach "Russische Sprache und Literatur" zu Wort. Auch sie begründet, wie bereits Fonjakov, die mangelnde Sprachbeherrschung bei Schülern mit der zu theoretischen Ausrichtung des Russischunterrichts. Die Schüler müBten sich eine Menge von Wissen aneignen, das sie weder für die Rechtschreibung noch für ihren sprachlichen Ausdruck gebrauchen könnten. Durch die Uberladung des Unterrichtsprogramms mit theoretischem Lernstoff bliebe nur noch wenig Zeit für Rechtschreibeübungen. Sie berichtet von einer Kommission, die in der Schule, an der sie lehrt, bei theoretisch geschulten Kindern größere sprachliche Unsicherheiten festgestellt habe als bei solchen, die mit der Theorie nicht zurechtgekommen waren. Daher schlägt sie vor, in der Schule dürfe nur noch so viel Theorie vermittelt werden, wie es zur Ausbildung eines fundierten Sprachbewußtseins unbedingt erforderlich sei. 
N.T. Fedorenko: ,Ne perevesti li na russkij?““

Der Literaturwissenschaftler Fedorenko mißbilligt in seinem Aufsatz das Uberhandnehmen von Fremdwörtern in literaturwissenschaftlichen Abhandlungen.

Fedorenko spricht sich nicht grundsätzlich gegen Fremdwörter aus. Den maßvollen und zielgerichteten Einsatz fremdsprachlicher Terminologie hält er besonders in Naturwissenschaft und Technik für notwendig. Er trennt auch internationale Termini (kibernetika) von solchen, für die es bereits ein russisches Aquivalent gibt (transplantacija : peresadka). In der Literaturwissenschaft, die eine ausreichende russische Terminologie besitze, findet er die ständige Verwendung von Fremdwörtern unangebracht, die nicht nur dem breiten Leserkreis, sondern auch Literaturwissenschaftlem das Verständnis literaturwissenschaf tlicher Abhandlungen erschweren.

Er erinnert daran, daß gerade bedeutende Schriftsteller und Literaturkritiker gegen die Ubermacht der Fremdwörter im Russischen eingeschritten seien, und zwar nicht nur Slavophile (Dostoevskij und Tolstoj), sondern auch Westler (Turgenev, Gercen und Belinskij).

Eine ungewöhnlich starke Ausbreitung hätten folgende Wörter erfahren:

- éskalacija, deéskalacija, antieskalacija, kontréskalacija

- trend, sékuljarizacija, diskretnost', detant, interpersonalizacija, dominanta, konformizm, nonkonformizm, mass medija, isteblišment, cheppening, bestseller

In erster Linie beanstandet Fedorenko jedoch Aneinanderreihungen von Fremdwörtern wie:

- metodologičeskaja koncepcija èstetičeskogo progressa,

die seiner Meinung nach den Inhalt eines Textes vernebeln.

LG $11 / 74(13.3 .74)$

(Jazyk moj - vrag moj)

S. 6

A. Petrova: „Ne nazvat' li košku koškoj““

Die Dozentin Anastasija Petrova richtet sich gegen die falsche Ubernahme 
von Fremdwörtern. Ihrer Meinung nach gelangen Fremdwörter auf zwei verschiedenen Wegen in die russische Sprache. Während Fachleute Termini aus Fremdsprachen vorwiegend in ,richtiger" Form einführten, brächten sprachlich unzulänglich gebildete Leute viele Wörter mit falscher Schreibweise und Bedeutung ein.

Beispiele:

- engl.nylon : russ. a) najion (wiss. Terminus)

b) rejlon

Das orthographische Wörterbuch verzeichne beide Formen mit der Betonung auf der letzten Silbe, während das enzyklopädische nur nájlon angebe.

- tschech. kalhotky : russ. kolgotki

- e(k)spander: Moskauer Produkt:

Rigaer Produkt:

- poetki

statt:

- filomentnyj

statt:

- meofonija

statt:

- džajf (,Tanz')

statt:

ekspander

espander

pajetki, blestki

filamentnyj

miofonija

dzajo ('Jazzstil')

Petrova fordert, da $\beta$ Wissenschaftler künftig bei der Ubernahme von Fremdwörtern eine aktivere Rolle spielen, damit die Entlehnungen in richtiger Form und Bedeutung in den russischen Wortschatz eingehen.

LG $16 / 74(17.4 .74)$

JAZYK I VREMJA

S. $6 / 7$

Der Beitrag des Lesers Fedorenko hat laut LG-Redaktion großes Interesse unter den Lesern der LG hervorgerufen. Briefe, die daraufhin an die LG geschrieben wurden, leitete die Redaktion an den Direktor des IRJaz F.P. Filin weiter, der in der Nr. 16 auf diese Briefe antwortet.

\section{F.P. Filin: „Kogda i kak perevodit'na russkij?““}

Filin erläutert, daß die Frage, ob das massenhafte Einströmen von Fremdwörtern besorgniserregend sei, unterschiedlich beantwortet werden müsse, je nachdem, ob sie sich auf die von der ganzen Bevölkerung verwendete Standardsprache oder auf eine Fachsprache beziehe. Er geht im folgenden zunächst auf Fremdwörter in Fachsprachen ein.

Um die sprachliche Gestaltung einer fachspezifischen Abhandlung zu beurteilen, müsse man sowohl das terminologische System des jeweiligen Wissensgebietes als auch das Thema der Abhandlung, ihre Adressaten und die 
Auflagenhöhe berücksichtigen. Terminologische Systeme müßten den Gesetzen der russischen Sprache entsprechen, denn völlige Willkür bei der Erstellung von Termini begünstige ein sklavisches Kopieren der fremdsprachigen Terminologie. Belege dafür seien Wörter wie:

- serial, najlon, displej, bojler, brojler, suip generator, vobulator

Filin lehnt es jedoch ab, einmal falsch eingebürgerte Fremdwörter kategorisch auszubessern. Viele solcher „Falsch"entlehnungen seien bereits seit langer Zeit integrierte Bestandteile des russischen Wortschatzes (z.B. galstuk statt chal'stuch, Šaromyžnik statt Y̌eramižnik). Wollte man alle derartigen Wörter, deren fremdsprachige Herkunft den Sprechern oft gar nicht mehr bewubt sei, abändern, müsse man bald ein neues Fremdwörterbuch herausgeben.

Filin kritisiert, daß bei der Bildung von Fachtermini die vielfältigen Möglichkeiten der russischen Wortbildung meist unbeachtet bleiben, was dazu führe, daß selbst Spezialisten Texte ihres Fachbereichs nicht mehr verstünden. Eine derartige Verantwortungslosigkeit sei besonders schwerwiegend, weil Fachterminologie und standardsprachliche Lexik nicht durch eine undurchlässige Mauer voneinander abgeschlossen seien. Vielmehr stelle im Zeitalter der wissenschaftlich-technischen Revolution die fachsprachliche Lexik eine der wichtigsten Quellen zur Auffüllung des Wortbestandes der allgemeinen Standardsprache dar. Dies beweise das Lexikon Novye slova i znaCenija*, denn fast alle dort verzeichneten Neologismen seien aus der Fachterminologie in den allgemeinen Sprachgebrauch übergegangen, ca. $70 \%$ davon aus Fremdsprachen entlehnt. Besorgt stellt Filin fest, der fremdsprachliche Einfluß sei seit Puskin nicht mehr so stark gewesen wie derzeit.

Nicht einmal der schlimmste Purist leugne heute die Notwendigkeit des Gebrauchs von fremdsprachiger Terminologie, denn die Zeit der SiłkovAnhänger und sonstiger Slavophiler sei endgültig vorbei. Fatalistisch sei aber die Vorstellung, die russische Sprache könne wegen ihres gesunden Grundgerüstes den Angriff von fremden Wörtern wie schon mehrmals so auch jetzt aus eigener Kraft abwehren. Die Tatsache, daß die russische Sprache den großen Ansturm von Wörtern aus westeuropäischen Sprachen unter Petr I verkraftet habe, dürfe man nicht als Resultat eines ausschließlich spontan innerhalb der Sprache verlaufenden Prozesses auffassen, denn um das Schicksal der russischen Sprache seien erbitterte Auseinandersetzungen geführt worden. Dank Pułkins Genie habe sich eine einheitliche Standardsprache mit deutlicher Eigenständigkeit bilden können, die altslavische Relikte und westeuropäische Sprachkultur einbezogen und assimiliert habe. Bei der Weiterentwicklung der russischen Standardsprache sei das Sprachschaffen von Schriftstellern, Wissenschaftlern und Publizisten dominierend 
gewesen. Als wesentliche Elemente nennt Filin dabei die Einbeziehung der Volkssprache, maßvolles Einführen von fremdsprachigen Elementen und zielgerichtete Bewahrung der Standardsprache vor jeder Art von Verschmutzung.

Filin befürwortet ein ständiges aktives Eingreifen in die Sprachentwicklung. Leider sei bei der Festsetzung von Termini alles dem Zufall überlassen; niemand kümmere sich um eine Regulierung. Der Kontrolle des Gosstandart unterlägen nur etwa $20 \%$ der Normensysteme. Meist würden Termini von Leuten aufgestellt, die nur sehr unklare Vorstellungen von den Gesetzen der russischen Wortbildung hätten. Die Linguisten könnten nicht eingreifen, weil es bisher kaum auf diese Arbeit vorbereitete Spezialisten, nämlich „russistische Terminologen" gäbe. Um diesen Zustand zu überwinden, fordert Filin die intensive Ausbildung von Linguisten in terminologischen Fragen und die Schulung von Spezialisten aller Wissenschaftszweige in den Regeln der Wortbildung. Im Bewußtsein dessen, daß solche Forderungen unrealistisch sind, prophezeit er resigniert, da $\beta$ vorläufig noch Tausende von vermeidbaren Fremdwörtern ins Russische eindringen werden.

Anschließend behandelt Filin fremdsprachige Elemente in der Standardsprache, die hauptsächlich aus Anglizismen bestünden. Er unterscheidet dabei zwei Gruppen von Fremdwörtern. Zur einen zählt er kurzlebige Begriffe, die mit dem Verschwinden der von ihnen bezeichneten Erscheinungen absterben:

smog, bitl, kètX, lobbi, lobbizm, lobbistka, lobbistskij, pop-art, pop-muzyka, rok-n-roll, chali-gali, tvist, chippi, striptiz

Die andere Gruppe enthalte heute bereits integrierte Fremdwörter wie komp'juter, lazer, mazer, ralli, riforming, transljator. Man hätte zwar in einigen Fällen rechtzeitig ein russisches Aquivalent bilden können, oft sei dies aber sehr schwierig. Fremdwörter dürfe man nicht nur wegen ihrer Herkunft aus einer anderen Sprache ablehnen. Wenn sie den bezeichneten Begriff richtig wiedergeben und den "Geist der russischen Sprache" nicht verletzten, ließen sie sich problemlos ins Russische einordnen. Für falsch hält Filin den Gebrauch von Fremdwörtern dann, wenn bereits ein russisches Aquivalent vorhanden ist, oder wenn der fremdsprachige Ausdruck zur Beschreibung russischer Verhältnisse unpassend sei (z.B. barmeny für Kellner auf einem Wolgadampfer).

\section{LG 29/74 (17.7.74) \\ (Pisatel' i slovo) \\ V. Roždestvenskij: „Vyrazitel'nost', dostupnost', točnost'“}

S. 6

1974 führte die Redaktion unter Schriftstellern und Publizisten eine Umfrage 
durch, in der unter anderem der Einfluß des Schriftstellers auf den allgemeinen Sprachgebrauch und die Normenbildung der Standardsprache beurteilt werden sollte. In diesem Zusammenhang wird in der LG 29 die Antwort von Vsevolod RoŽdestvenskij veröffentlicht.

Nach Roždestvenskij muß ein Schriftsteller in einer seinen Zeitgenossen verständlichen und gleichzeitig künstlerisch ausdrucksvollen Sprache schreiben. Derzeit sieht er eine Gefahr im gedankenlosen Jonglieren mit Wörtern, woraus kein poetisches Werk, sondern höchstens eine sinnlose Wortansammlung entstehe. Er fordert vom Schriftsteller eine genaue Kenntnis der Bedeutung von Wörtern und ihrer Abgrenzung gegenüber Synonymen. Diese Kenntnis sei leider oft zu vermissen, so habe z.B. ein Autor das Wort nachlebnica ('Kostgänger, Gnadenbrotempfänger') in der Bedeutung 'diejenige, die Brot kauft' verwendet.

Für Roł̌destvenskij ist die Sprache der Literatur eng mit dem Sprachschaffen der breiten Volksmassen verbunden. Obwohl sie sich nach eigenen Prinzipien richte, stelle sie nur eine besondere Spielart der Sprache des ganzen Volkes dar und dürfe sich deswegen nicht abkapseln. Heutzutage nähere sich die Sprache der Literatur mehr denn je an die allgemeine Volkssprache an. Roždestvenskij weist auf Gor'kijs Anleitungen für Schriftsteller hin, die auch heute noch uneingeschränkt gültig seien. Gor'kij habe vor allem unmotiviertes „Neuerertum" (,novatorstvo"), Manierismus und absichtliche Komplizierung des sprachlichen Stils bekämpft.

Ein ständiges Bemühen um die Qualität der literarischen Sprache hält Rozdestvenskij gerade derzeit, wo ein bis zwei Generationen die Sprachgewohnheiten von Grund auf änderten, für unbedingt erforderlich. In ihrem Streben nach echter Volksverbundenheit und immer breiterer Demokratisierung werde die literarische Sprache ihre Reinheit nicht trüben lassen durch den fremden Schmutz kurzlebiger Jargonausdrücke und die vulgäre Ausdrucksweise sprachlicher Minderheiten, die außerhalb des gesellschaftlichen Lebens stünden.

LG $31 / 74(31.7 .74)$

JAZYK I VREMJA

S. 6

\section{A.N. Rubakin: „Kogda ustricy stanovjatsja kljukvoj“"}

Der Mediziner Rubakin beanstandet die falsche Wiedergabe und oft unzutreffende Ubersetzung von fremdsprachigen Ausdrücken. Als Beispiel führt er einen sowjetischen Roman an, dessen Autor Pariser Straßennamen wörtlich übersetzt: 
- Rue Monsieur, Rue Madame, : ulica gospodina, ulica Rue Mademoiselle gospołi, ulica bary šni

statt : ulica brata, sestry, doceri korolja

- Rue de Bonne Nouvelle

- Rue de Mau vais Garçons Blagovešenskij bul'var ulica plochich mal'Cikov (mauvais garçons: „Verbrecher")

Außerdem stellt Rubakin in diesem Roman orthographische Fehler bei nichtübersetzten französischen Ausdrücken fest:
- kaufer
statt
- kon'jak Karvuaz'e
statt
kuafër
kon'jak Kurvuaz'e

Solange solche Unzulänglichkeiten auf belletristische Texte beschränkt bleiben, hält Rubakin sie jedoch nicht für gefährlich, weil sie höchstens den Verfasser diskreditieren. Schwerwiegend sei es jedoch, wenn sie in wissenschaftlichen Abhandlungen auftreten:

- Le`enie bronchita u bol'nych posle total'noj rezekcii pečenki statt: le Cenie bronchita total'nym ekstraktom peČnki

- primenenie terrenkura pri le Cenii bronchial'noj as tmy statt: konstitucional'noe lečenie bronchial'noj astmy

Gekennzeichnet als „Polemik" veröffentlicht die LG in dieser Ausgabe eine Beschwerde des Schriftstellers A. Gladilin über die sprachliche Zensur literarischer Werke in Verlagen und eine Gegendarstellung dazu von dem Verlagsdirektor L. Levin.

\section{A. Gladilin: „Nad slovom ja slezami obol'jus"“}

Gladilin meint, den Verlagslektoren werde zuviel Verantwortung aufgeladen, was bei ihnen eine Ausbesserungswut hervorrufe. Er weist ihnen ausschließ. lich die Aufgabe zu, aus den eingesandten Manuskripten die thematisch wichtigsten und vom Sujet her interessantesten für die Edition auszuwählen. Die sprachliche Form eines Textes sollte jedoch dem dafür kompetenteren Autor überlassen bleiben.

Anschließend führt Gladilin einige Beispiele dafür an, wie durch Einmischung des Lektors seine Romane verändert worden seien. Ein ungehobelter Soldat habe dadurch den Idiolekt eines Akademikers erhalten und eine andere 
Person sei völlig gestrichen worden, weil sie sich im Manuskript nicht standardsprachlich ausgedrückt habe.

\section{Levin: „.. . to to, čto est' Dunja, dolžno byt' mužčinoju“"}

Levin, Lektor eines Romanes von Gladilin, fühlt sich von dessen Kritik persönlich angesprochen. In seinem Artikel rechtfertigt er das Vorgehen von Verlagslektoren vor allem dadurch, daß er einerseits Aussagen berühmter Lektoren (Nekrasov, Cechov, Puškin, Saltykov Š̌edrin) zusammenträgt und andererseits Beispiele dafür bringt, wie Korrekturen des Lektors von angesehenen Schriftstellern dankbar aufgenommen worden seien (Cechov, Fadeev, Panov). Außerdem bezieht sich Levin auf ein Zitat von Gor'kij, in dem dieser den Lektoren die Aufgabe zuweist, die Schriftsteller zu schulen und zu erziehen. Erst wenn ein Schriftsteller ein gewisses Niveau erreicht habe, könne er selbst die Verantwortung für seine Werke übernehmen, ansonsten werde immer der Lektor für Unzulänglichkeiten zur Verantwortung gezogen. Wohl um zu beweisen, daß Gladilin dieses Niveau noch nicht erreicht hat, weist Levin auf den von Gladilin verwendeten Ausdruck on pereživaet iz-za mnogotočija hin, der grammatisch unmöglich sei.

\section{LG $43 / 74(23.10 .74)$ \\ (Pisatel' i slovo) \\ S. 6}

M. Borisova: „... i troj stil' sam nachodit sebja“

Die Schriftstellerin antwortet auf die bereits erwähnte LG-Umfrage.

Maja Borisova sieht die Einwirkung von literarischen Werken auf den alltäglichen Sprachgebrauch vor allem in Zitaten. Sie bezweifelt, daß dem einzelnen Sprecher bewußt sei, daß er fertige Wortblöcke in seine Rede aufnimmt, die er nicht selbst gedacht hat. Diese Zitate haben ihrer Meinung nach meist die Funktion, neben der reinen Information noch ein bestimmtes Gruppengefühl zu vermitteln. 


\section{$-1975-$}

LG 16/75 (16.4.75)

JAZYK I VREMJA

S. 6

L. Latynina / F.P. Filin / S. Barchudarov: "U slovarnych bogatstv“

Anläßlich des Erscheinens der ersten Lieferung des Slovar' russkogo jazyka XI - XVIII vekov* führt die LG-Redakteurin Latynia ein Interview mit dem Herausgeber des Wörterbuchs, S. Barchudarov, und F P. Filin durch.

Einleitend erklärt Latynina, ein Leben ohne Wörterbücher sei für sie unvorstellbar. Sie spricht von einer ungeheuren Anzahl von Leserbriefen, die regelmäßig in der Redaktion einträfen. In ihnen bekundeten Leser, die beruflich weder mit der Sprachwissenschaft noch überhaupt mit Philologie konfrontiert seien, großes Interesse an den verschiedensten Problemen der russischen Sprache. Einige seien vertraut mit dem Umgang von Wörterbüchern und wüßten deren Vorteile und Mängel einzuschätzen. Im Auftrag dieser Leser, von denen Latynina erwartet, daß sie den gerade erschienenen Band des genannten Wörterbuches zur Hand nehmen und mit Interesse lesen werden, stellt sie ihre Fragen an Filin und Barchudarov.

Gefragt nach der Stellung dieses Wörterbuches unter den in den letzten Jahren erschienenen, antwortet Filin, es fülle eine große Lücke in der russischen Lexikographie. In den letzten fün fzig Jahren seien an die 1000 Wörterbücher publiziert worden. Sie hätten dabei nicht nur einen rein praktischen Wert, vielmehr sei es die russische Sprache an sich wert, daß man ihr große Aufmerksamkeit widme. Besonders ihr unerschöpflicher Wortreichtum stelle einen bemerkenswerten Forschungsgegenstand dar. Die historische Lexikographie habe man bisher vernachlässigt. Das Wörterbuch von Sreznevskij erfülle nicht mehr die heutigen Anforderungen. Der Wortbestand der russischen Sprache müsse von den Anfängen bis in die Gegenwart lückenlos aufgezeichnet werden, denn im lexikalischen Bestand der Sprache eines Volkes spiegelten sich Jahrhunderte seiner Geschichte wider.

Barchudarov fährt fort mit einigen Bemerkungen zur Entstehungsgeschichte und zum Aufbau des Wörterbuches.

Anschließend macht Filin darauf aufmerksam, daß das neu erschienene Wörterbuch ein wichtiges Hilfsmittel für den zeitgenössischen Leser darstelle, da es ihm ermögliche, die Archaismen in Werken der Klassiker zu 
verstehen. Besucher des Films ,Mest' volchvov" beispielsweise hätten vergeblich auf das Auftreten von Wölfen (mest' volkov) gewartet und ein Philologiestudent habe das Wort episkop mit den Ausdrücken mikroskop und teleskop in Verbindung gebracht.

Schließlich geht Filin darauf ein, daB es ebenso wichtig sei, die "nicht in die Standardsprache eingegangenen Volksmundarten" aufzuzeichnen, da der Wortbestand der Volksmundarten die Standardsprache beträchtlich bereichert habe und nur in ihm die nichtkodifizierte Geschichte des russischen Volkes bewahrt sei. Es folgt ein Hinweis auf das unter seiner eigenen und Sorokoletovs Leitung erscheinende Slovar' russkich narodnych govorov.* Filin bedauert, daß die Akademie-Wörterbücher in zu niedriger Auflagenhöhe publiziert werden.

K. Seleznev: "Zadejstvovan igrok ne sousem chorołej kondicii"

Der Lehrer K. Seleznev wendet sich gegen die Ubernahme von Elementen aus Fachjargons in die Standardsprache.

Beispiele:

- zadejstuovat' ' to-libo: sei aus der Militärsprache entnommen, für falsch hält Seleznev den Ausdruck: akter zadejstuovan (statt zanjat) $v$ spektakle;

- dovesti do kondicii: Das aus der Handelssprache stammende kondicija beziche sich ursprünglich nur auf den Zustand von Waren, seit Bekanntwerden des Films "Brilliantovaja ruka" habe man es zunächst ironisierend in bezug auf Personen gebraucht (on dosel do kondicii), inzwischen habe es den ironischen Anstrich verloren und sei besonders bei Journalisten sehr beliebt.

- propiska:

trage eigentlich die Bedeutung "offizielle Registrierung der Aufenthaltsdaten, Anmeldeformular", inzwischen spreche man aber bereits von propiska ovošej ifruktov novych vid sporta, $\sim$ derev'ev i cuet, $\sim$ zuerej v zooparkach und $\sim$ novogo ljubitel'skogo kluba. 
Vorwiegend in der Presse treffe man auf "hybride Ausdrücke" wie podrobno ostanovit'sja, byt' na vysote momenta, gabaritnye razmery und realizovat' zadaču.

Die Festsetzung der Fachterminologie häl Seleznev für eine Aufgabe der Spezialisten des jeweiligen Gebietes. Wenn diese Termini aber die Grenzen ihres ursprünglichen Anwendungsbereiches verlassen, müBten sie daraufhin untersucht werden, ob sie in der Standardsprache angebracht seien. Hier sollten alle eingreifen, denen an der Erhaltung der Reinheit der russischen Sprache gelegen ist. Auf diesem Wege habe man oft schon erreicht, daB unpassende Ausdruicke aus dem Verkehr gezogen wurden. (Beispiel: statt mertiyj Cas, ,Mittagsruhe", tichij Cas.)

Seleznev beendet seinen Beitrag mit einer Aufforderung an die LG, auf alle bei Presse, Rundfunk und Fernsehen Beschäftigten einzuwirken, damit sie, bevor sie ein neues Wort in den allgemeinen Sprachgebrauch einführen, überdenken, ob es die russische Sprache bereichert oder ihr schadet, und wenn dieses neue Wort nicht unbedingt notwendig sei, dessen Anwendung vermeiden.

\section{A. Kalinin: „Sem'raz otmer”“}

A. Kalinin nimmt Stellung zu der Frage, ob, und wenn ja, unter welchen Bedingungen man der fachterminologischen Lexik den Weg in den allgemeinen Sprachgebrauch öffnen solle.

Zwischen Fachterminologie und allgemeinem Sprachgebrauch finde, so erläutert Kalinin, von jeher ein Austausch statt. Zum einen erhielten Ausdrücke der allgemein verwendeten Sprache neue Bedeutungen als Termini. (Beispiele: vychod, uyuod, norma, korridor, zerkalo, titul, zavod, korpus.) Zum anderen verwende man viele ursprüngliche Fachtermini schon lange in übertragenem Sinn:

- zenit, apogej, orbita

- strategija, front, pravoflangovyj, avangard

- agonija, infljacija, duet, start, prem'era, uvertjura

- akkord, koordinaty, meridiany, palitra

Als Beispiele für Schriftsteller, die Fachtermini in die Belletristik aufgenommen haben, erwähnt Kalinin Majakovskij (amortizacija serdca i duši), Voznesenskij (parabola) und Solouchin (vakuum). 
Kalinin räumt ein, daß die Verwendung von Termini in übertragener Bedeutung nicht immer angebracht sei. In den Jahren 1970 bis 1975 sei der Begriff épicentr in der Bedeutung "Zentrum" zum Schlagwort avanciert. Obwohl épicentr Erdbeben assoziiere, habe man damals sogar kurortnye épicentry gekannt. Wenn bei der Ubertragung eines Terminus in den allgemeinen Sprachgebrauch der Sinngehalt des Wortes dermaßen zerstört werde, sei die Metapher unpassend. Kalinin weist darauf hin, daß in dem Handbuch Trudnosti russkegejaz y ka viele solcher schlechten Metaphern kommentiert werden.

Anders müsse man das von Seleznev beanstandete zadejstvovat' beurteilen, $\mathrm{da}$ es sich hier nicht um eine Metapher handele. Bei solchen Wörtern solle untersucht werden, ob sie für den allgemeinen Sprachgebrauch tatsächlich notwendig sind, d.h. ob sie keine Dublette zu einem schon vorhandenen Ausdruck darstellen, und ob sie den Regeln der russischen Wortbildung entsprechen. Zadejstvovat' erfülle keine von beiden Anforderungen.

Jede Fachsprache, so bemerkt Kalinin, habe ihre eigenen Schrullen:

- kompleksnye čisla (Mathematik)

- dóbyča, rudnik (Bergbau)

- služit' na flote (aber $v$ artillerii, v pechote)

- technar' (mit unproduktivem Suffix - ar')

- volnitel'nyj

Hierin ähnele sie der literarischen Sprache, wo ebenfalls den Wortbildungsgesetzen weniger streng gehorcht werde als im Standardsprachgebrauch:

Beispiele: poèmimy, Čelovolki, lesalki (Voznesenskij)

sportsmednyj (Cvetaeva)

Solche Bildungen dürfe man aber nicht als Fehler ansehen, da sie für den literarischen Text notwendig seien.

LG $28 / 75(9.6 .75)$

JAZYK I VREMJA

S. 6

L. Uspenskij: „Sorazmerno i soobrazno....“

Auch Uspenskij versteht seinen Beitrag als Antwort auf Seleznevs Leserbrief. Seiner Meinung nach sind es weniger die Termini selbst als vielmehr deren schablonenhafte Anwendung, die Seleznev störe.

Uspenskij hält es für eine dringende Aufgabe, das Niveau der alltäglichen Sprachverwendung und besonders des Zeitungsstils zu verbessern. Neologis- 
men terminologischer Natur beurteilt er nach subjektiven Kriterien: Ausdrücke wie sputnik und prilunenie "gefallen" ihm, während er Termini wie subprodukty und skladirovat' als „abscheulich" ablehnt. Er schlägt eine Diskussion über Willkür und unzulässige Eigeninitiativen im Bereich der Terminologiebildung vor.

\section{L.I. Skvorcov: „O ,poeetiYeskich vol'nostjach'i zakonach jazyka“"}

Skvorcov kritisiert die Bemerkung Kalinins, in der Belletristik werde die standardsprachliche Norm nicht besonders streng befolgt. Der Schriftsteller sei, so Skvorcov, vielmehr aufgrund seiner künstlerischen Fähigkeiten in der Lage, die überlieferte Norm zu sprengen und weiterzuentwickeln. Sehr oft werde im Schaffen der Schriftsteller ein Konflikt zwischen dem Alten und dem Neuen in der Sprache entschieden und so das stilistische System der Standardsprache erweitert. Kein Wörterbuch könne die lebendige Entwicklung der Sprache erfassen, was zahlreiche, in der Umgangssprache längst geläufige, aber noch in keinem Wörterbuch verzeichnete Ausdrücke bewiesen. Viele dieser neuen Elemente kämen aus Fachsprachen, Argots, Dialekten und aus dem Prostorečie.

Neben dieser von ihm als positiv beurteilten Sprengung der Norm in der Entwicklung zum Neuen gebe es auch viele Beispiele für stilistische Mängel in der Belletristik. Skvorcov warnt aber davor, alles Ungewöhnliche im literarischen Stil als Fehler zu brandmarken, wie man es in vielen Leserbriefen beobachten könne. Der talentierte Schriftsteller erweitere die Ausdrucksmöglichkeiten der russischen Sprache, indem er u.2. volkssprachliche Elemente, Professionalismen, Neologismen und „berechtigte, unumgängliche” Entlehnungen einbeziehe. Einige dieser Elemente blieben beschränkt auf den Idiolekt des jeweiligen Autors, andere dagegen gelangten allmählich in den allgemeinen Sprachgebrauch.

Die Wortschöpfungen Čelovolki (Voznesenskij) und torł̌estuo (Evtusenko) beurteilt Svorcov als individuelle Prägungen, die aber nicht den Rahmen der russischen Wortbildungsmöglichkeiten sprengen. Ahnliche Bildungen finde man bei Belov, Suksin, Vikulov, Fokina, Liðutin, Nemと̌nko und Korotaev: - sumety, Zal'niki, ščrkunec, potasticha*

Ein talentierter Schriftsteller sei in der Lage, Wortgut aus allen stilistischen Ebenen in seinem Text zu verarbeiten. Dieses erfordere aber ein besonders ausgeprägtes Stilempfinden.

- Vgl. dazu auch Skvorcov 1980, S. 243, wo dieselben Beispiele genannt werden. 
Bezogen auf den Brief Seleznevs bemerkt Skvorcov, dieser übertreibe die Gefährlichkeit der erwähnten Ausdrücke und beurteile sie nicht immer richtig. Propiska werde nicht etwa erst seit kurzem, sondern bereits seit zwanzig Jahren von Journalisten in übertragener Bedeutung verwendet. Soviel auch Sprachwissenschaftler über diesen Ausdruck streiten mögen, werde er dennoch - wenn auch nur in der Zeitungssprache - weiterleben.

Skvorcov läßt nicht uneingeschränkt alle Elemente aus Fachjargons im allgemeinen Sprachgebrauch gelten. Alles Neue, das dem in der Sprache bereits Vorhandenen nichts hinzufüge, also reine Dublette sei, verunreinige die Sprache. Ausdrücke wie zadejstvovat', kondicija und ozadacit' stehen für ihn außerhalb der standardsprachlichen Norm.

Als ebenso unzulässig bezeichnet Skvorcov die hauptsächlich in der Lyrik zu beobachtenden Verstöße gegen die Betonungsregeln, die nur um des Reimes willen geschehen. Die Entwicklungsgesetze der Sprache dürften auch vom Schriftsteller nicht mißachtet werden. 
F.P. Filin: ,Zakony jazyka, tajny slova"

Filins Aufsatz behandelt neueste Tendenzen in der Sprache der russischen Literatur und die Frage nach dem Verhältnis zwischen schriftstellerischer Individualität und den allgemeinverbindlichen Normen der russischen Standardsprache.

Für Filin besteht die Individualität des Schriftstellers vorwiegend in der Selektion und Kombination aus den gegebenen Möglichkeiten der russischen Sprache. Hierbei stutze sich die Sprache der Literatur auf die Normen der Standardsprache, enthalte aber auch außerstandardsprachliche Elemente aus Prostorecie, Dialekten, Jargons und ungezwungener Umgangssprache. Bei der Verwendung solcher Elemente müsse der Schriftsteller jedoch beachten, daB die Allgemeinverständlichkeit des Textes gewährleistet bleibt und die Entwicklungsgesetze der Sprache, die der Schriftsteller mit seinem künstlerischen BewuBtsein zu erfassen habe, nicht verletzt werden.

Im weiteren führt Filin Besonderheiten in der Sprache der russischen Literatur seit 1960 auf. Er erwähnt eine Tendenz, aus der Sicht der handelnden Personen zu erzählen, die dazu geführt habe, daß mehr und mehr außerstandardsprachliche Elemente in die Sprache der Literatur eingegangen seien, besonders Elemente aus dem Prostorecie, Dialektismen, Jargonismen, amtssprachliche Ausdrücke, Zeitungsklischees und wissenschaftliche Termini.

Er wendet sich gegen den unmotivierten Gebrauch von Dialektismen, die, weil sie nur begrenzt verständlich seien, dem Leser die Lektüre erschwerten. Dies sei zum Beispiel in der Erzählung „N2 Enisee" von Viktor Astaf'ev der Fall, die für den Leser ein einziges Rebus darstelle. Filin beruft sich auf Gor'kij, der seinerzeit gegen die Verwendung von skukozit'sja eingeschritten sei.

Weiter kritisiert er die Aufnahme umgangssprachlicher Elemente in literarische Texte. Solche oft nicht nicht einmal in Wörterbüchern verzeichneten Wörter übten einen schlechten Einfluß auf die Sprachpraxis vornehmlich der heran wachsenden Generation aus. 
Beispiele:
- divizionka
- krugosuetka
für:
für:
divizionnaja gazeta
- podnevol'nik
für:
krugosvetnoe putesest vie
- rejsovik
für: podnevol'nyj Čelovek
- aktrisockka, vokalistočka, simpatjaga, prostjaga, dochodjaga;
- kodegarit', matrosit', slesarit', dubanit', pootkormit', podyznosit'sja;

Auf dem Gebiet der Lyrik stellt Filin eine starke Ausdehnung des Gebrauchs von Archaismen und eine Tendenz zur Neubildung von archaisierenden Wörtern fest.

Den Neologismen, die in der sowjetischen Gegenwartsliteratur auftauchen, räumt er keine Chancen ein, in den allgemeinen Wortschatz aufgenommen zu werden, weil sie sich nicht als Muster für aktivierbare Wortbildungsmöglichkeiten eigneten.

Beispiele:
- remartiki (remarka, mal'ziki)
- zimar' (zima, janvar')
- Kingizchamstvo (Yingizchan, chamstuo)
- chippičonocka (chippi, devčonotka)
bei RoŹdestvenskij,
bei Voznesenskij,
bei Voznesenskij,
bei Evtušenko;

Als Besonderheiten der Syntax in der Gegenwartsliteratur erwähnt Filin syntaktische Inkongruenz und die Imitiation des umgangssprachlichen Satzbaus.

Abschließend betont er, ein Künstler dürfe niemals die allgemein anerkannten sprachlichen Normen verletzen und sei jederzeit dazu verpflichtet, sich um die Verbesserung seiner Redekultur zu bemühen, denn Schriftsteller trügen eine besondere Verantwortung für das weitere Schicksal der russischen Sprache.

V. Gusev: „Muzyka i poézija prozy“

Bereits in der nächsten Ausgabe der LG antwortet der Schriftsteller Vladimir Gusev auf Filins Artikel. Grundsätzlich vertritt Gusev die Ansicht, es gebe zwei verschiedene Zugänge zu einem literarischen Text, den linguistischen und den poetischen, die $z$ war miteinander verbunden, aber nicht gleichzusetzen seien. 
Filins Vorwurf, Dialektismen gefährdeten die Allgemeinverständlichkeit eines Textes, weist Gusev zurück. Seiner Meinung nach muß dem Leser nicht unbedingt die Bedeutung jedes einzelnen Wortes klar sein, um den Sinn des Textes zu erfassen. Die Individualität des Schriftstellers drückt sich nach Gusev gerade in der Abweichung von den Normen des durchschnittlichen Sprachgebrauchs aus. Eine Gefahr für die Entwicklung der literarischen Sprache sieht er eher in dem normenkonformen Schreiberling ("gramotnyj grafoman") als in dem sich über Normen hinwegsetzenden Talent.

M. Borisova: , ,. . rossijskomu jazyku iskusen“**

Maja Borisova vergleicht die russische Sprache mit einem Ozean, der prinzipiell alle fremden Elemente aufnehmen kann. Dementsprechend sieht sie in Dialektismen und Jargonismen weniger eine Gefahr als vielmehr eine Bereicherung für die russische Sprache.

Sie wendet sich gegen die Trennung von künstlerischer Sprache und Sprache als Kommunikationsmittel, wie sie Gusev vertrete. Dem Schriftsteller ist ihrer Meinung nach zwar das Abweichen von den Normen erlaubt, nicht aber deren Unkenntnis.

Die größte Gefahr für die Sprachentwicklung stelle der ungenierte Umgang mit der Muttersprache dar. Als Beispiele dafür nennt sie vor allem die falsche Verwendung von fremdsprachigen, aber auch russischen Redewendungen und Sprichwörtern:

- takogo sé lja vi

- iš̃i ̌̌eršé lja fam

- vanfas

- kuda deněs'sja;

Außerdem mißbilligt sie Formulierungen wie skvoznjak dlja tvoego reumatizma beda.

Für die Ausbildung des Sprachgebrauchs einzelner Sprecher hält sie die Belletristik für weniger entscheidend als die Massenmedien Presse, Rundfunk und Fernsehen. 
B. Možaev: „Moment neponjatnosti i Zuustvo slova"

Boris MoŽaev spricht sich in seinem Beitrag für die Verwendung dialektaler Elemente in literarischen Texten aus. Dadurch, daß Dichter wie Turgenev oder Tolstoj sie in ihre Werke aufgenommen haben, sei bereits eine große Anzahl von Dialektismen in den allgemeinen Sprachgebrauch übergegangen und habe so zur Bereicherung der russischen Sprache beigetragen. Er kritisiert Filin, weil er Dialektismen als Fremdelemente bezeichnet hat. Die Bauern, deren Sprachform der Dialekt sei, machten achtzig Prozent der Bevölkerung aus. Daher sei es Unsinn zu behaupten, sie sprächen eine fremde Sprache.

Weniger positiv steht Možaev Jargonismen gegenüber, die er „Mißgeburten“ (,slova urodcy") oder "Wortparasiten" (,slova parazity") nennt. Solche Elemente schadeten der russischen Sprache:

skukožit'sja, blinochuat, capel'nik, rubat' (est'), travit' (rasskazyuat'), utartat' (uvezti), telepat'sja, zakidon,

Možaev kritisiert ferner die Imitation bäuerlicher Sprache, die zu solchen Paradoxa führe wie der graphischen Unterscheidung von in Standardsprache und Dialekt gleich ausgesprochenen Wörtern zur Charakterisierung von städtischer und ländlicher Bevölkerung:

$\begin{array}{lll}\text { čto: } & \text { für Städter: } & \text { čto } \\ & \text { für Dorfbewohner: } & \text { sto } \\ \text { とego: } & \text { für Städter: } & \text { čego } \\ & \text { für Dorfbewohner: } & \text { čevo. }\end{array}$

T. Žirmunskaja: „Takaja liričeskaja derzost"“

Źirmunskaja beschreibt in ihrem Aufsatz, daß Schriftsteller wie Puškin einerseits sie in ihrer dichterischen Freiheit einschränkende Sprachnormen bekämpften, ihnen andererseits grammatische Unsauberkeiten in eigenen Texten unangenehm sind. Einmal verbesserten sie auf Anraten von Freunden bereitwillig ihre Texte, während sie sich ein anderes $\mathrm{Mal}$ hartnäckig gegen die Umstellung einer einzigen Zeile wehrten. Sie ist der Meinung, die dichterische Freiheit könne und dürfe man nicht durch strenge Vorschriften einschränken. 
Uberzeugende Kühnheit im dichterischen Sprachschaffen entstehe nur dann, wenn der Dichter über ein angeborenes Sprachgefühl und ein sicheres poetisches Gespür verfüge und all seine künstlerischen Kräfte einsetze. Nicht einverstanden ist sie mit Filins Verhältnis zur lyrischen Kühnheit des Schriftstellers. Filin räume nur ungern und mit Vorbehalten dem Schriftsteller das Recht auf Sprachexperimente ein.

LG 29/76 (27.7.76)

S. 6

A. Kalinin: „Čuvstrovat' vozrast slova“

Wie der Titel seines Aufsatzes bereits andeutet, fordert Kalinin vom Schriftsteller sprachhistorische Kenntnisse. Er hält es für unzulässig, wenn ein Schriftsteller bei der Beschreibung einer historischen Epoche Wörter benutzt, die erst in späterer Zeit Eingang in die russische Sprache gefunden hätten. Erlaubt sei dies nur, wenn es als bewuBtes Mittel zur Ironisierung eingesetzt werde, wie dies Zoß̌enko in Golubaja kniga tue. Kalinin schlieBt seinen Beitrag mit der Aufforderung an die Schriftsteller, von Zeit zu Zeit Wörterbücher zu Rate zu ziehen.

LG 33/76 (18.8.76)

JAZYK I VREMJA

S. 6

A. Cudakov: „Soblazn uproß̌cenij“”

A. Cudakov kritisiert die an Schriftsteller gerichtete Aufforderung Kalinins, Wörterbücher zu benutzen. Nicht das Wörterbuch diene dem Schriftsteller als Quelle, sondern umgekehrt sei die Literatur die Quelle zur Erstellung eines Lexikons. Eine reine Wörterbuchbelesenheit des Dichters führe zu solchen Erscheinungen, daß unmotiviert Elemente aus den verschiedensten Dialekten in einem literarischen Text zusammengestellt werden, wie er das in der sowjetischen Gegenwartsliteratur beobachtet habe.

\section{Nersesov (Leserbrief ohne Titel)}

Nersesov tadelt, daß die Diskussionsteilnehmer sich in ihren Aussagen über zeitgenössische Sprache ständig auf Klassiker beziehen. Dieses in Sprachdiskussionen bereits zur Gewohnheit gewordene Vorgehen sei nicht gerechtfertigt, wenn es um die Beurteilung der gegenwärtigen russischen Sprache gehe. Er hält es für unsinnig, die Zahl der Dialektismen in Nekrasovs Werken zur Beurteilung des Sprachstils von Astaf'ev heranzuziehen, wie Filin dies in 
seinem Beitrag tue. Vielmehr müse man davon ausgehen, daß Astaf'ev, der einem bestimmten sprachlichen Milieu angehöre, vor allem für Dorfbewohner aus dieser Gegend schreibe, so daB die bei ihm auftretenden Dialektismen nicht etwas von außen Herangetragenes, sondern organischer Bestandteil seiner Sprache seien.

\section{A. Utockin (Leserbrief ohne Titel)}

A. Utockkin unterstreicht in seinem Brief die Notwendigkeit sprachlicher Experimente für die Weiterentwicklung der Sprache. Das, was heute als Verletzung der Norm verworfen werde, könne morgen schon die Sprache bereichern.

\section{Ju. Karpenko (Leserbrief ohne Titel)}

Karpenko stellt fest, in Diskussionen uber die Standardsprache rangierten Burokratismen an erster Stelle, in Diskussionen uber die Sprache der Literatur dagegen Dialektismen. Seiner Meinung nach darf man Dialektismen nicht als solche verwerfen, sondern muß sie nach ihrer Stellung und Funktion im Text beurteilen. Nur dann, wenn Dialektismen ohne Motivierung verwendet werden, könne man sie ablehnen.

\section{T. BakanoviC (Leserbrief ohne Titel)}

Der Leser Bakanovič aus Kyzyl wirft Možaev vor, er zähle volkssprachliche Ausdrucke zu Wortparasiten. Für skukoYit'sja führt er als Rechtfertigung einen Beleg bei Majakovskij an.

\section{Ja. Sabsovið (Leserbrief ohne Titel)}

Sabsovič nennt ein Beispiel für falschen Sprachgebrauch, das er in einem Buch gefunden habe:

- On stojal, oblokotjas' na chobot orudija.

Ein Schriftsteller dürfe nur solche Wörter verwenden, deren Bedeutung er kenne.

LG $42 / 76(20.10 .76)$

JAZYK I VREMJA

S. 6

V. Solov'ev: „Krasnorečie ili kosnojazy $\varkappa_{i e ? \cdots ”}$

Scharfe Kritik an der Haltung der Puristen übt V. Solov'ev. Die Sprache sei kein Museumsstück, sondern ein mit dem alltäglichen Leben verbundenes 
Arbeitsinstrument, das man, wenn nötig, überarbeiten und vervollständigen müsse. Die von Kalinin vorgebrachte Forderung, ein literarischer Text über eine bestimmte Epoche dürfe keine Wörter enthalten, die erst später Bestandteil der russischen Sprache geworden seien, führt Solov'ev ad absurdum, indem er darauf hinweist, daß dann folgerichtig jede Erzählung über die Schlacht auf dem Amselfeld auch heute noch auf altrussisch verfaßt werden müsse.

Was Fremdwörter betrifft, so vertritt Solov'ev die Auffassung, die russische Sprache sei stark genug, um sie aufnehmen und assimilieren zu können. Auch Neologismen steht er positiv gegenüber, sofern sie sich organisch in das Sprachsystem einfügen. Seiner Meinung nach muB dem Schriftsteller das Recht auf sprachliche Experimente zugesprochen werden, denn nur so könne sich die Sprache weiterentwickeln. Schlimmer als Holprigkeit in der Sprache junger Schriftsteller sei stures Festhalten an sprachlichen Traditionen.

LG 47/76 (24.11.76)

B. Anašenkov: „Ispytanie vyborom"

Boris Anašenkov bezweifelt, daß man Fragen über Tendenzen der zeitgenössischen Sprache der Literatur aus rein linguistischer Sicht beantworten könne. Seiner Meinung nach muß man die Abweichungen von den Normen der Standardsprache, die in der Literatur auftreten, als eine Abwehrreaktion auf eine Gesellschaft verstehen, die nur noch mithilfe vorgegebener Phrasen und Sprachklischees operiere.

Im weiteren äußert er sich vor allem zur Aufnahme terminologischer Lexik in die Sprache der Literatur. Dabei lehnt er die puristische Haltung einiger Kritiker $a b$, die sich über jeden neu in der Literatur auftauchenden Terminus entrüsten*. Er befürchtet allerdings, daß bei einem massenhaften Eindringen terminologischer Lexik in die literarische Sprache die Literatur kein künstlerisches Begreifen der Wirklichkeit mehr leisten könne.

LG 50/76 (15.12.76)

DISKUSSIONNYJ KLUB LG

S. 6

Beendet wird die Themenreihe mit einer Diskussion zwischen F.P. Filin und V. Gusev, die von der LG-Redakteurin A. Latynina geleitet wird.

* Vgl. dazu Kolesrikov 30/73. Im Original stimmt der Wortlaut mit dem bei Kolesnikov überein. 


\section{Garmonija i stichija"*}

Einleitend kommentiert Latynina die nicht veröffentlichten Leserzuschriften: Die große Mehrheit der Leser sehe in Filin die Autorität der Linguisten, der um die Entwicklung der Sprache besorgt sei. Gusevs Position werde nur von wenigen unterstützt, die meisten tadelten ihn, weil er den Durchschnittssprachgebrauch als minderwertig einstufe und das Recht des Schriftstellers auf willkürlichen Umgang mit der Sprache verteidige.

Gusev räumt daraufhin ein, daB auch er für die Individualität des Stils gewisse Grenzen anerkenne, die nicht überschritten werden dürften. Er sei mit Filin einer Meinung darüber, daß die Gesetze der Sprachentwicklung respektiert werden müBten, sie hätten jedoch unterschiedliche Vorstellungen vom Wesen dieser Gesetze. Filin betont noch einmal den allgemeinverbindlichen Charakter von Sprachnormen. Auf den Einwand Gusevs, bedeutende Dichter wie Puškin oder Griboedov hätten selbst zur Entwicklung der Sprache beigetragen, antwortet Filin, zu Pułkins Zeiten habe eine ganz andere Situation vorgelegen. Die Normen der Standardsprache seien damals noch nicht festgelegt gewesen. Heute dagegen sei das System der russischen Sprache abgeschlossen und jede weitere Entwicklung könne sich nur noch innerhalb dieses Systems vollziehen.

Mit Bezug auf den Beitrag Anasenkovs fragt Latynina nach den Bedingungen unter denen so viele neue Wörter und Begriffe in die dichterische Sprache aufgenommen werden können. Filin vertritt die Auffassung, die Aufnahme neuer Wörter aus Fachsprachen verändere nicht das Sprachsystem. Die Gefahr einer Uberladung der dichterischen Sprache mit Technizismen ist für ihn nur dann gegeben, wenn durch ihre Konzentration in einem literarischen Text eine Kluft zwischen Leser und Schriftsteller entstehe. Für Gusev steht Technik grundsätzlich im Widerspruch zu Literatur und Kunst. Eine besondere Gefahr für die Entwicklung der russischen Sprache sieht Filin in "unnötigen" Neologismen (smel'stvo für smelost'), die er als Fehlbildungen bezeichnet.

Filin schließt die Diskussion mit dem Hinweis darauf, daß die Auseinandersetzung über die Sprache der Literatur mit dieser Artikelreihe keineswegs abgeschlossen sei, sondern kontinuierlich fortgeführt werden müsse. 


\section{RUSSKIJ: SPORNYE PROBLEMY}

In der Nr. 11/77 eröffnet die LG eine neue Rubrik für Sprachfragen: „Russkij jazyk: spornye problemy".

L. Rachmanova/N. Formanovskaja: "Cto takoe chorołist?“"

Die Linguistinnen L. Rachmanova und N. Formanovskaja, Autorinnen des Nachschlagwerkes Trudnosti russkogo jazyka (Moskau 1974), beantworten Leserbriefe.

Einem Leser, der den Ausdruck nekaZestuennaja produkcija beanstandet, erklären sie, kaC'estuennyj weise heute die Nebenbedeutung, vysokokaZestvennyj" auf. Insofern sei der Ausdruck nekačestvennaja produkcija für produkcija nizkogo, plochogo katestua völlig richtig.

Ein anderer Leser fragt, ob man die Bezeichnung chunta, die sich seiner Meinung nach ausschließlich auf die Regimes spanischsprechender Länder bezieht, auch auf Vietnam und Griechenland anwenden düre. Rachmanova und Formanovskaja finden es richtig, den in erster Linie im Zusammenhang mit dem Pinochet-Regime in Chile bekannt gewordenen Begriff chunta auf vergleichbare Regimes in nicht spanischsprechenden Ländern auszudehnen, da er allgemein die Bedeutung, reakcionnaja terroristiXeskaja gruppirovka' trage.

Auf die Frage eines dritten Lesers, ob die Bezeichnung chorošist für einen mit der Note "chorošo" bewerteten Schüler der Norm entspreche, antworten die Verfasserinnen, daß dieses Wort außerstandardsprachlich sei, weil es mit dem unproduktiven Suffix -ist gebildet worden sei und fachspraçhlichen Charakter trage. Es habe keine Chance, in den Standardwortschatz aufgenommen zu werden, da heutzutage mit Ziffern benotet werde und bereits die Bezeichnung duoetnik existiere.

RUSSKJJ JAZYK: SPORNYE PROBLEMY

N. Formanovskaja: „Ołibka ili priem?“

Formanovskaja kommentiert einen Leserbrief, in dem die Zerstörung von Sprichwörtern und phraseologischen Ausdrücken bemängelt wird. 
Beispiele:

- Tiše edeł' - dal'కe ne budes' (dal 'Se budeš')

- Ne lomites' v zakrytye dueri (v otkrytye dueri)

Formanovskaja weist darauf hin, daß Schriftsteller und Journalisten mit Vorliebe die Veränderung von Sprichwörtern und Redewendungen als Stilmittel einsetzten. Solche bewußten Modifizierungen von festen Redewendungen machten gerade die Lebendigkeit und Individualität eines literarischen Textes aus. Die zweite der genannten Redewendungen hält jedoch auch sie für mißglückt, weil ihr Sinngehalt zerstört sei.

\section{Rachmanova: „On, ona, ono?“}

Auf Bitten eines Lesers gibt Rachmanova Regeln zur Bestimmung des grammatischen Geschlechts frisch entlehnter Wörter an. Danach erhalten alle entlehnten Substantive, die Menschen bezeichnen, ein Genus, das sich nach dem Geschlecht der bezeichneten Person richtet, alle Berufsbezeichnungen sind dagegen, unabhängig vom Geschlecht der Person, maskulin. Ebenfalls maskulin sind nach Rachmanova alle Tiernamen mit Ausnahme der femininen Namen cece, kuasi, kivi-kivi, alle Sachen bezeichnende Fremdwörter in der Regel Neutra. Einige Exotismen bildeten dabei Ausnahmen, weil ihr Genus sich nach dem Genus eines beschreibenden russischen Ersatzwortes richte:

- saljami: feminin (kolbaska)

- chindi, urdu: maskulin (jazyk)

Bei ralli, das inzwischen als Neutrum gelte, komme es deswegen, je nach Ersatzwort (probeg, gonka), zu Genusschwankungen.

LG $31 / 77$ (3.8.77)

S. 6

\section{RUSSKIJ JAZYK: SPORNYE PROBLEMY}

L. Rachmanova/N. Formanovskaja: „Dizajner ili chudoŽnik-konstruktor?"

Dem Beitrag von Rachmanova und Formanovskaja sind zwei Leserbeschwerden über die Ausbreitung fremdsprachiger Ausdrücke (dizajner, region) vorausgeschickt.

Rachmanova und Formanovskaja ziehen das Fremdwort dizajner dem im Leserbrief vorgeschlagenen Ausdruck chudoZnnik-konstruktor vor, weil letzterer die Bedeutung von dizajner als Berufsbezeichnung nicht adz̈quat wiedergebe. Die Ubernahme von region für oblast' halten sie dagegen, weil es eine reine Dublette darstelle, für nicht unbedingt nötig. 


\section{RUSSKIJ JAZYK: SPORNYE PROBLEMY}

K. Gorbačevič: „Oblono - on ili ono?"“

Gorbačevið antwortet Lesern, die eine Veränderung in der Zuordnung des grammatischen Geschlechts zu Abbreviaturen festgestellt haben und danach fragen, ob diese Anderungen normgerecht sind.

Einleitend erläutert er, daß die strengen Vorschriften in Grammatiken nicht mehr dem allgemeinen Sprachgebrauch entsprechen, weil sich die russische Sprache inzwischen weiterentwickelt habe. Viele Handbücher schrieben noch vor, das grammatische Geschlecht einer Abbreviatur von dem Geschlecht des Kernwortes abzuleiten:

TASS: neutrum $(\rightarrow$ agentsuo)

rono: maskulin ( $\rightarrow$ otdel)

Diese Norm gelte heute nicht mehr. Viele Abbreviaturen auf harten Konsonant behandele man inzwischen als Maskulina, auch wenn das Kernwort ein anderes Genus besitze:

ZEK (kontora), VTEK (komissija)

Neue Abkürzungswörter erhielten jetzt das Geschlecht nach ihrem Auslaut. Diese Entwicklungen zeigten, daß die Abbreviaturen als ganze Wörter angesehen werden. Gorbacevic hält die Anderung für vernünftig, da man früher oft aus Unkenntnis des Kernwortes ein falsches Genus gebraucht habe. Man dürfe aber deswegen nicht gleich die Regel als völlig veraltet verwerfen, denn besonders bei den nach Buchstaben ausgesprochenen Abkürzungen richte sich das Genus immer noch nach dem Kernwort. 


\title{
RUSSKIJ JAZYK: SPORNYE PROBLEMY
}

\author{
K. Gorbačevič: ,Maneur ili manëur?“
}

Gorbačevič kommentiert einen Leserbrief, der sich mit den Varianten manëur I maneur befaßt. Der Ingenieur S. Marinin fragt, wodurch sich in diesem Fall das Auseinandergehen von bestehender Norm (manëur) und tatsächlicher Aussprache (maneur) erklären lasse.

Für das Auftreten der Variante maneur macht er die derzeit stark verbreitete Tendenz, die Aussprache der Schrift anzugleichen, verantwortlich und stellt dabei manëur in eine Reihe mit den bereits als veraltet geltenden Varianten akušër, blëf, pompëznyj. Dieser Tendenz seien keineswegs nur Fremdwörter unterworfen, sondern auch viele russische Wörter:

Zel'̌' (žël'̌') belesyj (belesyj), bleknut' (blëknut'); sovremennyj (souremennyj).

Maßgebend für die Veränderung orthoepischer Normen seien darüber hinaus auch der Wunsch nach Loslösung von der fremdsprachigen Aussprache und das Bestreben, Wörter mit gleicher Wurzel zu vereinheitlichen (maneur maneuririvat', maneurovyj).

\section{LG 14/78 (5.4.78) KAK MY GOVORIM, KAK MY PIŠM S. 6 (Vorspann der Redaktion)}

In einem Vorspann zur Einrichtung einer neuen Rubrik erklärt die LG-Redaktion den in zahlreichen Leserbriefen erhobenen Protest gegen sprachliche Mängel in der Belletristik und in den Medien für gerechtfertigt angesichts der wachsenden Bedeutung des Russischen als Verkehrssprache zwischen den Nationalitäten der Sowjetunion und als Weltsprache. Drei solcher Leserbriefe veröffentlicht sie.

N. Roskina: ,, ,Lzvenite za ošibki “.”

Die Publizistin N. Roskina bedauert, daß zu wenig Wert auf orthographische Richtigkeit gelegt werde. Vielen Sprechern seien zwar ihre mangelhaften Recht- 
schreibkenntnisse bewußt, keineswegs aber peinlich. Nicht einmal Lehrer und Lektoren beherrschten die Orthographie des Russischen fehlerfrei.

Sie führt eine Liste von Fehlern in Schulaufsätzen an:

jumorestičeskij, posveščaju, junnyj technik, smyslo ulovitel', portsegar, ščolknul, po-angliski, on prišel s robotomi, rasmejalsja, ego perenisli, 0 ateli 5000 nomerov, spasobnyj syscik, na celil revol'ver, asual'tnaja doroga, kokoj besprojadok, ubita noZom ugrud', razbityj udrezgi servant, dostal Kertizi iz pis'mennogo stola, vyY̌l iz karoblja, podnjal ruki verch

Außerdem hält die Verfasserin die Interpunktion des Russischen für verarmt: Sie vermißt den Gedankenstrich, den Doppelpunkt und das Semikolon und beklagt weitverbreitete Unsicherheiten in der Kommasetzung.

Roskina vertritt die Ansicht, der Schulunterricht widme sich auf Kosten des Diktats zu einseitig der Entwicklung stilistischer Fähigkeiten. Ihrer Meinung nach sind aber gerade Diktate erfolgversprechend bei der Einübung der Rechtschreibung, die sie als die vordringliche Aufgabe der Schule bezeichnet. Ohne absolute Sicherheit in der Rechtschreibung könne von Bildung keine Rede sein.

\section{Cistjakov, „V zatorach kosnojazyðija“}

Der Ingenieur Čistjakov beginnt seinen Leserbrief mit einer Reminiszenz an die Orthographie-Diskussion von 1964. Auf die gleiche Ebene wie ogurci und zaec $^{*}$, die er als Erfindung ungeschickter Reformatoren bezeichnet, stellt er Phänomene wie:

pirožki s povidloj, grejfrukt, oplačivat' za proezd, kuartal, épicentr

Es sei höchste Zeit, ernsthaft über richtigen Sprachgebrauch zu diskutieren. Momentan werde die Autorität der Sprachrichtigkeit untergraben durch Hinweise auf ständige Zeitnot und darauf, daß die Massen größere Sörgen hätten, als sich um die tadellose Beherrschung der Sprache zu kümmern.

\section{N. Lebedev, „Vladet' slovom“}

Der Lehrer N. Lebedev findet es paradox, wenn, wie häufig anzutreffen, ein Fachmann mit dem höchsten Bildungsabschlu $B$ nicht richtig schreiben könne. Seiner Meinung nach darf der Sprachunterricht nicht mit dem Schulabschluß aufhören, sondern müsse auf den Universitäten fortgeführt werden. Besondere Kontrolle erfordere aber der Sprachgebrauch derjenigen, die in den Massenmedien beschäftigt seien. Laut Lebedev sind Fehler in der Deklination von 
Zahlwörtern für Medien charakteristisch (suyše duesti pjat'desjat). Als weitere Beispiele für Normverletzungen in den Medien nennt er igrok narušil pravila, o ćem zafiksiroval sud'ja, sčeta net: nol' - nol'.

Noch weniger Verständnis hat er für Fehler in Druckerzeugnissen: Bedeutungsverwechslungen, falscher Konsonantenwechsel und Deklinationsfehler:

- duižiteli raketonosca (dvigateli)

- o soderžanii Čemodana (o soderžimom)

- ja Ševelju manžetom na zapjast'e (manžetoj)

- sobytie stalo preponom na puti (preponoj)

- vypolnit'suoj dolg

Lebeder meint, es bedürfe keiner besonderen Begabung, um zu lemen, die Standardsprache zu beherrschen und klar, deutlich und grammatisch richtig zu schreiben.

\section{(Prodolłaem razgovor o kul'ture reči)}

\section{S. Povarcov: „Zamknutyj krug“"}

S. Povarcov führt das angeblich nicht seltene Phänomen des „bezgramotnyj uXitel'-vypusknik filologiZeskogo fakul'teta" darauf zurück, daß viele Jugendliche die philologische Fakultät nur deshalb besuchen, weil sie unbedingt studieren wollen und ihnen diese Fakultät leichter als die naturwissenschaftliche erscheint. Er kritisiert diesen Ansturm auf die philologische Fakultät, $\mathrm{da}$ bereits jetzt eine Philologenschwemme drohe und durch solche Studenten nur unnötiger Ballast die Universitäten fülle. Als Gründe für die Wahl des Studienfachs Russisch führten die Studienanfänger oft ihre Neigung zur Literatur an, ohne aber die Jugendliteraturzeitschriften Junost' und Avrora zu kennen, weil sie sich eher mit Fernsehen, Radio und Tonband beschäftigten als mit der Lektüre. Bezeichnenderweise gebe keiner als Beweggrund zur Fächerwahl eine Neigung zur russischen Sprache an. Bei Diktaten in den Kursen zu praktischer Grammatik, die 200-300 Wörter umfaßten, seien 10-20 Orthographie- und Interpunktionsfehler keine Seltenheit.

Fehlerbeispiele:

mysljuščee suščestvo, prinebrežitel'no, dosčatyj, kak ne stranno, $\checkmark$ otličae ot drugich, Rodiščev

Richtiger Sprachgebrauch ist seiner Meinung nach das Fundament jeglicher Bildung. Daher müsse in der Familie wie auch in der Schule und Universität die Sorge um den richtigen Gebrauch der Muttersprache im Mittelpunkt stehen. 
B. Junker: „Inžener doľ̌en byt' gramotny m“"

Auch der Ingenieur B. Junker unterstützt den Brief Roskinas. Er zählt Fehler bei Leuten mit Hochschulbildung auf:

- mexiki (metčiki), vintel' (ventil'), regilja (rigeli)

- zakryt' krany, otremontirovat' por'Ynja, proverit' klapana

- obsťitat' (proizuesti raš̌et Cego-to)

- srabotali (potrudilis', porabotali)

Der Ausdruck "gramotnost'“ bezeichnet für ihn nicht nur die Fähigkeit des Lesens und Schreibens an sich, sondern die tadellose Beherrschung der Muttersprache, die man heute, wo das Russische als Weltsprache eine groBe Bedeutung habe, von Russen verlangen müsse.

\section{Nikiforov: „Gramotnost' - ne fetiy““}

Anders reagiert der Arzt V. Nikiforov, der die Fetischisierung der Rechtschreibung angreift. Hierzu schildert er zwei Fälle: einem mathematisch begabten Schüler sei wegen orthographischer Fehler das Mathematikstudium verwehrt worden, einer Krankenschwester aus demselben Grund das Medizinstudium.

Nikiforov spricht dem bloßen Einpauken orthographischer Regeln keinen Erfolg zu. Er führt die Unsicherheit der Schüler in der Rechtschreibung auf die Kompliziertheit, die Unvollständigkeit und oft Unsinnigkeit der Orthographieregeln zurück. Er erinnert an die Orthographie-Diskussion von 1964 und fragt, ob es nicht an der Zeit sei, die Orthographie wieder einmal zu überarbeiten.

LG $17 / 78$ (26.4.78)

S. 6

\section{KAK MY GOVORIM, KAK MY PIŠM}

\section{Uspenskij: „Norma - ne dogma“"}

Uspenskij kritisiert, daß in der Diskussion der Ausdruck "gramotnost”“ des öfteren als „Beherrschung der Orthographie“ verstanden und somit die Bedeutung der Rechtschreibung überbewertet wurde. Er käme nie auf die Idee, den Wert der Birkenrindenschriften geringer zu schätzen nur weil sie nicht den orthographischen Normen ihrer Zeit entsprächen. Er verweist auf Puškin: „Kak ust rumjanych bez ulybki / bes grammatičeskoj ołibki / ja 
russkoj rexi ne ljublju"** und auf seine eigene Kartothek über Normabweichungen bei Cechov (Dialektismen und Gallizismen).

Uspenskij hebt die Relativität des Begriffs ,sprachliche Richtigkeit" hervor, indem er anmerkt, daß viele ,richtige" Schreibweisen ursprünglich auf Abweichungen zurückgehen, die erst durch häufigen Gebrauch gefestigt und legalisiert worden seien. Grammatische und orthographische Regeln hätten einzig und allein die Aufgabe, die schriftliche Verständigung zu erleichtern und sollten daher dieser Funktion angemessen und praktisch sein.

\section{G. Demina: „Razomknut' krug““}

Die Biologin G. Demina unterstützt in ihrem Leserbrief im großen und ganzen die Aussagen von Roskina, hält ihr aber vor, den Diktaten eine zu große Bedeutung beizumessen. Demina ist der Meinung, da die Ausbildung der Kommunikationsfähigkeit der einzige Weg zur Beseitigung sprachlicher Mängel sei. Darauf sollte nicht nur im Russischunterricht, sondern auch in anderen Schulfächern geachtet werden. Sie bemängelt, daß in demselben Sender, der die Sendung ,Russkaja re $\not$ ' “ ausstrahlt, Fehler vorkommen wie:

- predlagaem vaร̌emu unimaniju posmotret' p'esu

- ja sdelal èto skrepja serdcem

- suyše trista pjat'desjat tysjač

LG 22/78 (31.5.78)

\section{KAK MY GOVORIM, KAK MY PISEM}

S. 6

F. Bobkov: „Ołibki, kotorych ne bylo“"

Bobkov pflichtet Roskina bei und tadelt Uspenskij, weil er Fehler rechtfertige. Die Aufnahme dialektaler und umgangssprachlicher Lexik gesteht er den Schriftstellern jedoch als ihr berufliches Recht, ja sogar soziale Aufgabe zu, denn nur so könne der Wortbestand der russischen Sprache erweitert werden.

Er bedauert, daß in der begonnenen Diskussion sowohl puristische Haltungen als auch laissez-faire-Positionen vertreten sind und die Urteile über Sprache oft auf persönlichen Gewohnheiten und Geschmack basierten.

N. Gal': ,Navalit'sja vsem mirom"

Auch N. Gal' versteht ihren Leserbrief als Unterstützung von Roskina. Es ver-

aus „Evgenij Onegin“, vgl. Russkie pisateli ojzzzke (XVIII.XXvv), 1954, S. 83 
gehe kein Tag, an dem man nicht mit Fehlern gröbster Art in Rundfunk, Fernsehen, Presse oder Büchern konfrontiert werde.

Beispiele:

- naselenie, prozivajư̌čee v takich-to rajonach

- zakontil doumja sal 'tami

- edinstuennyj dubl'

Sie kritisiert ferner, daß sich überall auf Kosten des allgemeinen Sprachniveaus spezielle Berufsjargons ausbreiteten.

LG 23/78 (7.6.78)

S. 6

\section{KAK MY GOVORIM, KAK MY PISEM}

In einem Vorspann berichtet die Redaktion von zahlreichen Leserbriefen über das Absinken des sprachlichen Niveaus in der Bevölkerung und speziell über die Verletzung von Sprachnormen in Presse und Belletristik. Es wird weiter erwähnt, daß man einen Teil der Briefe dem Schriftsteller K. Vaň̌enkin übergeben habe, der in einem Artikel dazu Stellung nimmt.

\section{K. Vanšenkin: „Žuvaja reť ili negramotnost'?“}

K. Vanకenkin äußert den Verdacht, daß die Leser in belletristischen Texten Fehler geradezu suchen. Literatur spiegele aber das Leben und die lebendige Rede wider, daher dürfe dem Schriftsteller nicht verboten werden, Sprachnormen zu übertreten, denn sonst trockne die Sprache der Literatur aus und bleibe in ihrer Entwicklung stehen. Besonders kritisiert er, daß die Leser an die Sprache der handelnden Personen dieselben Maßstäbe anlegten wie an die des Erzählers. Die Verwendung von sprachlichen Besonderheiten zur Personencharakterisierung sei unbedingt notwendig, schließlich könnten Romanfiguren unmöglich in Lehrbuchsätzen reden.

\section{OHov (Mnenie Kitatelja)}

L. Orlov beklagt, daß Abweichungen von Akzentnormen mit dem Verweis darauf entschuldigt würden, das falsch betonte Wort unterscheide sich semantisch oder stilistisch von dem normgerecht betonten.

Beispiele:

srédstua (finansovye ): sredstuá (nagljadnye )

Er räumt ein, es gebe im Russischen tatsächlich einige Wörter, die je nach Lage des Akzents eine andere Bedeutung tragen: bronjá - brónja; stánkouyj 
- stankóvyj. Dies berechtige aber keinesfalls zu solchen Analogieschlüssen wie dem, aus dem Paar jazykowój - jazykóyyj das Paar jazýki (Sprachen) jazykí (Zungen) abzuleiten. Auch die Unterscheidung von kvártal (Quartier) und kuartál (Quartal) hält er für unzulässig, weil die Norm nur eine Form (kvartál) für alle Bedeutungen kenne. Da einige nichtstandardsprachliche Akzentvarianten in bestimmten Berufszweigen als Termini zugelassen sind (mil.: raport, Seefahrt: kompás, Luftfahrt: sopló, iskrá, Bergbau: dóbyとa, rúdnik) werde häufig versucht, Prostorečie-Formen als fachsprachlich auszuweisen: $\begin{array}{ll}\text { centnér: } & \text { angeblich Spezialausdruck von Kolchosarbeitern } \\ \text { izobrétenie: } & \text { angeblich Schaffnerjargon }\end{array}$

Die Bevölkerung müsse sich mit den Grundlagen der Sprachkultur befassen, um ein Gefühl für ihre Sprache zu bekommen. Bedauerlich findet er, daß Sprachkultur an Schulen, Lehrstätten und Universitäten nicht als Pflichtfach gelte.

LG 25/78 (21.6.78)

S. 6

\section{KAK MY GOVORIM, KAK MY PISEM}

\section{A. Prijma: "Cepnaja reakcija"}

Aleksej Prijma hält die Sorge um die Reinheit der russischen Sprache für eine der wichtigsten Pflichten jedes Philologen. Er wendet sich scharf gegen Uspenskij, der Fehler entschuldige. Nachsicht gegenüber Fehlern führe nur zu ihrer immer größeren Ausbreitung, und von Unachtsamkeit im Umgang mit grammatischen Regeln sei es nur noch ein kleiner Schritt zur Unachtsamkeit im gedanklichen Ausdruck.

Beispiele:

- vosstanavlivat'defekty (starinnych knig)

- pousjudu 0 carstue zuerej čuvstvo materinstua sposobno preobrazit' lišennogo santimentov životnogo;

- antresol 'nyjètaz, raspoložennyj po unešnemu perimetru zdanija;

- bespamjatstwo bylo niX tožnym - dlinoj v blik

- glucho šumeli ballony po mostovoj

- cuustuo suoego finiša

- televidenie ... učity vaet problemu zritel'nogo ožidanija

- v. . obrazno moral'nom smysle

- raznye konca beskonelnosti

- o čem nadeždy

- načal'nik v suoej zoloćenoj kokarde 
- odety v zelenye dolgopolye thani

- utka... cepko schuatila seleznja

- pozitok statt pozitkov

- kolodca statt kolodcy

\section{KAK MY GOVORIM, KAK MY PIŠEM}

Ju. Kostinskij: „Gramota, grammatika i Zivoe slovo“"

Der Philologe Ju. Kostinskij möchte an der Diskussion über den Sprachgebrauch der Bevölkerung vor allem Philologen, Schriftsteller und Lehrplanersteller beteiligt wissen. Er übt Kritik am muttersprachlichen Unterricht in den Schulen, weil dieser lediglich die Rechtschreibung und die Grammatik des Russischen lehre. Er hält es für notwendig, den Sprachunterricht zu überdenken. So solle man beispielsweise den Schüler im Umgang mit Orthographieund Synonymwörterbüchern anleiten.

In der Auseinandersetzung über sprachliche Richtigkeit dürfe man die Begriffe Grammatik und Orthographie nicht verwechseln. Wie Uspenskij sieht auch er keinen direkten Zusammenhang zwischen der Kenntnis von Orthographieund Interpunktionsregeln und einer fundierten Allgemeinbildung. Es sei falsch, wenn einige Diskussionsteilnehmer behaupteten, die Beherrschung der Rechtschreibung stelle das eigentliche Fundament der Kultur dar (Povarcov) oder Bildung bedeute absolute orthographische Sicherheit (Roskina).

Kostinskij betrachtet nicht alle Normabweichungen als Fehler. Beispielsweise gelte ložit' als verbotenes Verb, obwohl davon dreißig Ableitungen existierten, während das erlaubte klast' nur dreizehn, zudem vorwiegend in Dialekten und Prostorečie gebräuchliche Ableitungen vorweisen könne. Auch die Norm müsse letztendlich das schon von vielen russischen Schriftstellern verwendete ložit' anerkennen. Die Akzentabweichungen kraný, poršnjá und klapaná verurteilt er nicht, weil sie den Gesetzen der Sprachentwicklung entsprächen und als Termini akzeptiert seien.

Er mahnt zur Vorsicht bei der Verurteilung außerstandardsprachlicher Lexik. Nicht alle Neologismen könne man als Modewörter, nicht jeden Archaismus als überholt abtun. Dialektismen dürfe man nicht als sprachliche Charakteristika rückständiger Personen verwerfen. Dialektwörter hätten gemeinsam mit buchsprachlichen Wörtern die Standardsprache gebildet, sie jahrhundertelang vervollständigt. Der Dialekt werde die Standardsprache auch in Zukunft bereichern, denn ohne ihn sei sie farblos und schwerfällig. Besonders die städtischen Schulen müßten ihre überhebliche Einstellung gegenüber dem Dialekt 
ablegen. Den Gebrauch von Jargonismen könne man kaum unterbinden, denn der Jargon enthalte die Expressivität, die der gewöhnlichen Standardlexik fehle.

LG 34/78 (23.8.78)

S. 6

\section{KAK MY GOVORIM, KAK MY PISEM}

M. Sinel'nikov: „O rogatych krasavicach, stydlivych kavy ckach

i fenomene vosklicatel'noj zapjatoj"

Laut Sinel'nikov wird der Sprachkultur zu wenig Aufmerksamkeit geschenkt, was um so bedenklicher sei, als die sichere Beherrschung der Muttersprache Fundament der menschlichen Kultur sei. Er behauptet, „bezgramotnost”“ breite sich immer stärker aus.

Beispiele:

- oplativajte za proezd

- igrat'znaCenie

- vemaja pozicija na reY̌enie souremennoj temy

- pochiscenie iz gosudarstuennoj kazny poltora milliona dollarov.

Unsicherheiten bei Zahlenangaben machen seiner Meinung nach die am weitesten verbreitete Fehlerkategorie in Rundfunk und Fernsehen aus. Als Phänomen der Zeitungssprache bemängelt er den ständigen Gebrauch von Metaphern. Beispiele:

- zoloto

- pacharizelenogo okeana für:

rabotniki lesnoj promyslennosti

- golubaja strada

für: rabota po razvedeniju

- kladovaja sbereženij v ozerach ryby

- sladkij cholod

- cholodnoe lakomstvo

- klykastye

- rogatye krasavicy

für: sberkassa

für: moroženoe

für: volki

für: oleni

Der Kampf für einen richtigen Sprachgebrauch erfordert, so Sinel'nikov, ständig gemeinsame Anstrengungen. Für notwendig hält er Arbeiten zu Sprachfragen wie die von Čukovskij, A. Jugov oder L. Uspenskij.* 


\section{KAK MY GOVORIM, KAK MY PISEM}

A. Tekuð̌ev: „Ne sotvori sebe kumira"

Der Pädagoge Tekučev wendet sich entschieden gegen die Behauptung Roskinas, die russische Bevölkerung verhielte sich gleichgültig gegenüber den erwähnten Fehlern. Sie sei vielmehr so sehr an ihrer Sprache interessiert, daß ihr Wissensdurst nicht hätte gestillt werden können, obwohl in Periodika, den Fernsehsendungen „Potemu my tak govorim", „Iz istorii slov" und „V mire slov" sowie in zahlreichen Publikationen immer wieder Sprachfragen behandelt worden seien.

Tekučev warnt vor einer Uberbewertung der orthographischen Richtigkeit, die bereits 1915 Žitomirskij veranlaßt habe, die Orthographie mit einem Moloch zu vergleichen, dem all zu viele der kindlichen Kräfte geopfert werden. Eine Tendenz dazu bestehe nach wie vor, denn gemäß dem Lehrplan und dem Handbuch Pravila russkoj orfografii i punktuacii (1956) müßten sich die Schüler 421 Regeln aneignen und 106000 Wörter des Orfograficeskij slovar' einpauken. Schon Scerba habe darauf hingewiesen, daß nur einige Korrektoren und Russischlehrer absolut sicher in der Rechtschreibung sein könnten. Tekučev selbst gibt zu, auch er komme nicht ohne Nachschlagen im Wörterbuch aus. Er warnt davor, die orthographische Richtigkeit zum Fetisch zu machen und erinnert an die Pädagogen Bunakov, Šeremetevskij, Žitomirskij und Cernyłev, die schon seit 100 Jahren gegen die harte orthographische Zucht in den Schulen gekämpft hätten, die der großen Mehrheit den Zugang zur Bildung verwehre.

Strenge Beachtung orthographischer Regeln ist seiner Meinung nach nur erforderlich im offiziellen Schriftverkehr: bei Verträgen, Bekanntmachungen, Erklärungen, auf Hinweisschildern und in der Presse. In der Schule sollte nur die Beherrschung eines Minimums an Orthographie- und Interpunktionsregeln verlangt werden. Dabei seien folgende Leitsätze angebracht:

- durch orthographische Normabweichungen darf keine Mehrdeutigkeit entstehen (z. B. bei bal - ball),

- Verstöße gegen grammatische Regeln sind unzulässig,

- der Schüler soll sich 3000-4000 Wörter aneignen, die Ausnah. men darstellen, aber weder veraltet, noch reine Jargonismen oder Professionalismen sind. 


\section{KAK MY GOVORIM, KAK MY PIঙ̌M}

\section{K. Gorbą̌evið: „Zakonomernosti mira slov“}

Gorbačevič bedauert, daß Diskussionen über Sprachpflege nur sporadisch geführt werden. Auf einige erregte Leserbriefe folgten 2-3 Artikel von Fachleuten,und schon sei das Thema für Jahre abgeschlossen. Seiner Meinung nach gehört die Erörterung von Problemen der Sprachkultur zum Grundbestand der Allgemeinbildung.

Im weiteren kritisiert er Dilettantismus auf dem Gebiet der Sprachwissenschaft. Schuld daran tragen, so Gorbačevið̌, zum Teil die Sprachwissenschaftler selbst, da sie dem breiten Leserkreis nur vereinfachte und dogmatische Traktate zugänglich machten. Der zeitgenössische Leser begnüge sich aber nicht mit derartigen Belehrungen und entwickle daher eigene Vorstellungen über Sprache. Anstelle von vereinfachten Belehrungen benötige die Bevölkerung Erklärungen für die komplizierten und widersprüchlichen sprachlichen Erscheinungen, wie z.B. die Beschreibung der Sprachentwicklung als Folge der Veränderung objektiver Bedürfnisse des Menschen. Die Kriterien der Sprachwissenschaft zur Trennung des akzeptablen Neuen vom Falschen sollten aufgedeckt werden. Als solche Kriterien nennt er den Wortgebrauch der „mastera slova“, Ergebnisse von Meinungsumfragen und statistischen Berechnungen, Vergleiche mit anderen Sprachen, vor allem aber die Aufzeichnung und Analyse der Sprachentwicklung und das Prinzip der Zweckmäßigkeit.

Nur mit Hilfe kühler, verstandesmäßiger Beobachtung könne man die Gesetzmäßigkeiten der Sprache erfassen, keinesfalls dürfe man sich am eigenen Geschmack orientieren, dem oft das Alte angenehmer als das Neue erscheine.

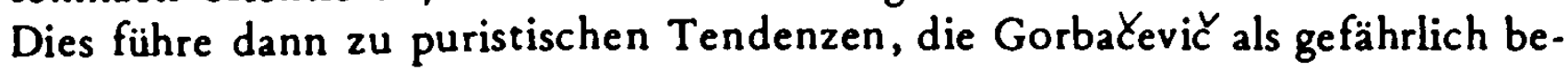
zeichnet.

Was die orthographische Richtigkeit betrifft, so unterstützt Gorbačevið uneingeschränkt die Ausführungen Tekuěevs. Er fügt hinzu, daß auch die Vermittlung des von Tekuðev beschriebenen orthographischen Minimums nicht durch bloßes Einpauken von Regeln und Ausnahmen geleistet werden kann. Der unbestrittene Nutzen von Diktaten dürfe nicht zu einem Orthographieterror führen. 


\section{KAK MY GOVORIM, KAK MY PIŠEM}

\section{Fonjakov: „Pravo na bezgramotnost'?“}

Il'ja Fonjakov wirft Tekučev vor, sein Artikel vermittle den Eindruck, als sei man schon bereit, vor der „,bezgramotnost" zu kapitulieren, und bemühe sich nur noch darum, die besten Bedingungen herauszuschlagen. Fonjakov dagegen ist davon überzeugt, daß der tadellose Sprachgebrauch ein erreichbares Lernziel für jeden einzelnen ist. Wenn die Schule heute nicht mehr in der Lage sei, dies zu gewährleisten, dann dürfe man nicht resignieren, sondern müsse nach den Ursachen dafür suchen. Fonjakov zweifelt daran, daB jemand, dem Fehler wie izvenite, ezdijut, poluklinika unterlaufen,je ein guter Mathematiker wird, da solche Fehler auf Denkfaulheit schließen ließen. Jeder müsse sich um Sprachkultur bemühen. Dies heiße jedoch nicht, dilettantische Urteile, die nicht auf wissenschaftlicher Untersuchung basieren, über die russische Sprache zu fällen, wie es etwa $K$. Jakovlev in seiner Broschüre Kak my portim

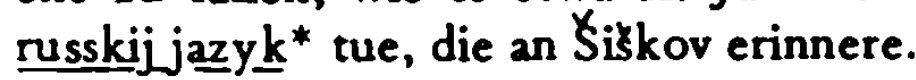

Fonjakov kritisiert vor allem Jakovlevs ablehnende Haltung gegenüber Fremdwörtern:

rev'ju, chobbi, motel', servis, autsajder, referi, plantacija

Er verteidigt die Fremdwörter, indem er darauf hinweist, daß sie sich nicht einfach durch russische Wörter austauschen ließen und auf keinen Fall russische Wörter verdrängten.

Die Unterstützer einer sterilen Reinheit des Russischen wendeten sich jedoch nicht allein gegen Fremdwörter, sondern auch gegen manche russische Bildung, wie z.B. das Suffix - šcina:

Jaroslaułzina, Pskoušcina

Ihrer Behauptung, diese Ableitungen assoziierten tureť̌ina, nemeť̌ina, inozemščina, hält er die Bildungen Zadonšcina und sel'ščina (Esenin) entgegen.

Für Fonjakov ist tadellos richtiger Sprachgebrauch ebenso bindend wie die Schulpflicht. Fehler seien zwar möglich, man müsse sich ihrer aber schämen und sie so schnell wie möglich verbessern. 


\title{
KAK MY GOVORIM, KAK MY PISEM
}

\section{Arkin: „Russkij jazyk i 'teorija otnositel'nosti'“}

Arkin sieht die Ursache für falschen Sprachgebrauch darin, daß in den Klassen 9 und 10 der Russischunterricht fehle. Der Ausschluß des Faches Russisch aus den Lehrplänen der obersten Klassen führe zur Verschlechterung des Sprachgebrauchs der Schüler und somit auch zur Verringerung ihres Bildungsniveaus.

Die Wichtigkeit der Orthographie sollte jedoch nicht überbewertet werden, da die Grundlage für richtigen Sprachgebrauch das Sprachgefühl des Schülers und seine ästhetische Unduldsamkeit gegenüber Fehlern sei. Gerade in der 9. und 10. Klasse sollten den Schülern das Sprachsystem und dessen innere Logik und Gesetzmäßigkeit vermittelt und komplizierte Fragen der Sprachkultur und Stilistik behandelt werden.

\section{KAK MY GOVORIM, KAK MY PIŠEM}

\author{
Ju. Glazkov: „Čast' našej Žizni““
}

Der Kosmonat Glazkov äußert sein Erstaunen über das Interesse, mit dem so viel Menschen über die russische Sprache schreiben. Als Grund dafür sieht er die wichtige Rolle, die das Russische als Muttersprache, Internationalitätenkommunikationsmittel und Weltsprache spiele, die muttersprachlich Russischsprechenden zu richtigem Sprachgebrauch verpflichte.

\section{Uspenskij: „Orfografija i živaja reł”“}

Der Leser M. Uspenskij weist nochmals auf die Gefahr einer Uberbewertung der orthographischen Richtigkeit hin, die schon mehrfach zu dramatischen Konflikten geführt habe. Anstelle von Orthographie- und Interpunktionsübungen sollten Úbungen stehen, mithilfe derer sich die Schüler zunächst eine sichere Sprachpraxis aneigenen können, die dann auch die Entwicklung orthographischer Fertigkeiten erleichtere. Gerade die Schriftsteller müßten seiner Meinung nach der einseitig an orthographischen Kriterien orientierten Bewertung des Sprachgebrauchs von Schülern eine Absage erteilen. 


\section{T. Lipatnikova: „Kto platit 'za ošibki'?““}

Lipatnikova bemängelt, daß kaum jemanden sprachliche Fehler auf Hinweisschildern und Bekanntmachungen störten. Gerade hier müsse die Allgemeinheit eingreifen, da auf der Straße keine sprachliche Kontrolle durchgeführt werde, vgl.:

Beispiele:

- oplačivat'za proezd;

- u graŻdan s pugovicami veک̌ci v čistku ne prinimajut;

- nesminaemaja skladka na bjurkach $i$ jubkach plisse garantiruet nesminaemost'v teל enie mesjaca,

- - naY̌ej stolovoj otkryta predprazdnitnaja torgoulja polufabrikatovi kulinarnych izdelij;

- antrikot

- beušteks

- grej frukty

Sie appelliert an das Verantwortungsbewubtsein der Verwaltungsangestellten für die sprachliche Form öffentlicher Bekanntmachungen. Außerdem schlägt sie die Aufstellung einer "Sprachpatrouille" (patrul' gramotnosti) in Pionierabteilungen und "Kontrollposten für die sprachliche Richtigkeit" (kontrol'nye posty gramotnosti) in Schulkomitees vor.

LG 52/78 (27.12.78)

\section{KAK MY GOVORIM, KAK MY PIŠEM}

\section{"Ctob slovom vyrazit' sebja" (Rundgespräch)}

Zum Abschluß der Artikelreihe organisiert die LG ein Rundgespräch mit Schriftstellern (V. Subbotin, L. Uspenskij, I. Fonjakov), Pädagogen (V.A. TekuZev, I.I. Arkin, Ju.M. Kostinskij, Ju. Ravenskij und dem Leiter der Sektion für Sprachkultur am IRJaz, L.I. Skvorcov.

In diesem Rundgespräch geht es in erster Linie um die Frage, ob tatsächlich in der Bevölkerung ein derartig niedriges Sprachniveau bestehe, wie dies in einigen der vorangegangenen Artikel behauptet wurde, und wie man diesen $\mathrm{Zu}$ stand beheben könne.

Besonders Fonjakov bejaht die erste Frage. Tekučev, Uspenskij und Skvorcov weisen darauf hin, daß man nicht alle Abweichungen von der Norm als Fehler bezeichnen dürfe, da sie oft darauf zurückgeführt werden müßten, daß sich die Norm verändere. Uspenskij ist dabei der Auffassung, die Bevölkerung sei heute 
zu schnell bereit, nach vermeintlichen Fehlern zu suchen. Er spricht sich vor allem gegen die Uberbewertung orthographischer Unzulänglichkeiten aus.

Fonjakov unterstreicht noch einmal sein Erstaunen darüber, da $B$ es laut Tekučev unmöglich sein solle, bei Schülern in zehn Schuljahren eine absolute Beherrschung der Muttersprache zu erreichen, während man innerhalb von wenigen Monaten eine Fremdsprache erlernen könne. Anscheinend orientiere man sich, wenn es um die Muttersprache gehe, ausschließlich an den faulen und desinteressierten Schülern.

Tekučev kritisiert Fonjakov heftig. Den Fremdsprachenunterricht könne man unmöglich mit dem muttersprachlichen vergleichen. Die heutige Schule orientiere sich in ihren Anforderungen an den Möglichkeiten der Schüler und den Erfordernissen der Gesellschaft. Er verteidigt die in seinem Artikel vorgebrachte Forderung, die Vermittlung von Orthographieregeln in der Schule auf ein Minimum zu beschränken. Eine Vorstellung von der Struktur und der Funktion seiner Sprache sei für den Schüler wichtiger als die detaillierte Kenntnis orthographischer Regeln, meint auch Ju. Kostinskij. Seiner Meinung nach müßte der Russischunterricht Schritt für Schritt in die Lexik, die Phonetik, die Grammatik und Stilistik einführen und darüber hinaus auch Kenntnisse in Sprachgeschichte vermitteln.

Auch das Problem der Sprachklischees wird angeschnitten, deren Verwendung Subbotin für gefährlicher als orthographische Fehler hält.

Subbotin meint, Zeitungen müßten regelmäßig spracherzieherische Artikel veröffentlichen. Skvorcov unterstützt ihn, indem er fordert, daß die Rubrik „Kak my govorim, kak my pišem" zu einem festen Bestandteil der LG wird. Fonjakov dagegen hält einen "Tag der Sprache" für sinnvoller, wie ihn bereits Cukovskij vorgeschlagen habe. 


\section{ANHANG}


af

14 If

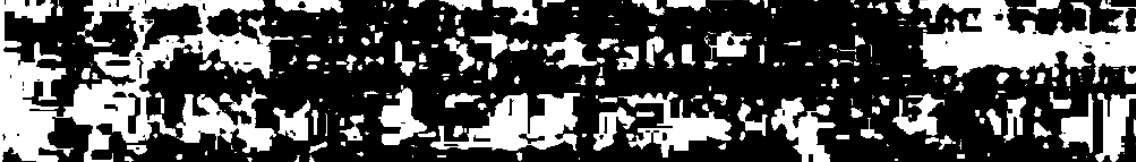

$=0$

3 tipitis

-

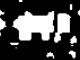

$\operatorname{lin}_{1}$

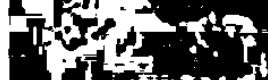

20 rom

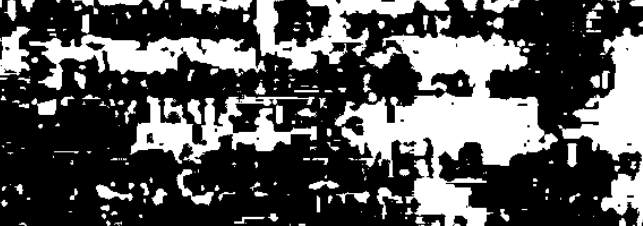

ing $y^{2} 17$

- $\quad \therefore \rightarrow=3$

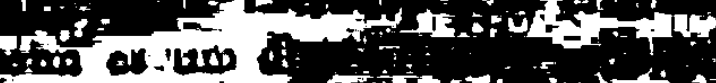

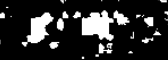

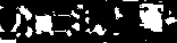

inte

:

:5 : :

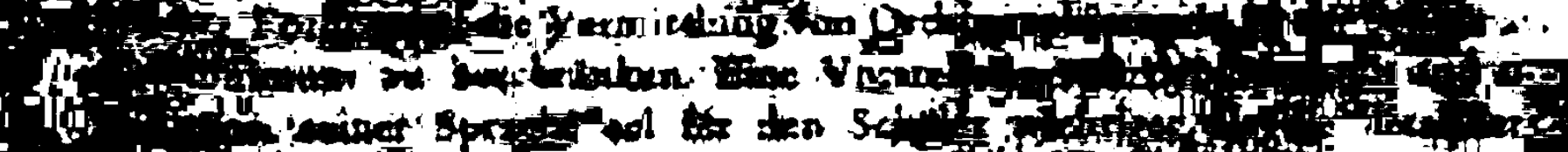

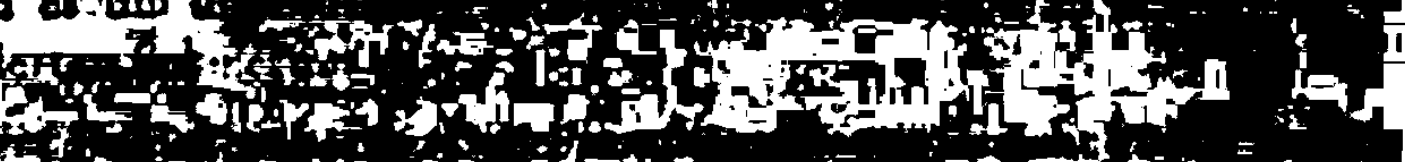

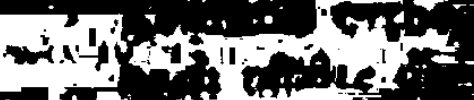

F' yis :

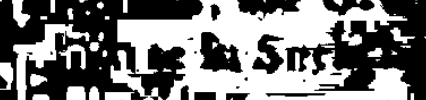

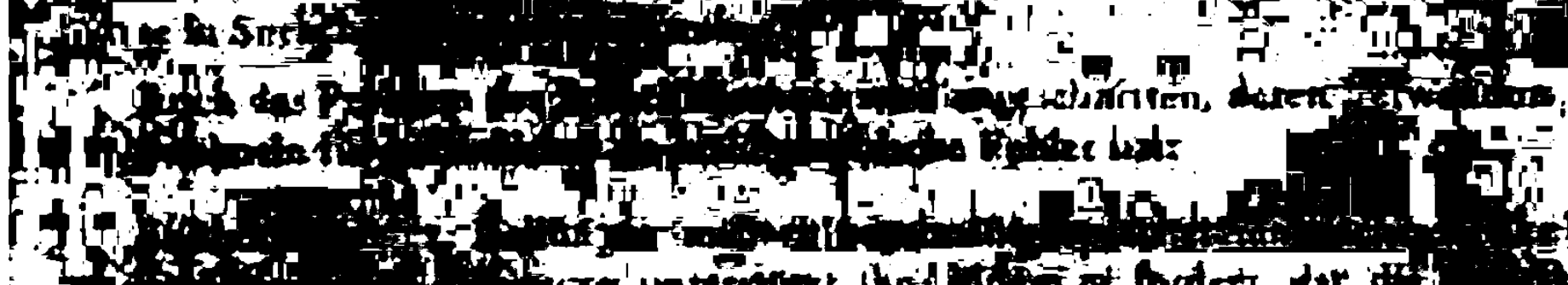

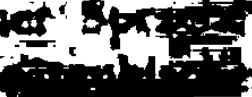
and

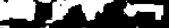

Cin of 1

光

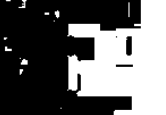

sta

80.42

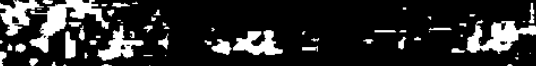

Hif

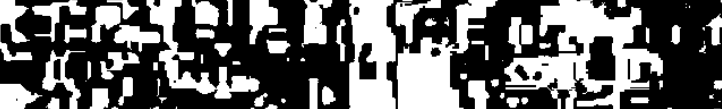

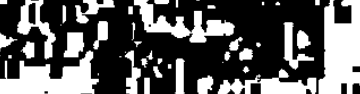

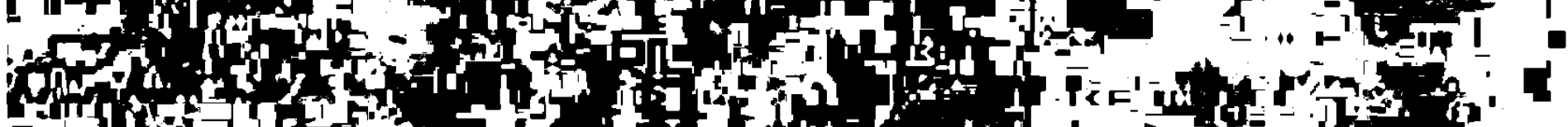

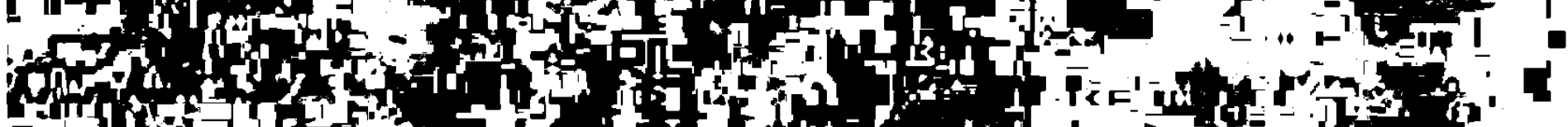

2.

It

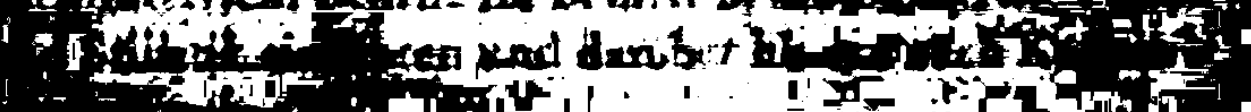

10

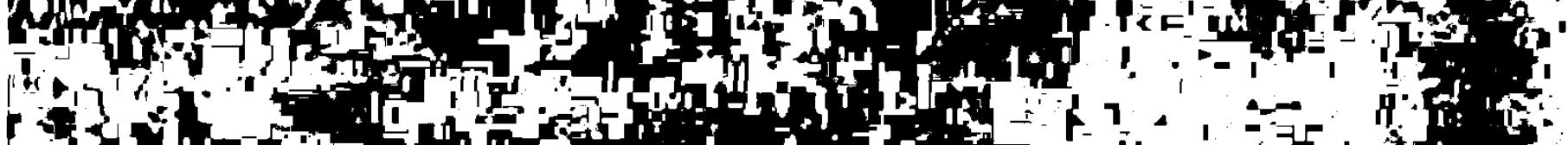

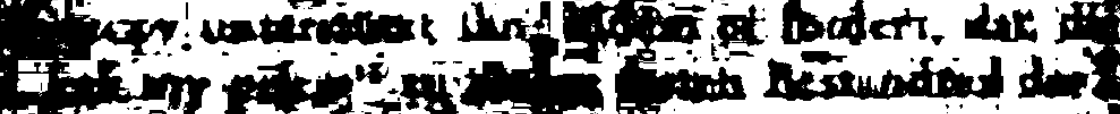

trit

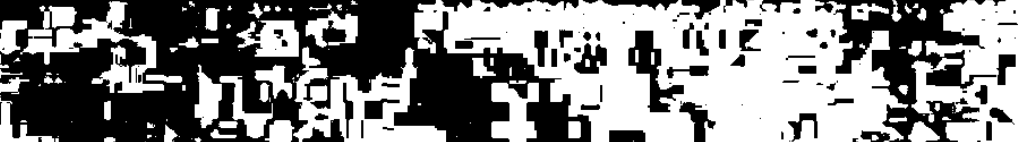

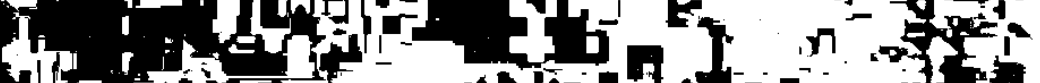

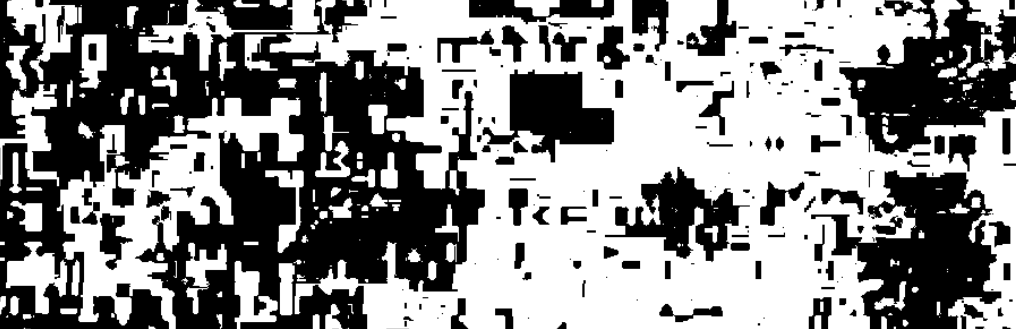

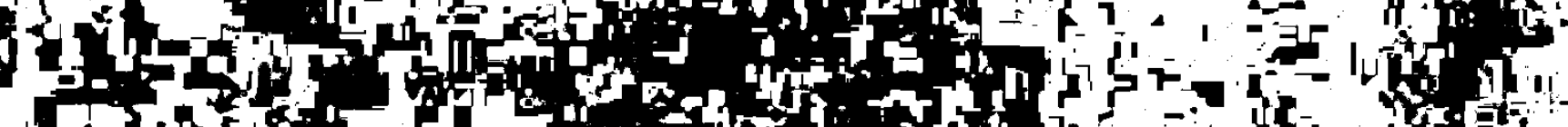

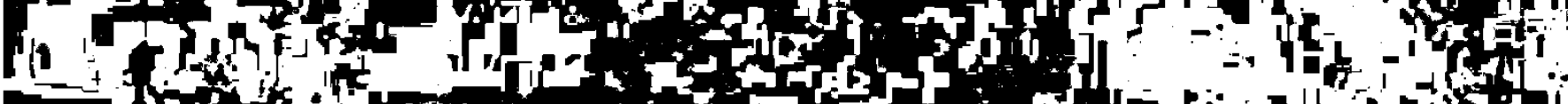
culy

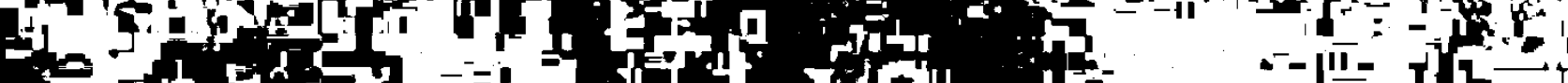

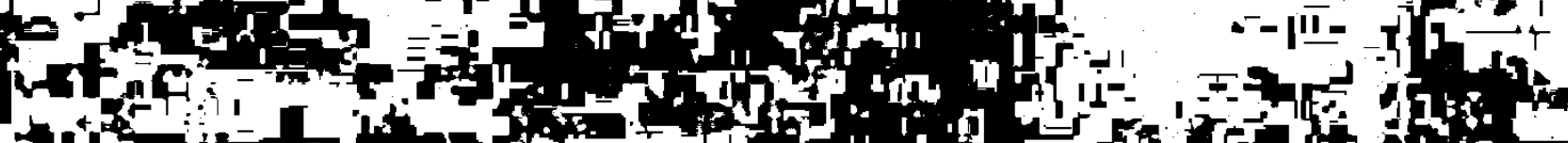

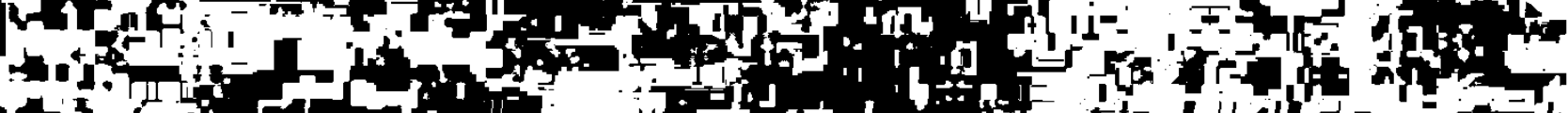
E la

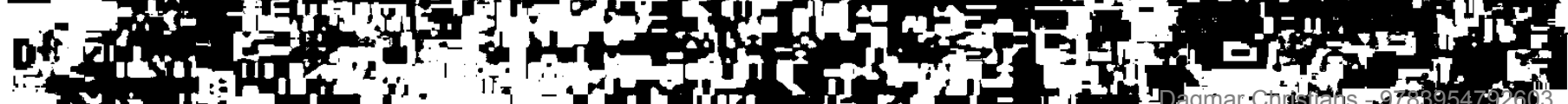
in 


\section{Index zur Dokumentation}

ABDULLIN

ABRAMOV

ALEKSEEV u.a.

ANASENKOV

ANDREEVA

ANDRJJAYYVIN

ANTOKOL SKIJ

ARDABYVSKAJA

ATAROV

ARKIN

A VILOVA/

DERJAGIN

AVRACHOV

AZBEL

BABKIN

BAKANOVIČ

BARUZDIN

BARYKIN

BELJAREV

96/65 : Abdullin, ,Po ili o?", in LG 96/65 (S. 134)*

47/72 : F.Abramov, ,Jazyk na kotorom govorit vremja", in: $L G$ 47/72, (S. 191)

21/71 : M. Alekseev/ S. Baruzdin/ G. Berezko/ V. Kožemnikov/ L. Tat'janizeva, ,Zaslon slovesnoj Keluche!", in: LG 21/71, (S. 168)

47/76 : B. AnaY̌enkov, "Ispytanie vyborom", in: LG 47/76, (S. 225)

44/71 : V. Andreeva, "Moj drug, moe vtoroe ja", in: LG 44/71, (S. 180)

42/71 : N. Andrijałvin, (Leserbrief o. Titel), in: LG $42 / 71,($ S. 180)

7/65 : P. Antokol'skij, „Smotret' v koren'!“, in: LG $7 / 65,($ S. 131)

84/64 : E. Ardabyvskaja, „Susuar' i ingibitor", in: LG $84 / 64$, (S. 119)

35/71 : N. Atarov, ,Zamutilis' li vody?", in: LG 35/71, (S. 175)

48/78 : I. Arkin, „Russkij jazyk i teorijz otnositel'nosti", in: LG 48/78, (S. 242)

13/69 : N. Avilova/ V. Derjagin, „Nužna li èta załtita?“, in: LG 13/69, (S. 159)

38/71 : P. Avrachov (Leserbrief o. Titel), in: LG 38/71, (S. 177)

21/68 : M. Azbel', „O nauke i ee jazyke“, in: LG 21/68, (S. 153)

31/72 : A. Babkin, „NastojaSčemu slovu-nastojaščee mesto", in: LG 31/72, (S. 189)

41/72 : ders.: „Bogatstva russkoj re ${ }^{i}$ “, in: LG 41/72, (S. 191)

33/76 : T. Bakanovit, (Leserbrief o. Titel), in: LG 33/76, (S. 224)

$127 / 65$ : S. Baruzdin, „Kaleten'e slovom", in: LG 127/65, (S. 136)

34/67 : K. Barykin, „Skoraja lingvistiદeskaja otve飞aet", in: LG 34/67, (S. 146)

36/67 : A. Beljarev, (Leserbrief o. Titel), in: LG 36/67, (S. 147)

- Die in Klammern gesetzten Seitenzahlen beziehen sich auf die Dokumentation. 
BËLZA

BIRJUKOV

BLOCHIN

BOBKOV

BOKOV

BORISOV

BORISOVA

BOROVOJ

BOROVSKIJ

BRAGINA

ČERNUCHIN

CHODI-ZADE்

ČISTJAKOV

ČIVILICHIN (S. 140)

С̆TOB SLOVOM ... 52/78 : „Čtob slovom vyrazit' sebja“, (Rundgespräch),

in: LG 52/78, (S. 243)

ČUDAKOV

ČUKOVSKIJ

13/69 : I. Bèlza, „V pylu polemiki“, in: LG 13/69, (S. 160)

12/66 : F. Birjukov, „Blił̌e k Kivomu slovu“, in: LG 12/66, (S. 143)

44/71 : ders., "O kristallach slov, o slovesnoj pyli“, in: LG 44/71, (S. 181)

8/73 : M.A. Blochin, „Ne pridetsja li menjat' grammatiku?", in LG 8/73, (S. 194)

22/78 : F. Bobkov, „Ołibki, kotorych ne bylo", in: LG 22/78, (S. 234)

92/64 : V. Bokov, „Sokrovennoe", in: LG 92/64, (S. 120)

$6 / 73$ : ders., „Rodnoe slovo, bogatstvo nase ...", in: LG 6/73, (S. 194)

2/68 : L. Borisov, „Letajte samoletami!“, in: LG 2/68, (S. 150)

29/71 : M. Borisova, „Muki slova“, in: LG 29/71, (S. 150)

43/74 : dies., ". . . i tvoj stil' sam nachodit sebja", in: LG 43/74, (S. 212)

20/76 : dies., ,... rossijskomu jazyku iskusen“, in : LG 20/76, (S. 221)

$2 / 68$ : L. Borovoj, „Mnogoe v nemnogom", in: LG 2/68, (S. 149)

$7 / 69$ : Ja. Borovskij, „Živoe slovo i normalizatory“, in: $L G$ 7/69, (S. 159)

44/69 : A. Bragina, „Metafory podlinnye, metafory ložnye", in: LG 44/69, (S. 163)

38/71 : L. Cernuchin, (Leserbrief o. Titel), in: LG 38/71, (S. 177)

38/71 : R. Chodi-Zade, "S to乙ki zrenija istorizma", in: LG 38/71 (S. 178)

14/78 : V. Ċistjakov, „V zatorach kosnojazyčija“, in: LG 14/78, (S. 231)

148/65 : V. Civilichin, „Replika v spore", in: LG 148/65,

41/73 : A. Čudakov, „Zivoe slovo i kanony chrestomatij", in: LG 41/73, (S. 201)

33/76 : ders., ,Soblazn uproščenij“, in: LG 33/76, (S. 223)

144/64 : K.I. Cukovskij, „Na tu Že temu“, in: LG $144 / 64$, (S. 129) 
ČURMAEVA

DAVYDOV

DEMINA

DICKSON

DIK

DZEVANOVSKI]

EFIMOV

ES'KOVA

FEDORENKO

FILIMONOV

FILIN

FIRSOV

FONJAKOV
51/68 : N. Curmaeva, „Ostroumnyj - ,bystroumnyj”“, in: LG 51/68, (S. 158)

18/71 : V. Davydov, ,... ne v stroku“, in: LG 18/71, (S. 167)

17/78 : G. Demina, „Razomknut' krug“, in: LG 16/78, (S. 234)

21/68 : B. Dickson, „Połemu tak govorit?", in: LG 21/68, (S. 154)

5/68 : I. Dik, „IŠcite kosku!“, in: LG 5/68, (S. 152)

80/64 : Ju. Dzevanovskij, „Slovoprodukty“, in: LG 80/64, (S. 118)

34/64 : A.I. Efimov, ,,Sila tradicii ili . ..“, in: LG 34/64, (S. 112)

29/68 : N.A. Es'kova, „Žjul' Vermu ili Žjulju Vemu?”, in: LG 29/68, (S. 155)

5/74 : N.T. Fedorenko, „Ne perevesti li na russkij?“, in: $L G 5 / 74$, (S. 206)

27/73 : M. Filimonov, (Leserbrief o. Titel), in: LG 27/73, (S. 199)

16/74 : F.P. Filin, „Kogda i kak perevodit' na russkij?“", in: LG 16/74, (S. 207)

17/76 : ders., „Zakony jazyka, tajny slova", in: LG 17/76, (S. 219)

23/68 : O. Firsov, „Učti!“, in: LG 23/68, (S. 155)

43/73 : I. Fonjakov, „Sadis', Mašen'ka, pjaterka!“", in: LG 43/73, (S. 201)

44/78 : ders., „Pravo na bezgramotnost'?“, in: LG 44/78, (S. 241)

FORMANOVSKAJA 14/77 : N. Formanovskaja, „Osibki ili priem?“, in: LG 14/77, (S. 227)

GAL'

22/78 : N. Gal', „Navalit'sja vsem mirom“, in: LG

GALACHOV

GARMONIJA I STICHIJA

GAZARJAN

GECOV

GIL'VARG
22/78, (S. 234)

28/69 : G. Galachov, (Leserbrief o. Titel), in: LG 28/69, (S. 162)

"Garmonija i stichija" (Gespräch zwischen A.

50/76 : Latynina, F.P. Filin und V. Gusev), in: LG 50/76, (S. 226)

50/72 : S. Gazarjan, „Skol'ko vesit slovo?“, in: LG 50/72, (S. 193)

5/68 : A. Gecov, (Leserbrief o. Titel), in: LG 5/68, (S. 152)

28/69 : S. Gil'varg, (Leserbrief o. Titel), in: LG 28/69, (S. 162) 
GLADILIN

GLAZKOV

GORBAČEVIC̆

GORBUNOV

GRIGOR'EV

GRIGORJAN

GULJANICKAJA

GUSEV

INBER

ISAKOVSKIJ

JUGOV

JUNKER

KAKOJ NAM NUŽEN ...

KALININ
32/74 : A. Gladilin, „Nad slovom ja slezami obol'jus”“, in: LG 32/74, (S. 211)

49/78 : Ju. Glazkov, "Cast' našej žizni“, in: LG 49/78, (S. 242)

47/69 : K.S. Gorbačevið, „BárŽa ili barzaá?“, in: LG 47/69, (S. 164)

12/72 : ders., „Vol'nost'? Skoree ołibka . . .", in: LG 12/72, (S. 185)

34/77 : ders., „Oblono - on ili ono?", in: LG 34/77 (S. 229)

5/78 : ders., Maneur ili manëur?", in: LG 5/78, (S. 230)

39/78 : ders., „Zakonomernosti mira slov", in: LG 39/78, (S. 240)

28/69 : V. Gorbunov, (Leserbrief o. Titel), in: LG 28/69, (S. 162)

12/66 : V. Grigor'ev, "I poètam nužno znat' lingvistiku", in: LG 12/66, (S. 144)

20/69 : V. Grigorjan, „Čto sčitat' normoj?“, in: LG 20/69, (S. 140)

5/68 : G. Guljanickaja, (Leserbrief o. Titel), in: LG 5/68, (S. 152)

18/76 : V. Gusev, „Muzyka i poezzija prozy“, in: LG 18/76, (S. 220)

120/64 : V. Inber, „Davajte podumaem chorołen'ko“, in: LG 120/64, (S. 126)

135/64 : M. Isakovskij, "Možno li postroit' ozero?“, in: LG 135/64, (S. 108)

128/65 : A. Jugov, „Okean za reYetkoj“, in: LG 128/65, (S. 136)

16/78 : B. Junker, „Inžener dolžen byt' gramotnym", in: LG 16/78, (S. 233)

23/72 : „Kakoj nam nužen slovar'?“, (Rundgespräch mit Latynina, Filin, Babkin, Protčenko, Abramov und Uspenskij', in: LG 23/72, (S. 188)

35/71 : A. Kalinin, „Naprasnye strachi“, in: LG 35/71, (S. 176)

$27 / 73$ : ders., „Ne edinoj merkoj“, in: LG 27/73, (S. 199)

50/73 : ders., „Kak slovo naše otzovetsja“, in: LG 50/73, (S. 205)

21/75 : ders., ,Sem' raz otmer"“, in: LG 21/75, (S. 215)

26/76 : ders., "Cuvstvovat' vozrast slova“, in: LG 26/76, (S. 223) 
KANA

KAPANAD $\overline{\mathbf{Z}} \overline{\mathbf{E}} \mid$

KRYSIN

KARBOVSKAJA

KARPENKO

KAŠIN

KAS'JANOVA

KAZANCEV

KIPNIS

KIRSANOV

KLENICKAJA

KOGAN

KOLESNIKOV

KONDYREV

KOROBAN

KOROSTYLEVA

KOSINSKIJ

KOSTINSKIJ

KRON/

USPENSKIJ

KRYSIN

KURTYNIN

LANŠČIKOV

LASKIN
52/71 : V. Kanaš, ,Točki nad ë", in: LG 52/71, (S. 184)

$5 / 68$ : L. Kapanadze/ L. Krysin, ,Možno li sest' tri tarelki", in: LG 5/68, (S. 151)

30/68 : V. Karbovskaja, „Nu propalo, čto Ze izmenilos'?", in: LG 30/68, (S. 156)

33/76 : Ju. Karpenko, (Leserbrief o. Titel), in: LG 33/76, (S. 224)

35/67 : L. Kašin, (Leserbrief o. Titel), in: LG 35/76, (S. 147)

38/71 : V. Kas'janova, (Leserbrief o. Titel), in: LG $38 / 71,(S .177)$

84/64 : P. Kazancev, „Objazany, no...", in: LG 84/64, (S. 119)

39/67 : S. Kipnis, (Leserbrief o. Titel), in: LG 39/67, (S. 148)

$117 / 64$ : S. Kirsanov, „Vopreki bukve i duchu“, in: LG 117/64, (S. 124)

51/73 : I. Klenickaja, „Ne nado zubrežki!", in: LG 51/73, (S. 205)

115/64 : B. Kogan, „I tak, i èdak“, in: LG 115/64, (S. 124)

30/73 : N. Kolesnikov, „Novye obrazy - novyj jazyk“, in: LG 30/73, (S. 200)

117/64 : L. Kondyrev, „Edva li èto blagotvorno?", in: LG 117/64, (S. 125)

9/66 : V. Koroban, „Pritiny i sledstvija“, in: LG 9/66, (S. 143)

46/73 : B. Korostyleva, „Bagrjannaja zol'?“, in: LG 46/73, (S. 203)

20/69 : I. Kosinskij, „Ne putanica, a tradicija“, in: LG 20/69, (S. 162)

$31 / 78$ : Ju. Kostinskij, „Gramota, grammatika i živoe slovo", in: LG 31/78, (S. 237)

123/65 : A. Kron/ L. Uspenskij, „Kavycki i kakbyčegonevyčki", in: LG 123/65, (S. 135)

3/71 : L. Krysin, "Spory i normy" in LG 3/71, (S. 166)

25/71 : M. Kurtynin, „Esli ty Žrnalist", in: LG 25/71, (S. 170)

14/72 : A. Lanšcikov, „Ne pokuకajas' na normu“, in: LG 14/72, (S. 186)

109/64 : B. Laskin, „Rasskaz na zakaz", in: LG 109/64, (S. 123) 
LEBEDEV

LEJTES

\section{LEONOV}

LEV

LEVIN

LEVIN

LIPATNIKOVA

LIPATOV

LYŠČINSKIJ

MAKSIMOVA

MALOV

MOCAREV

MOISEEV

MOROZOV

MOŽAEV

MUCHOV

NAZARENKO

NERSESOV

NIKIFOROV

NIKOLAEV

NIKONOV
14/78 : N. Lebedev, „Vladet' slovom“, in: LG 14/78, (S. 231)

62/65 : A. Lejtes, „Vozmožnosti slova“, in: LG 62/65, (S. 132)

$148 / 65$ : ders., „Sobor, a ne summa kamnej“, in: LG 148/65, (S. 140)

$118 / 64$ : L. Leonov, „Prołu slovo“, in: LG 118/64, (S. 105)

$14 / 72$ : F. Lev, „Cto my ostavim detjam?", in: LG 14/72, (S. 187)

$134 / 65$ : F. Levin, „K to chołet posadit' derevo ... .“, in: LG 134/65, (S. 138)

$32 / 74$ : L. Levin, „.. . to, ¿to est' Dunja, dolŽno byt' mužinoju", in: LG 32/74, (S. 212)

49/78 : T. Lipatnikova, „Kto platit za ošibki?“, in: LG 49/78, (S. 243)

34/71 : V. Lipatov, "Slovo v opasnosti“, in: LG 34/71, (S. 174)

21/68 : G. Lyš̌̌inskij, „Suščestvuet li takaja problema?“ in: LG 21/68, (S. 154)

$120 / 64$ : L. Maksimova, „Usvaivat' pravila budet leg飞e“, in: LG 120/64, (S. 126)

9/66 : F. Malov, „Poš adim koromyslo“, in: LG 9/66, (S. 142)

4/65 : I. Mocarev, „Modnye slove ¿ki“", in: LG 4/65, (S. 131)

96/65 : Z. Moiseev, „Prilip ̌ivaja bolezn' : kanceljarit“, in: LG 96/65, (S. 133)

101/64 : A. Morozov, „... a poisk prodolžaetsja“, in: LG 101/64, (S. 121)

23/76 : B. Možaev, ,Moment neponjatnosti i Cuvstvo slova", in: LG 23/76, (S. 222)

8/73 : A. Muchov, „Pora rešat'!“, in: LG 8/73, (S. 195) 140/65 : V. Nazarenko, „Chudožnik ili pisar'?“, in: LG 140/65, (S. 139)

33/76 : L. Nersesov, (Leserbrief o. Titel), in: LG 33/76, (S. 223)

16/78 : V. Nikiforov, „Gramotnost' - ne fetiš“, in: LG 16/78, (S. 233)

48/73 : Nikolaev, „E்to volnuet vsech", in: LG 48/73, (S. 204)

51/68 : N. Nikonov, „Genij i Vinegret“, in: LG 51/68, (S. 158) 
ORLOV

PETROVA

PETUŠKOV

PLENKIN

POKROVSKIJ

POLIŠČUK

POLKOVNIKOV

PONOMAREV

POVARCOV

PRIJMA

PROCEROV

RACHMANOVA

RACHMANOVA/
FORMANOVSKAJA

RED.

REZNIK

RODIONOV

ROSKINA

ROŽANSKIJ

ROŽDESTVENSKI

23/78 : L. Orlov, (Leserbrief o. Titel), in: LG 23/78, (S. 235)

11/74 : A. Petrova, „Ne nazvat' li košku kołkłoj?“, in: LG 11/74, (S. 183)

40/71 : V. Petuškov, „Pravil'no li my govorim?“, in: LG 40/71, (S. 178)

54/64 : N. Plenkin, "Eto vse polumery", in: LG 54/64, (S. 114;

28/69 : A. Pokrovskij, (Leserbrief o. Titel), in: LG 28/69, (S. 163)

$3 / 66$ : Ja. Polišuk, „Bantiki fel'etona", in: LG 3/66, (S. 142)

20/69 : B. Polkovnikov, „Vezde nužna mera", in: LG 20/69, (S. 161)

72/64 : R. Ponomarev, (Leserbrief o. Titel), in: LG 72/64, (S. 118)

16/78 : S. Povarcov, ,Zamknutyj krug", in: LG 16/78, (S. 232)

25/78 : A. Prijma, "Cepnaja reakcija“, in: LG 25/78, (S. 236)

22/73 : B. Procerov, „NauXno-techni LG 22/73, (S. 199)

14/77 : L. Rachmanova, „On, ona, ono“, in: LG 14/77, (S. 228)

$11 / 77$ : L. Rachmanova/ N. Formanovskaja, „Cto takoe chorošist?", in: LG 11/77, (S. 227)

31/77 : dies., "Dizajner ili chudožnik-konstruktor?“, in: LG 31/77, (S. 228)

29/71 : Red., "Idet letuckka", in: LG 29/71, (S. 171)

34/71 : Red., "PriglaSenie $k$ razgovoru", in: LG 34/71, (S. 173)

18/71 : P. Reznik, ,Ja za, no ...“, in: LG 18/71, (S. 167)

21/68 : M. Rodionov, „Éto delo samych učenych", in: LG 21/68, (S. 154)

$14 / 78$ : N. Roskina, „Izvenite za ošibki"“, in: LG 14/78, (S. 230)

144/64 : A. Rožanskij, „Obnovlenie s ušcerbom", in: LG 144/64, (S. 128)

V. RoZdestvenskij, „Osnovanija dlja trevogi est'!", in: LG 42/71, (S. 179)

29/74 : ders., ,Vyrazitel'nost', dostupnost', tołnost “", in: LG 29/74, (S. 209) 
RUBAKIN

RUBCUV

RYLENKOV

SABSOVIČ

SAFONOV

SAGINJAN

SAKK

SELEZNEV

SELIVERSTOVA

SEMENOV

SEMENOV

SEREBRJAKOVA 120/64:

ŠERGIN

92/64 : N. Rubcov, ,Monomachova papacha“, in: LG 92/64, (S. 120)

31/74 : A.N. Rubakin, „Kogda ustricy stanovjatsja kljukvoj", in: LG 31/74 (S. 210)

„Russkij jazyk - problemy real'nye i mnimye“" (Interview mit F.P. Filin), in: LG 16/73, (S. 196)

96/64 : N. Rylenkov, „Iz rodnikovych glubin“, in: LG $96 / 64,($ S. 121)

33/76 : Ja. Sabsovit, (Leserbrief o. Titel), in: LG 33/76, 33/76, (S. 224)

31/67 : V. Safonov, „Echajte!", in: LG 31/67, (S. 146)

$126 / 64$ : M. Saginjan, „Ne vklučajas' v spor", in: LG $126 / 64$, (S. 127)

37/64 : S. Sakk, „Ugroza . . . novoj reformy“, in: LG 37/64, (S. 113)

80/64 : ders., "Slova-sornjaki“, in: LG 80/64, (S. 118)

16/75: K. Seleznev, „Zadejstvovan igrok ne sovsem chorołej kondicii" in: LG 16/75, (S. 214)

42/71 : E. Seliverstova, (Leserbrief o. Titel), in: LG $42 / 71$, (S. 180)

7/64 : M. Semenov, „Vo kuznice ...", in: LG 7/64, (S. 111)

29/67 : A. Semenov, (Leserbrief o. Titel), in: LG 29/67, (S. 146)

G. Serebrjakova, „OstoroŽno!“, in: LG 120/64, (S. 127)

SILINA

SINEL'NIKOV

క̌KLOVSKIJ

SKVORCOV

SMIRIN

SOLGANIK

151/65 : B. Šergin, „Slư̌t' reč' narodnuju“, in: LG 151/65, (S. 141)

29/71 : G. Silina, (telefonisch übermittelter Bericht o. Titel), in: LG 29/71, (S. 170)

34/78 : M. Sinel'nikov, „O rogatych krasavicach, stydlivych kavyðkach i fenomene vosklicatel'noj zapjatoj", in: LG 34/78, (S. 238)

$118 / 64$ : V. Sklovskij, „Reforma pravil'na“, in: LG 118/64, (S. 126)

80/64 : L.I. Skvorcov, (,NaY komentarij“), in: LG 80/64, (S. 118)

40/75 : ders., „O 'poetiteskich vol'nostjach' i zakonach jazyka", in: LG 40/75, (S. 217)

$120 / 64$ : V. Smirin, „'Logika' uproščenija i živaja logika jazyka", in: LG 120/64, (S. 127)

8/73 : G. Solganik, „Gnev - plochoj sovetnik“, in: LG 8/73, (S. 195) 
SOLOUCHIN

SOLOV'EV

SOLŽENICYN

SPASOKUKOCKIJ 117/64 :

SPIRIN

STASINEVIČ

ŠURTAKOV

SVIRIDENKO

TARNARUCKIJ

TEKUČEV

TJULENEVA

TOLSTICHIN

UDALOV

U SLOVARNYCH BOGATSTV

USPENSKIJ
45/71 : V. Solouchin, „Okean rodnoj reči“, in: LG 45/71, (S. 182)

42/76 : V. Solov'ev, „Krasnorečie ili kosnojazyčie“, in: LG 42/76, (S. 224)

131/65 : A.I. Solženicyn, ,Ne obyčaj degtem š̌xi belit', na to smetana", in: LG 131/65, (S. 137)

A. Spasokukockij, „Beregite russkij jazyk!“, in: LG 117/64, (S. 125)

32/69 : A. Spirin, „Kak roždaetsja pogovorka?", in: LG 32/69, (S. 163)

20/69 : D. Stasinevič, „Neobchodim spravočnik“, in: LG 20/69, (S. 161)

47/71 : S. Surtakov, „Selucha i jantarnoe zerno“, in: LG 47/71, (S. 183)

25/64 : I. Sviridenko, "Ne zvuk okostenelyj", in: LG 25/64, (S. 111)

42/71 : G. Tarnaruckij, (Leserbrief o. Titel), in: LG 42/71, (S. 180)

$37 / 78$ : A. Tekucev, "Ne sotvori sebe kumira", in: LG 37/78, (S. 239)

28/69: N. Tjuleneva, (Leserbrief o. Titel), in: LG 28/69, (S. 163)

101/64 : A. Tolstichin, „Bez krajnosti“, in: LG 101/64, (S. 122)

$115 / 64$ : V. Udalov, „Esli už mesti, tak Xisto“, in: LG $115 / 64$, (S. 123)

16/75 : „U slovarnych bogatstv" (Interview mit F.P. Filin und S. Barchudarov), in: LG 16/75, (S. 213)

68/64 : L. Uspenskij, „Dorogie moi bolel'šciki“, in: LG 68/64, (S. 115)

84/64 : ders., („Kommentarij“), in: LG 84/64, (S. 119)

92/64 : ders., (o. Titel), in: LG 92/64, (S. 120)

108/64 : ders., „Rozovod? - Da. Zaryblenie? - gm, gm ...", in: LG 108/64, (S. 122)

$117 / 64$ : ders., „Strannoe i neprivy Znoe stanet privyčnym i obyčnym", in: LG 117/64, (S. 125)

$129 / 64$ : ders., "Tjä̌ñie begemota iz bolota", in: LG 129/64, (S. 128)

4/65 : ders., "Ne tak-to prosto", in: LG 4/65, (S. 131)

37/65 : ders., „Otvet zarubežnym bolel'̧̌̌ikam“, in: LG 37/65, (S. 132) 
150/65 : ders., „Polboršča? Ničego strašnogo", in: LG 150/65, (S. 140)

15/68 : ders., ,Jazyk, jazyka, jazyku . . . ‘, in: LG 15/68, (S. 152)

21/71 : ders., ,Moroz krepcal", in: LG 21/71, (S. 169)

28/75 : ders., „Sorazmerno i soobrazno“, in: LG 28/75, (S. 216)

$17 / 78$ : ders., „Norma - ne dogma“, in: LG 17/78, (S. 233)

USPENSKIJ, $M$.

UTOČKIN

VANŠENKIN

VASIL'EV

VETKOVSKIJ

VINOGRADOV

VINOKUROV

VLADIMIROV

ZADORNOV

ZADOV

ZALYGIN

ŽILIN
49/78 : M. Uspenskij, „Orfografija i živaja reł’“, in: LG 49/78, (S. 242)

33/76 : A. Utołkin, (Leserbrief o. Titel), in: LG 33/76, (S. 224)

23/78 : K. Vanšenkin, „Živaja reč' ili negramotnost'?“, in: LG 23/78, (S. 235)

$112 / 64$ : S. Vasil'ev, "Gde ovsjug, gde zlak“, in: LG 112/ 64, (S. 123)

$37 / 72$ : M. Vetkovskij, „Vchod osuščestuljaetsja čerez kalitku", in: LG 37/72, (S. 190)

70/64 : V.V. Vinogradov, „Kul'tura reči i orfografija“, in: $L G 70 / 64,(S .116)$

124/65 : ders., „Zametki o stilistike sovremennoj sovetskoj literature", in: LG 124/65, (S. 135)

23/67 : ders./ R.I. Avanesov/ S.G. Barchudarov/ F.P. Filin/ L.S. Kuznecov/ V.D. Levin/ A.A. Reformatskij/ V.J. Sidorov/ Ju.S. Sorokin/ G.V. Gornung/ S.K. Saumjan/ J.F. Prot tenko/ L.I. Skvorcov/ V.A. Redkin/ S.S. Vysotskij, (Leserbrief o. Titel), in: LG 23/67, (S. 144)

$7 / 72$ : E. Vinokurov, „So slovom šutki plochi“, in: LG $7 / 72,\left(S_{\dot{x}} 185\right)$

48/73 : ders., "Cistopisanie ili bol'Y̌aja literatura?", in: LG 48/73, (S. 204)

31/71 : N. Vladimirov, „V svoi vorota“, in: LG 31/71, (S. 172)

$115 / 64$ : N. Zadornov, „Doč cigana s'ela ogurci“, in: LG $115 / 64$ (S. 123)

92/64 : Ja. Zadov, ,Jazyk ulicy“, in: LG 92/64, (S. 120) $46 / 73$ : S. Zalygin, "O 'kul'ture vyvesok' i urokach stilistiki", in: LG 46/73, (S. 203)

38/71 : V. Žilin, (Leserbrief o. Titel), in: LG 38/71, (S. 177) 
ZIMIN

115/64 : P. Zimin, „Sem' raz otmer"“, in: LG 115/64, (S. 124)

ŽIRMUNSKAJA 27/76 : T. Žirmunskaja, „Takaj liričeskaja derzost”“, in: LG 27/76, (S. 222)

ZLUKTENKO

18/71 : Ju. Zluktenko, „Tajny “bilingva”“, in: LG 18/71, (S. 167)

ZNAT'I LJUBIT' 51/68 : „Znat' i ljubit”“ (Interview mit V.I. Borkovskij), in: LG 51/68, (S. 157)

ZOR'KIN

38/71 : L. Zor'kin, „Nado li sporit'?“, in: LG 38/71, (S. 176)

ŽURAVLEV

54/64 : I. Žuravlev, „Zlaja volšebnica grammatika“, in: LG 54/64, (S. 114) 


\section{Namensregister zur Dokumentation}

Aksakov, S.T.: 201

Aksenov, V.: 131, 138, 144

Alekseev, MN.: 140

Astaf'ev, V.P.: 140, 202f., 219, 223

Babel', I.E.: 143

Bachtin, M.M.: 144

Belov, V.I.: 140, 217

Belinskij, V.G.: 115, 206

Blok, A.A.: 194

Bunakov, N.F.: 239

Bunin, I.A.: 143

Buslaev, F.I.: 137

Čapygin, A.P.: 143

Cechov, A.P.: 138, 183, 212 ,

234

Černyక̌ev, V.I.: 239

Chlebnikov, V.: 122

Čukovskij, K.I.: 118, 133, 135 , $175,197,244$

Cvetaeva, M.I.: 216

Cybin, V.: 140

Dolmatovskij, E.: 133

Dostoevskij, F M.: 206

Esenin, S.A.: 204, 241

Evtušenko, E.A.: 217, 220

Fadeev, A.A.: 212

Fokina, O.A.: 217

Fonvizin, D.I.: 181

de Gaulle, Ch.: 196

Gladkov, F.V.: 135, 143

Gogol', N.V.: 204

Gor'kij, M.: 138, 143, 177, $180,187,192,204,210$, 212,219

Grec, N.I.: 144

Griboedov, A.S.: 226

Herzen, A.I.: 206
Jakovlev, K.: 241

Jakubinskij, J P.: 179

Jugov, A.: 135, 144, 159

Kačenovskij, M.T.: 144

Karamzin, NM.: 161

Kasatkin, N.A.: 143

Krylov, I.A.: 181

Lenin, V.I.: 176, 180

Lermontov, M.Ju.: 183, 185

Leskov, M.S.: 183

Lomonosov, M.V.: 141, 181

Lunatarskij, A.V.: 162

Majakovskij, V.V.: 130, 138, 215,224

Malov, F.: 162

Morozov, A.: 135

Nekrasov, N.A.: 138, 205, 212

Ožegov, S.I.: $144 f$.

Panferov, F.I.: 138, 143

Petr I.: 181, 208

Pod-jačev, S.P.: 143

Paustovskij, K.G.: 133, 189, 190

Prišvin, M.M.: 194, 201

Puskin, A.S.: 138, 140, 141, 161, $175,177,183,185,187$, $194,204,208,212,222$, 226,233

Roždestvenskij, V.: 220

Sachmatov, A.A.: 137

Saltykov-Šcedrin,M.E.: 131, 212

Ščerba, L.V.: 239

Sejfullina, L.N.: 143

Senkovskij, O.I.: 144

Serafimovič, A.: 143

Siłkov, A.S.: 161, 175, 208, 241

Šiškov, V.Ja.: 143

Skvorcov, L.l.: 150 
Šlochov, M.A.: 187, 194

Solouchin, V.A.: 215

Suuǩsin, V.M.: 217

Sumarokov, P.P.: 181

Tarkovskij, A.: 149

Timofeev, B.: 135, 197

Tolstoj, L.N.: 112, 131, 143,

$183,187,192,194,201$,

204, 206

Turgenev, I.S.: 206

Tuwim, J.: 121

Uspenskij, L.I.: 118, 135

Veselyj, A.: 133, 149

Vinogradov, V.V.: 144

Vinokur, G.O.: 144

Višnevskij, V.V.: 143

Voznesenskij, A.A.: $215 f ., 217$, 220

ZošŽenko, M.M.: 138, 143, 223

Zukovskij, V.A.: 159 


\section{Literaturverzeichnis}

Bibliographien :

BRANG/ZULLIG 1981 : P. Brang/ M. Züllig, Kommentierte Bibliographic zur slavischen Soziolinguistik, Frankturt / Bern 1981

SOVETSKOE

1966 : Sovetskoe literaturovedenie i kritika. Russkaja LITERATUROVEDENIE sovetskaja literatura. (ObకX $x_{i e}$ raboty.) Knigi i stat'i 1917-1962 godov. Bibliografičeskij ukazatel', Moskau 1966

SLAVJANSKOE JAZYKOZNANIE

1980 : Slavjanskoe jazykoznanie. Ukazatel' literatury, izdannoj v SSSR s 1971 po 1975 g. s dopolnenijami za predydušie gody. Istorija slavjanskogo jazykoznanija. Russkij jazyk, pod red. F M. Berezina, Moskau 1980

Enzyklopädien, Handbücher, Lexika:

BSE், Bd. 25

Bd. 14

Bd. 24 II

FRIEDERICH/ GEIS GRIGOR'EV

KOLESNIKOV

KOTELOVA/

SOROKIN

ROZENTAL'
1954 : Bol'saja sovetskaja enciklopedija, Bd. 25, 2. Aufl., 1954

1973 : Bol'乡aja sovetskajz enciklopedija, Bd. 14, 3. Aufl., 1973

1977 : Bol'šaja sovetskrja enciklopedija, Bd. 24, II, Sojuz sovetskich socialisti使kich respublik, Moskau, 2. Aufl., 1977

1976 : W. Friederich / S. Geis, Russisch-deutsches Neuwörterbuch, München 1976

1973 : Poet i slova, pod red. V.P. Grigor'eva, Moskau 1973

1979 : V.P. Grigor'ev, Poetika slova. Na materiale russkoj sovetskoj poézii, Moskau 1979

1971 : N.P. Kolesnikov, Slovar' paronimov russkogo jazyka, Tbilisi 1971

1971 : N.S. Kotelova/ Ju.S. Sorokin, Novye slova i znatenija, Moskau 1971

1967 : D.E. Rozental', Sppravočnik po pravopisaniju i literaturnoj-pravke, Moskau 1967 
RUSSKIJ JAZYK 1979: Russkij jzzyk. Énciklopedijz, pod glavn. red. F.P. Filina, Moskau 1979

Slovar' russkogo jazyka XI-XVIIL v, pod red. G.S. Barchudarova, Moskau $1975 \mathrm{ff}$.

Slovar' russkich narodnych govorov, pod red. F P. Filina i F.P. Sorokoletova, Moskau $1965 \mathrm{ff}$.

TRUDNOSTI

TRUDNOSTI

RUSSKOGO

JAZYKA

1974 : Trudnosti slovoupotreblenije i varianty norm russkogo literatumogo jazyka, Slovar'. spravoknik, pod red. K.S. Gorbačeviča, 1974 : Leningrad 1974

Trudnosti russkogo jazyka, Slovar'-spravočnik zurnalista, pod red. L.I. Rachmanovoj, Moskau 1974

Sonstige Veröffentlichungen

AKSENOV

APKR

BOECK/

FLECKENSTEIN/

FREYDANK

BRANG

BUKČINA/

KALAKUCKAJA/

CEL COVA

CUKOVSKIJ
1967 : V. Aksenov, „Tam gde rastut rododendrony, gde igrajut patefony, gde ulybki na ustach", in: Nedelja, 20/1967

1970 : Aktual'nye problemy kul'tury rexi pod red. V.G. Kostomarova i L.I. Skvorcova, Moskau 1970

1974 : W. Boeck/ Ch. Fleckenstein/ D. Freydank, Geschichte der russischen Literatursprache, Leipzig 1974

1973 : P. Brang, „Úber die Aufgaben der sprachsoziologischen Forschung, vornehmlich am Beispiel der russischen Literatursprache", in: Schweizer Beiträge zum VIl. Internationalen Slavistenkongre $B$ in Warschau 1973, Luzern / Frankfurt 1973, S. 3-33

1969 :

B.Z. Buktina/ L.P. Kalakuckaja/ L.K. Cel'cova, Pis'ma ob orfografii, Moskau 1969

1962 : K.I. Cukovskij, Živojkak Zizn', Moskau, 2. Aufl., 1962 
ČnMAEVA

DANILENKO

EISMANN

FILIN

\section{FOMIČEVA}

GIRKE

GIRKE/

JACHNOW

GORBACEVIC

GRIGOR'EV

ISSATSCHENKO
1969 : N.V. Curmaeva, „Počemu ostroumnyj?“, in: RR $1 / 69$, S. 85

1968 : V.P. Danilenko, "Romany Žjulja Verna", in: RR 2/68, S. 108

1978 : W. Eismann, „Erziehung der Massen und Literatursprache. Zur Diskussion um die Sprache Anfang der dreißiger Jahre", in: Mannheimer Beiträge zur slavischen Philologie, hrsg. v. J. Matełić, Mannheim 1978, S. 53-82

1969 : F.P. Filin, „Institut russkogo jazyka teper' i v buduščej pjatiletke", in: RR 3/69, S. 3-6

1973 : ders., „O strukture sovremennogo russkogo literaturnogo jazyka", in: VJa 6/75, S. 3-12

1975 : ders., „O svojstvach i granicach literaturnogo jazyka", in: VJa 6/75, S. 3-12

1977 : ders., ,Jazyk chudožestvennoj literatury i Citatel'", in: RR 4/77, S. 22-33

1978 : Literaturnaja gazeta i ce auditorija, pod red. J. D. Fomičevoj, Moskau 1978

1977 : W. Girke, „Probleme der intraethnischen Sprachpolitik. Eine kritische Betrachtung der Sprachkulturtheorie in der Tschechoslowakei", in: OBST 4 (Sprachenrecht. Sprachpolitik. Sprachplanung I), Osnabrück 1977, S. 134-146

1974 : W. Girke/ H. Jachnow, Sowjetische Soziolinguistik. Probleme und Genese, Kronberg 1974

1975 : dies., „Zur gesellschaftsbezogenen Sprachwissenschaft in der Sowjetunion ", in: dies. (Hrsg.), Sprache und Gesellschaft in der Sowjerunion, München 1975, S. 7-14

1971 : K.S. Gorbacevič, Izmenenie norm russkego literaturnogojazyka, Leningrad 1971

1978 : ders., Variantnost' slova ijazykovaja norma. Na materiale sovremennogo russkogojazy ka, Leningrad 1978

1961 : V.P.Grigor'ev, „O normalizatorskoj dejatel'nosti i jazykovom ,pjatačke“", in: VKR III, 1961, S. $3-20$

1965 : ders., Slovar' jazyka sovetskoj_poezzii, Prospekt, obrazcy slovarnych statej, instruktivnye materialy, Moskau 1965

1974 : A. Issatschenko, „Vorgeschichte und Entstehung der modernen russischen Literaturspra- 
che", in: ZfslPh, Jg. 37, 1974, H. 2,S. 235-274

1975 : ders., Mythen und Tatsachen über die Entstehung der russischen Literatursprache, Wien 1975

JAKOVLEV

JUGOV

KALAKUCKAJA/ STALTMANE

KASACK

KASATKIN

KEIPERT

KOGOTKOVA

KOSTOMAROV

KOSTOMAROVI

ŠVARCKOPF

KRYSIN

KUCHAK/ STICH
1976 : K. Jakovlev, Kak my portim russkij_jazyk, Moskau, 2. Aufl., 1976

1962 : A. Jugov, Sud'by rodnogo slova, Moskau, 2. Aufl., 1962

1967 : L.P. Kalakuckaja/ B.E. Staltmane, „Pol'skie i češskie familii po-russki", in: RR 1/67, S. 71-73

1972 : W. Kasack, Die Akademie der Wissenschaften der UdSSR, Wiesbaden, 2. Aufl., 1972

1967 : L.L. Kasatkin, „O russkich dialektach", in: RR 5/67, S. 86-91

1978 : H. Keipert, „Puristische Tendenzen in der russischen Sprachpflege der Gegenwart", in: Osteuropa, 4/78, S. 286-309

1970 : T.S. Kogotkova, „Literaturnyj jazyki dialekty“, in: Aktual'nye problemy kul'tury reči, pod red. V.G. Kostomarova i L.I. Skvorcova, Moskau 1970, S. 104-152

1976 : V.G. Kostomarov, „Tendencii razvitija sovremennogo russkogo jazyka", in: RJaS 6/76, S. 4-14

1965 : V.G. Kostomarov/ B.S. Švarckopf, „Raboty po voprosam kul'tury re $i$ (1962-1965)", in: VJa $4 / 65$, S. $121-128$

1966 : dies., „Ob izučenii otnošenija govorjašcich k jazyku", in: VKR VII, 1966, S. 23-36

1974 : L.P. Krysin, Russkijjazyk po dannym massovoge obsledovanija, Moskau 1974

1976 : ders., „Zur Soziolinguistik der 60er und 70er Jahre in der UdSSR ", in: W. Girke/ H. Jachnow (Hrsg.), Theoretische Linguistik in Osteuropa. (Originalbeiträge und Erstübersetzungen), Tübingen 1976, S. 197-216

1976 : J. Kuchařl A. Stich, „Theorie und Praxis der Sprachkultur der Gegenwart", in: J. Scharnhorst/ E. Ising, Grundlagen der Sprachkultur Beiträge der Prager Linguistik zur Sprachtheorie und Sprachpflege Teil 1. Berlin 1976, S. 331-354 
KUZNECOV/

FINGERT

LJUSTROVA/

SKVORCOV/

DERJAGIN

MURATOVA

NARODNOE

OBRAZOVANIE

NIKONOV

PANOV

PREDISLOVIE

PREDLOŽENIJA

PROTČENKO
PISATELI

1972 : I.V. Kuznecov/ E.M. Fingert, Gazernyj mir sovetskoge sojuza 1917-1970gg, T.I: Central'nye gazety, Moskau 1972

1978 : ZN. Ljustrova/ L.I. Skvorcov/ V.Ja. Derjagin, Besedy o russkom slove, Moskau, 2. Aufl., 1978

1958 : K.D. Muratova, M. Gor'kij v bor'be za razvitie sovetskoj literatury, Moskau / Leningrad 1958

1971 : Narodnoe obrazovanie, nauka i kul'tura v SSSR. StatistiYeskij sbornik, Moskau 1971

1969 : N. Nikonov, „Ivan i Vinegret", in: RR 1/69, S. $80-84$

1962 : M.V. Panov, „O razvitii russkogo jazyka v sovetskom obščestve. K postanovke problemy", in: VJa $3 / 62$, S. 3-16

1974 : Pisateli o literaturnom jazyke, (Sbornik), Moskau 1974

1970 : „Predislovie“, in: Aktual'nye problemy kul'tury reči, Moskau 1970, S. 5-8

1964 : „Predloženija po usoverకenstvovaniju russkoj orfografii“", in: Izvestija $\mathrm{Nr} .228 / 64$ (24.9.64)

1974 : P.F. Protčenko, „Institut russkogo jazyka AN SSSR - v pomošč srednej i vysł̌j łkole. (K 250-letiju Akademii nauk SSSR)“, in: RR 6/74, S. 3-13

RUSSKIE PISATELI 1954 : Russkie pisateli o jazyke, Chrestomatija, pod O JAZYKE red. A.M. Dokusova, Leningrad 1954

(Chrestomatija)

RUSSKIE PISATELI 1954 : Russkie pisateli o jazyke (XVIII-XX vv), pod O JAZYKE (XVIII-XX vv) SCHARNHORST/ ISING

SCHMIDT

SK VORCOV red. B.V. TomaŠevskogo i Ju.D. Levina, Moskau 1954

1976 : J. Scharnhorst/ E. Ising, Grundlagen der Sprach: Sprachtheorie und Sprachpflege, Teil 1, Berlin 1976

1976 : W. Schmidt, „Zum Verhältnis von Sprachkultur und Allgemeinbildung in der sozialistischen Gesellschaft", in: WZUGr, Gesellschafts- und sprachwissenschaftliche Reihe, Jg. XXV, 1976, H. 4, S. 135-139

1967a: L.I. Skvorcov, „Kul'tura reči i lirǐ̌eskaja idiosinkrazija", in: RR 1/67, S. 53-59 kultur. Beiträge der Prager Linguistik zur 
SOLGANIK

SUPERANSKAJA

ŠARCKOPF

TIMOFEEV

TRUBAČEV

USPENSKIJ 1967b:ders., „Možno li letet' samoletom?“, in: RR 3/67, S. 92-94

1970 : ders., „Norma. Literaturnyj jazyk. Kul'tura reči", in: Aktual'nye problemy kul'tury reći. pod red. V.G. Kostomarova i L.I. Skvorcova, Moskau 1970, S. 40-103

1980 : ders., TeoretiYeskie osnovy kul'tury rełi, Moskau 1980

1976 : G.Ja. Solganik, „Zametki ○ jazyke nau ñotechničeskich Zurnalov", in: RR 5/67, S.44-47

1957 : A.V. Superanskaja, „GrammatiXeskie nabljudenija nad imenami sobstvennymi", in: VJa 4/57, S. 79-82

1967 : B.S. Švarckopf, „Vnimanie: kavyðki!“, in: RR $4 / 67$, S. 60-64

1970 : ders., „Problema individual'nych i obščestvenno-gruppovych ocenok reči", in: Aktual'nye problemy kul'tury rexi, pod red. V.G. Kostomarova i L.I. Skvorcova, Moskau 1970, S. 277-304

1963 : V. Timofeev, Pravil'no li my_govorim? Zametki pisatelja, Leningrad, 2. Aufl., 1963

1978 : O.N. Trubatev, „Fedot Petrovið Filin. K 70 letiju so dnja roždenija", in: IAN SSSR, Serija literatury i jazyka, Jg. 37, 1978, H. 1, S. 81-84 1957 : L. Uspenskij, Slovo o slovach. (Oterki ojazyke), Moskau 1957 


\section{Verzeichnis benutzter Abkürzungen}

Akt.

APKR

Gen.

Imp.

IAN SSSR

IRJaz

LG

Lok.

Nom.

obl.

OBST

Part.

Pass.

Pers.

Pl.

Präs.

Prät.

prof.

razg.

Red.

RJaS

RR

Sg.

SLUŽBA

Trudnosti

VJa

VKR

WZUGr

$\mathrm{ZfslPh}$
Aktiv

Aktual'nye problemy kul'tury rexi

Genitiv

Imperativ

Izvestija Akademii Nauk SSSR

Institut russkogo jazyka

Literaturnają gazeta

Lokativ

Nominativ

oblastnoe

Osnabrücker Beiträge zur Sprach theorie

Partizip

Passiv

Person

Plural

Präsens

Präteritum

professional'noe

razgovornoe

Redaktion der LG

Russkijjazy $\underline{\text { v } \mathbf{y k o l e}}$

Russkaja rę

Singular

Služba russkogo jazyka

Trudnosti slovoupotreblenija i varianty norm russkogo literaturnogo jazyka, pod red. K.S. GorbačeviCa, Leningrad 1974

: Voprosyjazykoznanija

: Voprosy kul'tury rexi

: Wissenschaftliche Zeitschrift der Ernst-MoritzAnndt-Universität Greifswald

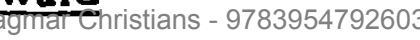

Zeitschrift furrnslavische Philologie 2019 via free access 


\section{SLAVISTISCHE BEITRAGE}

150. Deppermann, M.: Andrej Belyjs asthetische Theorie des schöpferischen BewuBtseins. Symbolisierung und Rrise der Kultur um die Jahrhundertwende. 1982. X, $256 \mathrm{~S}$.

151. Meichel, J.: Zur Entfremdungs- und Identitatsproblematik in der Sowjetprosa der 60er und 70er Jahre. Eine literatursoziologische Untersuchung. 1981. $217 \mathrm{~S}$.

152. Davydov, S.: "Teksty-Matres̄ki" Vladimira Nabokova. 1982. VI, 252 S.

153. Wallrafen, C.: Maksimilian Vološin als Künstler und Kritiker. 1982. IV, 273 S.

154. Dienes, L.: Russian Literature in Exile: The Life and Work of Gajto Gazdanov. 1982. XII, 224 S., 7 Abb.

155. Bulgarien 1300. Referate der Sektion "Sprache und Literatur" des Symposiums "Bulgarien in Geschichte und Gegenwart", Hamburg 9.-17. Mai 1981. Herausgegeben von Peter Hill. 1982. $97 \mathrm{~S}$.

156. Bock, I.: Die Analyse der Handlungsstrukturen von Erzahlwerken an Beispiel von N.V. Gogol's "Die Nase" und "Der Mantel". 1982. VIII, $168 \mathrm{~S}$.

157. Pihler, M.: Die ,Progressive Form des englischen Verbs und ihre Ubersetzungsmoglichkeiten im Slowenischen. 1982. $170 \mathrm{~s}$.

158. Sesterhenn, R.: Das Bogostroitel'stvo bei Gor'kij und Lunac̈arskij bis 1909. Zur ideologischen und literarischen Vorgeschichte der Parteischule von Capri. 1982. VIII, $366 \mathrm{~s}$.

159. Kunstmann, H.: Vorlaufige Untersuchungen uber den bairischen Bulgarenmord von 631/632. Der Tatbestand. Nachklänge im Nibelungenlied. 1982. $104 \mathrm{~S}$.

160. Slavistische Linguistik 1981. Referate des VII. Konstanzer Slavistischen Arbeitstreffens Mainz 30.9.-2.10.1981. Herausgegeben von Wolfgang Girke. 1982. $264 \mathrm{~S}$.

161. Stobbe, P.: Utopisches Denken bei V. Chlebnikov. 1982. VIII, $157 \mathrm{~S}$.

162. Neureiter, F.: WeiBrussische Anthologie. Ein Lesebuch zur weibrussischen Literatur (mit deutschen Ubersetzungen). 1983. $230 \mathrm{~S}$.

163. Witte, G.: Die sowjetische Rolchos- und Dorfprosa der funfziger Jahre. Zur Evolution einer literarischen Unterreihe. 1983. X, $292 \mathrm{~S}$.

164. Timroth, W.v.: Russische und sowjetische Soziolinguistik und tabuisierte Varietaten des Russischen. 1983. VIII, $194 \mathrm{~S}$.

165. Christians, D.: Die Sprachrubrik in der Literaturnaja gaze $\pm a$ von 1964 bis 1978. Dokumentation und Auswertung. 1983. 266 S.

166. Koschmal, W.: Das poetische System der Dramen I.S. Turgenevs. Studien $z u$ einer pragmatischen Dramenanalyse. 1983. X, $453 \mathrm{~S}$. 